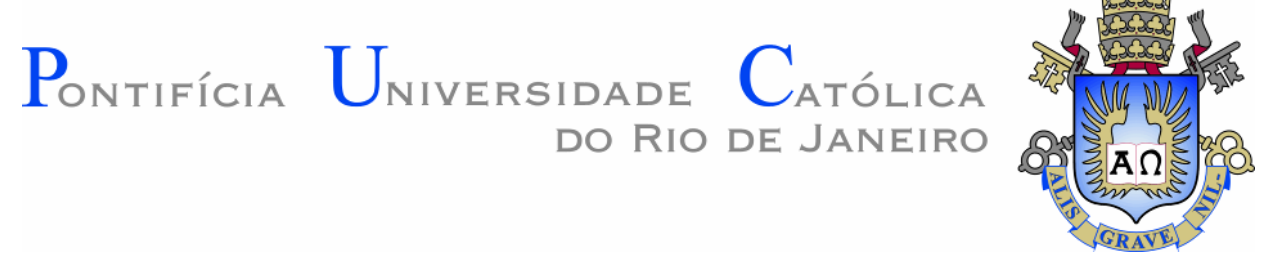

Karen Soares Augusto

Microtomografia Computadorizada de Raios X Aplicada à Caracterização de Porosidade em Pelotas de Minério de Ferro

Tese de Doutorado

Tese apresentada como requisito parcial para obtenção do grau de Doutor pelo Programa de PósGraduação em Engenharia de Materiais e de Processos Químicos e Metalúrgicos da PUC-Rio.

Orientador: Prof. Sidnei Paciornik

Rio de Janeiro

Agosto de 2016 
Pontifícia Universidade $C_{\text {ATtólica }}$

Karen Soares Augusto

\section{Microtomografia Computadorizada de Raios X Aplicada à Caracterização de Porosidade em Pelotas de Minério de}

Ferro

Tese apresentada como requisito parcial para obtenção do grau de Doutor pelo Programa de Pós-Graduação em Engenharia de Materiais e de Processos Químicos e Metalúrgicos da PUC-Rio. Aprovada pela Comissão Examinadora abaixo assinada.

Prof. Sidnei Paciornik

Orientador

Departamento de Engenharia Química e de Materiais - PUC-Rio

Prof. Celso Peres Fernandes

Departamento de Engenharia Mecânica - UFSC

Prof. Otávio da Fonseca Martins Gomes

Centro de Tecnologia Mineral - CETEM

Prof. Reiner Neumann

Centro de Tecnologia Mineral - CETEM

Dr. Marcos Henrique de Pinho Maurício

Departamento de Engenharia Química e de Materiais - PUC-Rio

Prof. Márcio da Silveira Carvalho

Coordenador Setorial de Pós-Graduação do Centro Técnico Científico -

PUC-Rio 
Todos os direitos reservados. É proibida a reprodução total ou parcial do trabalho sem autorização da universidade, da autora e do orientador.

\section{Karen Soares Augusto}

Formada em Engenharia Química pela Universidade do Estado do Rio de Janeiro em 2010. Mestre em Engenharia de Materiais e de Processos Químicos e Metalúrgicos pela PUC-Rio em 2012. As áreas de atual interesse são Ciência dos Materiais, Microscopia Digital, Microtomografia Computadorizada de Raios X e Processamento e Análise de Imagens (2D e 3D).

Ficha Catalográfica

Augusto, Karen Soares

Microtomografia computadorizada de Raios $X$ aplicada à caracterização de porosidade em pelotas de minério de ferro / Karen Soares Augusto ; orientador: Sidnei Paciornik. - 2016.

156 f. : il. color. ; $30 \mathrm{~cm}$

Tese (doutorado)-Pontifícia Universidade Católica do Rio de Janeiro, Departamento de Engenharia Química e de Materiais, 2016. Inclui bibliografia

1. Engenharia Química - Teses. 2. Engenharia de Materiais Teses. 3. Pelotas de minério de ferro. 4. Caracterização de porosidade. 5. Microtomografia de Raios X. 6. Análise de imagens. I. Paciornik, Sidnei. II. Pontifícia Universidade Católica do Rio de Janeiro. Departamento de Engenharia Química e de Materiais. III. Título. 


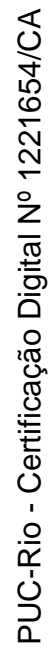

Aos meus pais Luiz e Dalva, à minha irmã Erika e ao meu noivo Rodrigo com todo o meu amor! 


\section{Agradecimentos}

A Deus e a São Francisco de Assis.

Aos meus pais, por apoiarem todas as minhas escolhas. Por lutarem sempre ao meu lado para que eu consiga atingir meus objetivos. Pela sabedoria com que me guiaram para que eu pudesse ser quem sou hoje. Por todo amor, carinho e compreensão.

À minha irmã Erika e ao meu cunhado Márcio, pelo incentivo dado e por sempre estarem dispostos a me ajudar. Pelos momentos de alegria compartilhados ao longo de todos esses anos.

Ao meu noivo Rodrigo, por todo amor e paciência. Por incentivar todos os meus passos, compreender meus estresses e tornar minha vida tão mais feliz. Por cada estímulo e força para que eu continue conquistando meus objetivos. Tenho muita sorte por ter uma pessoa tão especial cuidando de mim.

Ao meu orientador Prof. Sidnei Paciornik, por todo conhecimento compartilhado nesses 6 anos. Por ser, além de tudo, meu amigo. Por trabalhar com tanto amor e, por isso, fazer com que seus alunos se apaixonem pela pesquisa. Minha eterna gratidão, pois devo a ele grande parte do que sou hoje.

Ao amigo e meu eterno orientador Otávio Gomes, por sempre estar disposto a me ajudar e ensinar, ao longo desses 8 anos, colaborando positivamente para o meu crescimento profissional. Pelas pesquisas envolvendo a técnica de DART e pelas análises em MEV para este trabalho.

À amiga Debora Wagner, por estar presente em todos os momentos da minha vida. Por compartilhar tanta experiência e conhecimento acerca do meu trabalho. Pelas 
lições no intuito de me ajudar profissionalmente e na vida pessoal. Por todo carinho e lealdade. É mais que uma amiga, é minha irmã de alma.

Ao amigo Julio Cesar, pela convivência maravilhosa no laboratório, fazendo com o que o trabalho seja mais prazeroso. Pela parceria, por todos os ensinamentos e pela ajuda nos momentos necessários.

Aos amigos do LPDI e ex-LPDI, David, Luciana, Reynel e Loren e todos os demais, por todos os momentos e aprendizados divididos. Em especial ao Marcos e ao Haimon, pela ajuda nas análises em MicroCT e ensinamentos envolvidos na técnica.

Ao Alei Domingues, por disponibilizar todas as amostras para as análises. Por possibilitar as análises de caracterização de porosidade na Vale. Por todos os ensinamentos. Pela atenção e disponibilidade, sempre fazendo o melhor possível para me atender. Agradeço também à Valdirene Resende, por realizar as análises de porosimetria de mercúrio nas minhas amostras e ensinar sobre a técnica nos momentos em que precisei, e à Ana Calazans, pelas análises de microscopia ótica.

Ao CETEM/MCTI, pelo apoio na aquisição de imagens em MEV.

À Capes e ao CNPq, pelo apoio financeiro em momentos distintos. E à PUC-Rio pela isenção de mensalidades do Doutorado. 


\section{Resumo}

Augusto, Karen Soares; Paciornik, Sidnei. Microtomografia Computadorizada de Raios X Aplicada à Caracterização de Porosidade em Pelotas de Minério de Ferro. Rio de Janeiro, 2016. 156p. Tese de Doutorado - Departamento de Engenharia Química e de Materiais, Pontifícia Universidade Católica do Rio de Janeiro.

As pelotas de minério de ferro são uma das principais matérias-primas, juntamente com o minério granulado e o sínter, do processo de fabricação do aço. São produzidas pelo processo de pelotização, aproveitando a parcela ultrafina do minério, que antes era considerada rejeito do processo de beneficiamento. A porosidade gerada no processo de fabricação das pelotas é uma importante característica do material, pois permite o fluxo interno de gases, aumentando a sua redutibilidade e consequentemente a eficiência do processo. Por outro lado, a porosidade afeta a resistência física das pelotas, que precisam suportar todos os esforços sofridos durante as operações de manuseio, transporte e dos processos metalúrgicos. Dessa forma, a quantidade, tamanho, forma e a distribuição espacial dos poros são características importantes no controle de qualidade das pelotas, que são produzidas em grande escala e vem ganhando cada vez mais importância nas usinas siderúrgicas. Tradicionalmente, as técnicas analíticas mais utilizadas na caracterização da porosidade desses materiais são porosimetria por intrusão de mercúrio (PIM) e microscopia ótica (MO). A PIM só permite avaliar poros que estão conectados à superfície, além de utilizar o mercúrio que é um material volátil e tóxico, que oferece riscos ao meio ambiente e à saúde humana. A MO é limitada ao espaço bidimensional, podendo trazer informações pouco representativas. Ambas as técnicas são destrutivas, podendo degradar o material no processo de preparação e também impossibilitando análises posteriores numa mesma amostra. O presente trabalho propõe desenvolver uma metodologia de caracterização tridimensional de porosidade em pelotas de minério de ferro, envolvendo a técnica de microtomografia de raios $\mathrm{X}$ (MicroCT) e análise de imagens, a fim de estudar separadamente os diferentes tipos de poros (abertos e fechados), e comparar com as técnicas clássicas citadas anteriormente. Foram utilizadas 25 amostras cedidas pela Vale, analisadas 
primeiramente por MicroCT e posteriormente por PIM ou MO. Para tentativas de otimização, foram testados alguns parâmetros de análise em MicroCT, tais como o uso de lentes, diferentes configurações geométricas dos dispositivos que compõem o equipamento e número de projeções, que afetam diretamente a resolução e o tempo de análise. Comparou-se os resultados obtidos em MicroCT com os obtidos por PIM e MO, em amostras equivalentes, observando-se valores menores de porosidade para a técnica de MicroCT, devido à pior resolução do sistema. Porém, a metodologia apresentada foi capaz de quantificar a porosidade aberta e fechada separadamente, descrever a distribuição espacial, além de medir tamanho e forma, dos poros.

\section{Palavras-chave}

Pelotas de Minério de Ferro; Caracterização de Porosidade; Microtomografia de Raios X; Análise de Imagens. 


\section{Abstract}

Augusto, Karen Soares; Paciornik, Sidnei (Advisor). Porosity Characterization of Iron Ore Pellets by X-Ray Microtomography. Rio de Janeiro, 2016. 156p. PhD Thesis - Departamento de Engenharia Química e de Materiais, Pontifícia Universidade Católica do Rio de Janeiro.

Iron ore pellets are one of the major iron-bearing raw materials, along with lump ore and sinter, for the steelmaking processes. Pellets are produced from ultrafine fractions of iron ores, which were previously considered as tailings of mineral beneficiation. The porosity generated during the pelletizing process is an important characteristic of the material because it allows internal gas flow, increasing its reducibility and consequently the process efficiency. On the other hand, the porosity affects the physical strength of the pellets, which must withstand all loads during handling operations, transportation and metallurgical processes. Thus, the amount, size, shape and spatial distribution of pores are important features for the pellet quality control. Traditionally, most analytical techniques used to characterize the porosity of pellets are mercury intrusion porosimetry (MIP) and optical microscopy (OM). Nevertheless, MIP allows evaluating only pores connected to the surface, in addition mercury is volatile and toxic, offering risks to the environment and human health. OM, in turn, is limited to two-dimensional space and can reveal unrepresentative information. Both techniques are destructive and consequently prevent further analysis of the same sample. The present work proposes the development of a methodology for the tridimensional characterization of the porosity in iron ore pellets through X-ray microtomography (MicroCT) and image analysis in order to separately determine the different types of pores (open and closed). 25 samples provided by the Vale mining company were first analyzed by MicroCT and then by MIP or OM. For optimization purposes, some operating parameters of MicroCT were tested, such as the use of lenses, different geometric configurations, and the number of projections, which directly affect the obtained image resolution and the analysis time. Comparing the results obtained in MicroCT with the results obtained by MIP and OM in equivalent samples, smaller porosity measurements were 
observed for MicroCT, due to the poorer resolution of the system. However, this methodology has been able to separately quantify the open and closed porosity, to describe the spatial distribution of pores, and to measure their size and shape.

\section{Keywords}

Iron Ore Pellets; Porosity Characterization; X-Ray Microtomography; Image Analysis. 


\section{Sumário}

1 Introdução 22

1.1. Motivação 23

1.2. Objetivos 25

2 Revisão bibliográfica 26

2.1. As pelotas de minério de ferro e o processo de pelotização 26

2.2. Porosidade 30

2.2.1. Porosidade em pelotas de minério de ferro 33

2.3. Porosimetria por intrusão de mercúrio 34

2.4. Microscopia ótica 38

2.5. Microtomografia de raios $X \quad 40$

2.5.1. Mecanismos de produção de raios $X \quad 40$

2.5.2. A interação dos raios X com a matéria 43

2.5.3. O processo de MicroCT 46

2.5.4. Resolução da imagem e magnificação 49

2.6. Processamento e análise digital de imagem 55

2.7. Trabalhos relacionados 56

3 Materiais e métodos $\quad 65$

3.1. Amostras 65

3.2. Porosimetria por intrusão de mercúrio 67

3.2.1. Preparação das amostras 67

3.2.2. Análise 67

3.3. Microtomografia de raios $X \quad 68$

3.3.1. Preparação das amostras 68

3.3.2. Aquisição de imagens 69

3.3.3. Reconstrução das imagens 74

3.3.4. Processamento e análise digital de imagens 78

3.3.5. Otimização da análise 79

3.3.5.1. Definição da resolução 79 
3.3.5.2. Número de projeções e faixa angular de rotação

3.4. Microscopia ótica 81

3.4.1. Preparação das amostras 81

3.4.2. Aquisição de imagens 82

3.4.3. Processamento e análise digital de imagens 84

3.5. Microscopia eletrônica de varredura (MEV) 84

3.5.1. Preparação das amostras 84

3.5.2. Aquisição de imagens 84

4 Resultados e discussão $\quad 86$

4.1. Porosimetria por intrusão de mercúrio 86

4.2. Microtomografia de raios $X$

4.2.1. Processamento digital de imagens 88

4.2.1.1. Aquisição de imagens (fatias 2D e volumes 3D) 88

4.2.1.2. Pré-processamento 96

4.2.1.3. Segmentação 99

4.2.1.4. Pós-processamento 101

4.2.2. Otimização da análise 123

4.2.2.1. Definição da resolução 123

4.2.2.2. Número de projeções e faixa angular de rotação 126

4.2.3. Comparação da porosidade -

PIM x MicroCT (2 ${ }^{\mathrm{a}}$ etapa - grupo aplicação) 131

4.2.4. Comparação da distribuição de diâmetro de poros PIM x MicroCT (2 ${ }^{\underline{a}}$ etapa - grupo aplicação) 133

4.3. Microscopia ótica 137

4.3.1. Processamento digital de imagens 137

4.3.2. Comparação da porosidade - MicroCT x MO 140

4.4. Microscopia eletrônica de varredura 141

5 Conclusões e trabalhos futuros 147

6 Bibliografia 149

Apêndice A - Imagens correspondentes de MicroCT e MO 154 


\section{Lista de siglas e abreviaturas}

MO: Microscopia ótica

PIM: Porosimetria por intrusão de mercúrio

MicroCT: Microtomografia computadorizada de raios $\mathrm{X}$

NLM: Filtro Non Local Means

ROI: Região de interesse

MEV: Microscopia eletrônica de varredura

EDS: Espectroscopia por dispersão de energia de raios $X$ 


\section{Lista de figuras}

Figura 1 - Produção Anual de Pelotas de Minério de Ferro

(Fonte: MCDIC/ALICEweb [3])

Figura 2 - Pelota de minério de ferro [7]

Figura 3 - Mecanismo de formação da pelota crua [7]

Figura 4 - Classificação das pelotas cruas [9]

Figura 5 - Fluxograma de pelotização

Figura 6 - Paradigma da ciência dos materiais [11]

Figura 7 - Ilustração esquemática da seção transversal de um sólido poroso

(a: poros fechados; b, c, d, e, f: poros abertos; g: rugosidade) [13].

Figura 8 - Métodos de determinação de tamanho de poros [13]

Figura 9 - Representação das energias superficiais

Figura 10 - Princípio da PIM [20]

Figura 11 - Curva de intrusão de mercúrio [21]

Figura 12 - Exemplos de poros do tipo garganta.

$r_{g}$ é o raio da garganta e $r_{p}$ é o raio do poro [20]

Figura 13 - Mosaico cobrindo toda a seção transversal da pelota

Figura 14 - Espectro eletromagnético [22]

Figura 15 - Produção de raios X (espectro contínuo) [22]

Figura 16 - Produção de raios X (espectro característico) [22]

Figura 17 - Espectro de raios X do Mo como função

da voltagem aplicada [22]

Figura 18 - Efeito fotoelétrico [23]

Figura 19 - Espalhamento Compton [24]

Figura 20 - Produção de pares [25]

Figura 21 - Atenuação da radiação na matéria

Figura 22 - Interação dos raios X com a matéria em função

do número atômico do material e da energia dos fótons

Figura 23 - Processo de microtomografia de raios X [20]

Figura 24 - Tubo de raios X: (a) convencional; (b) microfoco [28].

Figura 25 - Projeções da amostra a partir do feixe incidente, 
do feixe atenuado e do calculado pela Lei de Lambert-Beer.

$\begin{array}{ll}\text { Adaptado de [29]. } & 48\end{array}$

Figura 26 - Perfil de intensidade para determinado ângulo $\Theta[29] \quad 48$

Figura 27 - Sinograma [29] 49

Figura 28 - Resolução espacial como uma função de medida de separação entre estruturas. Para um mesmo par de características, quanto menor a resolução, maior a separação entre as estruturas [29]. 49

Figura 29 - Alvo-padrão para medida da resolução espacial [29]. 50

Figura 30 - Geometria cônica [20] 50

Figura 31 - Projeção cônica com lentes [31-32] 51

Figura 32 - Resolução obtida com o uso de lentes para diferentes distâncias fonte-amostra-detector [32] 52

Figura 33 - Representação de um pixel e de um voxel [20] 53

Figura 34 - (a) Projeçao; (b) Camada 2D no plano XY; (c) Modelo 3D. $\quad 54$

Figura 35 - Sequência padrão de processamento e

análise digital de imagem [34].

Figura 36 - Visualização 3D das trincas de uma mesma pelota

em diferentes tempos de redução [35]

Figura 37 - Comparação entre porosidade aberta obtida por MicroCT e PIM 58

Figura 38 - Valores médios de porosidade relativa das pelotas

em cada um dos estágios de produção [37].

Figura 39 - Imagens de MicroCT das pelotas em diferentes

estágios de produção [37]

Figura 40 - Comparação da porosidade entre diferentes técnicas [38].

Figura 41 - Em azul, distribuição de tamanho de poros obtidos por PIM;

e, em vermelho, a distribuição obtida pelo modelo multiescala

(por morfologia matemática nas imagens 3D) [20].

Figura 42 - Resultados obtidos por análise de imagens, picnometria e porosimetria [39].

Figura 43 - À esquerda: resultados por PIM,

com as respectivas máximas pressões; à direita:

resultados por MicroCT após cada ensaio de injeção de mercúrio [40].

Figura 44 - Análise de porosidade por MicroCT integrada à 
petrografia em rocha dolomítica: A) Fotografia da rocha carbonática;

B) Corte efetuado na amostra a fim de obter melhor correlação com os cortes virtuais executados por MicroCT (Cc: calcita; Dol: dolomita; Min.

Opac: mineral opaco); C) Imagem de microscópio ótico.

D) Seção microtomográfica selecionada com demarcação das fases correlacionadas com a petrografia. E) Modelo tridimensional gerado após a separação das fases nas seções microtomográficas;

F) Fotografia da rocha utilizada para as quantificações apresentadas, com o volume selecionado demarcado. G) Um dos modelos tridimensionais gerados a partir do volume selecionado para quantificação [33].

Figura 45 - Porosímetro de Mercúrio, pertencente à Vale, modelo Auto-Pore III

Figura 46 - Amostra pronta para análise em MicroCT

Figura 47 - Visão externa do microtomógrafo Zeiss XRadia Versa 510 com a respectiva especificação técnica do equipamento.

Figura 48 - Visão interna do MicroCT Zeiss XRadia Versa 510:

(a) Fonte de raios $\mathrm{X}$ (esquerda), detector e conjunto de lentes (direita) e amostra de pelota de minério de ferro (meio); (b) Imagem ampliada de (a) para melhor visualização do sistema fonte-amostra-detector.

Figura 49 - Determinação da faixa de "Center Shift" para a escolha do melhor valor.

Figura 50 - (a) Imagem reconstruída com Shift $=-10$;

(b) Imagem reconstruída com Shift $=10$;

(c) Imagem reconstruída com Shift $=-4$ (melhor valor).

Figura 51 - Determinação da faixa de "Beam Hardening” para a escolha do melhor valor

Figura 52 - Escolha do parâmetro "Beam Hardening":

(a) Beam Hardening $=0.0$; (b) Beam Hardening $=0.50$;

(c) Beam Hardening $=0.12$ (melhor valor).

Figura 53 - Imagem de microtomografia de raios X, com seu respectivo histograma de intensidades

Figura 54 - Preparação das amostras para MO: (a) embutimento em resina; (b) fixação em um suporte para que a pelota não se mova; 
(c) retirada do embutimento; (d) corte e polimento da amostra;

(e) Amostras polidas.

Figura 55 - Imagem típica de uma pelota de minério de ferro

obtida por microscopia ótica com uma lente de 10X,

com seu respectivo histograma de intensidades.

Figura 56 - MEV utilizado (FEI Quanta 400).

Figura 57 - Análise de PIM - $1^{\mathrm{a}}$ etapa

Figura 58 - Aquisição em 0.4X (Resolução $8 \mu \mathrm{m}$ ): (a) Fatia 2D;

(b) Volume 3D.

Figura 59 - Aquisição em 4X (Resolução $4 \mu \mathrm{m}$ ): (a) Fatia 2D;

(b) Volume 3D.

Figura 60 - Região analisada pela lente de $4 \mathrm{X}$ em relação a lente de $0.4 \mathrm{X}$ :

(a) Plano XY; (b) Plano XZ; (c) Plano YZ;

(d) Corte do volume em 0.4X para visualização do volume 4X.

Figura 61 - Aquisição em 0.4X (Resolução $4 \mu \mathrm{m}$ ): (a) Fatia 2D;

(b) Volume 3D.

Figura 62 - Aquisição em 4X (Resolução $2 \mu \mathrm{m}$ ): (a) Fatia 2D;

(b) Volume 3D.

Figura 63 - (a) Região analisada pelo mosaico obtido pela lente de $4 \mathrm{X}$ em relação à região analisada pela lente de 0.4X; (b) Região analisada pela lente de $0.4 \mathrm{X}$ com melhor resolução em relação à região analisada a $0.4 \mathrm{X}$ com pior resolução.

Figura 64 - (a) Imagem original; (b) Imagem após aplicação do filtro Non-Local Means

Figura 65 - Imagem resultante da aplicação do realce de bordas (Delin)

Figura 66 - Imagem resultante da aplicação do

ajuste de contraste (Enhance Contrast)

Figura 67 - (a) Ampliação de uma região da imagem original;

(b) Segmentação: Limiar $=125$, Porosidade $=19,27 \%$;

(c) Segmentação: Limiar $=145$, Porosidade $=26,02 \%$.

Figura 68 - Imagem binária resultante da segmentação dos poros 101

Figura 69 - Segmentação das fases: (a) 0.4X; (b) 4X. 103

Figura 70 - Imagem resultante do ROI Shrink-wrap 104 
Figura 71 - Criação da ROI: (a) Aumento de uma região da Figura 69;

(b) Aumento de uma região da Figura 70. 105

Figura 72 - ROI das imagens obtidas pela lente de 4X 105

Figura 73 - Poros total: (a) 0.4X; (b) 4X. 106

Figura 74 - Porosidade total: (a) 0.4X; (b) 4X. 108

Figura 75 - Imagem resultante da aplicação do Despeckle: (a) 0.4X; (b) 4X. 110

Figura 76 - Imagem resultante da aplicação do XOR -

poros abertos: (a) $0.4 \mathrm{X}$; (b) $4 \mathrm{X}$.

Figura 77 - Corte da pelota mostrando a porosidade aberta (em verde):

(a) $0.4 \mathrm{X}$; (b) $4 \mathrm{X}$.

Figura 78 - Aplicação do NOT na imagem segmentada: (a) 0.4X; (b) 4X. 115

Figura 79 - Aplicação do NOT na imagem resultante do

Despeckle (Figura 75): (a) 0.4X; (b) 4X.

Figura 80 - Imagem resultante da aplicação do XOR - poros fechados:

(a) $0.4 \mathrm{X}$; (b) $4 \mathrm{X}$

Figura 81 - Corte da pelota mostrando a porosidade fechada (em vermelho)

Figura 82 - Corte da pelota mostrando a porosidade aberta (em verde) e fechada (em vermelho): (a) 0.4X; (b) 4X.

Figura 83 - Distribuição de volume da porosidade aberta em $0.4 \mathrm{X}$ :

(a) Todos os poros abertos; (b) Poros abertos dentro de uma faixa de tamanho.

Figura 84 - Distribuição de volume da porosidade fechada em 4X:

(a) Todos os poros fechados; (b) Poros fechados dentro de uma

faixa de tamanho (os poros em branco são poros com valores fora da

faixa de tamanho selecionada).

Figura 85 - Corte da pelota mostrando os poros fechados:

poros pequenos (em roxo); trinca (em vermelho).

Figura 86 - Comparação da porosidade por PIM e

MicroCT (Resolução de $8 \mu \mathrm{m}$ )

Figura 87 - Comparação da porosidade por PIM e

MicroCT (Resolução de $4 \mu \mathrm{m}$ )

Figura 88 - Comparação de porosidade em um mesmo campo: (a) 0.4X;

(b) $4 \mathrm{X}$. 
Figura 89 - Camadas 2D reconstruídas com: (a) 800 projeções;

(b) 1600 projeções; (c) 3200 projeções.

Figura 90 - Histogramas das imagens da Figura 89 após a aplicação

do filtro Non Local Means e do Delin: (a) 800 projeções;

(b) 1600 projeções; (c) 3200 projeções.

Figura 91 - Camadas 2D reconstruídas com: (a) 800 projeções com rotação da amostra de $0-180^{\circ}$; (b) 1600 projeções com rotação da amostra de $0-180^{\circ}$; (c) 1600 projeções com rotação da amostra de $0-360^{\circ}$.

Figura 92 - Histogramas das imagens da Figura 91 após a aplicação do

filtro Non Local Means e do Delin: (a) 800 projeções com rotação da amostra de $0-180^{\circ}$; (b) 1600 projeções com rotação da amostra de $0-180^{\circ}$;

(c) 1600 projeções com rotação da amostra de $0-360^{\circ}$.

Figura 93 - Comparação da porosidade por PIM e MicroCT

(Resolução de $4 \mu \mathrm{m}$ )

Figura 94 - Análise de PIM - 2 ${ }^{\mathrm{a}}$ etapa

Figura 95 - Comparação da distribuição de diâmetro de poros entre

MicroCT e PIM: (a) Amostras P1-13+P1-14;

(b) Amostras P2-14+P2-15; (c) Amostras P2-16+P2-17.

Figura 96 - Distribuição de diâmetro dos poros por MicroCT,

com a separação em poros abertos e fechados, para as amostras P1-13+P1-14. 135

Figura 97 - Curvas de distribuição de diâmetro de poros comparando-se

variação de limiar

Figura 98 - Histogramas das imagens de MO:

(a) Antes da aplicação do realce de bordas;

(b) após a aplicação do realce de bordas.

Figura 99 - Imagem binária da segmentação: (a) MO; (b) MicroCT 138

Figura 100 - ROI criada: (a) MO; (b) MicroCT 139

Figura 101 - Imagem de poros: (a) MO; (b) MicroCT 139

$\begin{array}{ll}\text { Figura } 102 \text { - Comparação da porosidade entre MO e MicroCT } & 140\end{array}$

Figura 103 - Camadas correspondentes: (a) MicroCT; (b) MO. 141

Figura 104 - Análise em MEV - Imagens variando a resolução de

$8 \mu \mathrm{m}$ a $70 \mathrm{~nm} /$ pixel. A região em destaque de (h) foi analisada por um

aumento maior ainda (30 nm/pixel). 
Figura 105 - Imagem de MEV de um campo com resolução de $30 \mathrm{~nm} /$ pixel referente à região em destaque na última imagem da Figura 104.

Figura 106 - Cortes das imagens em diferentes resoluções.

O destaque em vermelho em (a) e (b) se referem a regiões

próximas de (c) e (d): (a) $8 \mu \mathrm{m} /$ pixel; (b) $4 \mu \mathrm{m} /$ pixel; (c) $1 \mu \mathrm{m} /$ pixel;

(d) $0,5 \mu \mathrm{m} /$ pixel.

Figura 107 - Mapeamento de raios X:

(a) Imagem de elétrons retroespalhados; (b) Fe; (b) Ca; (c) Si; (e) Al. 146

Figura 108 - Amostra P1-7: (a) MicroCT; (b) MO 154

Figura 109 - Amostra P1-10: (a) MicroCT; (b) MO 154

Figura 110 - Amostra P1-11: (a) MicroCT; (b) MO 155

Figura 111 - Amostra P2-1: (a) MicroCT; (b) MO 155

Figura 112 - Amostra P2-2: (a) MicroCT; (b) MO 156

Figura 113 - Amostra P2-3: (a) MicroCT; (b) MO 156 


\section{Lista de tabelas}

Tabela 1 - Classificação dos poros de acordo com seu tamanho, conforme a IUPAC [13]. 31

Tabela 2 - Especificação química das pelotas P1 e P2 65

Tabela 3 - Grupo Desenvolvimento - Amostras para o

desenvolvimento da metodologia 66

Tabela 4 - Grupo Aplicação - Amostras para a aplicação da metodologia 66

$\begin{array}{ll}\text { Tabela } 5 \text { - Amostras para PIM } & 67\end{array}$

Tabela 6 - Condições de aquisição no MicroCT - Grupo Desenvolvimento 72

Tabela 7 - Condições de aquisição no MicroCT - Grupo Aplicação 73

Tabela 8 - Configuração geométrica dos dispositivos na $1^{\text {a }}$ etapa 80

Tabela 9 - Configuração geométrica dos dispositivos na $2^{\mathrm{a}}$ etapa 80

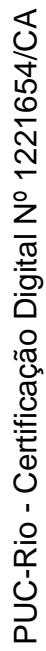

Tabela 10 - Amostras para MO 81

Tabela 11 - Comparação quantitativa de medida de porosidade

em camadas $2 \mathrm{D}$ obtidas com diferentes números de projeções 


\section{Introdução}

O minério de ferro é o principal precursor dos produtos siderúrgicos. No processo de produção do aço, o minério de ferro é reduzido a ferro primário, que é posteriormente refinado até chegar ao produto final.

Antes de entrar no processo siderúrgico, o minério de ferro precisa passar por etapas de beneficiamento para a retirada de impurezas, aumento da concentração e modificação da granulometria [1]. Nesse processo, ocorre a separação do minério em três diferentes granulometrias: minério granulado, com granulometria entre 31,0 e $6,3 \mathrm{~mm}$; sínter feed, que são partículas com tamanho variando entre $0,15 \mathrm{~mm}$ e $6,3 \mathrm{~mm}$; e o pellet feed, com granulometria abaixo de $0,15 \mathrm{~mm}$.

O minério granulado possui granulometria adequada para entrar nos fornos de redução. Já o sínter feed e o pellet feed, por serem a parcela fina do minério, não podem ser utilizados dessa forma, pois podem provocar entupimento dos altosfornos, além de prejudicar o transporte dos gases no leito. Por muitos anos, a fração grossa do minério era carregada nos altos-fornos e a fração fina acumulava-se continuamente em pilhas, sem valor econômico. Para o aproveitamento desta fração fina do minério, foram desenvolvidas as tecnologias de aglomeração, como sinterização e pelotização, cujos produtos adquirem a forma e a granulometria requeridas (alguns centímetros no caso do sínter e cerca de $12 \mathrm{~mm}$ (podendo variar entre 10-16 mm), em geral, no caso da pelota). Assim, a carga de minério de ferro que alimenta os altos-fornos pode ser constituída de uma mistura de: minério granulado, sínter de minério de ferro e pelota de minério de ferro.

O processo de fabricação de pelotas é composto por três etapas principais, que são a preparação das matérias-primas, a formação da pelota crua e o endurecimento desta pelota por meio de um tratamento térmico. O produto final deve ser um material poroso, a fim de aumentar a transferência de calor e acelerar o processo de redução, porém sem que haja perda de resistência mecânica. 
Esse balanceamento entre boa redutibilidade do material e boa resistência física faz com que a caracterização da porosidade em pelotas de minério de ferro seja uma importante etapa de controle de qualidade do material.

\section{1.}

\section{Motivação}

O Brasil é o segundo maior produtor de minério de ferro do mundo. De acordo com o Instituto Brasileiro de Mineração (IBRAM), o país produziu cerca de 400 milhões de toneladas no ano de 2014 , o que equivale a $12 \%$ do total mundial, ficando atrás somente da Austrália [2].

De acordo com a Secretária do Comércio Exterior (SECEX), em 2014, o minério de ferro permaneceu liderando, mais uma vez, a pauta de exportações de Produtos Básicos. Apesar da variação no preço em 2014 (-20,54\%), o minério de ferro representou $11,47 \%$ dos produtos básicos, seguido da soja com $10,34 \%$.

O minério de ferro brasileiro é de altíssima qualidade. Seu teor de ferro alcança $66 \%$, um dos mais ricos do mundo. As pelotas chegam a alcançar o teor de $67 \%$ de ferro. Devido à escassez das reservas e da produção de minério granulado, ao impacto ambiental gerado pelas usinas de sinterização e à maior produtividade nos altos-fornos aliada à geração de menos escória no processo, a utilização das pelotas de minério de ferro vem ganhando cada vez mais importância nas usinas siderúrgicas. A Figura 1 apresenta a exportação anual de pelotas de minério de ferro no Brasil no período de 2004-2015.

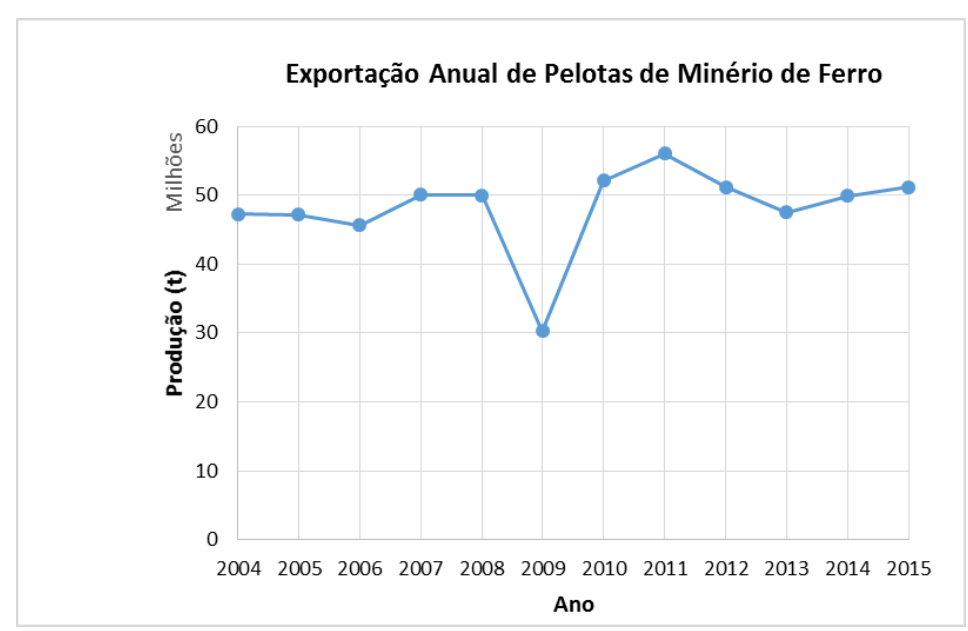

Figura 1 - Produção Anual de Pelotas de Minério de Ferro

(Fonte: MCDIC/ALICEweb [3]). 
Com a enorme escala de produção, pequenos ganhos de eficiência em cada etapa do processo geram resultados consideráveis. Como a caracterização microestrutural permite identificar fatores que influenciam o comportamento das pelotas nos fornos de redução, é uma importante etapa de controle de qualidade.

O microscópio ótico de luz refletida vem sendo utilizado na caracterização de minérios de ferro há muitos anos, já que as fases mais comumente presentes são facilmente discriminadas por meio de suas refletâncias [4]. Variáveis como frações de fases predominantes, a distribuição e a morfologia de poros, e a conectividade entre as fases são fundamentais para o entendimento do comportamento da pelota no processo. No entanto, as propriedades neste tipo de material são altamente heterogêneas e a análise tradicional por meio de microscopia ótica (MO), tipicamente limitada ao espaço bidimensional, pode trazer informações pouco representativas. Uma forma de se obter informações 3D, neste caso, é o uso da estereologia para a extrapolação dos dados 2D (fração de pontos, fração de linhas ou fração de área) para o espaço tridimensional (fração de volume). No entanto, materiais que contenham objetos de formas arbitrárias e rede de conectividade complexa não podem ser completamente descritos por métodos estereológicos [5].

Outra técnica analítica amplamente utilizada na caracterização da porosidade de pelotas, cuja quantidade e distribuição tem grande influência no que diz respeito à qualidade física e metalúrgica como dito anteriormente, é a porosimetria por intrusão de mercúrio (PIM). No entanto, a PIM só permite avaliar poros que estão conectados à superfície, limitando a técnica à caracterização de poros abertos, impedindo a análise de poros fechados. Além disso, o mercúrio é um metal volátil e tóxico, que oferece riscos à saúde humana e ao meio ambiente, e, devido a isso, muitas empresas vem desistindo desta técnica de caracterização [6].

Mais uma desvantagem de ambas as técnicas citadas acima, que são utilizadas tradicionalmente, por exemplo, na Vale, é o fato de que são destrutivas, isto é, não permitem posteriores análises em uma mesma amostra, caso haja necessidade.

Recentemente, diversos tipos de trabalho de caracterização de porosidade por meio de análise de imagens obtidas por microtomografia computadorizada de raios $\mathrm{X}$ (MicroCT) vem sendo realizados. A MicroCT é a microscopia em 3D que fornece informações externas e internas da estrutura de materiais sólidos. O avanço tecnológico da MicroCT permite a caracterização tridimensional dos poros nas pelotas de minério de ferro em microescala. A técnica permite a visualização 
tridimensional do material, a realização de medidas verdadeiramente $3 \mathrm{D}$ e requer pouca ou nenhuma preparação de amostras, o que facilita a própria análise e outras que precisem ser realizadas na mesma amostra.

Assim, busca-se desenvolver uma metodologia de caracterização de porosidade de pelotas de minério de ferro, na tentativa de complementar ou até mesmo substituir técnicas clássicas, com uma técnica tridimensional promissora, conhecendo-se as limitações de cada uma delas.

A presente tese está organizada em cinco capítulos. O primeiro capítulo consiste nesta introdução, que engloba a motivação do trabalho e os objetivos. O segundo capítulo ("Revisão Bibliográfica") traz uma breve apresentação dos conceitos referentes ao material estudado e às técnicas utilizadas, além de apresentar trabalhos encontrados na literatura sobre o tema abordado. $\mathrm{O}$ capítulo 3 ("Materiais e Métodos") explica em detalhes as etapas experimentais, que incluem preparação de amostras, equipamentos e metodologia utilizada. O capítulo 4 ("Resultados e Discussão") contem os resultados obtidos com as devidas discussões apresentadas. E, por fim, o quinto capítulo (“Conclusões e Trabalhos Futuros”) apresenta as conclusões acerca do trabalho proposto, incluindo possíveis trabalhos futuros.

\section{2. \\ Objetivos}

O objetivo do presente trabalho é desenvolver uma metodologia de caracterização tridimensional de porosidade em pelotas de minério de ferro, que seja capaz de estudar separadamente porosidade aberta e fechada, e comparar os resultados obtidos com técnicas clássicas de porosimetria, como a PIM e a MO.

A metodologia em questão baseia-se na aquisição de imagens de MicroCT de pelotas de minério de ferro, envolvendo diferentes configurações geométricas e conjuntos de lentes permitidos pelo equipamento, a fim de comparar menores e maiores resoluções, e, em seguida, no processamento e análise dessas imagens para a avaliação qualitativa e quantitativa do material. 


\section{2 \\ Revisão bibliográfica}

Este capítulo apresenta a base teórica necessária para o desenvolvimento da metodologia proposta no presente trabalho. Além disso, apresenta trabalhos já existentes sobre o tema abordado, permitindo a construção de novas ideias para a análise do problema em questão.

\section{1.}

\section{As pelotas de minério de ferro e o processo de pelotização}

As pelotas de minério de ferro (Figura 2) são aglomerados aproximadamente esféricos, em geral, com tamanho entre 10 e $16 \mathrm{~mm}$, produzidos no processo de pelotização.

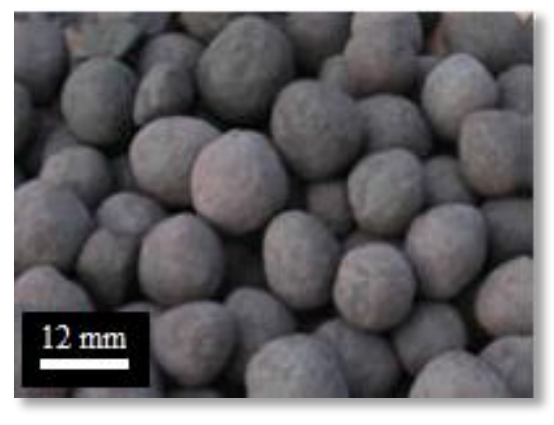

Figura 2 - Pelota de minério de ferro [7]

O processo de pelotização consiste em três etapas: preparação das matériasprimas, formação das pelotas cruas e queima.

Na preparação das matérias-primas, o pellet feed - finos de minério de ferro concentrados na fração menor que $0,15 \mathrm{~mm}$ - gerado no beneficiamento do minério é processado para o aumento do teor de ferro, sendo reduzidos componentes indesejáveis, tais como sílica e alumina. Em seguida, o concentrado é moído e filtrado para aumentar a superfície específica do material e fazer com que ele contenha uma percentagem de água (entre 8 e 10\%), facilitando a aglomeração. Os principais insumos utilizados são: carvão mineral (antracito), calcário, 
magnesita/olivina, bentonita, aglomerantes orgânicos e, em alguns casos, cal hidratada. Em seguida, é feita uma mistura de todos os insumos, em proporções adequadas, para a homogeneização do material que, posteriormente, alimentará os discos ou tambores de pelotização.

$\mathrm{O}$ antracito introduz energia térmica no processo de endurecimento, no qual ocorre sua queima, melhorando a distribuição de calor no interior da pelota. O calcário e/ou magnesita são fundamentais para as características metalúrgicas, modificando a composição química das pelotas, especialmente corrigindo a basicidade, e proporcionando maior rigidez mecânica. Os aglutinantes, em geral bentonita, aglomerantes orgânicos e calcário facilitam o pelotamento, além de proporcionar resistência para o transporte e manuseio das pelotas até a etapa de queima.

Em seguida, ocorre a etapa de formação das pelotas cruas. Este processo pode ser visualizado na Figura 3. Quando uma partícula é umedecida, um filme fino de água é formado na sua superfície. Ao entrar em contato com outra partícula úmida, ocorre uma ligação entre estes filmes. As partículas inicialmente unidas por esta ligação formam o núcleo, em torno do qual ocorrerá todo o crescimento da pelota. Os núcleos formados vão sendo girados e mais partículas vão aderindo a eles, gerando esferas [7]. O processo é similar ao de uma bola de neve rolando em uma ladeira íngreme.

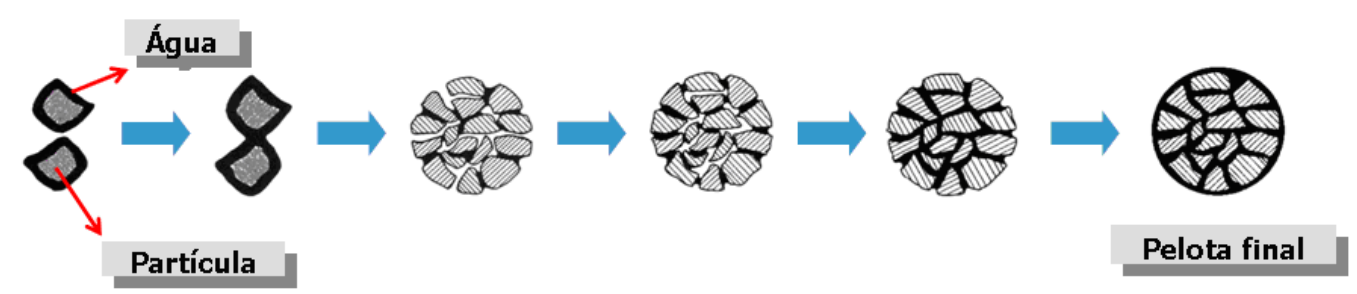

Figura 3 - Mecanismo de formação da pelota crua [7]

Os principais fatores que influenciam na taxa de crescimento dos aglomerados são: quantidade de água utilizada, velocidade de rotação do equipamento, taxa de alimentação do material no disco de pelotização, distribuição de tamanho das partículas das matérias-primas, tensão superficial do líquido e presença de núcleos menores, uma vez que partículas com tamanhos insuficientes, 
ao passarem por uma peneira antes de entrar na etapa de queima, retornam ao processo [8], como pode ser visto na Figura 4.

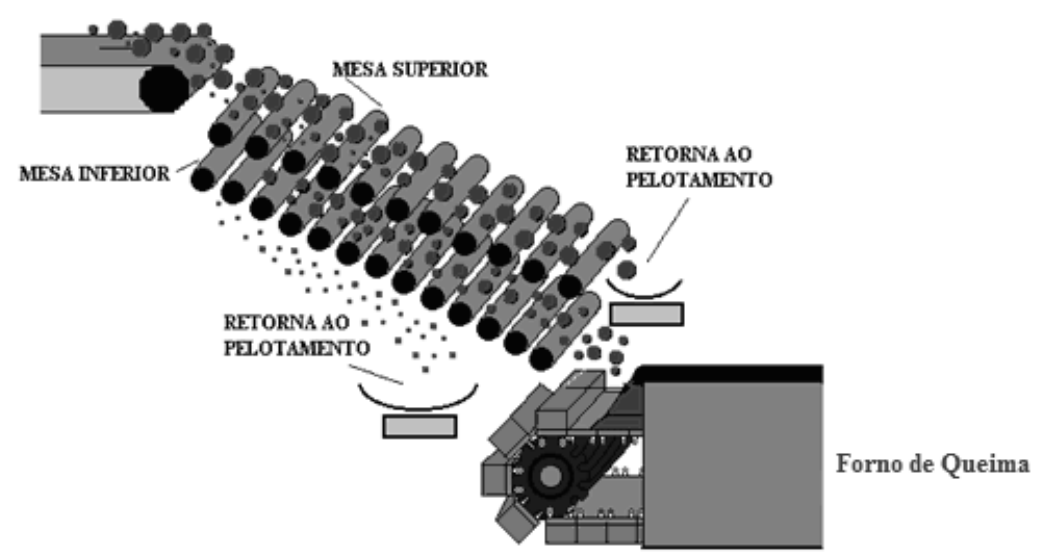

Figura 4 - Classificação das pelotas cruas [9]

A pelota crua ainda não possui resistência física e mecânica suficiente para suportar as operações de manuseio e transporte até o cliente, isto é, estocagem no pátio, carregamento, transporte e descarga do navio, e nem para resistir aos esforços durante os processos metalúrgicos, na formação do ferro-esponja (redução direta) ou ferro-gusa (alto-forno). Para isso, passam por um processo de endurecimento, no qual sofrem um tratamento térmico em uma atmosfera controlada.

O processo de endurecimento pode ser dividido em 3 etapas principais, que são secagem, queima e resfriamento, todas muito bem controladas para que não ocorram rachaduras ou fragmentações nas pelotas, devido às tensões internas que surgem em função da evaporação da água. É na etapa de queima que ocorre a fusão parcial de alguns componentes e as pontes cristalinas começam a ser criadas, resultando em maior resistência mecânica.

Uma visualização do processo completo de pelotização é apresentada na Figura 5. 


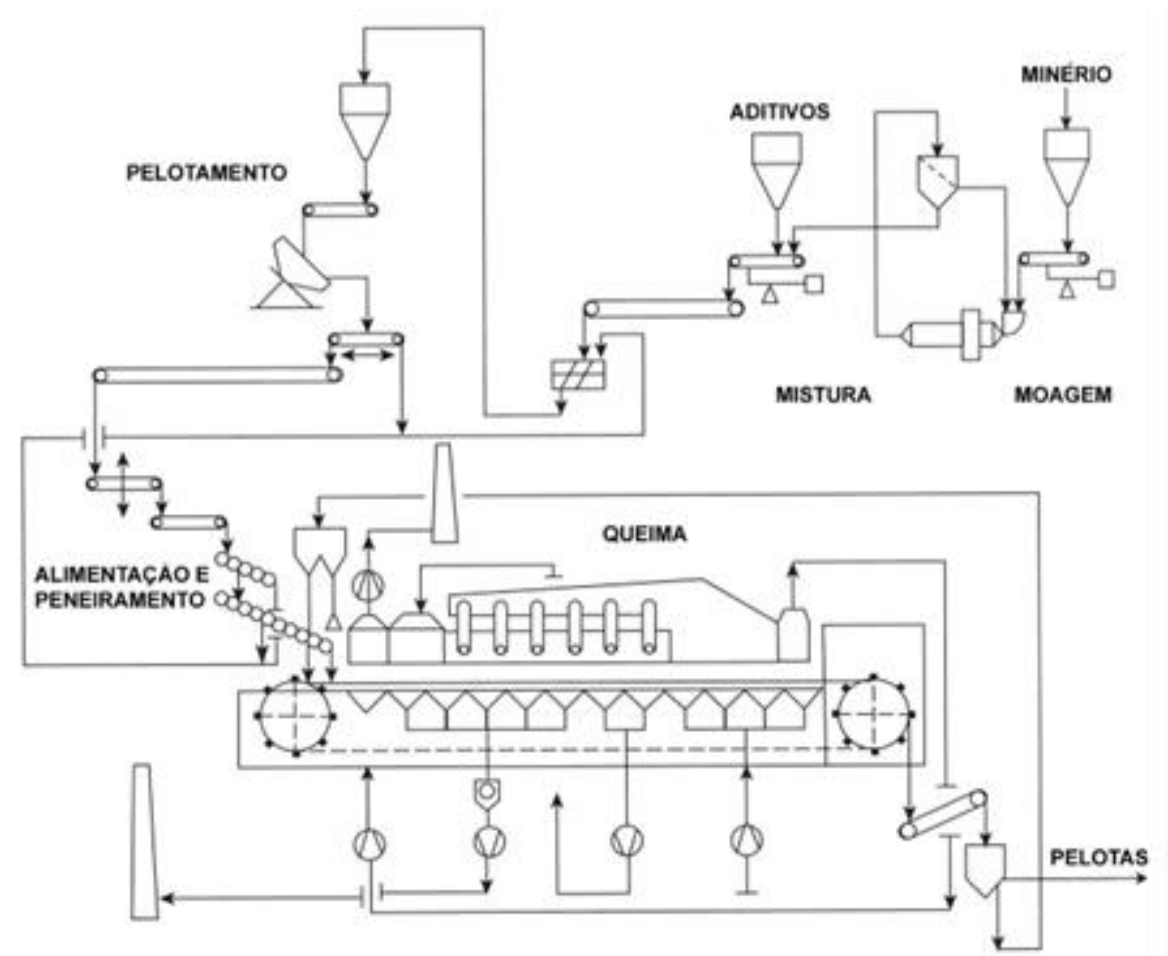

Figura 5 - Fluxograma de pelotização

Após o processo de pelotização, os produtos apresentam uma grande heterogeneidade química e microestrutural devido à fusão de alguns constituintes minerais da carga durante o tratamento térmico. Na pelota, em geral, as fases predominantes são hematita, silicatos, ferritos e poros [10].

O coração do paradigma da ciência dos materiais é a estrutura, ou seja, a distribuição espacial das coisas visíveis e invisíveis, que, por sua vez, se conecta com o processo e com as propriedades, conforme a ilustração da Figura 6. A microestrutura influencia praticamente em todos os aspectos o comportamento do material [11].

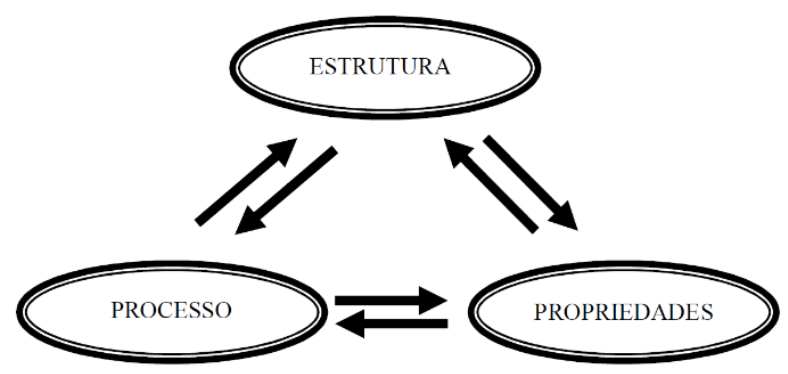

Figura 6 - Paradigma da ciência dos materiais [11] 
Assim, as características microestruturais das pelotas de minério de ferro permitem avaliar fatores que influenciam o seu comportamento nos processos de redução. A porosidade, por exemplo, deve ser suficiente para permitir o fluxo dos gases, aumentando a eficiência do processo, sem deixar haver perda de resistência mecânica, necessária para o seu transporte e manuseio. Por isso, as distribuições de tamanho e forma dos poros são aspectos importantes nas propriedades da pelota. A fração volumétrica e a morfologia de cada uma das fases presentes também são características relevantes para que as pelotas apresentem boa qualidade metalúrgica.

\section{2. \\ Porosidade}

Os poros são descontinuidades, que são introduzidos, normalmente, durante as etapas de processamento e de fabricação [12]. Porosidade pode ser definida como a fração, $\varepsilon$, do volume específico aparente da amostra que é atribuído aos poros: $\varepsilon$ $=\mathrm{Vp} / \mathrm{V}$. O valor desta fração depende do método utilizado para determinar o volume específico aparente, $\mathrm{V}$, que exclui os vazios interpartículas, e do método utilizado para determinação do volume específico de poro, Vp. [13].

De acordo com a Figura 7, os poros podem ser classificados de acordo com sua acessibilidade ao fluido externo. Poros fechados consistem nos poros que são inacessíveis ao fluido externo e totalmente isolados de outros poros (a). Os poros fechados influenciam propriedades macroscópicas, tais como densidade, elasticidade, resistência mecânica e condutividade térmica, porém são irrelevantes para processos em que há fluxo de fluidos e adsorção de gases. Os poros que possuem um canal de comunicação com a superfície exterior do sólido (como b, c, d, e, f) são denominados poros abertos. Os poros abertos recebem ainda outras denominações, como "poros-através", que possuem um canal aberto que começa em uma posição da superfície, atravessa a partícula e emerge em outra posição da superfície (como, por exemplo, c-e-c e c-e-d), e como "poros-cegos", cuja abertura está apenas para uma extremidade (como é o caso dos poros b e f). Apesar de pequenas irregularidades da superfície (como g) serem tecnicamente poros-cegos, é mais adequado tratá-los separadamente como um atributo diferente, chamado de rugosidade da superfície [13]. 


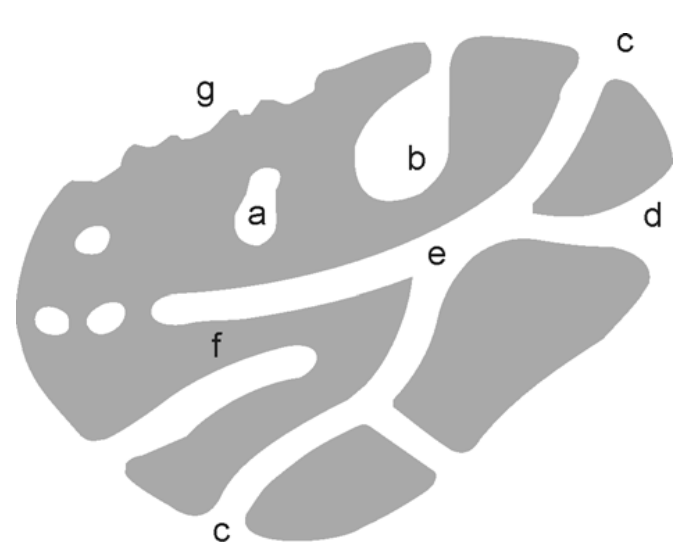

Figura 7 - Ilustração esquemática da seção transversal de um sólido poroso (a: poros fechados; b, c, d, e, f: poros abertos; g: rugosidade) [13].

O tamanho do poro não tem uma definição precisa, pois a forma é geralmente irregular e muito variável. A descrição quantitativa do tamanho de poros é feita por modelos de um pequeno número de formas, tais como cilindros, prismas, cavidades e janelas, fendas, ou esferas. A classificação dos poros, baseada no tamanho, recomendada pela IUPAC é mostrada na Tabela 1 [13].

Tabela 1 - Classificação dos poros de acordo com seu tamanho, conforme a IUPAC [13].

\begin{tabular}{cc}
\hline Classificação & Tamanho do poro \\
\hline Microporos & Diâmetro $<2 \mathrm{~nm}$ \\
Mesoporos & $2 \mathrm{~nm}<$ Diâmetro $<50 \mathrm{~nm}$ \\
Macroporos & Diâmetro $>50 \mathrm{~nm}$ \\
\hline
\end{tabular}

Existem diversas técnicas de caracterização de porosidade, como podem ser visualizadas na Figura 8. Alguns métodos só conseguem acessar poros abertos, outros ambos os poros (abertos e fechados). Assim, o valor de porosidade depende do material e do método utilizado para sua determinação [13].

Algumas técnicas utilizadas na caracterização de porosidade são porosimetria por intrusão de mercúrio, absorção de água, picnometria de hélio e análise de imagem [6]. Uma comparação de cada um desses métodos, com suas vantagens e limitações, estão listadas a seguir: 
- Porosimetria de mercúrio: É uma técnica simples. Detecta porosidade aberta com precisão, porém fornece valores menores de porosidade total por não medir porosidade fechada [14];

- Absorção de água: É uma técnica barata e simples. Porém não fornece resultados muito confiáveis, isso porque as condições em que se realiza as medidas podem não ser adequadas para permitir que a água preencha as cavidades [14]. Além disso, apenas a porosidade efetiva (aberta) é determinada;

- Picnometria de hélio: Uma vez conhecida a densidade dos materiais, pode-se determinar porosidade aberta e fechada por esta técnica, mas sem distinguí-los. Além disso, não se pode medir diâmetro ou tamanho dos poros;

- Análise de imagem: Pode ser feita por imagens de microscopia ou de microtomografia de raios X. Pode ser utilizada para diferenciar, através do processamento de imagens, porosidade fechada ou aberta. Permite a determinação da distribuição do tamanho e da morfologia dos poros, porém os resultados são limitados pela resolução espacial da imagem.

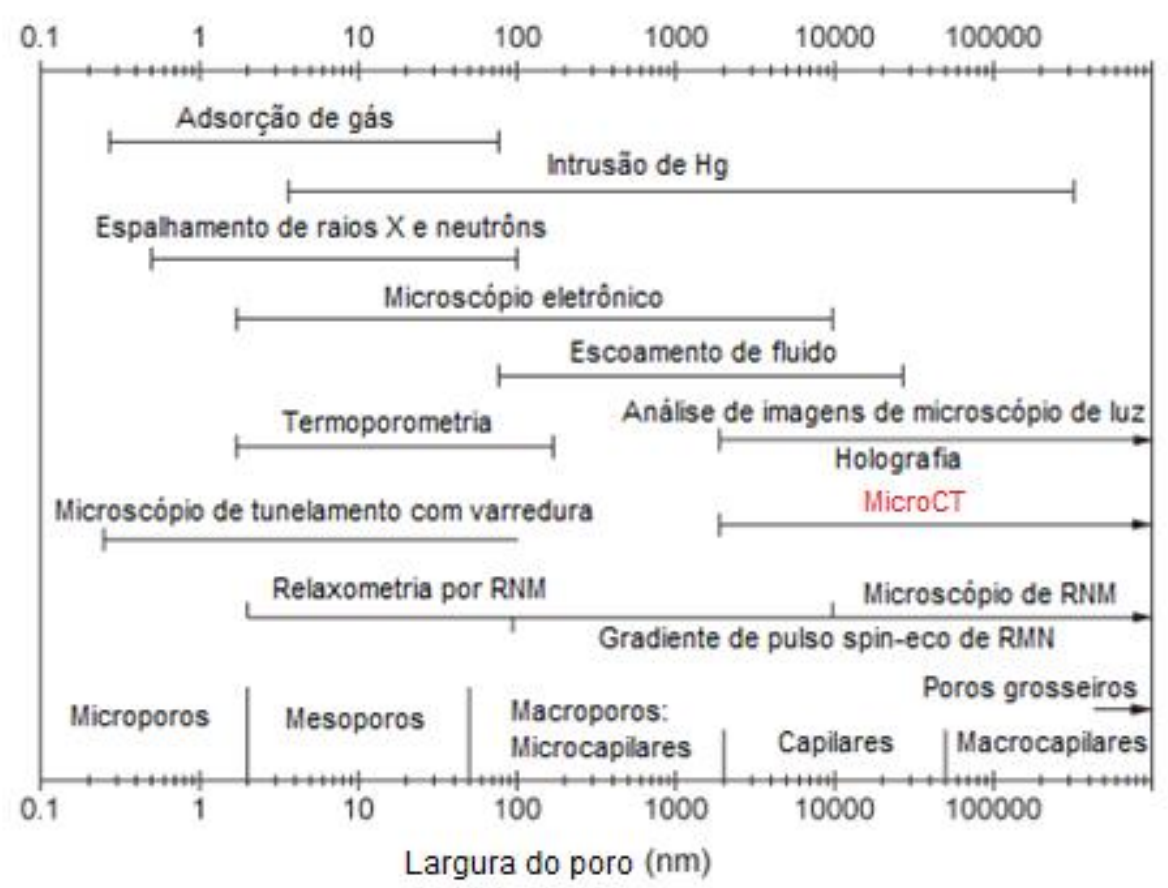

Figura 8 - Métodos de determinação de tamanho de poros [13] 


\subsection{1. Porosidade em pelotas de minério de ferro}

A porosidade é uma característica intrínseca na estrutura das pelotas de minério de ferro, permitindo a difusão dos gases e fornecendo área superficial para as reações.

Há muitos fatores que podem influenciar a formação e a estrutura de poros em pelotas de minério de ferro, tais como o tamanho das partículas de minério de ferro, a quantidade de calcário, carvão e outras matérias-primas envolvidas, a porosidade inicial, temperatura e assim por diante. Portanto, o controle destas variáveis pode contribuir para melhorar a quantidade e a estrutura dos poros [15].

Yang [15] concluiu que os principais tipos de poros formados em pelotas são:

1. Poros formados pelos locais de consumo de calcário;

2. Vazios não preenchidos ou parcialmente preenchidos entre partículas de minério de ferro;

3. Vazios não preenchidos ou parcialmente preenchidos dentro das partículas de minério de ferro;

4. Poros formados em locais de consumo de partículas de carvão;

5. Poros formados em locais de outros aditivos;

6. Poros (ou trincas) formados quando calcário e/ou partículas de carvão completamente fundidos escoam entre partículas de minério de ferro.

Foi concluído também que em pelotas ácidas, os poros são formados, principalmente, por vazios entre partículas de minério de ferro [15].

Uma estrutura de poros abertos pode ser obtida a partir do controle de temperatura e uso de quantidades adequadas de partículas de calcário, carvão e outros aditivos. A estrutura de poros ideal para que o material tenha alta redutibilidade - que é a medida da facilidade da remoção do oxigênio, combinado ao ferro do minério, sob a ação de um agente redutor - é a de poros abertos [15].

Muitos pesquisadores afirmam que a redutibilidade aumenta com o aumento da porosidade. Sivrikaya [16] menciona que a porosidade na faixa de $22-30 \%$ para pelotas queimadas está associada com boa redutibilidade. 
Por outro lado, a resistência aumenta com a diminuição da porosidade. Para alcançar alta resistência e alta redutibilidade simultaneamente, a solução talvez seja a produção de uma pelota com a estrutura de poros abertos ou poros fechados perto de abrir, mas com baixa porosidade [15].

\section{3. \\ Porosimetria por intrusão de mercúrio}

Uma das técnicas mais importantes para a determinação de porosidade de materiais é a porosimetria pelo método da intrusão de mercúrio (PIM). Poros entre $600 \mu \mathrm{m}$ e 3,5 nm, em geral, podem ser caracterizados por esta técnica [17].

A técnica se baseia nos fenômenos de capilaridade por líquidos que não molham os sólidos e que só serão introduzidos nos poros mediante aplicação de pressão, conforme será explicado a seguir.

Quando uma superfície de um sólido é colocada em contato com um líquido, sem que haja reações químicas envolvidas ou dissolução do sólido pelo líquido, a gota se espalhará pela superfície até uma geometria de equilíbrio.

A forma final da gota é uma relação entre as energias de superfícies, vide Figura 9, que são: sólido-líquido $\left(\gamma_{\mathrm{SL}}\right)$, sólido-vapor $\left(\gamma_{\mathrm{SV}}\right)$ e líquido-vapor $\left(\gamma_{\mathrm{LV}}\right)$. A Equação 1 pode ser obtida, relacionado essas energias e o ângulo de contato entre o líquido e o sólido.

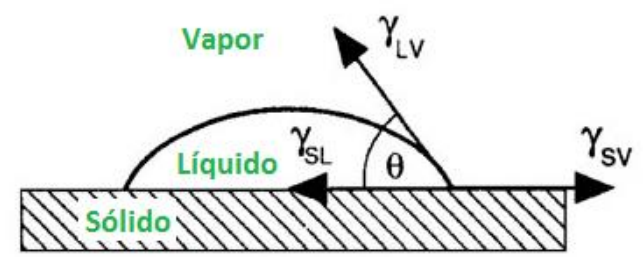

Figura 9 - Representação das energias superficiais

$$
\cos \theta=\frac{\left(\gamma_{S V}-\gamma_{S L}\right)}{\gamma_{L V}}
$$

Quando o ângulo de contato é maior do que $90^{\circ}$, então o líquido não molha o sólido, isto é, não há uma superfície sólido-líquido extensa e o líquido permanece na forma de uma gota. Para a maioria dos sólidos, o mercúrio apresenta ângulo de contato que varia entre $135^{\circ}$ e $142^{\circ}$. 
Assim, o princípio da técnica se baseia no fato de que o mercúrio $(\mathrm{Hg})$ não penetra em materiais porosos com os quais esteja em contato, e para que se consiga introduzir o mercúrio é preciso aplicar uma pressão, de forma que a força externa seja superior à tensão superficial do mercúrio.

Com isso, foi proposto como se obter uma distribuição de tamanho de poros a partir de dados de volume de intrusão de mercúrio num meio poroso, em função de valores de pressão. Admitindo-se as hipóteses de menisco esférico em poro cilíndrico, uma equação entre o diâmetro do poro e a pressão exercida para a intrusão do mercúrio em diferentes tamanhos de poros pode ser obtida, conforme a equação de Washburn abaixo [18]:

$$
D=\frac{-4 \gamma \cos \theta}{P}
$$

Onde:

$\mathrm{D}=$ diâmetro do poro

$\gamma=$ tensão superficial entre o sólido e líquido $(\mathrm{Hg})$

$\Theta=$ ângulo de contato

$\mathrm{P}=$ pressão externa

Na prática, a técnica de PIM consiste em colocar a amostra em um recipiente chamado penetrômetro. A amostra é previamente evacuada e depois imersa em mercúrio. Aumenta-se a pressão por incrementos sucessivos e, para cada valor de pressão, atinge-se um equilíbrio e o volume de mercúrio penetrado fica registrado pela diminuição do volume no capilar. Este dado determina o volume de poros no material que tem um certo intervalo de tamanho de acesso. Registrando-se a redução do nível de mercúrio no capilar juntamente com a pressão aplicada, constrói-se a curva porosimétrica [19]. A Figura 10 ilustra o princípio da técnica. 


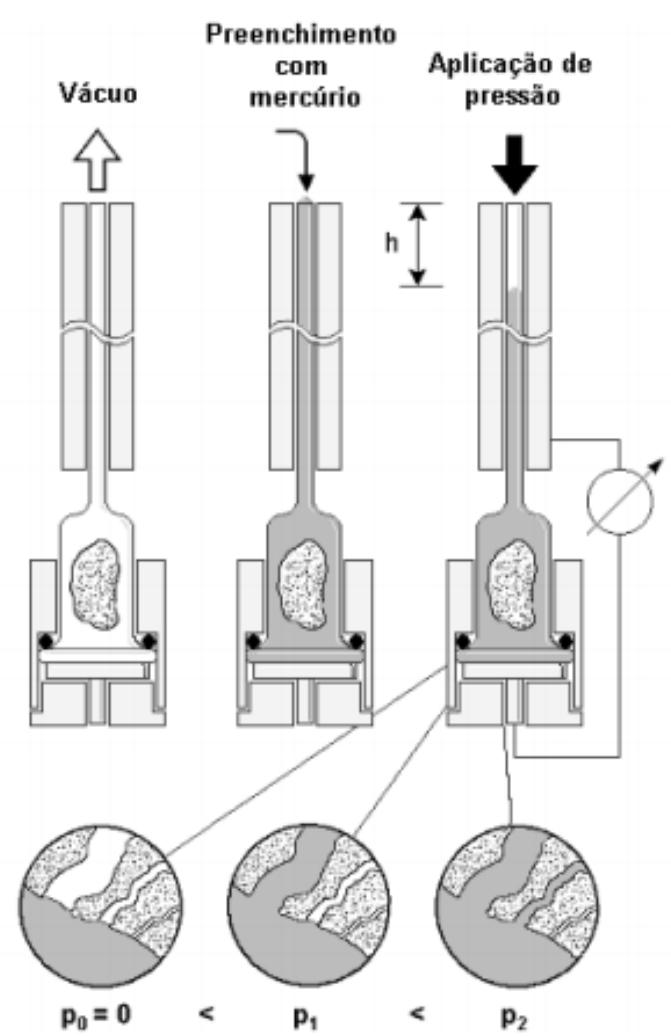

Figura 10 - Princípio da PIM [20]

Uma curva típica de PIM pode ser visualizada na Figura 11. A distribuição de tamanhos de poros pode ser derivada da curva de intrusão, atribuindo-se um volume $\mathrm{d} V$ a poros com diâmetros entre $d_{i} \mathrm{e}\left(d_{i}+\mathrm{d} d_{i}\right)$. Assim:

$$
d V=f_{y}\left(d_{i}\right) d d_{j}
$$

Sendo $f_{\mathrm{v}}\left(d_{i}\right)$ a função densidade de probabilidade para o diâmetro dos poros, que corresponde à derivada da curva porosimétrica, após a conversão dos valores de pressão para valores de diâmetro utilizando a equação 2 . 


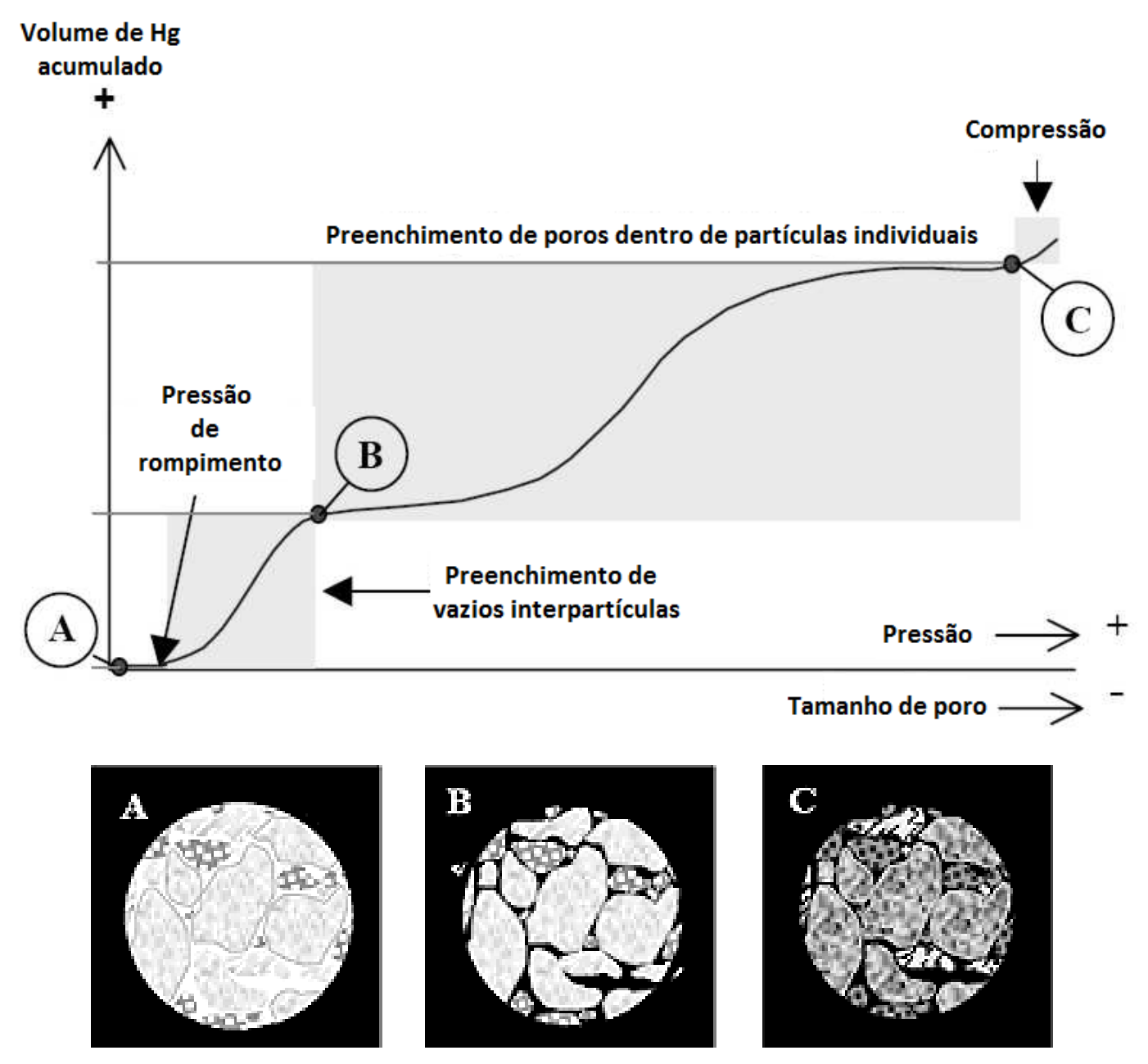

Figura 11 - Curva de intrusão de mercúrio [21]

Com os dados experimentais de PIM, determina-se vários parâmetros importantes na caracterização do meio poroso, tais como: distribuição de tamanho de poros, volume total de poros, área superficial total, diâmetro médio dos poros, massa específica aparente e real da amostra.

Existem alguns poros, denominados poros do tipo garganta (Figura 12), nos quais o preenchimento do poro está condicionado à abertura da garganta. Isso faz com que haja uma medição errônea no volume do mercúrio penetrante, superestimando poros menores, pois o afunilamento da estrutura impossibilita a penetração do mercúrio a pressões menores [20]. 


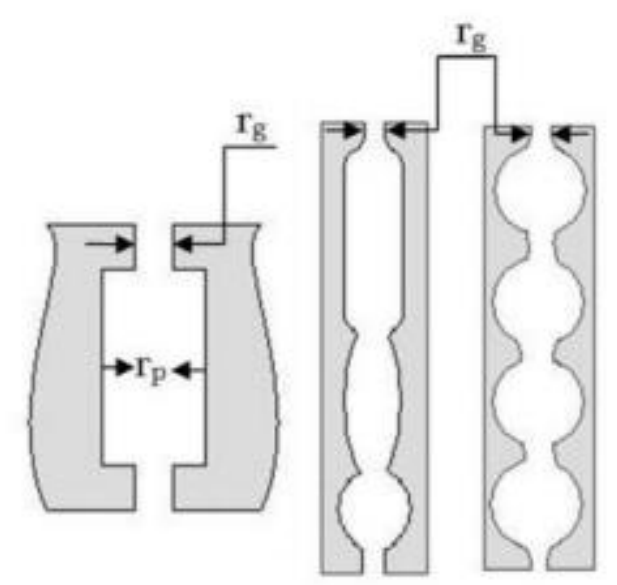

Figura 12 - Exemplos de poros do tipo garganta. $\mathrm{r}_{\mathrm{g}}$ é o raio da garganta e $\mathrm{r}_{\mathrm{p}}$ é o raio do poro [20]

Assim, como qualquer outra técnica de caracterização, a porosimetria por intrusão de mercúrio apresenta limitações. A presença de poros do tipo garganta é uma delas. Ou seja, a técnica determina a entrada do poro e não o real tamanho do poro. O menor tamanho de poro que pode ser preenchido pelo mercúrio é limitado pela máxima pressão possível do sistema. O maior tamanho de poro é limitado pela altura da amostra, que determina a pressão mínima a ser exercida [16]. Além disso, poros fechados que estão dentro do material e não têm comunicação com a superfície externa não podem ser avaliados.

A qualidade de pelotas de minério de ferro já foi estudada a partir da determinação de parâmetros estruturais, tais como porosidade, volume de poros e distribuição de tamanho de poros, por meio da técnica de PIM [22].

\section{4 . \\ Microscopia ótica}

A microscopia ótica de luz refletida em campo claro (MO) é tipicamente utilizada na caracterização de pelotas de minério de ferro, pois as fases mais comumente presentes são facilmente discriminadas através das suas diferentes refletâncias.

Em campo claro, quando um feixe de luz incide na amostra, os fótons interagem com os elétrons dos átomos do material. Os elétrons são excitados e reemitem a luz, que é capturada ou não pela lente do microscópio, proporcionando o contraste na imagem formada. 
Com o avanço da microscopia digital, os sistemas controlados por software e rotinas desenvolvidas em ambientes de programação passaram a oferecer automação completa do microscópio, gerando análises com grande região amostral, mais confiáveis, rápidas e reprodutíveis.

Uma imagem típica de um mosaico, isto é, imagens concatenadas cobrindo toda a superfície da seção polida de uma pelota de minério de ferro, obtida por microscópio ótico, pode ser visualizada na Figura 13.

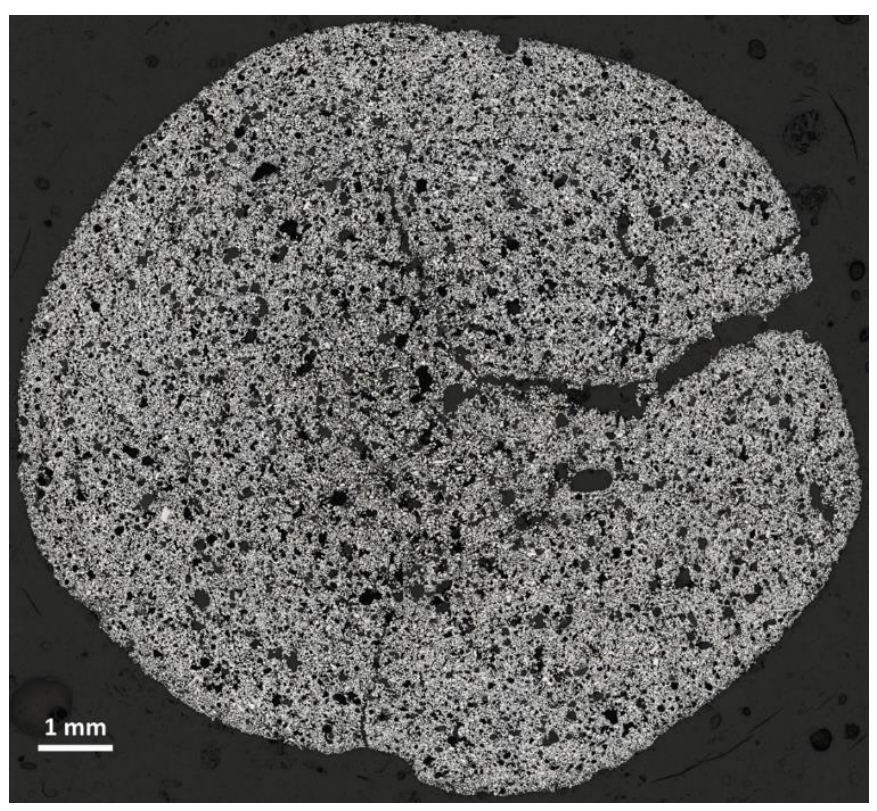

Figura 13 - Mosaico cobrindo toda a seção transversal da pelota

$\mathrm{Na}$ Vale, por exemplo, a avaliação qualitativa da microestrutura das pelotas de minério de ferro é feita visualmente por um técnico, utilizando um microscópio ótico de luz refletida. Em virtude de uma parceria com o Grupo de Microscopia Digital e Análise de Imagens do Departamento de Engenharia Química e de Materiais (DEQM), da Pontifícia Universidade Católica do Rio de Janeiro (PUCRio), ferramentas de caracterização de aglomerados de minério de ferro por processos automatizados baseados em Processamento e Análise Digital de Imagens (PADI) vem sendo desenvolvidas e utilizadas na empresa, substituindo aos poucos as análises visuais tradicionais. Resultados como mapa de distribuição de porosidade, fração de fases e exemplos de micrografias ao longo da pelota são disponibilizados em um relatório de análise para o cliente. 
Entretanto, a maioria das técnicas microscópicas, como a MO, oferece informações apenas de seções ou superfícies, o que torna os resultados pouco representativos. Uma forma de se obter informações 3D, neste caso, é o uso da estereologia para a extrapolação dos dados 0D, 1D ou 2D (fração de pontos, fração de linhas ou fração de área, respectivamente) para o espaço tridimensional (fração de volume) [5]. No entanto, é impossível extrapolar informações de medidas de tamanho e forma de objetos 2D para 3D em microestruturas complexas, com propriedades não uniformes, o que evidencia a importância da utilização de uma técnica de análise tridimensional. Além disso, requerem preparação das amostras, tais como embutimento, polimento, recobrimento com metais etc., que podem comprometer a qualidade do material, além de demandarem tempo e impossibilitarem futuras análises com outras técnicas que precisem de preparação de amostra diferente.

\section{5 . Microtomografia de raios $\mathrm{X}$}

A microtomografia computadorizada de raios X (MicroCT) é a microscopia em 3D que fornece informações externas e internas da estrutura de materiais sólidos. A técnica permite a visualização tridimensional do material e a realização de medidas verdadeiramente 3D. Em geral, requer pouca ou nenhuma preparação de amostras, possibilitando a realização de outras análises em MicroCT ou outras técnicas de uma mesma amostra.

No contexto do trabalho, é possível a caracterização tridimensional dos poros de pelotas de minério de ferro em microescala.

Serão discutidos, a seguir, os conceitos teóricos envolvidos para melhor entendimento da técnica de MicroCT.

\subsection{1.}

\section{Mecanismos de produção de raios $X$}

Os raios $\mathrm{X}$ são ondas eletromagnéticas com comprimento de onda $(\lambda)$ da ordem de 0,001 a $1 \mathrm{~nm}$. Podem ser produzidos quando partículas carregadas, com alta energia cinética, são desaceleradas rapidamente. A Figura 14 mostra o espectro eletromagnético. 


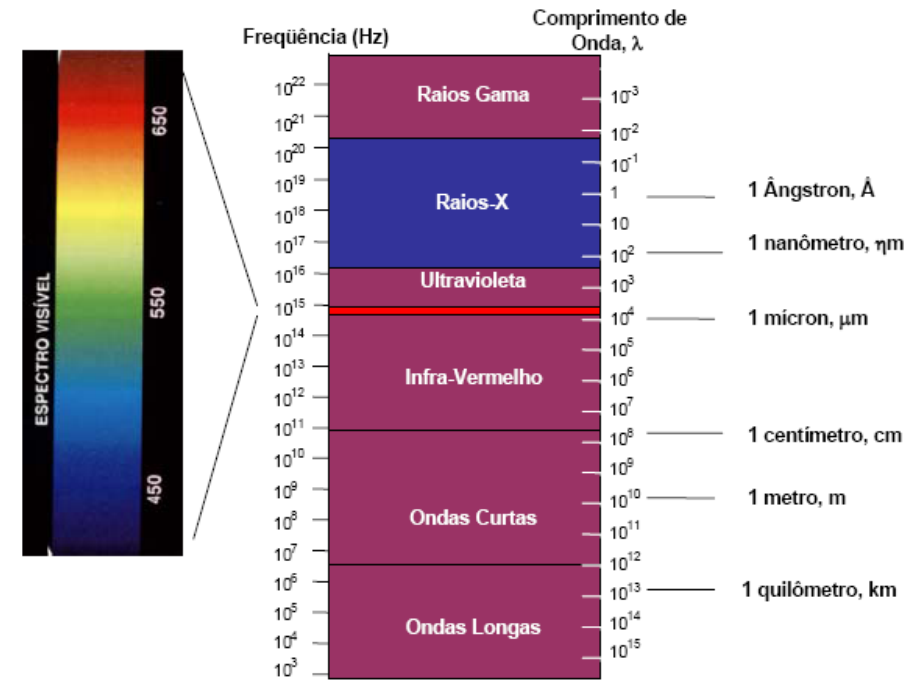

Figura 14 - Espectro eletromagnético [22]

Os mecanismos de produção de raios X podem ser de dois tipos:

- $\quad$ Espectro contínuo: Produzido pela desaceleração (Bremsstrahlung) dos elétrons do feixe devido à interação com o potencial Coulombiano gerado pelo núcleo e elétrons internos de um alvo. Neste caso, os elétrons do feixe são desviados de sua trajetória perdendo parte ou até toda sua energia (Figura 15). Este processo irá gerar radiação com um espectro largo e contínuo de energias (frequências).

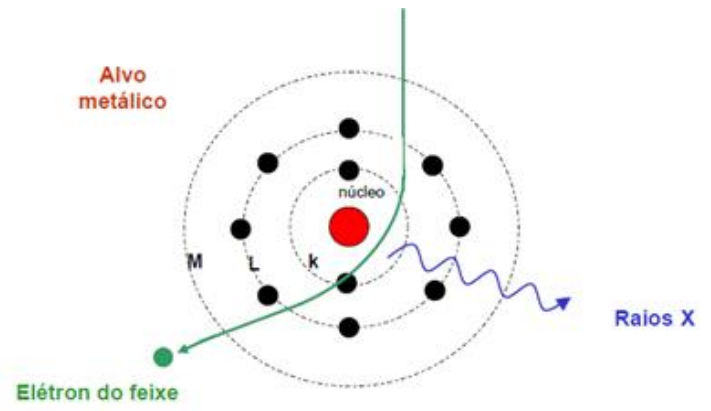

Figura 15 - Produção de raios X (espectro contínuo) [22]

- $\quad$ Espectro característico: Resulta do arrancamento dos elétrons das camadas mais internas de um átomo pelos elétrons incidentes. Assim, elétrons de camadas mais externas decaem para a camada mais interna liberando energia, 
que pode ser emitida na forma de um fóton de raios $\mathrm{X}$ ou na expulsão de um outro elétron da camada mais externa, chamado elétron Auger. Os fótons emitidos terão energia e frequência bem definidas, associadas às diferenças de energia entre as duas camadas envolvidas. $\mathrm{O}$ processo pode ser visualizado na Figura 16.

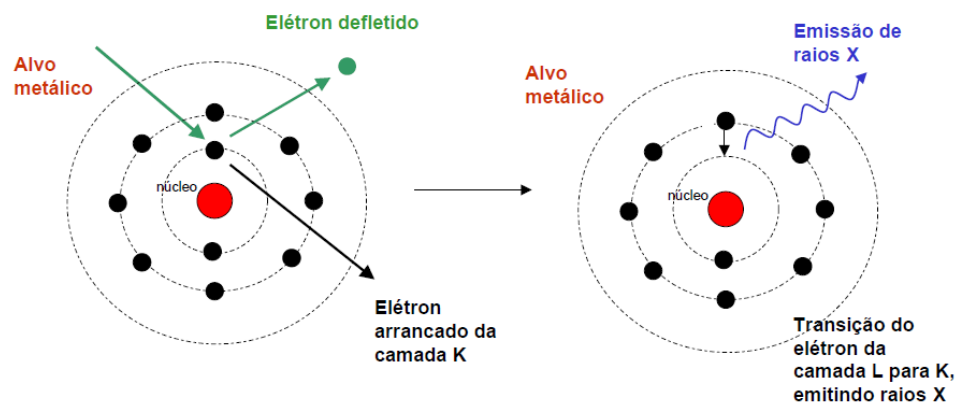

Figura 16 - Produção de raios X (espectro característico) [22]

Um exemplo de espectro contínuo e espectro característico pode ser observado na Figura 17.

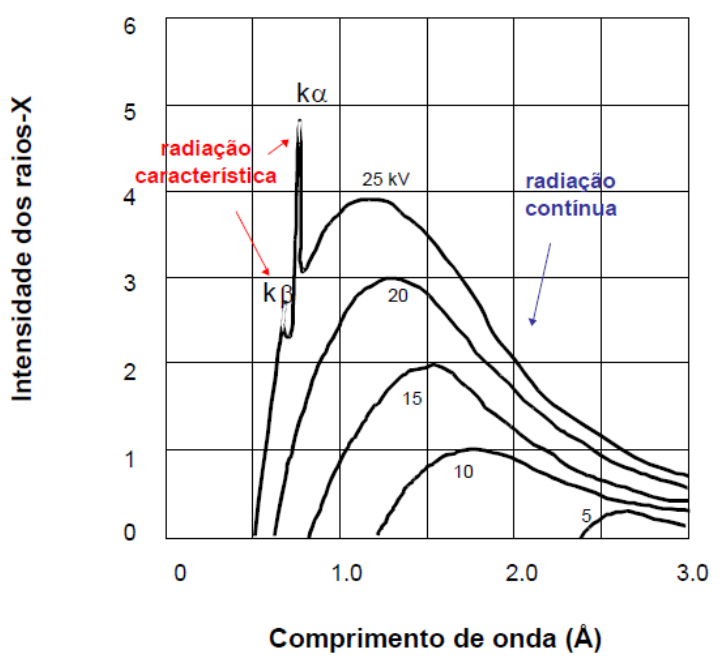

Figura 17 - Espectro de raios X do Mo como função da voltagem aplicada [22] 


\subsection{2.}

\section{A interação dos raios $X$ com a matéria}

Uma vez que os raios $X$ tenham sido gerados, eles vão interagir com a matéria (amostra). Os três modos mais importantes de interação são:

- $\quad$ Absorção fotoelétrica: ocorre quando o fóton interage com um elétron de um orbital mais interno. A energia deste fóton é totalmente absorvida pelo elétron e o fóton desaparece por completo. Com o excesso de energia, o elétron se desprende do átomo (Figura 18);

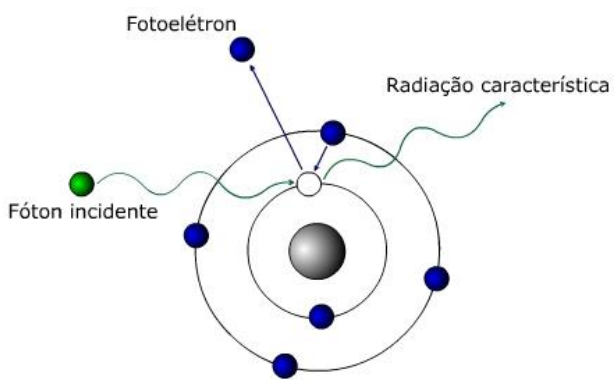

Figura 18 - Efeito fotoelétrico [23]

- Espalhamento Compton: ocorre quando há interação entre o fóton e um elétron pouco ligado ou livre (camadas mais externas). O fóton incidente cede ao elétron uma parte de sua energia, arrancando-o e sofrendo um desvio na sua trajetória inicial (Figura 19);

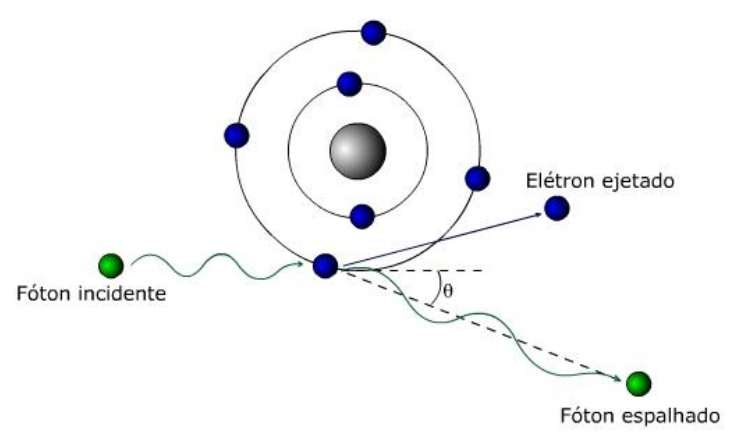

Figura 19 - Espalhamento Compton [24]

- $\quad$ Produção de pares: Consiste na interação de um fóton de alta energia com o núcleo do átomo. Há a formação de um par elétron-pósitron e o desaparecimento do fóton (Figura 20); 


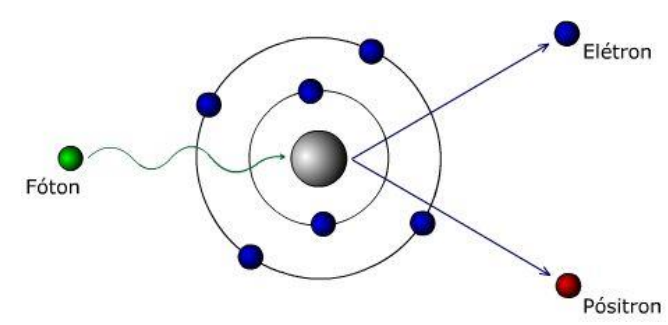

Figura 20 - Produção de pares [25]

Todos esses fenômenos podem ocorrer simultaneamente, fazendo com que o feixe incidente seja atenuado, conforme a representação na Figura 21.

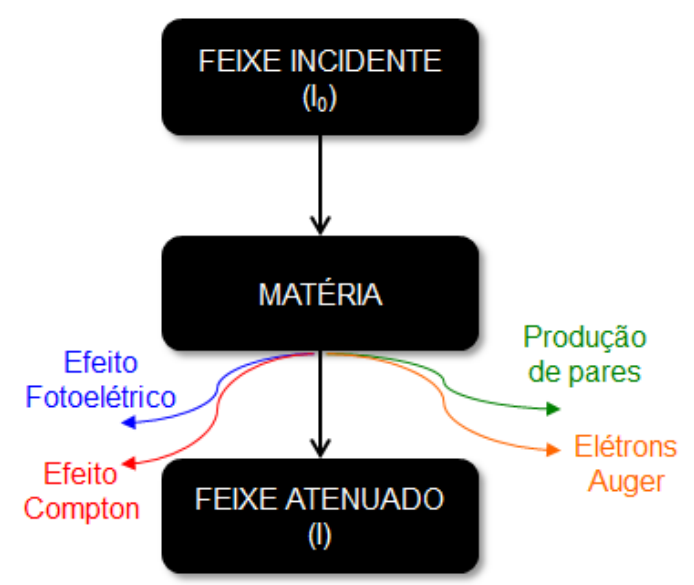

Figura 21 - Atenuação da radiação na matéria

Cada fenômeno pode ser caracterizado por um coeficiente de atenuação, função da energia do feixe de raios $\mathrm{X}$ e do número atômico do material. A soma dos coeficientes de atenuação por absorção, espalhamento e produção de pares resulta no coeficiente de atenuação total do material.

Então, quando um feixe de raios $\mathrm{X}$ incide sobre um material de espessura $\mathrm{x}$, parte do feixe é espalhada, parte é absorvida pelos processos já descritos e uma fração atravessa o material sem interagir. A intensidade I do feixe emergente está associada à intensidade $\mathrm{I}_{0}$ do feixe incidente, pela relação descrita pela Lei de Lambert-Beer (Equação 4), que estabelece que a intensidade de um feixe decresce exponencialmente à medida que a espessura do meio absorvente aumenta aritmeticamente. 
$I=I_{0} e^{-\mu x}$

Onde:

$\mathrm{I}_{0}=$ intensidade do feixe incidente

$\mathrm{I}=$ intensidade do feixe emergente

$\mu=$ coeficiente de atenuação linear total

$\mathrm{x}=$ espessura do material

Pode-se definir a atenuação total ao longo do caminho como o produto entre o coeficiente de atenuação linear total e a espessura do material, como mostra a Equação 5.

$$
\mu x=\ln \left(\frac{I_{0}}{I}\right)
$$

A Figura 22 apresenta a interação dos raios X com a matéria em função do número atômico e da energia dos fótons. Assim, o coeficiente de atenuação linear total pode ser descrito como:

$\mu=\sigma+\kappa+\tau$

Onde:

$\sigma$ é o coeficiente de atenuação linear Compton;

$\tau$ é o coeficiente de atenuação devido ao efeito fotoelétrico; e

$\kappa$ é o coeficiente de atenuação linear devido à formação de par. 


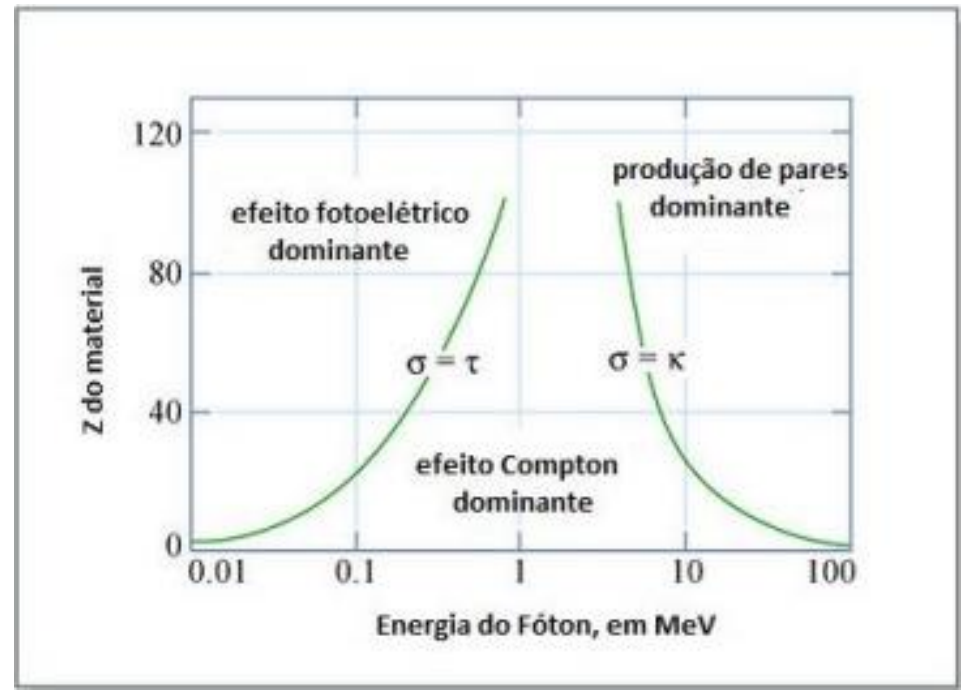

Figura 22 - Interação dos raios X com a matéria em função do número atômico do material e da energia dos fótons

Como os microtomógrafos possuem energia máxima típica de $200 \mathrm{KeV}$, não ocorre o fenômeno de produção de pares, apenas os efeitos fotoelétrico e Compton.

\subsection{3. O processo de MicroCT}

A base da MicroCT consiste na aquisição de várias projeções, enquanto a amostra é girada em pequenos intervalos angulares. $\mathrm{O}$ feixe de raios $\mathrm{X}$ atravessa a amostra, passa por um cintilador, que transforma o feixe em luz visível. A luz é, então, capturada pelo fotodetector e os dados são registrados na forma de projeções. O processo simplificado de MicroCT pode ser descrito conforme a ilustração da Figura 23.

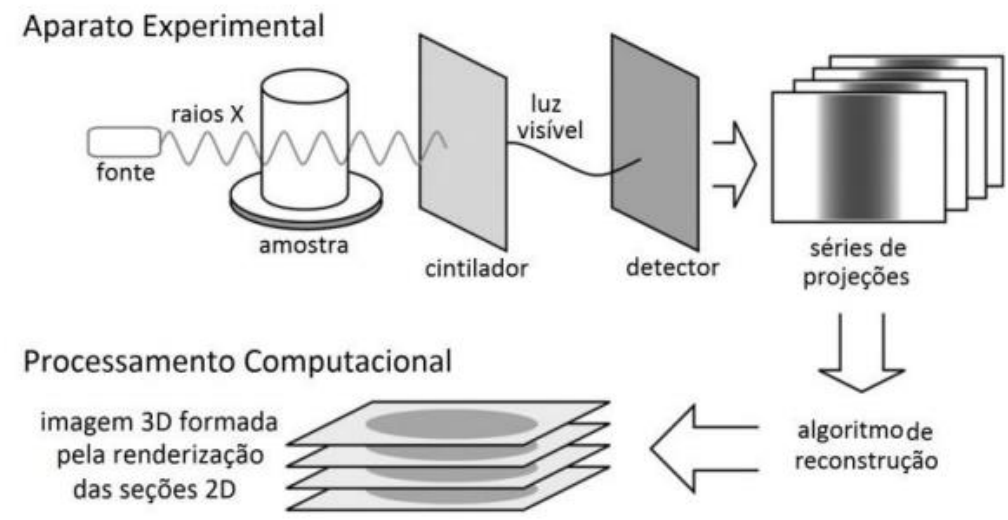

Figura 23 - Processo de microtomografia de raios X [20] 
Uma das fontes de raios $\mathrm{X}$ é o tubo de raios $\mathrm{X}$ convencional. $\mathrm{O}$ tubo de raios $\mathrm{X}$ possui um catodo, no qual um filamento aquecido gera um feixe de elétrons, e um anodo, que consiste num alvo de metal para atrair os elétrons através do tubo. Aplica-se uma diferença de potencial entre estes dois eletrodos, os elétrons são enviados em direção ao alvo metálico e os raios X são gerados (Figura 24).

No caso de aplicações não destrutivas que demandam imagens tomográficas de alta resolução, o tubo de raios $X$ deve possuir tamanho focal pequeno (cerca de alguns micra), chamado de tubo de raios $\mathrm{X}$ de microfoco. $\mathrm{O}$ tamanho e a forma do ponto focal dependem do tamanho do filamento que constitui o anodo e das características de construção do dispositivo de focalização do tubo, que, de menor dimensão, permite que a amostra seja colocada mais perto do tubo de raios $\mathrm{X}$, proporcionando maior ampliação e melhor resolução [27].

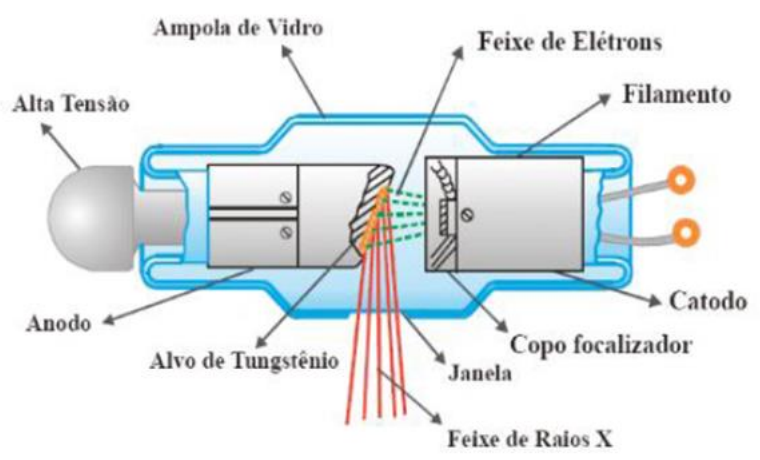

(a)

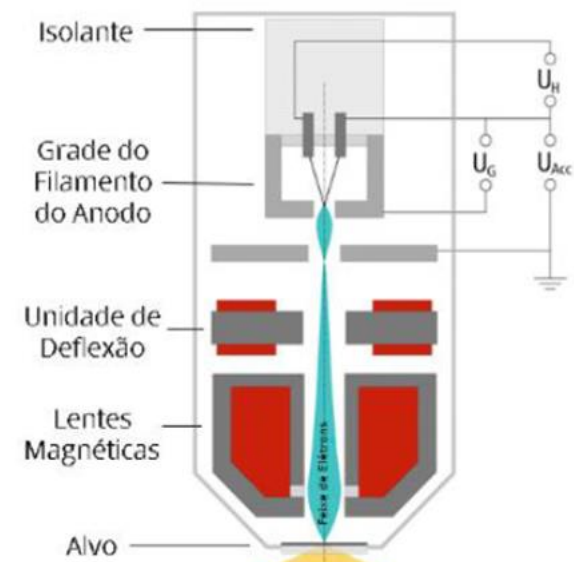

(b) Raios X

Figura 24 - Tubo de raios X: (a) convencional; (b) microfoco [28].

Para uma amostra qualquer analisada pelo MicroCT, a intensidade $\mathrm{I}(\mathrm{x}, \mathrm{z})$ pode ser modelada como uma integral de linha da absorção dos raios $\mathrm{X}$ ao longo do caminho percorrido. A projeção da intensidade $\mathrm{I}(\mathrm{x}, \mathrm{z})$, então, é formada por um conjunto de integrais de linha. A projeção final é obtida pela equação 5 , conforme Figura 25. 


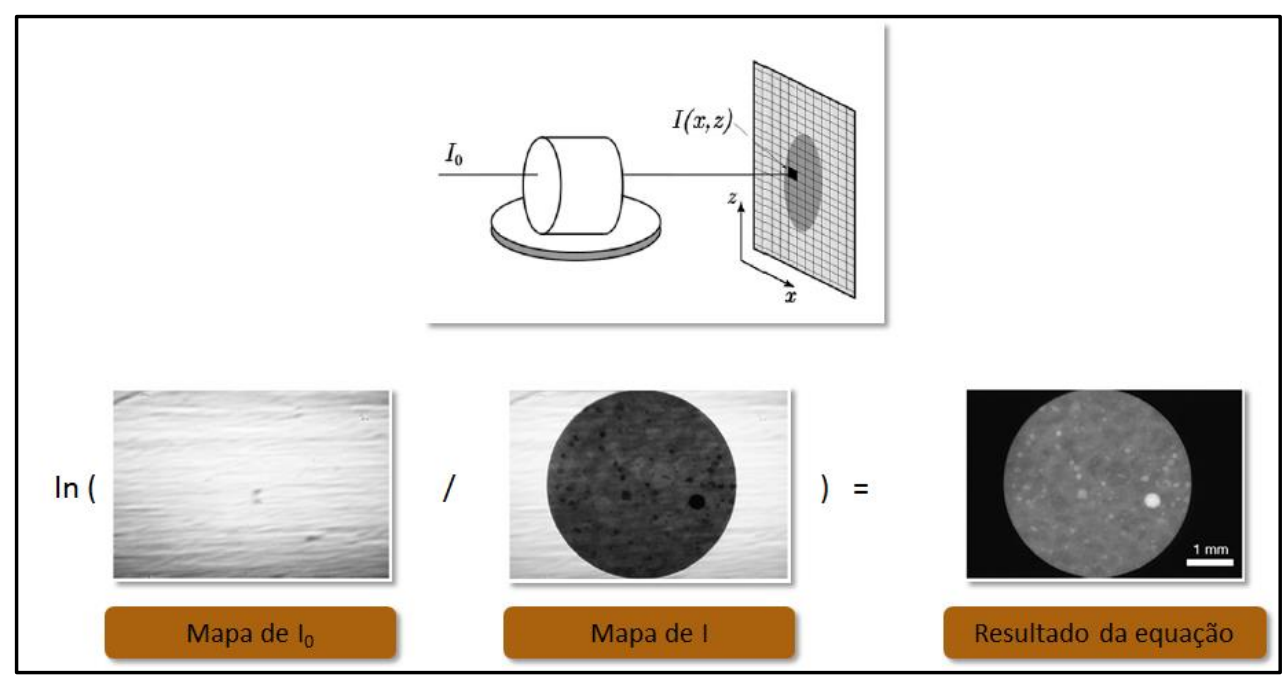

Figura 25 - Projeções da amostra a partir do feixe incidente, do feixe atenuado e do calculado pela Lei de Lambert-Beer. Adaptado de [29].

Com as projeções capturadas, o próximo passo é a reconstrução tomográfica. Para isso, um perfil de intensidade é adquirido para cada projeção, incrementada por um ângulo $\Theta$ (Figura 26). Juntando-se todas as projeções de cada $\Theta$, obtém-se um conjunto de dados chamado Sinograma, isto é, uma matriz com todas as projeções alinhadas (Figura 27).

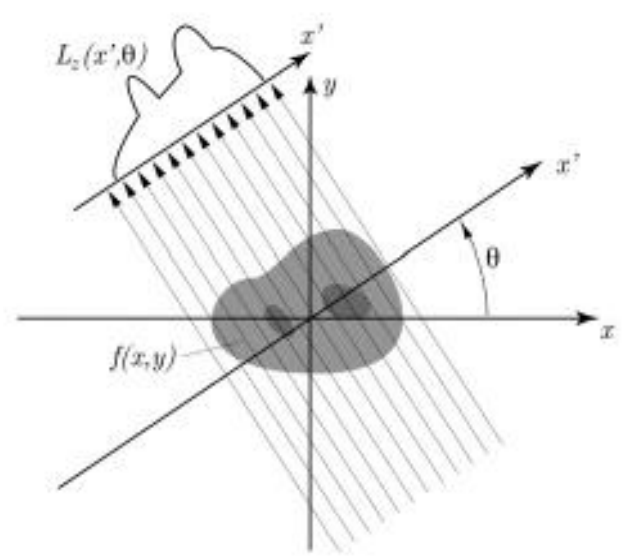

Figura 26 - Perfil de intensidade para determinado ângulo $\Theta$ [29] 


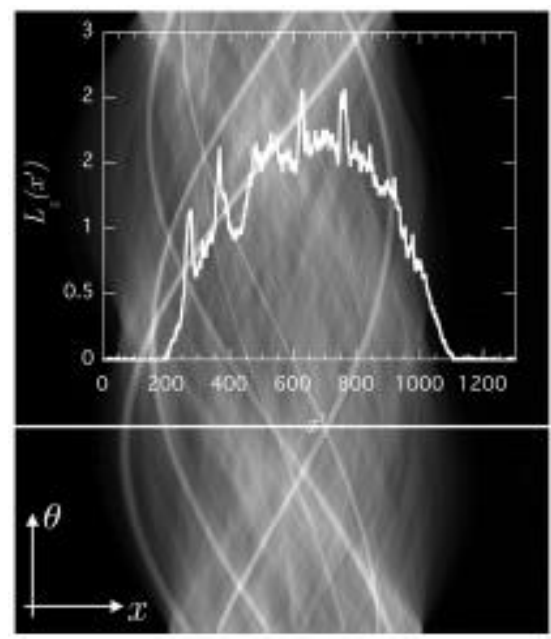

Figura 27 - Sinograma [29]

A partir dos sinogramas, realiza-se uma reconstrução matemática por meio de algoritmos computacionais sofisticados, produzindo cortes transversais (fatias 2D), perpendiculares à dimensão axial do material analisado.

\subsection{4.}

\section{Resolução da imagem e magnificação}

A resolução espacial refere-se à distância mínima entre duas estruturas que o sistema é capaz de distinguir. Um par de estruturas, conforme ilustrado na Figura 28, pode ou não ser resolvido dependendo da resolução do sistema.
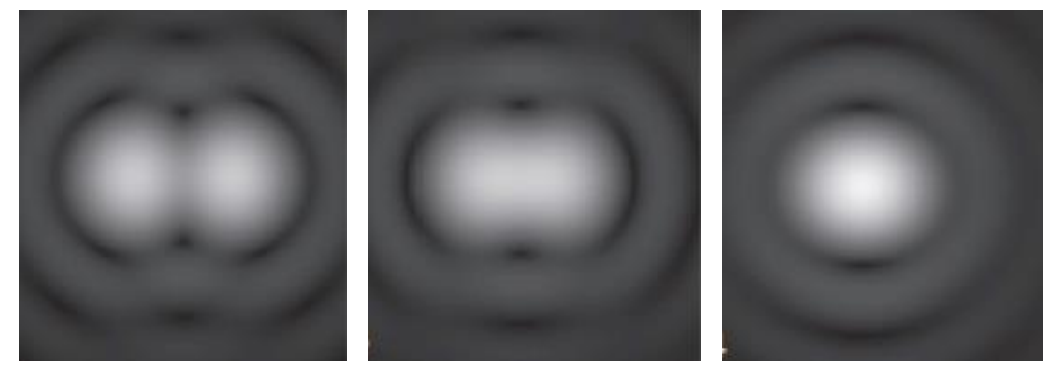

Figura 28 - Resolução espacial como uma função de medida de separação entre estruturas. Para um mesmo par de características, quanto menor a resolução, maior a separação entre as estruturas [30].

Um dos fatores limitantes do poder de resolução do equipamento, ou seja, a capacidade do sistema em identificar estruturas pequenas, é o tamanho do ponto focal discutido anteriormente. 
A resolução espacial é tipicamente medida através de um alvo-padrão de resolução espacial com um conjunto de linhas pretas paralelas progressivamente menores separadas por espaços brancos (Figura 29).

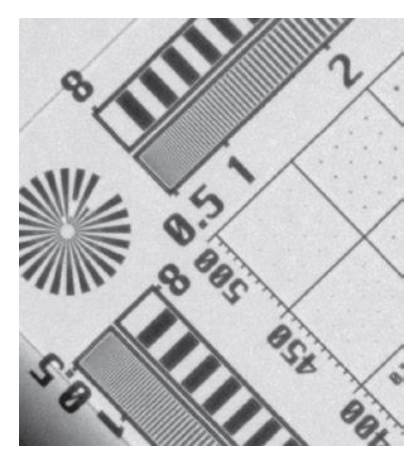

Figura 29 - Alvo-padrão para medida da resolução espacial [30].

Os equipamentos de MicroCT, em geral, utilizam dois tipos de geometria de feixe: paralela e cônica. O sistema de projeção cônico permite maximizar o aproveitamento do feixe de raios $\mathrm{X}$ produzidos pelo tubo de raios $\mathrm{X}$. O feixe cônico é o mais utilizado comercialmente e foi o utilizado neste trabalho.

Uma das formas de melhorar a resolução espacial na geometria de feixe cônico é através da magnificação geométrica, de acordo com a equação 7. O fator de magnificação (M) pode ser obtido conforme a equação 8, com base na Figura 30, na qual é ilustrada a geometria de feixe cônico.

$$
R=\frac{k}{M}
$$

Onde $R$ é a resolução espacial, $k$ é o tamanho do pixel no detector e $M$ o fator de magnificação. Assim $M$ tem um valor limite para o qual a resolução não será comprometida.

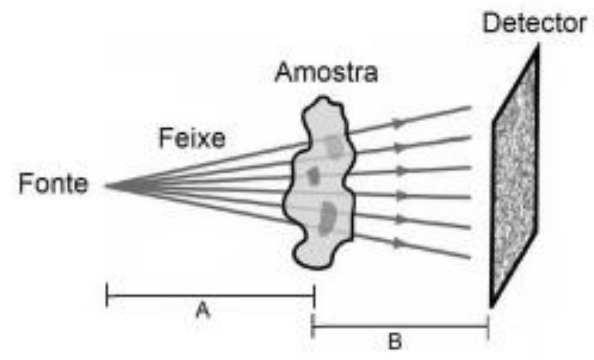

Figura 30 - Geometria cônica [20] 


$$
M=\frac{A+B}{A}
$$

Onde A é a distância fonte-amostra e B é a distância entre a amostra e o detector.

Além da possibilidade de mudança geométrica entre fonte-amostra-detector, alguns equipamentos fazem uso de um conjunto de lentes objetivas, como é o caso do microtomógrafo utilizado neste trabalho. Assim, pode-se optar em utilizar a magnificação geométrica ou a magnificação ótica, ou uma combinação entre as duas, para alcançar uma melhor resolução espacial.

Os microtomógrafos equipados com lentes objetivas são denominados microscópios de raios X (Figura 31). As lentes possuem um cintilador na entrada, convertendo os raios X em luz visível, ampliando a imagem de uma projeção.

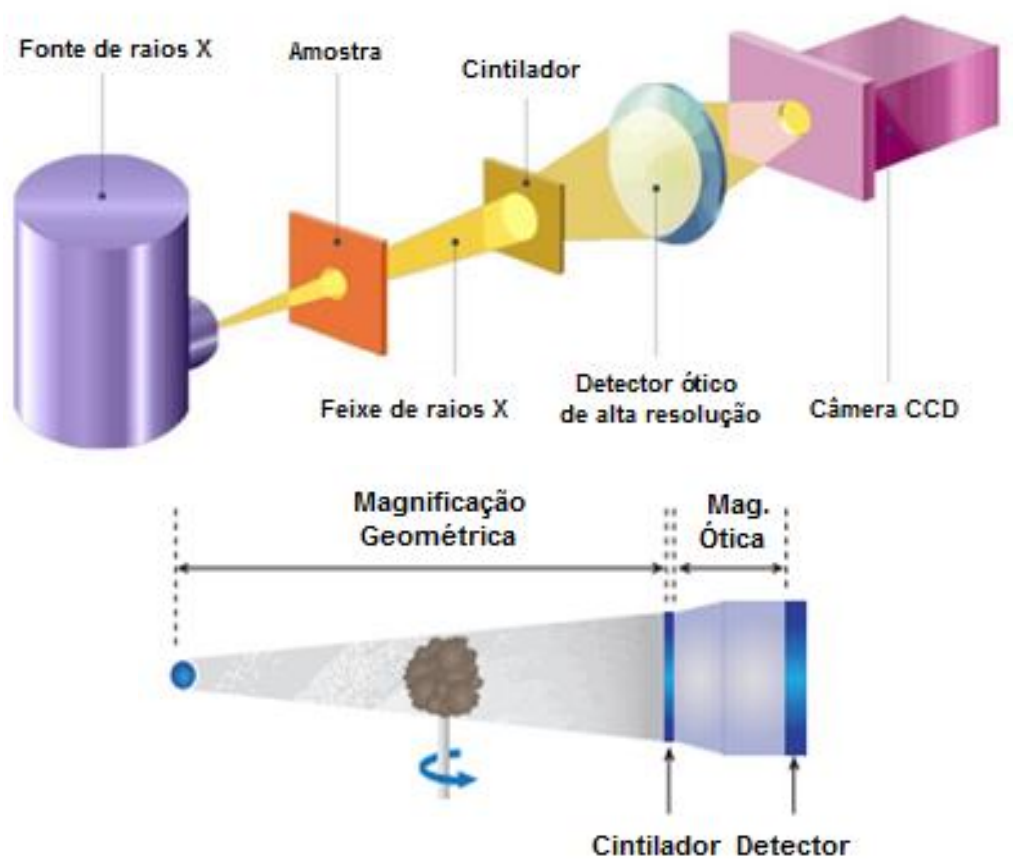

Figura 31 - Projeção cônica com lentes [31-32]

Com isso, a resolução das imagens geradas se torna independentemente do tamanho da amostra, permitindo a análise de microestruturas em diversas escalas com alta resolução e boa qualidade de contraste. A Figura 32 apresenta as resoluções para as configurações sem e com o uso de lentes objetivas, como é o 
caso do MicroCT Xradia Versa, que é o equipamento em questão no presente trabalho.

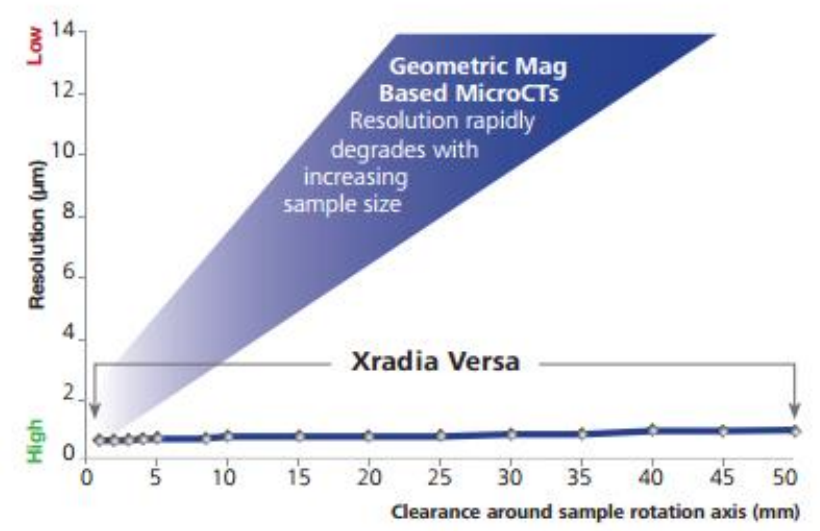

Figura 32 - Resolução obtida com o uso de lentes para diferentes distâncias fonte-amostra-detector [32]

Observa-se que, para sistemas sem lentes dos microtomógrafos convencionais, a resolução diminui rapidamente com o aumento do tamanho da amostra. Já para sistemas com lentes, a resolução é mantida alta mesmo para amostras muito grandes. Isso ocorre porque, para amostras muito grandes ou experimentos que demandem de condições de análise in situ, nas quais a distância de trabalho deva ser maior, a resolução é influenciada pela impossibilidade de aproximar a fonte, como explicado pelas equações 5 e 6 . Porém, consegue-se obter altas resoluções graças à utilização de lentes óticas, mas, para isso, a representatividade da amostra diminui.

O algoritmo de reconstrução para a geometria de feixe cônico obtém o espaço 3D diretamente dos dados 2D das projeções, sem que seja necessário reconstruir cada fatia até a formação do volume. $\mathrm{O}$ algoritmo mais utilizado para este fim é o de Feldkamp ou Retroprojeção Filtrada.

As fatias 2D reconstruídas são unidas, fornecendo a imagem tridimensional, onde o pixel é matematicamente transformado em voxel, capaz de representar a profundidade na imagem (Figura 33). 


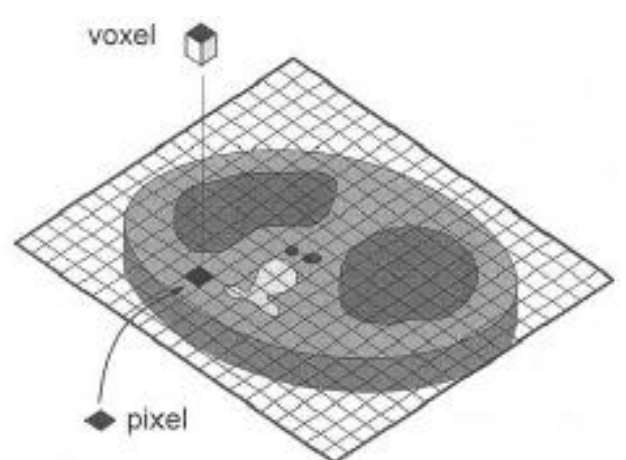

Figura 33 - Representação de um pixel e de um voxel [20]

Na prática, o ideal é que o tamanho do pixel seja duas vezes menor do que a resolução desejada [40].

A Figura 34 apresenta uma projeção, obtida em um ângulo qualquer, típica de uma pelota de minério de ferro (a), uma fatia 2D reconstruída a partir de todas as projeções (b) e um modelo 3D renderizado a partir das camadas 2D (c). 


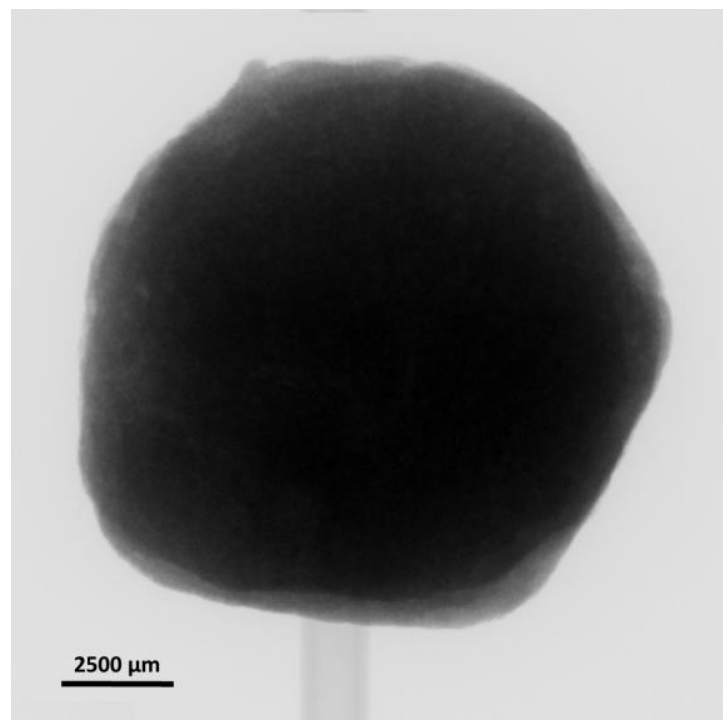

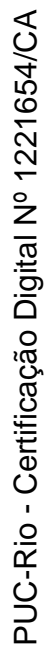
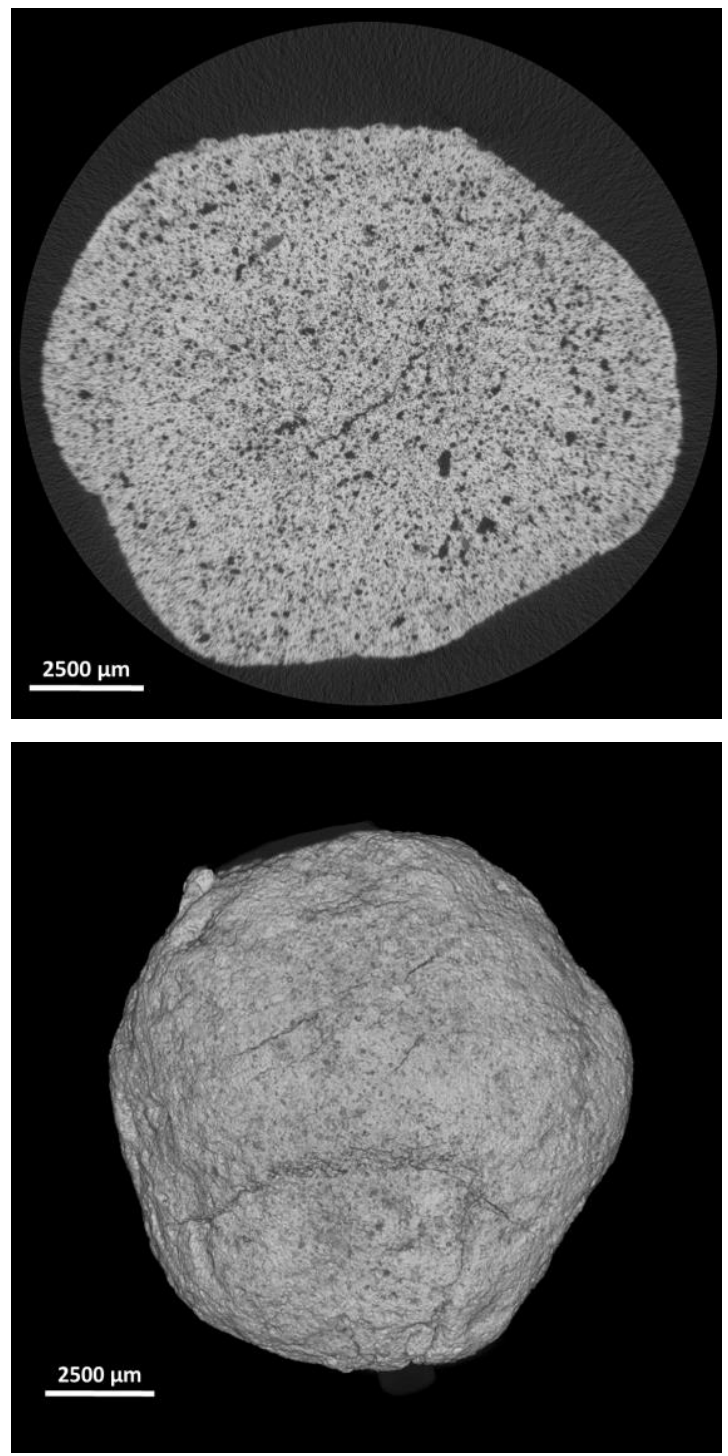

Figura 34 - (a) Projeçao; (b) Camada 2D no plano XY; (c) Modelo 3D. 


\section{6. Processamento e análise digital de imagem}

As imagens 2D e os modelos 3D são posteriormente processados através de operações matemáticas que possam corrigir defeitos ou realçar regiões de interesse, além de extrair e tratar dados quantitativos, de acordo com a sequência padrão de processamento e análise digital de imagens mostrada na Figura 35 [7].

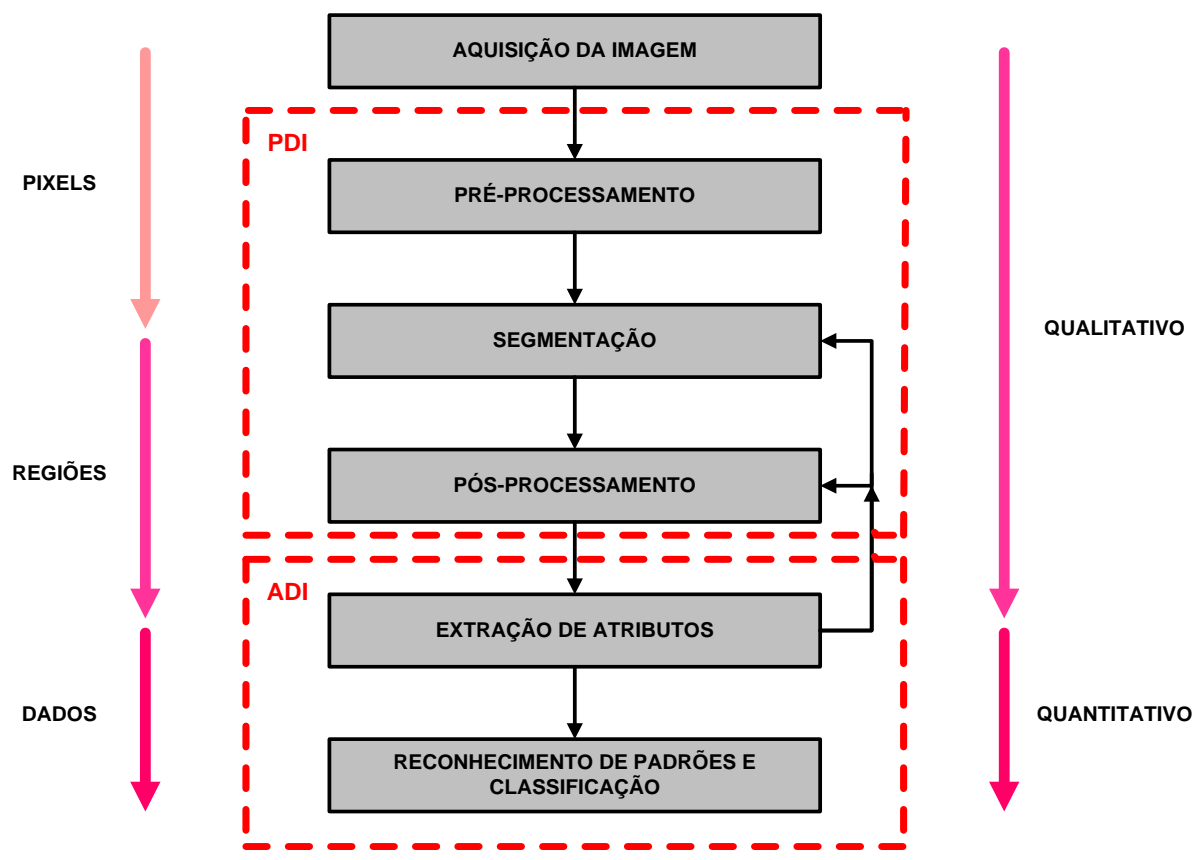

Figura 35 - Sequência padrão de processamento e análise digital de imagem [33].

O primeiro passo no processo é a aquisição da imagem, que é feita num instrumento formador de imagem, que, neste caso, é o MicroCT.

O segundo passo (pré-processamento) consiste em melhorar a imagem para as próximas etapas, corrigindo algum defeito proveniente da aquisição e/ou realçando detalhes importantes. Um exemplo disso é a aplicação de filtros para a redução de ruídos, que são muito comuns em imagens obtidas por MicroCT.

Em seguida, a segmentação, separa a imagem em objetos de interesse e fundo, gerando uma imagem binária, que contém somente pixels brancos (constituindo objetos de interesse) e pixels pretos (representando o fundo), sobre a qual se realiza as medidas. Em geral, utiliza-se o método de limiarização para a seleção das fases de interesse, com a escolha de um ou mais limiares (tons de cinza). 
No entanto, a imagem resultante da segmentação pode conter defeitos, tais como, objetos espúrios que possuem tonalidade parecida com a fase requerida e também foram segmentados, sendo necessária a etapa de pós-processamento. $\mathrm{O}$ pós-processamento corrige defeitos residuais nas imagens provenientes da segmentação a partir de operações lógicas e morfológicas entre as imagens.

A imagem de saída do pós-processamento está pronta para a etapa de extração de atributos, que é a parte quantitativa do processo, fornecendo dados numéricos para a descrição de atributos característicos.

A última etapa da sequência - reconhecimento de padrões e classificação tem como objetivo atribuir uma descrição a um objeto, baseado na informação fornecida pelo seu descritor, para que o sistema seja capaz de conferir um significado para um conjunto de objetos desconhecidos. Porém, esta etapa está fora do escopo do trabalho.

Maiores detalhes acerca do processamento e análise de imagens serão apresentados na seção de "Materiais e Métodos" e de "Resultados e Discussão".

\section{7. Trabalhos relacionados}

A literatura apresenta ainda poucos trabalhos de caracterização 3D de aglomerados de minério de ferro.

Bhuiyan propôs uma metodologia de análise quantitativa de poros de pelotas de minério de ferro cruas por MicroCT [6]. O trabalho consistiu na validação de um método estereológico, inicialmente desenvolvido para imagens de microscopia eletrônica de varredura (MEV), no qual extrapolou-se os dados de cada camada 2D da MicroCT para 3D e comparou-se com as medidas reais 3D. Para encontrar o melhor limiar de segmentação das imagens de MicroCT, ajustou-se a curva dos dados de uma camada 2D de MicroCT o mais próximo possível da curva dos dados da camada 2D obtida pelo MEV.

Forsberg e Hjortsberg estudaram o desenvolvimento de trincas em pelotas de minério de ferro durante o processo de redução [34]. Para isso, interromperam a redução da pelota em 4 tempos diferentes: $10 \mathrm{~min}, 20 \mathrm{~min}, 30 \mathrm{~min}$ e $60 \mathrm{~min}$. O processamento das imagens de $\mu \mathrm{CT}$ seguiu a seguinte sequência: segmentação de trincas e poros, separação das trincas através de atributos de forma, e obtenção de 
volume e comprimento das trincas. Os resultados de volume de trincas para uma mesma pelota em diferentes tempos de redução podem ser visualizados na Figura 36. Além disso, avaliaram a distribuição espacial das trincas, a fim de estudar a propagação das mesmas e, consequentemente, a desintegração das pelotas, durante o processo de redução.

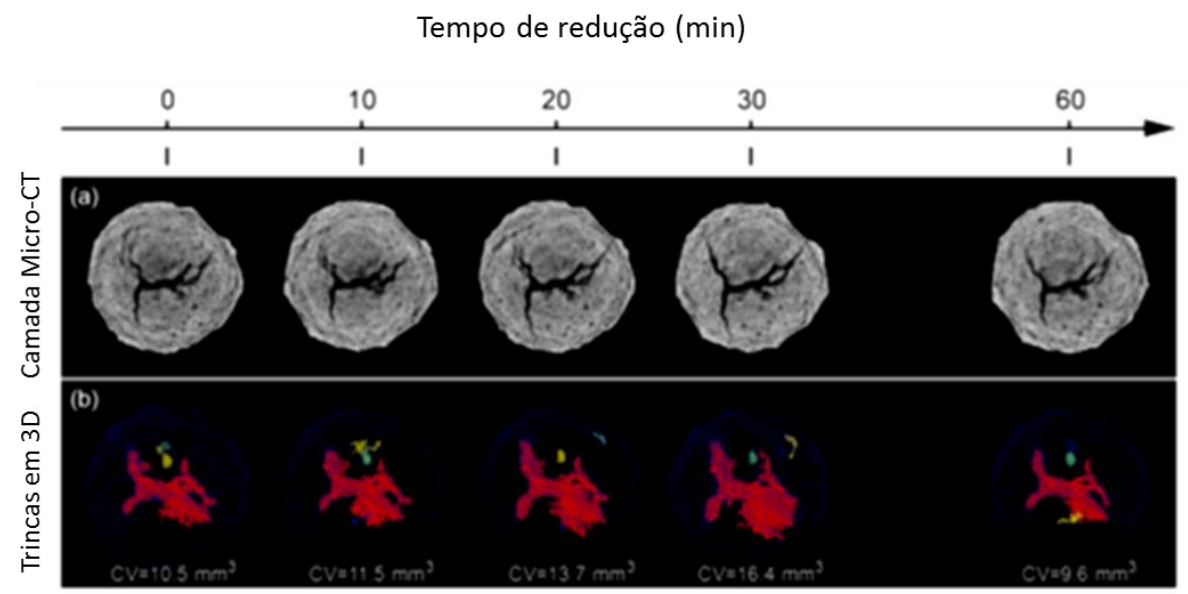

Figura 36 - Visualização 3D das trincas de uma mesma pelota em diferentes tempos de redução [34]

Shatokha et al. [35] estudaram a porosidade, por MicroCT, em sínter de minério de ferro, com diferentes composições e basicidades. Desenvolveram uma metodologia baseada em processamento de imagens para obtenção de volume de poros abertos e compararam os resultados com os obtidos em PIM. A comparação pode ser visualizada na Figura 37. Os autores explicam os valores de porosidade aberta mais baixos em porosimetria de mercúrio pelo limite do equipamento utilizado no trabalho, que avaliou somente poros entre $329 \mu \mathrm{m}$ e $0,01 \mu \mathrm{m}$. Além disso, quantificaram a porosidade aberta em amostras com diferentes basicidades em diferentes tempos de redução, confirmando que há um aumento da redutibilidade com o aumento da quantidade de poros abertos. 


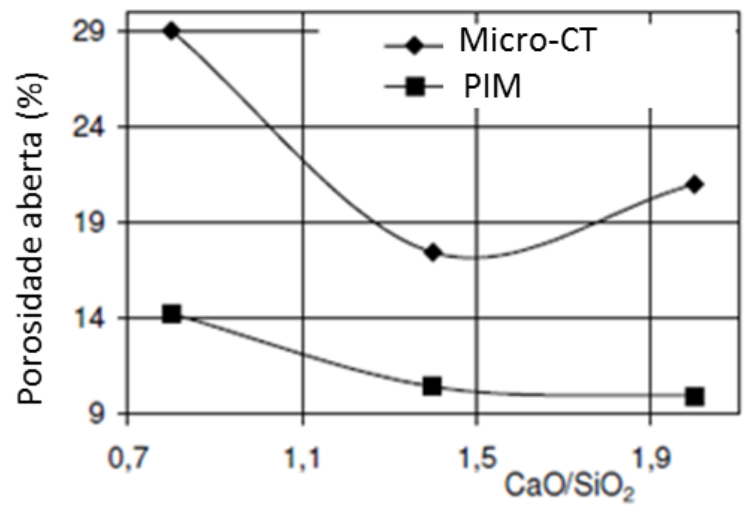

Figura 37 - Comparação entre porosidade aberta obtida por MicroCT e PIM

A evolução da estrutura interna de pelotas produzidas com diferentes agentes aglomerantes em três estágios de produção (crua, seca e queimada) foi avaliada por Silva et al. [36]. A metodologia envolve processamento de imagens de MicroCT para a obtenção de porosidade e mapa de distribuição de densidade.

A Figura 38 e a Figura 39 apresentam, respectivamente, a porosidade relativa, que consistiu em três medidas de porosidade sendo o maior desvio padrão encontrado inferior a $2 \%$, e a distribuição de densidade das pelotas em diferentes estágios de produção [36]. Os autores concluíram que as pelotas apresentam mais regiões de maior densidade, identificadas pela cor vermelha, ao atingirem o estágio de pelota queimada.

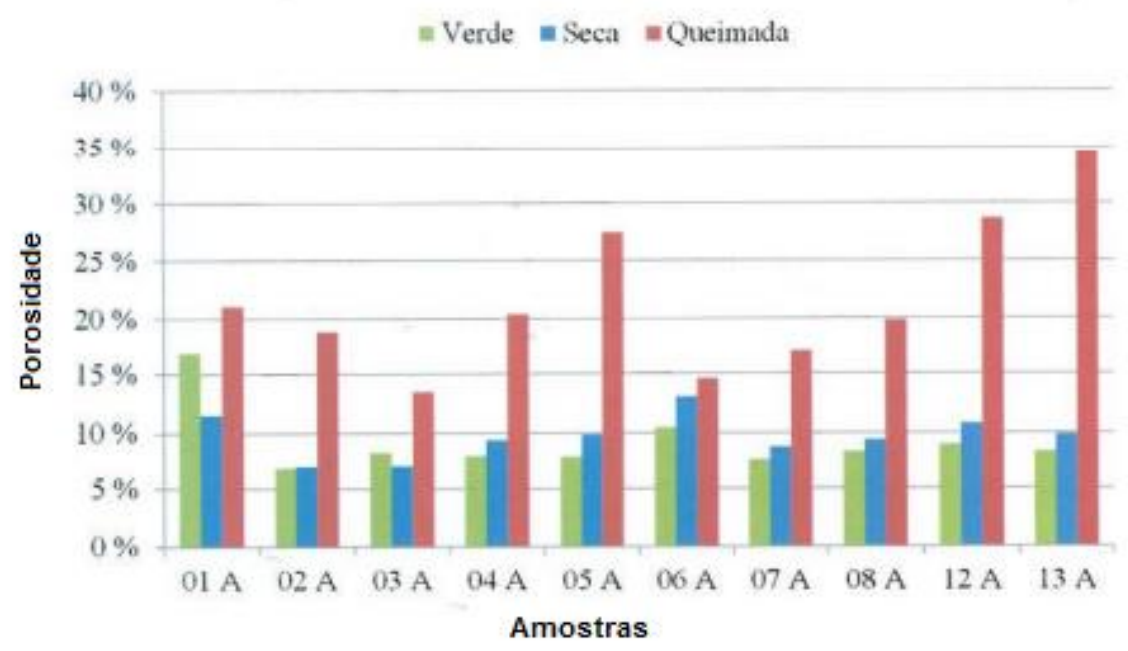

Figura 38 - Valores médios de porosidade relativa das pelotas em cada um dos estágios de produção [36]. 

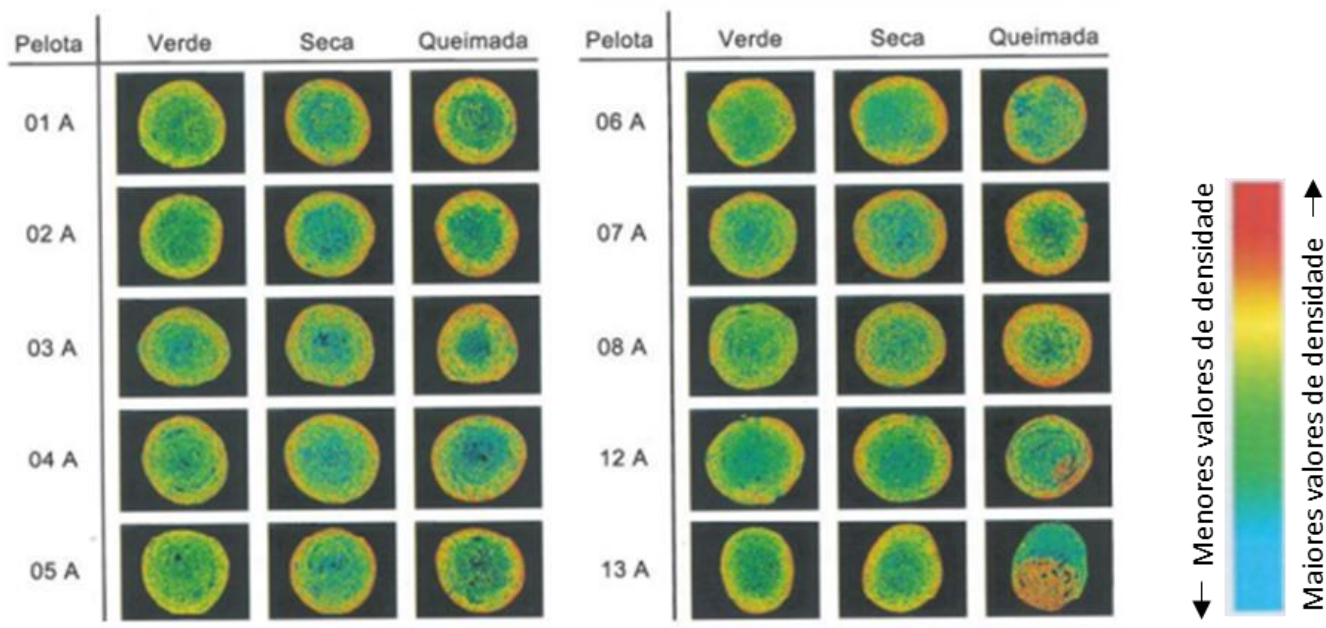

Figura 39 - Imagens de MicroCT das pelotas em diferentes estágios de produção [36]

Rocha \& Castro [37] estudaram a porosidade em pelotas autorredutoras contendo poeiras de forno a arco elétrico, por meio de seccionamento em série da microestrutura da pelota. A reconstrução tridimensional se deu a partir de imagens obtidas em MO de 85 seções. Também foram feitas análises em MEV de 5 campos aleatórios e com a técnica de picnometria, a fim de comparar os resultados obtidos. Os resultados são apresentados na Figura 40.

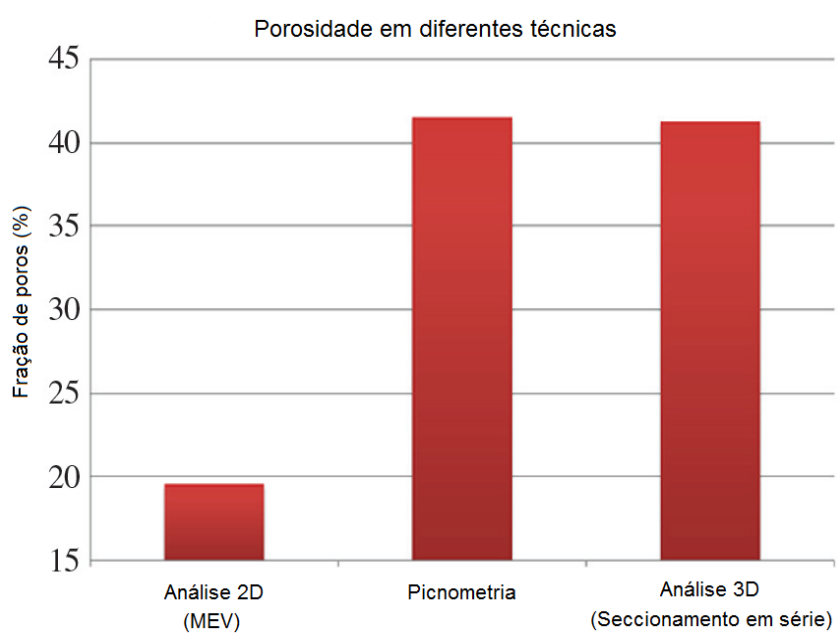

Figura 40 - Comparação da porosidade entre diferentes técnicas [37]. 
Os autores explicaram que os valores muito menores da análise 2D provavelmente são devido à anisotropia do material. Além disso, a análise bidimensional utilizando imagens de MEV requer um grande número de imagens de toda a superfície da amostra.

Para trabalhos envolvendo caracterização de porosidade e comparação entre técnicas de MicroCT e PIM, encontra-se alguns em análise de rochas. Um deles desenvolveu uma metodologia de composição multiescala de rochas reservatório de petróleo a partir de imagens de microtomografia e nanotomografia de raios $\mathrm{X}$, além de MEV, em volumes adequados de amostras [20]. Obteve-se a porosidade total e a distribuição de tamanho de poros, que, posteriormente, foram comparadas com os resultados obtidos por PIM. Mantovani [20] explica o deslocamento da curva por PIM para a esquerda pela presença de microporos (raios menores do que $1 \mu \mathrm{m}$ ), os quais não foram detectados pelo modelo multiescala (por morfologia matemática nas imagens 3D), devido ao limite dado pela resolução espacial das imagens de MicroCT utilizadas para compor uma das escalas. As comparações encontram-se na Figura 41.

Outro trabalho envolvendo análise de porosidade de rochas a partir de análise de imagens de microscopia foi feito por Labus [38]. O autor comparou os resultados obtidos com as técnicas de PIM e picnometria e concluiu que os resultados por microscopia foram próximos aos resultados por PIM. Além disso, verificou que o valor de porosidade aumentou com o obtido por maior magnificação, provavelmente por revelar poros menores. No entanto, esses poros menores não influenciam na porosidade efetiva da rocha. Os resultados obtidos são apresentados na Figura 42. 


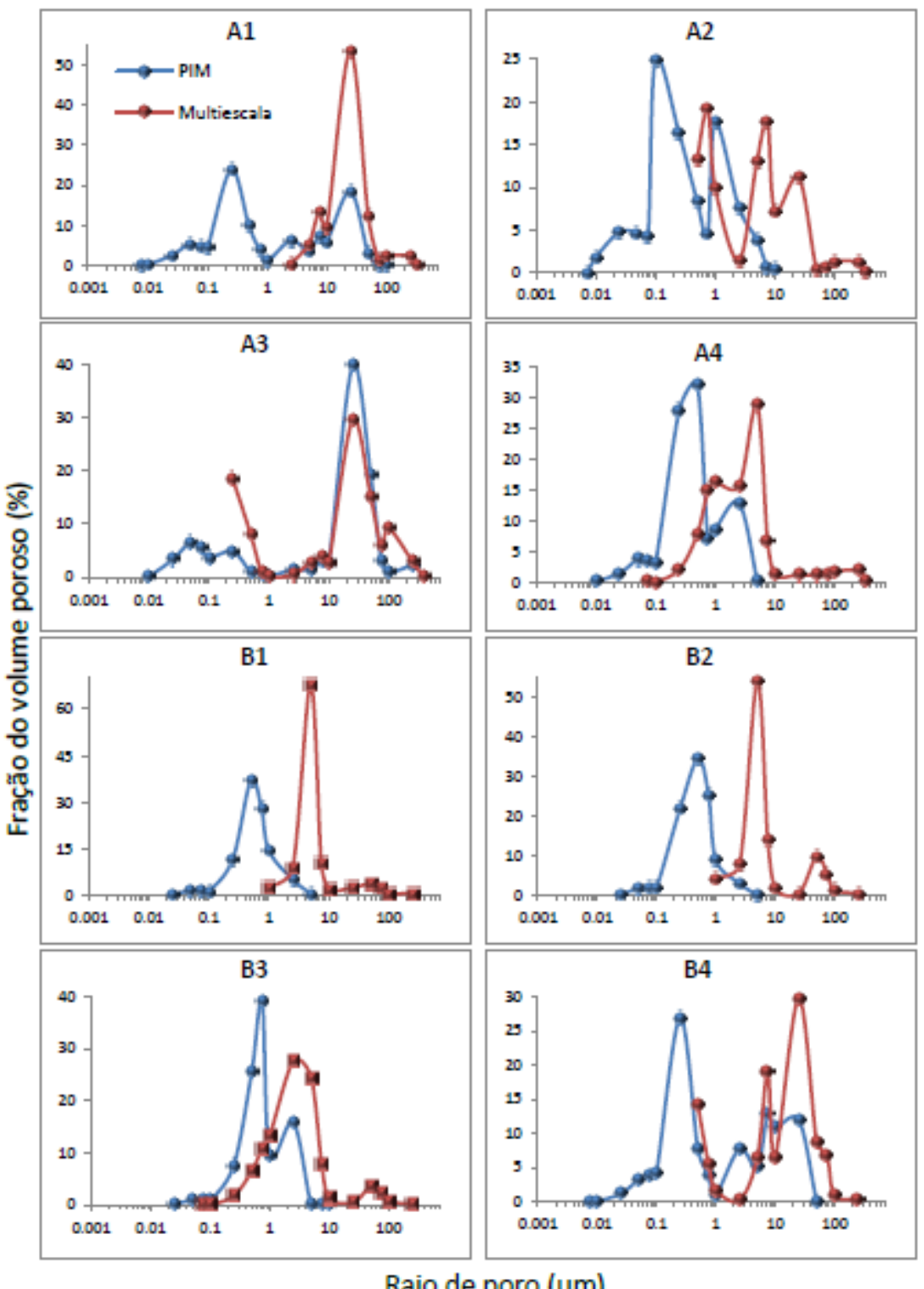

Raio de poro $(\mu \mathrm{m})$

Figura 41 - Em azul, distribuição de tamanho de poros obtidos por PIM; e, em vermelho, a distribuição obtida pelo modelo multiescala (por morfologia matemática nas imagens 3D) [20]. 


\begin{tabular}{|c|c|c|}
\hline \multirow{2}{*}{ Amostras } & \multicolumn{2}{|c|}{ Fração de área de poros (\%) } \\
\cline { 2 - 3 } & \multicolumn{2}{|c|}{ Magnificação } \\
\cline { 2 - 3 } & $\mathrm{x} 100$ & $\mathrm{x} 200$ \\
\hline 1 & 13.37 & 13.40 \\
\hline 2 & 15.28 & 16.10 \\
\hline 3 & 16.82 & 20.27 \\
\hline 4 & 5.15 & 6.39 \\
\hline 5 & 3.10 & 3.52 \\
\hline 6 & 10.43 & 12.51 \\
\hline 7 & 9.50 & 9.36 \\
\hline 8 & 5.22 & 6.30 \\
\hline 9 & 15.98 & 17.60 \\
\hline
\end{tabular}

\begin{tabular}{|c|c|c|c|c|c|}
\hline \multirow{2}{*}{ Amostras } & \multicolumn{2}{|c|}{ Picnômetro } & \multicolumn{3}{c|}{ Porosimetria } \\
\cline { 2 - 6 } & $\begin{array}{c}\text { densidade } \\
{\left[\mathrm{g} / \mathrm{cm}^{3}\right]}\end{array}$ & $\begin{array}{c}\text { Porosidade } \\
\text { total [\%] }\end{array}$ & $\begin{array}{c}\text { Porosidade } \\
{[\%]}\end{array}$ & $\begin{array}{c}\text { Diâmetro } \\
\text { mediano } \\
{[\mathrm{mm}]}\end{array}$ & $\begin{array}{c}\text { Área total } \\
\text { de poros } \\
{\left[\mathrm{m}^{2} / \mathrm{g}\right]}\end{array}$ \\
\hline 1 & 2.30 & 12.32 & 10.92 & 0.81 & 0.24 \\
\hline 2 & 2.26 & 15.67 & 13.60 & 0.33 & 0.73 \\
\hline 3 & 2.22 & 15.81 & 13.62 & $p .42$ & 0.58 \\
\hline 4 & 2.51 & 5.25 & 4.88 & 0.26 & 0.30 \\
\hline 5 & 2.56 & 3.68 & 3.48 & 0.10 & 0.55 \\
\hline 6 & 2.43 & 9.26 & 8.40 & 0.28 & 0.49 \\
\hline 7 & 2.43 & 9.62 & 8.78 & 0.21 & 0.70 \\
\hline 8 & 2.55 & 4.43 & 4.16 & 0.02 & 2.14 \\
\hline 9 & 2.46 & 14.46 & 12.29 & 0.04 & 1.28 \\
\hline
\end{tabular}

Figura 42 - Resultados obtidos por análise de imagens, picnometria e porosimetria [38].

Klobes et al. [39] propôs uma metodologia para determinação de porosidade em rochas a partir da combinação das técnicas de PIM e MicroCT. A metodologia consistiu em três ciclos de injeção de mercúrio com a subsequente análise em MicroCT. Os resultados podem ser encontrados na Figura 43. 

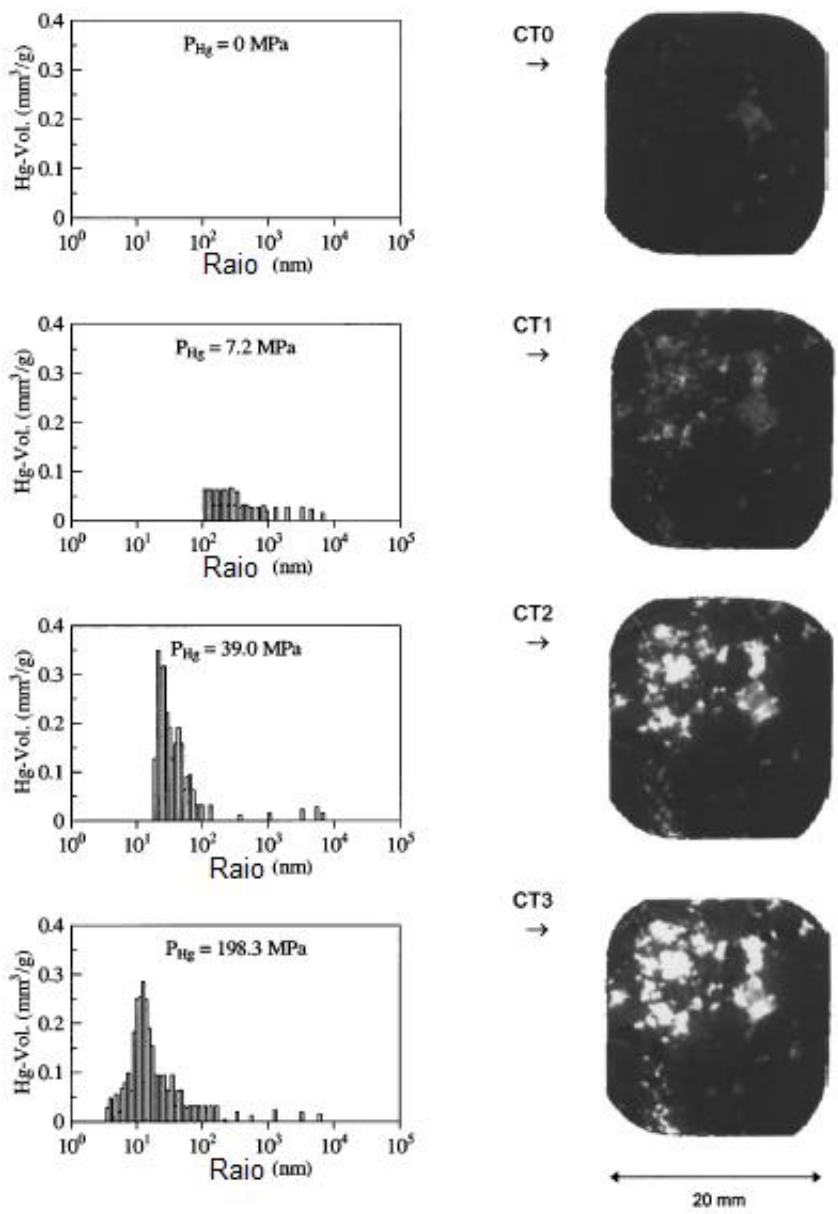

Figura 43 - À esquerda: resultados por PIM, com as respectivas máximas pressões; à direita: resultados por MicroCT após cada ensaio de injeção de mercúrio [39].

Com o aumento da pressão de intrusão de mercúrio, há uma penetração não homogênea na amostra, mostrada pelas alterações do nível de cinza nas imagens. Segundo os autores, o método proposto pode ser usado para caracterizar qualitativamente a distribuição espacial da porosidade.

Reis Neto et al. [40] também estudaram a porosidade em rochas por MicroCT integrada à petrografia, permitindo a identificação de fases minerais com diferentes atenuações e o melhor entendimento do meio poroso e das relações entre diferentes fases. Um dos resultados obtidos neste trabalho encontra-se na Figura 44. 


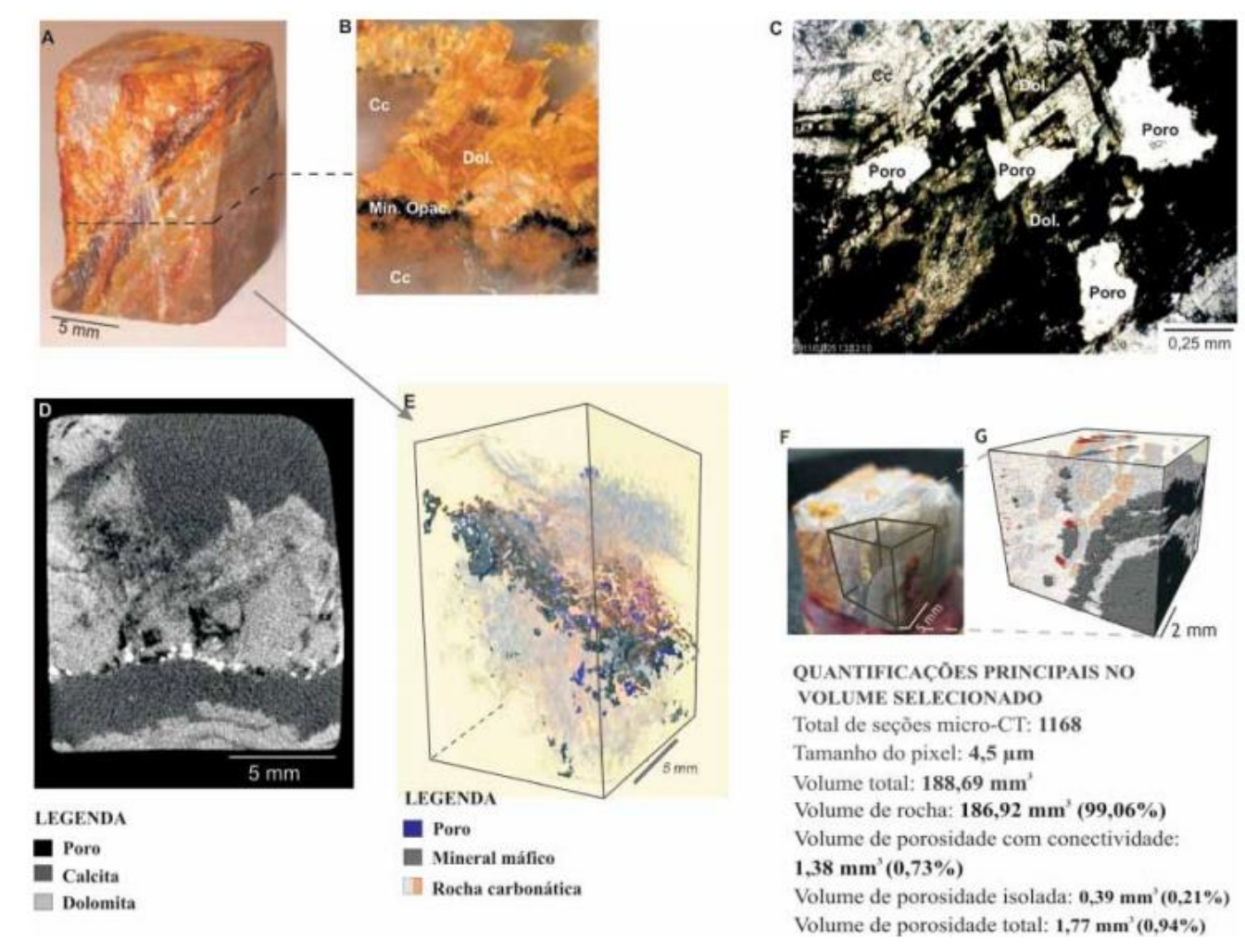

Figura 44 - Análise de porosidade por MicroCT integrada à petrografia em rocha dolomítica: A) Fotografia da rocha carbonática; B) Corte efetuado na amostra a fim de obter melhor correlação com os cortes virtuais executados por MicroCT (Cc: calcita; Dol: dolomita; Min. Opac: mineral opaco); C) Imagem de microscópio ótico. D) Seção microtomográfica selecionada com demarcação das fases correlacionadas com a petrografia. E) Modelo tridimensional gerado após a separação das fases nas seções microtomográficas; F) Fotografia da rocha utilizada para as quantificações apresentadas, com o volume selecionado demarcado. G) Um dos modelos tridimensionais gerados a partir do volume selecionado para quantificação [40].

Para a obtenção dos dados, as imagens das rochas obtidas por MicroCT foram correlacionadas com informações obtidas por microscopia ótica em lâminas confeccionadas a partir do mesmo material. Dessa forma, foi possível identificar as fases minerais presentes nas imagens de MicroCT a partir da descrição petrográfica. Além disso, a análise por MicroCT possibilitou a análise qualitativa e quantitativa da forma, tamanho, volume, distribuição e conectividade dos poros. 


\section{3 \\ Materiais e métodos}

Este capítulo descreve detalhadamente os procedimentos experimentais realizados neste trabalho, apresentando as técnicas e os equipamentos utilizados. Cabe ressaltar que, uma vez que o objetivo do trabalho é o desenvolvimento de uma metodologia, parte das etapas experimentais são resultados e, por isso, foram colocadas no capítulo de "Resultados e Discussão".

\section{1.}

\section{Amostras}

Para a execução deste trabalho, a Vale forneceu ao DEQM 25 pelotas de minério de ferro de 2 tipos diferentes, denominadas de P1 e P2. Os dois tipos de pelotas, P1 e P2, são para alto-forno, mas produzidas em usinas distintas a partir de minérios muito diferentes texturalmente. As especificações químicas das pelotas encontram-se na Tabela 2.

Tabela 2 - Especificação química das pelotas P1 e P2

\begin{tabular}{|c|c|c|}
\multirow{2}{*}{ Composição } & P1 & Pelotas \\
\cline { 2 - 3 } & 65,51 & 65,36 \\
\hline $\mathbf{F e}(\%)$ & 2,57 & 2,57 \\
\hline $\mathbf{S i O}_{\mathbf{2}}(\mathbf{\%})$ & 0,59 & 0,83 \\
\hline $\mathbf{A l}_{\mathbf{2}} \mathbf{O}_{\mathbf{3}}(\mathbf{\%})$ & 2,80 & 2,41 \\
\hline $\mathbf{C a O}(\%)$ & 0,032 & 0,052 \\
\hline $\mathbf{P}(\mathbf{\%})$ & 0,07 & 0,07 \\
\hline $\mathbf{M n}(\%)$ & 1,09 & 0,86 \\
\hline $\mathbf{B 2}\left(\mathbf{C a O} / \mathbf{S i O}_{2}\right)$ & &
\end{tabular}

Dessas 25 amostras, utilizou-se um grupo contendo 17 pelotas para o desenvolvimento da metodologia, chamado neste trabalho de "Grupo Desenvolvimento" e o restante das amostras, contendo 8 pelotas, foi utilizado com a metodologia já definida, com o intuito de apenas aplicá-la, denominado, então, de "Grupo Aplicação". 
Todas as amostras dos dois grupos foram analisadas por MicroCT. No entanto, como as técnicas de PIM e MO são destrutivas, separou-se as amostras em dois grupos, onde um grupo foi analisado por PIM e outro grupo analisado por MO, permitindo a comparação dos resultados obtidos entre as técnicas tradicionais e a MicroCT. A Tabela 3 e a Tabela 4 apresentam as nomenclaturas das amostras do Grupo Desenvolvimento e do Grupo Aplicação, respectivamente.

Tabela 3 - Grupo Desenvolvimento - Amostras para o desenvolvimento da metodologia

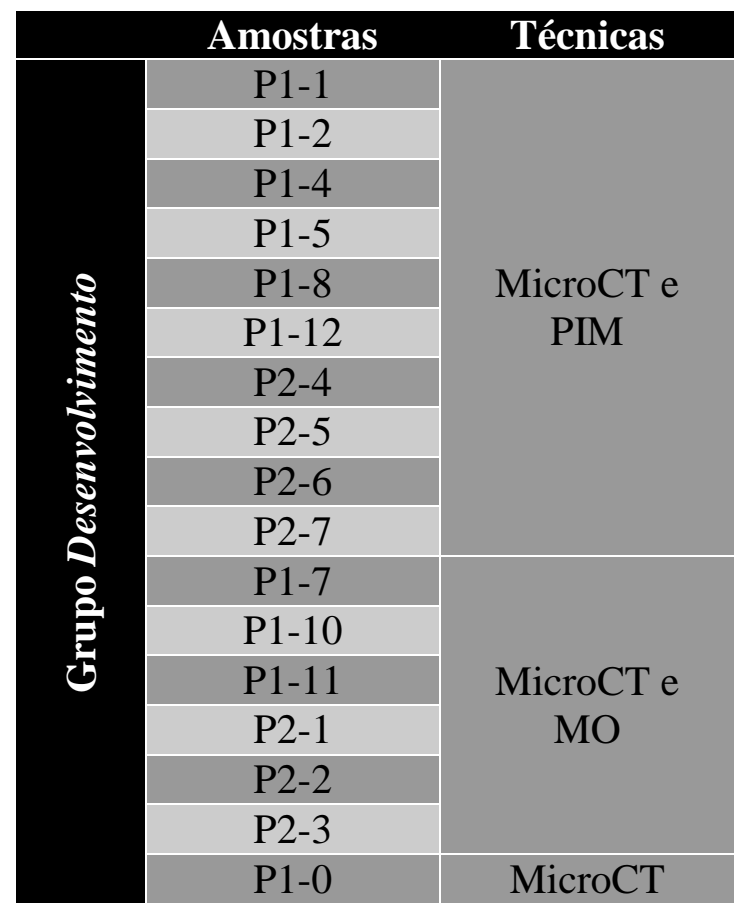

Tabela 4 - Grupo Aplicação - Amostras para a aplicação da metodologia

\begin{tabular}{|c|c|c|}
\hline & Amostras & Técnicas \\
\hline \multirow{8}{*}{0} & P1-13 & \multirow{6}{*}{$\begin{array}{c}\text { MicroCT e } \\
\text { PIM }\end{array}$} \\
\hline & P1-14 & \\
\hline & P2-14 & \\
\hline & P2-15 & \\
\hline & P2-16 & \\
\hline & P2-17 & \\
\hline & P1-17 & \multirow{2}{*}{$\begin{array}{c}\text { MicroCT e } \\
\text { MO }\end{array}$} \\
\hline & P2-18 & \\
\hline
\end{tabular}




\section{2.}

Porosimetria por intrusão de mercúrio

\subsection{1.}

\section{Preparação das amostras}

Não é necessário nenhum tipo de preparação das amostras para as análises de porosimetria de mercúrio.

As pelotas foram analisadas inteiras, duas a duas, ou seja, conforme a Tabela 5.

Tabela 5 - Amostras para PIM

\begin{tabular}{|c|cc|}
\hline \multicolumn{1}{|c|}{ Pelotas } & Grupo Desenvolvimento & Grupo Aplicação \\
\cline { 2 - 3 } P1 & P1-1+ P1-4 & \\
& P1-2 + P1-5 & P1-13 + P1-14 \\
\hline \multirow{2}{*}{ P2 } & P1-8 + P1-12 & P2-14 + P2-15 \\
\hline
\end{tabular}

\subsection{2.}

Análise

A análise dos parâmetros de porosidade das amostras pelo método da porosimetria por intrusão de mercúrio foi realizada na Vale, em um porosímetro Micromeritics modelo Auto-Pore III, nos estágios de baixa e alta pressão (até 60000 psi), apresentado na Figura 45. 


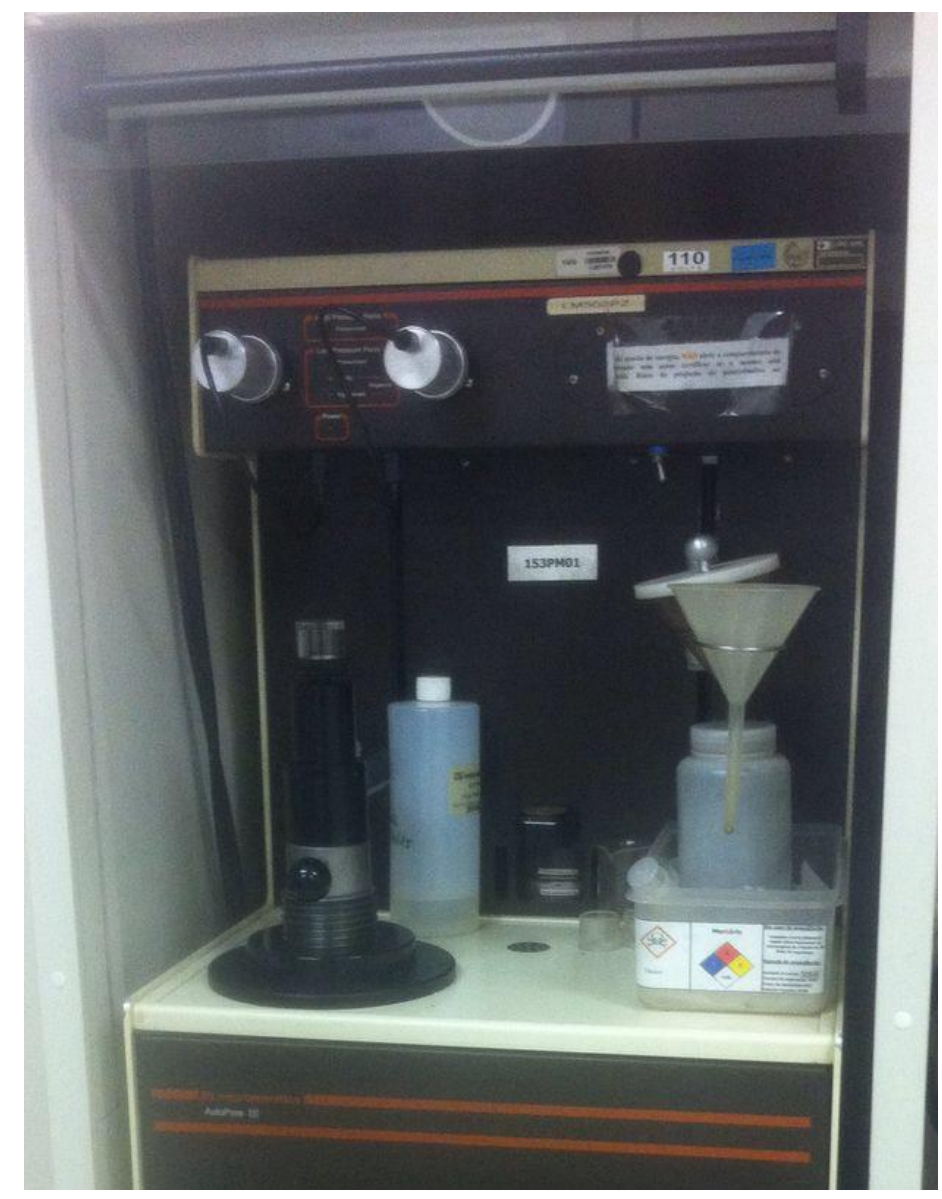

Figura 45 - Porosímetro de Mercúrio, pertencente à Vale, modelo Auto-Pore III

Neste método de análise, o diâmetro dos poros é inversamente proporcional à pressão exercida, ou seja, quanto maior a pressão de intrusão do mercúrio menor é o diâmetro do poro analisado. $\mathrm{O}$ equipamento em questão é capaz de analisar meso e macroporos com diâmetros entre $0,003 \mu \mathrm{m}$ a $360 \mu \mathrm{m}$.

O tempo de análise é, em geral, de $1 \mathrm{~h}$ à $2 \mathrm{~h}$.

\section{3.}

\section{Microtomografia de raios $\mathrm{X}$}

\subsection{1.}

\section{Preparação das amostras}

Para a microtomografia de raios $X$ não foi necessário nenhum tipo de preparação de amostra. No caso do presente trabalho, apenas prendeu-se a amostra em um suporte bem fino para encaixá-la no porta-amostra do MicroCT, como visto na Figura 46, com a identificação da amostra para a posterior análise (PIM ou MO). 
Como será visto mais adiante, o suporte fino serviu como referência para o embutimento das amostras para MO, visto que a superfície exposta deve ser um plano perpendicular ao eixo do suporte, da mesma forma que a fatia $2 \mathrm{D}$ obtida da reconstrução das análises em MicroCT.

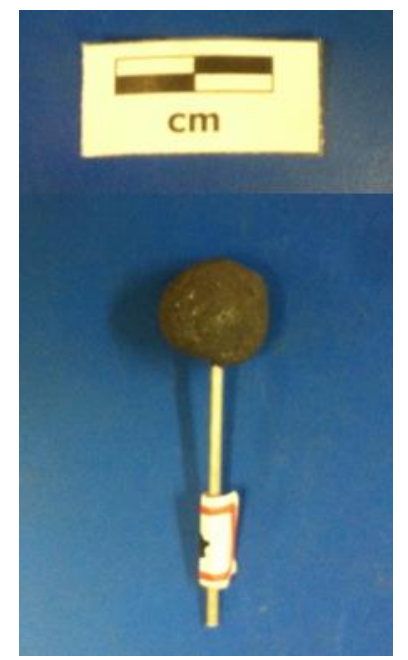

Figura 46 - Amostra pronta para análise em MicroCT

\subsection{2.}

\section{Aquisição de imagens}

Para a aquisição de imagens, foi utilizado o microtomógrafo de raios $\mathrm{X}$ modelo ZEISS Xradia 510 Versa (Figura 47 e Figura 48). O software de aquisição é específico do sistema Zeiss, chamado Scout-and-Scan ${ }^{\mathrm{TM}}$ Control System. As condições de aquisição para cada amostra analisada são mostradas na Tabela 6 e na Tabela 7. 


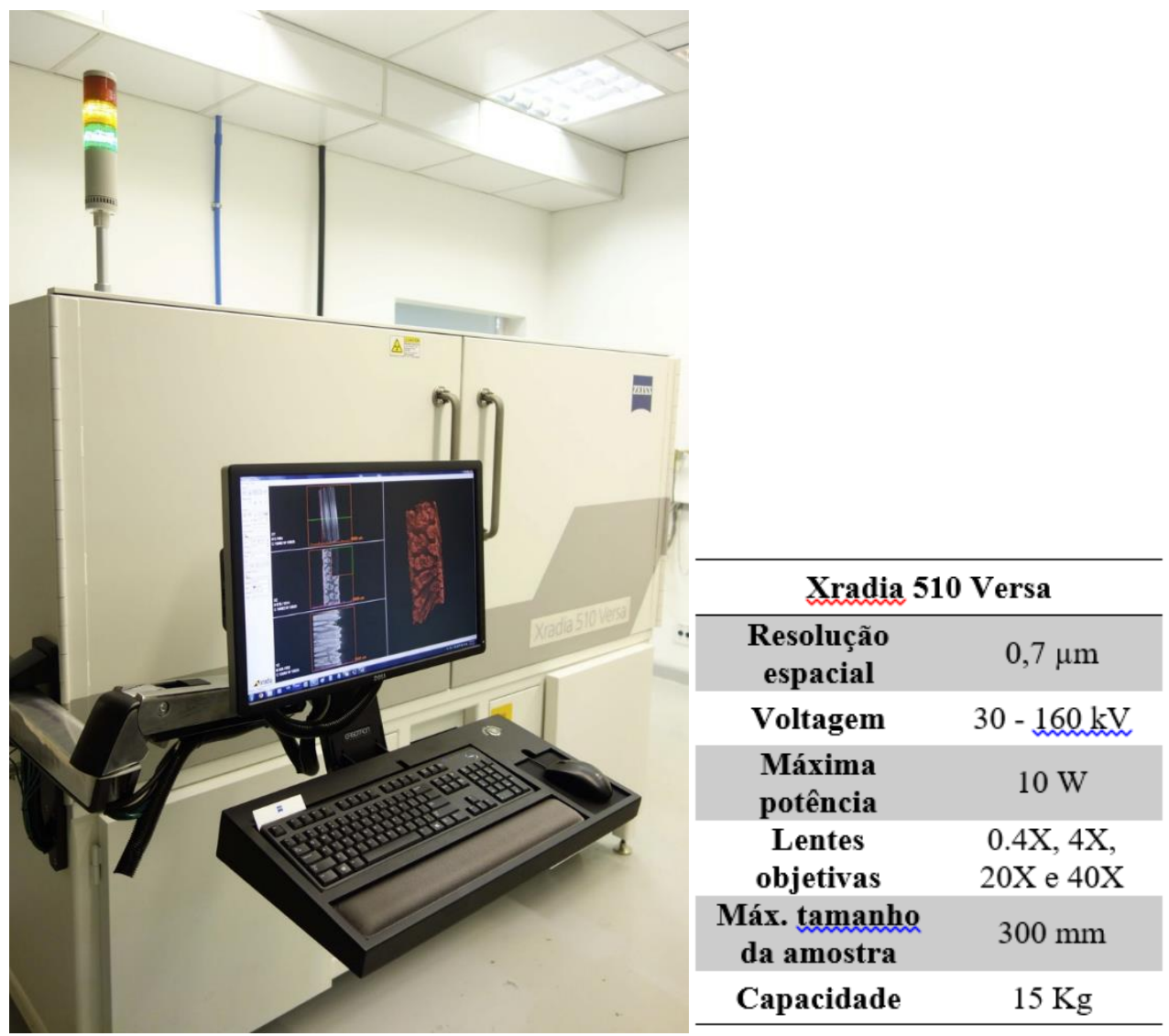

Figura 47 - Visão externa do microtomógrafo Zeiss XRadia Versa 510 com a respectiva especificação técnica do equipamento. 


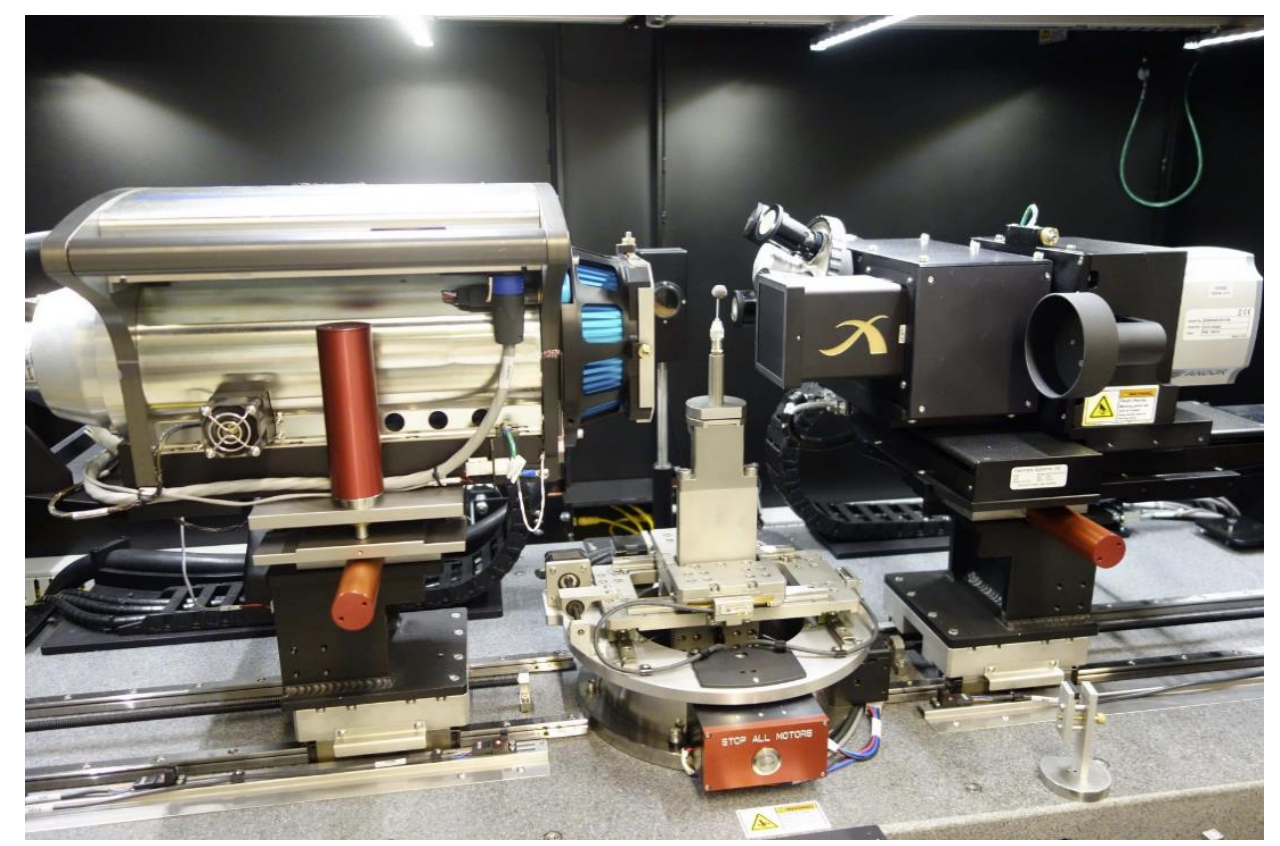

(a)

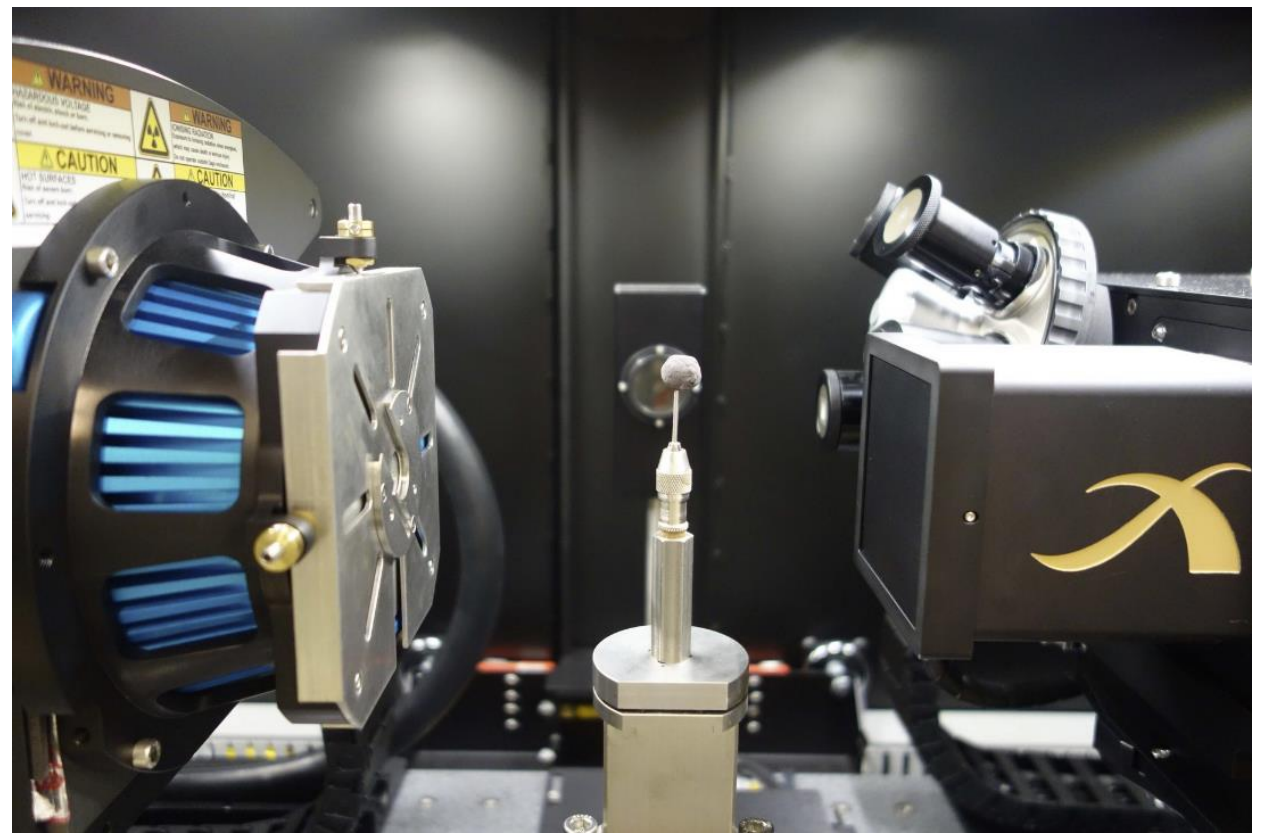

(b)

Figura 48 - Visão interna do MicroCT Zeiss XRadia Versa 510: (a) Fonte de raios $\mathrm{X}$ (esquerda), detector e conjunto de lentes (direita) e amostra de pelota de minério de ferro (meio); (b) Imagem ampliada de (a) para melhor visualização do sistema fonte-amostra-detector. 
Tabela 6 - Condições de aquisição no MicroCT - Grupo Desenvolvimento

\begin{tabular}{|c|c|c|c|c|c|c|}
\hline Amostra & $\begin{array}{c}\text { Tempo } \\
\text { de } \\
\text { exposição } \\
\text { (s) }\end{array}$ & $\begin{array}{c}\text { Lente } \\
\text { objetiva }\end{array}$ & Binning & $\begin{array}{l}\text { Pixel } \\
\text { size } \\
(\mu \mathrm{m})\end{array}$ & $\begin{array}{l}\text { Número } \\
\text { de } \\
\text { projeções }\end{array}$ & $\begin{array}{l}\text { Tempo de } \\
\text { varredura } \\
\text { (h) }\end{array}$ \\
\hline & 7,0 & $0.4 \mathrm{X}$ & 1 & 7,752 & 4000 & 10,6 \\
\hline P1-1 & 3,5 & $4 X$ & 2 & 3,9601 & 4000 & 5,9 \\
\hline & 7,0 & $0.4 \mathrm{X}$ & 1 & 7,8706 & 4000 & 10,6 \\
\hline P1-2 & 3,5 & $4 X$ & 2 & 3,9597 & 4000 & 5,9 \\
\hline & 7,0 & $0.4 \mathrm{X}$ & 1 & 7,753 & 4000 & 10,6 \\
\hline P1-4 & 3,5 & $4 X$ & 2 & 3,9788 & 4000 & 5,9 \\
\hline & 7,0 & $0.4 \mathrm{X}$ & 1 & 7,7523 & 4000 & 10,6 \\
\hline P1-5 & 3,5 & $4 X$ & 2 & 3,9597 & 4000 & 5,9 \\
\hline & 7,0 & $0.4 \mathrm{X}$ & 1 & 7,6989 & 4000 & 10,6 \\
\hline P1-8 & 3,5 & $4 X$ & 2 & 3,9874 & 4000 & 5,9 \\
\hline P1-12 & 7,0 & $0.4 \mathrm{X}$ & 1 & 7,7011 & 4000 & 10,6 \\
\hline P1-12 & 3,5 & $4 X$ & 2 & 4,104 & 4000 & 5,9 \\
\hline & 7,0 & $0.4 \mathrm{X}$ & 1 & 7,7011 & 4000 & 10,6 \\
\hline P2-4 & 3,5 & $4 X$ & 2 & 4,0706 & 4000 & 5,9 \\
\hline & 7,0 & $0.4 \mathrm{X}$ & 1 & 7,4246 & 4000 & 10,6 \\
\hline P2-5 & 3,5 & $4 X$ & 2 & 4,0859 & 4000 & 5,9 \\
\hline P2-6 & 7,0 & $0.4 \mathrm{X}$ & 1 & 8,6718 & 4000 & 10,6 \\
\hline$P 2=0$ & 3,5 & $4 X$ & 2 & 4,0369 & 4000 & 5,9 \\
\hline P2 7 & 7,0 & $0.4 \mathrm{X}$ & 1 & 8,6721 & 4000 & 10,6 \\
\hline P2-7 & 3,5 & $4 X$ & 2 & 3,9103 & 4000 & 5,9 \\
\hline P1-10 & 7,0 & $0.4 \mathrm{X}$ & 1 & 7,6983 & 4000 & 10,6 \\
\hline РI-10 & 3,5 & $4 X$ & 2 & 4,0916 & 4000 & 5,9 \\
\hline P1 11 & 7,0 & $0.4 \mathrm{X}$ & 1 & 7,7011 & 4000 & 10,6 \\
\hline PI-11 & 3,5 & $4 X$ & 2 & 4,1790 & 4000 & 5,9 \\
\hline P2-1 & 7,0 & $0.4 \mathrm{X}$ & 1 & 7,4714 & 4000 & 10,6 \\
\hline P2-1 & 3,5 & $4 X$ & 2 & 3,9208 & 4000 & 5,9 \\
\hline D? 2 & 7,0 & $0.4 \mathrm{X}$ & 1 & 7,7011 & 4000 & 10,6 \\
\hline$P 2-2$ & 3,5 & $4 X$ & 2 & 4,0983 & 4000 & 5,9 \\
\hline & 7,0 & $0.4 \mathrm{X}$ & 1 & 7,7003 & 4000 & 10,6 \\
\hline P2-3 & 3,5 & $4 X$ & 2 & 4,0368 & 4000 & 5,9 \\
\hline & 7,0 & $0.4 X$ & 1 & 7,7015 & 4000 & 10,6 \\
\hline D1_0 & 25,0 & $0.4 \mathrm{X}$ & 1 & 4,0472 & 3201 & 34,6 \\
\hline P1-0 & 3,5 & $4 X$ & 2 & 4,0816 & 4000 & 5,9 \\
\hline & 12,0 & $4 X^{*}$ & 1 & 2,0104 & 4000 & 22,8 \\
\hline
\end{tabular}

* Essa análise consiste em um mosaico vertical. Para isso, foi preciso fazer 4 aquisições, a fim de cobrir completamente o diâmetro da pelota. O tempo descrito na tabela equivale a apenas uma aquisição, ou seja, o tempo total seria de $22,8 \mathrm{~h}$ vezes 4 , que é $91,2 \mathrm{~h}$. 
Tabela 7 - Condições de aquisição no MicroCT - Grupo Aplicação

\begin{tabular}{|c|c|c|c|c|c|c|}
\hline Amostra & $\begin{array}{c}\text { Tempo } \\
\text { de } \\
\text { exposição } \\
\text { (s) }\end{array}$ & $\begin{array}{c}\text { Lente } \\
\text { objetiva }\end{array}$ & Binning & $\begin{array}{l}\text { Pixel } \\
\text { size } \\
(\mu \mathrm{m})\end{array}$ & $\begin{array}{l}\text { Número } \\
\text { de } \\
\text { projeções }\end{array}$ & $\begin{array}{c}\text { Tempo } \\
\text { de } \\
\text { Varredura } \\
\text { (h) }\end{array}$ \\
\hline P1-13 & 25 & $0.4 \mathrm{X}$ & 1 & 4,0475 & 1601 & 17,4 \\
\hline P1-14 & 25 & $0.4 \mathrm{X}$ & 1 & 4,0479 & 1601 & 17,4 \\
\hline P2-14 & 25 & $0.4 \mathrm{X}$ & 1 & 4,0482 & 1601 & 17,4 \\
\hline P2-15 & 25 & $0.4 \mathrm{X}$ & 1 & 4,0451 & 1601 & 17,4 \\
\hline P2-16 & 25 & $0.4 \mathrm{X}$ & 1 & 4,0453 & 1601 & 17,4 \\
\hline P2-17 & 25 & $0.4 \mathrm{X}$ & 1 & 4,0453 & 1601 & 17,4 \\
\hline P1-17 & 25 & $0.4 X$ & 1 & 4,0482 & 1601 & 17,4 \\
\hline P2-18 & 25 & $0.4 \mathrm{X}$ & 1 & 4,0453 & 1601 & 17,4 \\
\hline
\end{tabular}

Todas as tomografias foram realizadas a $150 \mathrm{kV}$ e $10 \mathrm{~W}$ e com a rotação da amostra em $360^{\circ}$. O tempo de exposição e o número de projeções afetam diretamente o tempo total de análise. O Binning, que é um processo de agrupamento de pixels, também afeta o tempo de análise, pois melhora a relação sinal-ruído, mas reduz a resolução espacial, afetando também o pixel size.

Todas as aquisições foram feitas com o uso do filtro HE5, que é um tipo de filtro mais espesso indicado para análises de amostras mais densas que necessitam de alta voltagem. Os filtros são utilizados para remover raios $\mathrm{X}$ de menor energia, que seriam preferencialmente absorvidos mais próximo à superfície da amostra. Esta absorção preferencial é denominada endurecimento do feixe (Beam Hardening) e gera um artefato que degrada a imagem - as bordas da amostra ficam mais claras como se ali o material fosse mais denso.

A escolha do filtro se dá com base no valor de transmissão, que, por sua vez, é uma relação entre o sinal de raios $\mathrm{X}$ recebidos com a amostra e sem a amostra.

No entanto, apenas a remoção dos raios $\mathrm{X}$ de baixa energia por meio de filtros físicos não é suficiente para eliminar completamente esse tipo de efeito, sendo necessário realizar uma correção por algoritmos na etapa de reconstrução, como será discutido na seção a seguir. 


\subsection{3.}

Reconstrução das imagens

A reconstrução tomográfica das imagens de raios $\mathrm{X}$ foi feita com o software XMReconstructor - Cone Beam - 10.7.2936.12969, também específico do sistema Zeiss.

A primeira etapa da reconstrução das imagens consiste na escolha de um parâmetro denominado “Center Shift” (Figura 49).

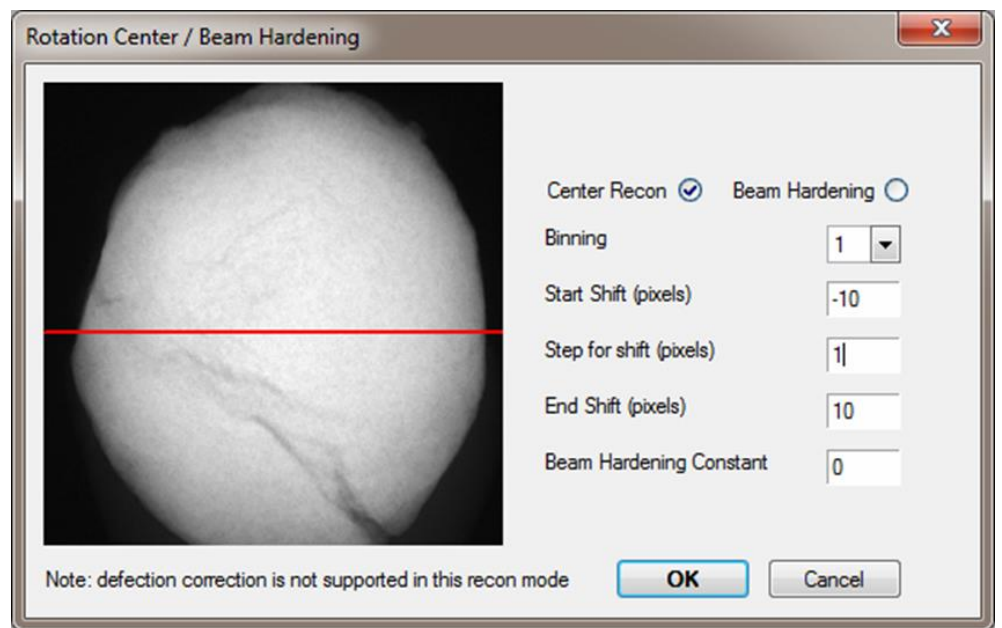

Figura 49 - Determinação da faixa de "Center Shift" para a escolha do melhor valor.

Este parâmetro é a quantidade em pixels que o eixo de rotação da amostra está deslocado em relação ao centro da coluna do detector. Assim, a imagem reconstruída conterá artefatos, que podem ser corrigidos, ajustando a distância de deslocamento, conforme mostrado na Figura 50. A imagem da Figura 50-c é a única efetivamente em foco e o valor de "Center Shift" correspondente, então, será utilizado na reconstrução. 


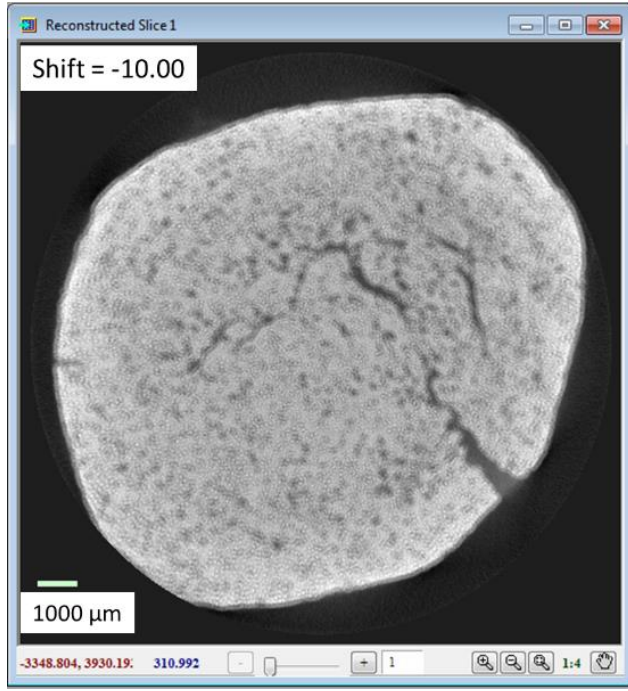

(a)

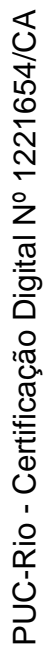
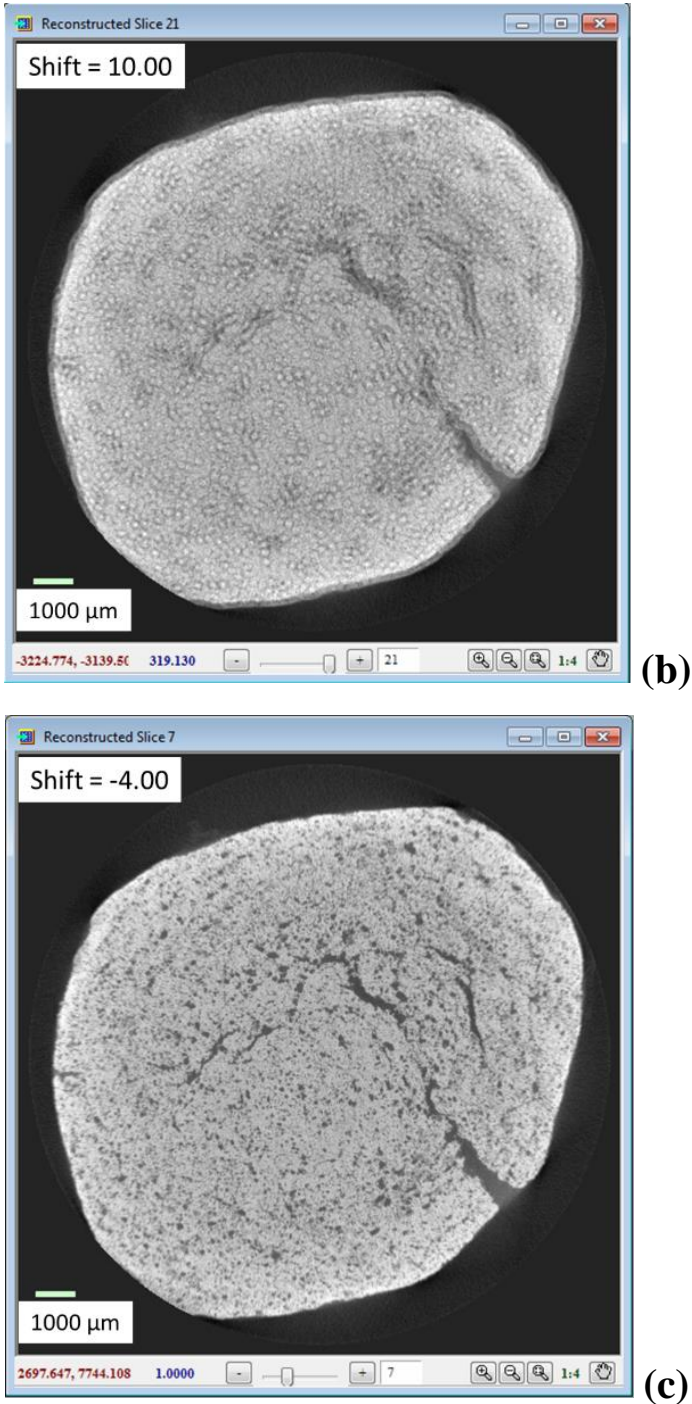

Figura 50 - (a) Imagem reconstruída com Shift = -10; (b) Imagem reconstruída com Shift = 10; (c) Imagem reconstruída com Shift $=-4$ (melhor valor). 
A segunda etapa da reconstrução consiste na escolha do parâmetro "Beam Hardening", determinando-se uma faixa de valores, como ilustrado na Figura 51.

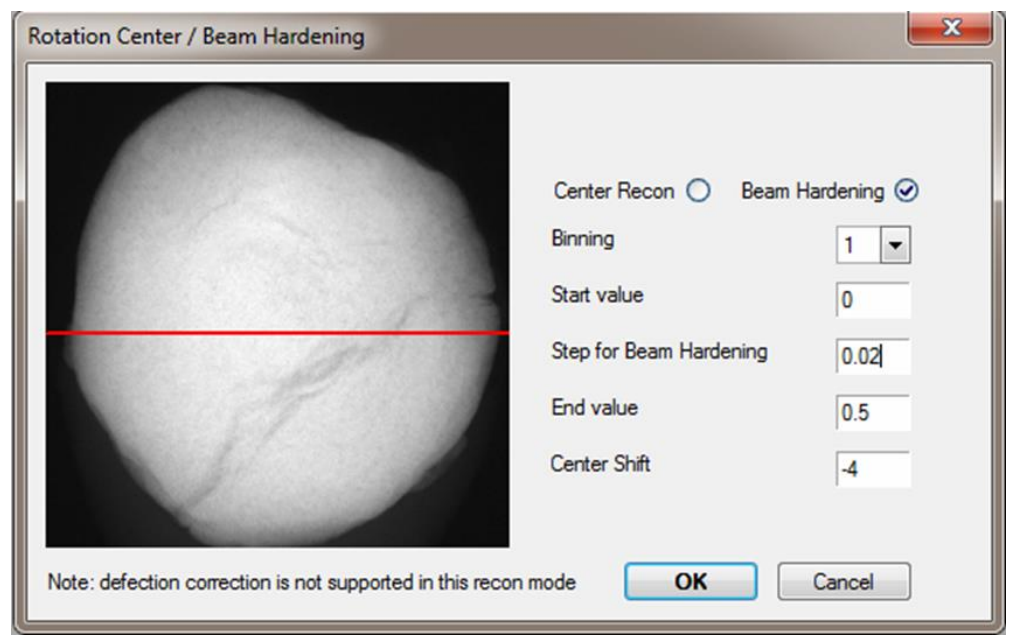

Figura 51 - Determinação da faixa de "Beam Hardening” para a escolha do melhor valor

A Figura 52 apresenta a correção do artefato de Beam Hardening em uma seção 2D da amostra. Para a escolha do melhor parâmetro, traça-se uma linha na imagem e quantifica-se os tons de cinza em cada ponto desta linha. Assim, uma curva se formará nos gráficos, como mostrado nas Figura 52-a (concavidade para cima) e Figura 52-b (concavidade para baixo) devido ao artefato em questão. $\mathrm{O}$ valor ideal a ser utilizado na reconstrução é aquele cujo gráfico seja o mais plano possível, tal como na Figura 52-c.

Cabe ressaltar que o efeito de Beam Hardening só foi considerado nas aquisições realizadas com a lente de $0.4 \mathrm{X}$. Isto porque, como as análises em $4 \mathrm{X}$ correspondem à uma pequena região no centro da amostra, considerou-se que os raios $\mathrm{X}$ de baixa energia já haviam sido absorvidos antes de chegarem a esta posição. 


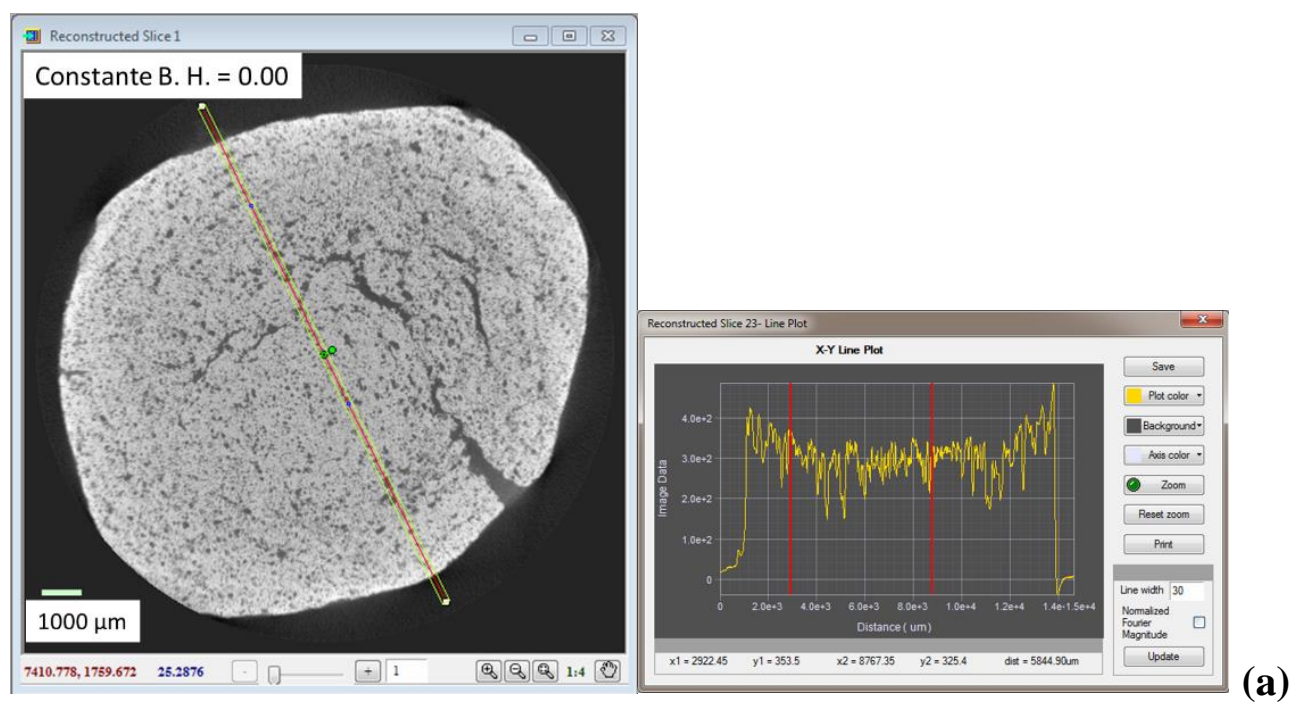

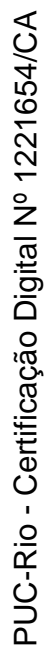

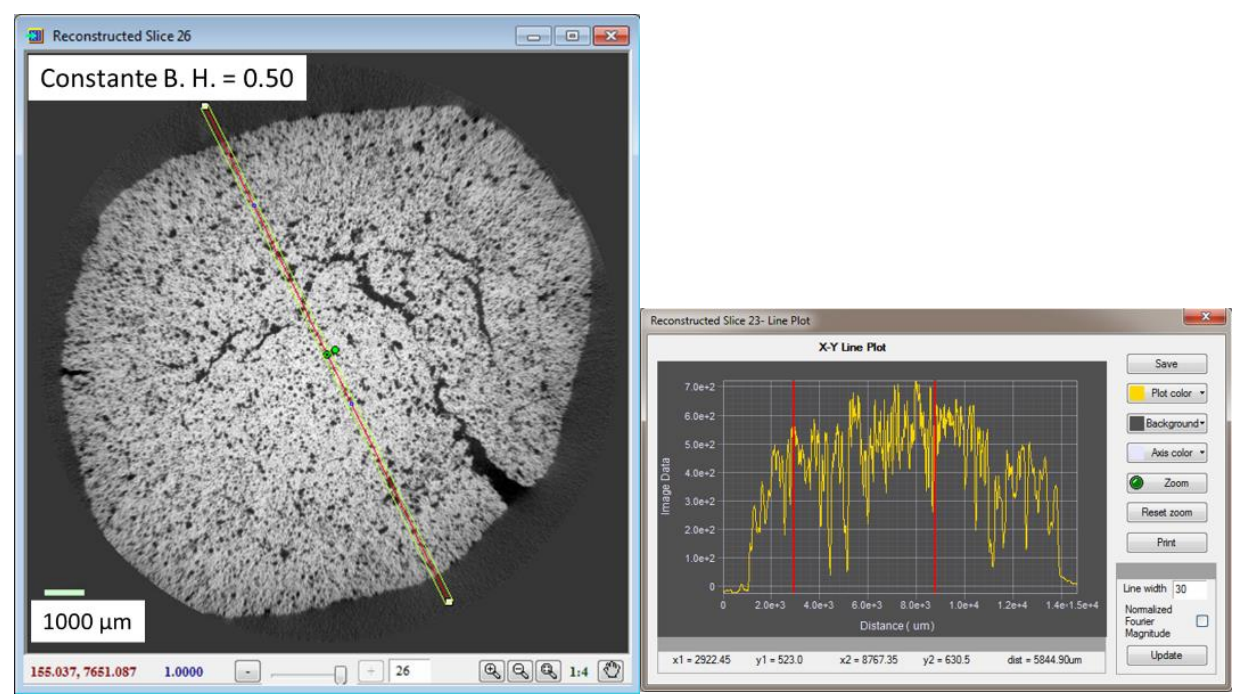

(b)
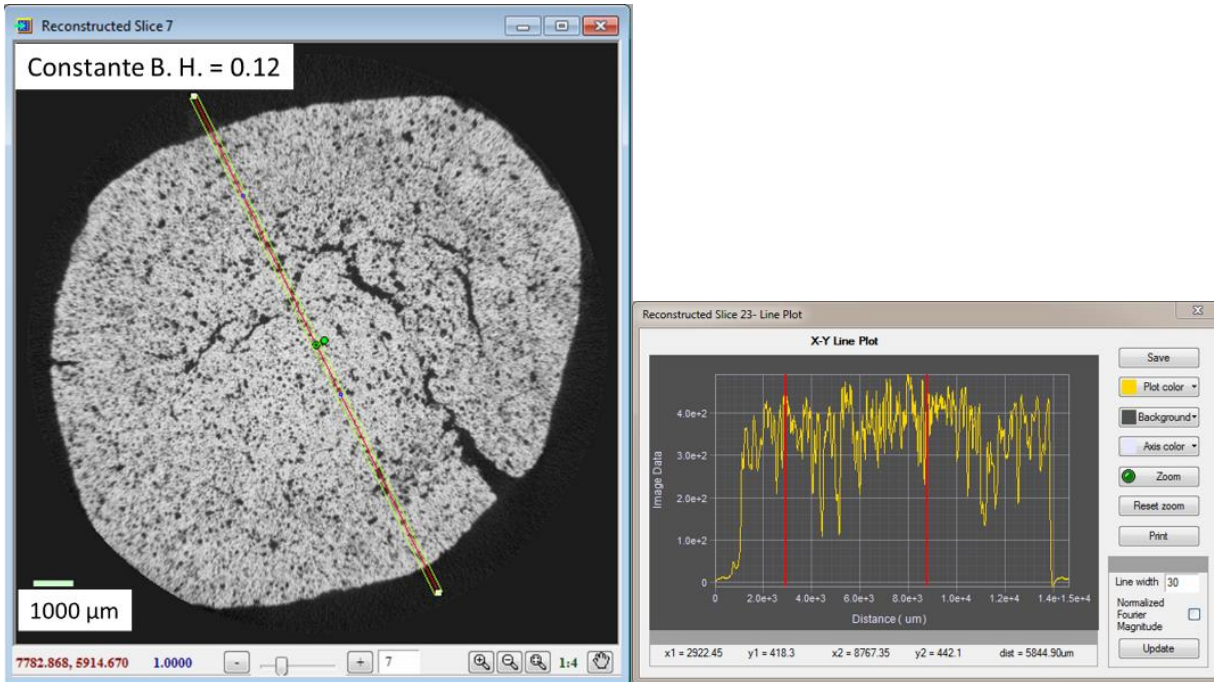

(c)

Figura 52 - Escolha do parâmetro "Beam Hardening”: (a) Beam Hardening = 0.0; (b) Beam Hardening $=0.50$; (c) Beam Hardening $=0.12$ (melhor valor). 


\subsection{4. \\ Processamento e análise digital de imagens}

Uma imagem 2D típica de microtomografia de raios $\mathrm{X}$ e seu respectivo histograma de intensidades pode ser visualizada na Figura 53. O pico correspondente aos poros é o mais próximo do 0 no histograma.
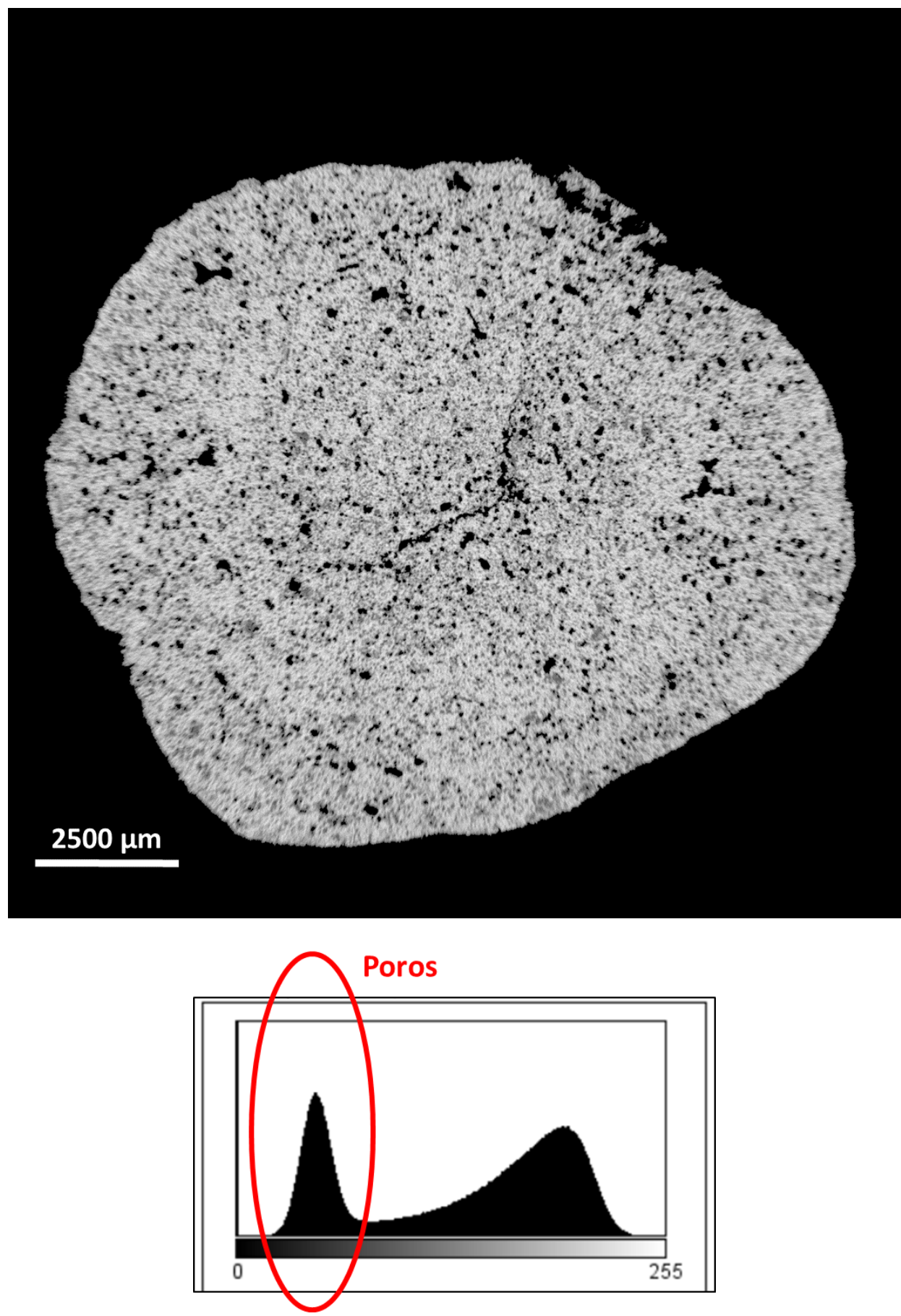

Figura 53 - Imagem de microtomografia de raios $\mathrm{X}$, com seu respectivo histograma de intensidades 
O processamento e análise das imagens foi feito em diferentes softwares. Essa variação é bastante comum em processamento de imagens em 3D e se dá pelo melhor desempenho, assim como também pela limitação, em determinados processamentos oferecidos por cada software.

Para o pré-processamento das imagens foi utilizado o software livre FIJI/ImageJ [41].

Para o pós-processamento foi utilizado o software SkyScan CTAn da Bruker [42].

A extração dos atributos (medidas) e a visualização dos modelos 3D foram feitas no software ORS Visual [43].

\subsection{5.}

\section{Otimização da análise}

Em busca de melhores condições de análise no que diz respeito à qualidade da imagem e ao tempo de aquisição, testou-se a variação de alguns parâmetros, tais como diferentes configurações geométricas na aquisição, que consequentemente alteram a resolução da imagem, a redução no número de projeções e a redução da faixa angular de rotação da amostra de $360^{\circ}$ para $180^{\circ}$.

\subsubsection{1. \\ Definição da resolução}

Para melhor entendimento dos procedimentos experimentais adotados na escolha da resolução de trabalho, dividiu-se este item em 2 etapas.

\section{- $\underline{1}^{\mathrm{a}}$ etapa:}

Sabendo-se previamente, através das análises de PIM ao longo dos anos, que a maior quantidade relevante de poros nas pelotas analisadas está em torno de 10 $\mu \mathrm{m}$, optou-se por utilizar inicialmente uma resolução em torno de $8 \mu \mathrm{m}$ nas análises de MicroCT, permitindo uma análise da pelota completa num tempo razoável. Para isso, utilizou-se a lente de $0.4 \mathrm{X}$ sob as condições já descritas na Tabela 6.

Além disso, também foram feitas análises em MicroCT com a lente de $4 X$, num pequeno subvolume da pelota, reduzindo a resolução para a metade, ou seja, para aproximadamente $4 \mu \mathrm{m}$. Nesta etapa, realizou-se medidas quantitativas a partir 
destas análises em 0.4X $(8 \mu \mathrm{m})$ e 4X $(4 \mu \mathrm{m})$ com as pelotas P1-1, P1-2, P1-4, P15, P1-7, P1-8, P1-12, P2-4, P2-5, P2-6 e P2-7.

A configuração geométrica do equipamento nesta etapa pode ser visualizada, para ambos os tipos de lentes, na Tabela 8.

Tabela 8 - Configuração geométrica dos dispositivos na $1^{\text {a }}$ etapa

\begin{tabular}{|c|cccc|}
\hline Lente & $\begin{array}{c}\text { Resolução } \\
(\boldsymbol{\mu m})\end{array}$ & $\begin{array}{c}\text { Distância } \\
\text { fonte-amostra } \\
(\mathbf{m m})\end{array}$ & $\begin{array}{c}\text { Distância } \\
\text { amostra- } \\
\text { detector }(\mathbf{m m})\end{array}$ & Binning \\
\hline $\mathbf{0 . 4 X}$ & $\sim 8$ & -30 & 103 & 1 \\
\hline $\mathbf{4 X}$ & $\sim 4$ & -17 & 12 & 2 \\
\hline
\end{tabular}

- $\underline{2^{a} \text { etapa: }}$

Verificando-se que estas condições de análise não foram adequadas para análise de porosidade em pelotas de minério de ferro, buscou-se a melhora da resolução, possibilitada por outras configurações geométricas dos dispositivos. Para isso, utilizou-se apenas a amostra P1-0.

Uma das alternativas foi utilizar a lente de $0.4 \mathrm{X}$, mas com outras posições da fonte e do detector, conseguindo-se atingir uma resolução de $4 \mu \mathrm{m}$. Outra alternativa foi utilizar a lente de $4 \mathrm{X}$, chegando a uma resolução de $2 \mu \mathrm{m}$, com uma configuração geométrica muito parecida com a da $1^{\text {a }}$ etapa, porém sem o uso do Binning. Devido à pouca representatividade da amostra com o uso da lente de $4 \mathrm{X}$, optou-se por uma captura de mosaico (apenas vertical), que é uma opção disponível no sistema.

A configuração geométrica do equipamento para estes dois tipos de análises é apresentada na Tabela 9.

Tabela 9 - Configuração geométrica dos dispositivos na $2^{\mathrm{a}}$ etapa

\begin{tabular}{|c|ccc|c|}
\hline Lente & $\begin{array}{c}\text { Resolução } \\
(\boldsymbol{\mu m})\end{array}$ & $\begin{array}{c}\text { Distância } \\
\text { fonte-amostra } \\
(\mathbf{m m})\end{array}$ & $\begin{array}{c}\text { Distância } \\
\text { amostra- } \\
\text { detector }(\mathbf{m m})\end{array}$ & Binning \\
\hline $\mathbf{0 . 4 X}$ & $\sim 4$ & -30 & 225 & 1 \\
\hline $\mathbf{4 X}$ & $\sim 2$ & -16 & 11 & 1 \\
\hline
\end{tabular}




\subsubsection{2.}

\section{Número de projeções e faixa angular de rotação}

A fim de reduzir o tempo de análise, avaliou-se qualitativamente e quantitativamente imagens reconstruídas a partir de diferentes números de projeções. Foram testadas reconstruções a partir de 3201 projeções, 1600 projeções e 800 projeções.

Também foram testadas imagens reconstruídas a partir de aquisições com rotação da amostra de $0-180^{\circ}$ e de $0-360^{\circ}$.

\section{4 . Microscopia ótica}

\subsection{1. Preparação das amostras}

As amostras analisadas por microscopia ótica estão apresentadas na Tabela 10.

Tabela 10 - Amostras para MO

\begin{tabular}{|c|c|c|}
\hline Pelotas & Grupo Desenvolvimento & Grupo Aplicação \\
\hline \multirow{2}{*}{ P1 } & P1-7 & P1-17 \\
& P1-10 & \\
\hline \multirow{2}{*}{ P2 } & P1-11 & P2-18 \\
\hline
\end{tabular}

Para esta análise, foram preparadas seções polidas, de modo que a estrutura interna da pelota fosse exposta. Todo o procedimento de preparação das amostras e de aquisição de imagens foi feito no Centro de Tecnologia de Ferrosos da Vale.

Como dito anteriormente, o suporte fino serviu como referência para o embutimento, garantindo que o plano exposto para a superfície seja um plano próximo ao obtido por MicroCT, também perpendicular ao eixo. 

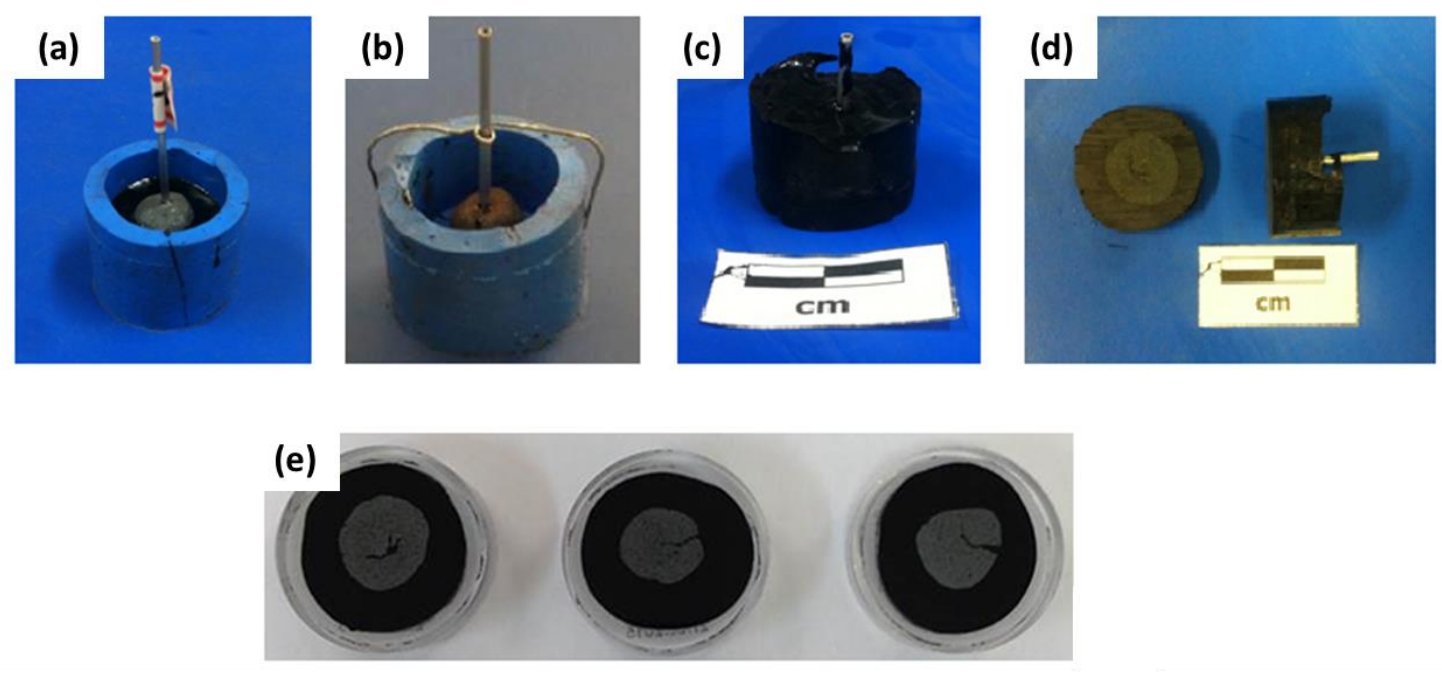

Figura 54 - Preparação das amostras para MO: (a) embutimento em resina;

(b) fixação em um suporte para que a pelota não se mova; (c) retirada do embutimento; (d) corte e polimento da amostra; (e) Amostras polidas.

\subsection{2. \\ Aquisição de imagens}

A aquisição das imagens das pelotas em microscopia ótica foi feita na Vale com um microscópio de luz refletida da marca Carl Zeiss modelo AxioImager Z2m.

Foram capturados mosaicos com a lente de 10X (resolução de 1,06 $\mu \mathrm{m} / \mathrm{pixel}$ ) de forma a obter imagens de toda a superfície da pelota na seção polida. As fases mais discriminantes presentes, tais como hematita, magnetita, goethita, silicatos, quartzo e poros, apresentam diferentes refletâncias, configurando diferentes tons de cinza na imagem e picos correspondentes às fases no histograma de intensidades.

Uma imagem típica de pelota em microscópio ótico de luz refletida pode ser observada na Figura 55. Esta imagem, na verdade, é um mosaico, ou seja, foi obtida pela concatenação de várias imagens de campos menores, a fim de cobrir toda a superfície da pelota, utilizando-se uma lente objetiva de 10X. 

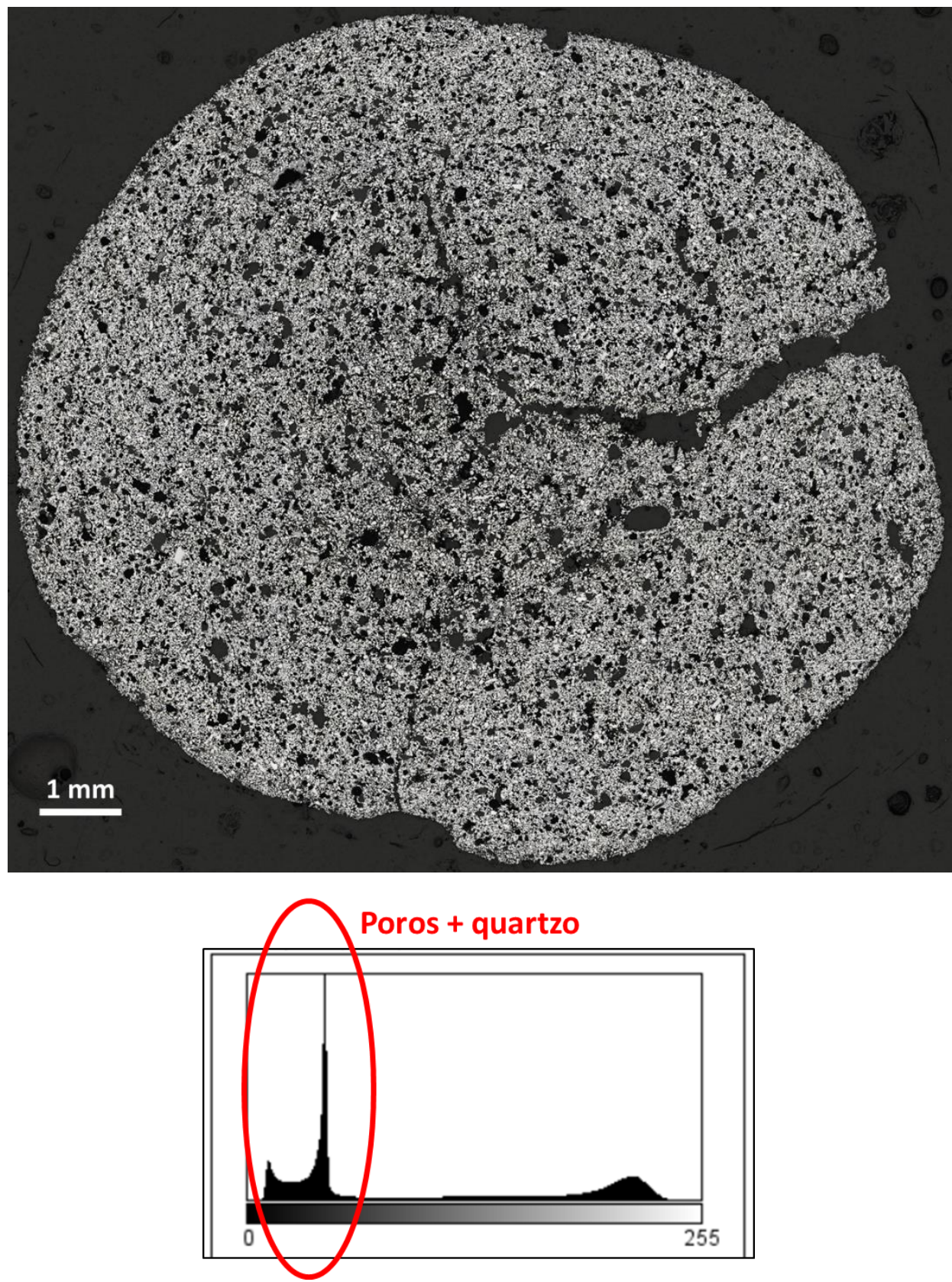

Figura 55 - Imagem típica de uma pelota de minério de ferro obtida por microscopia ótica com uma lente de 10X, com seu respectivo histograma de intensidades.

Neste trabalho, avaliou-se apenas a porosidade, que corresponde aos picos mais escuros próximos da intensidade 0 no histograma, como apresentado na Figura 55. A presença de dois picos de deve aos poros vazios e poros preenchidos com resina. No entanto, os quartzos apresentam tonalidade bem próximas à dos poros preenchidos com resina, dificultando esta separação na etapa de segmentação. Assim, os valores de porosidade incluem poros e quartzo. 


\subsection{3.}

\section{Processamento e análise digital de imagens}

O processamento apresentado neste trabalho para as imagens de microscópio ótico foi realizado com o software FIJ//ImageJ.

\section{5. \\ Microscopia eletrônica de varredura (MEV)}

Apesar desta técnica não estar na proposta inicial do trabalho, utilizou-se o MEV apenas para visualizar um campo da amostra em um aumento maior, a fim de encontrar poros muito pequenos detectados pela PIM, porém não detectados pela MicroCT e pela MO, e conseguir identificar outras fases por meio da espectroscopia por dispersão de energia de raios X (EDS), garantindo que apenas os poros estejam sendo segmentados.

\subsection{1.}

Preparação das amostras

A preparação de amostras para o $\mathrm{MEV}$, neste caso, é basicamente a mesma que para a MO. No MEV, no entanto, é necessário tornar a amostra condutora e, para isso, a amostra foi recoberta com ouro com o metalizador.

Para a análise em MEV, utilizou-se apenas uma das amostras embutidas, a amostra P1-7.

\subsection{2.}

\section{Aquisição de imagens}

O MEV utilizado foi um FEI Quanta 400 equipado com um sistema de EDS (Figura 56). 


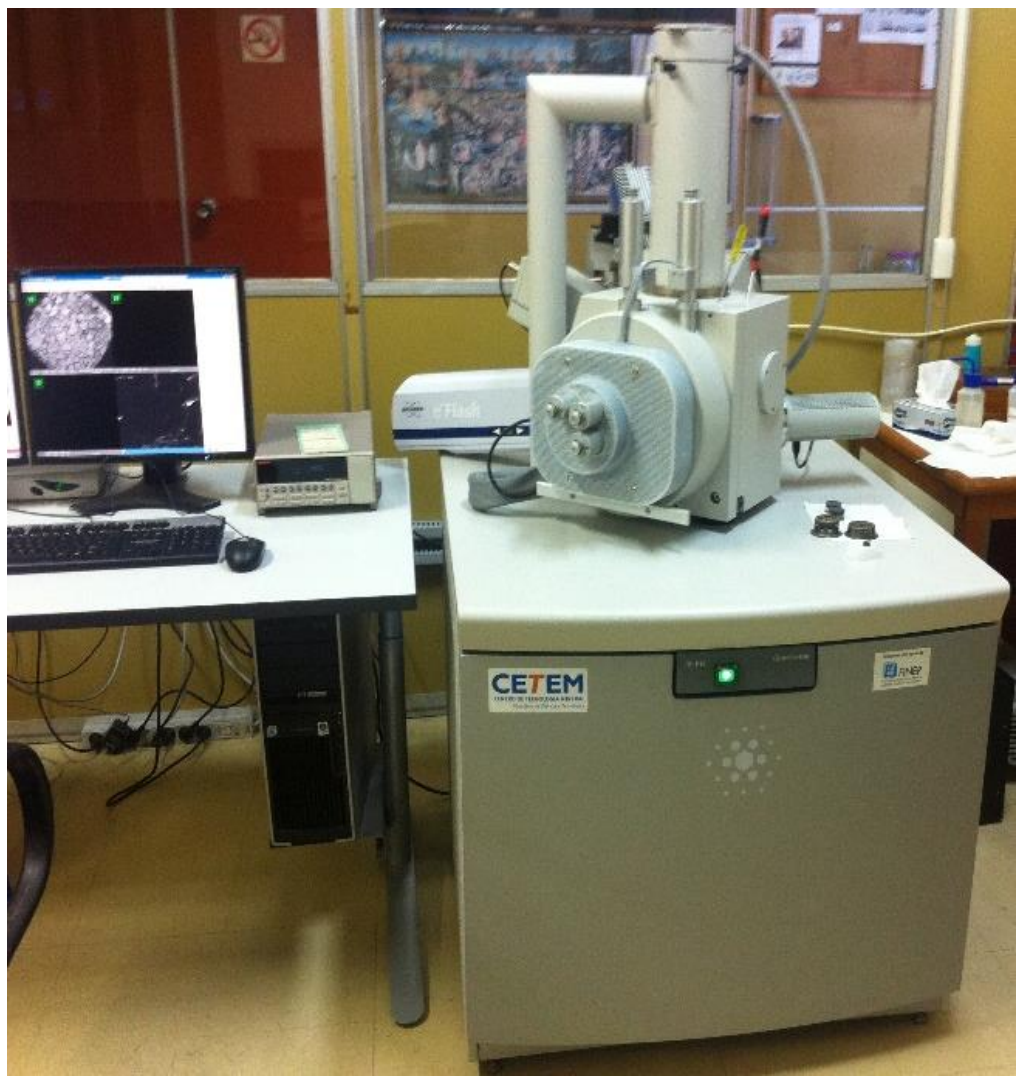

Figura 56 - MEV utilizado (FEI Quanta 400).

O detector utilizado foi o de elétrons retro-espalhados (BSE), que, no caso de uma superfície plana (polida), forma uma imagem contendo pouca informação topográfica e a intensidade de cada pixel é proporcional ao número atômico médio na posição correspondente. Dessa forma, é possível distinguir fases com número atômico médio diferente a partir dos níveis de cinza característicos da imagem [44]. Também foram adquiridas imagens de mapeamento de raios $\mathrm{X}$ de $\mathrm{Si}, \mathrm{Al}, \mathrm{Ca}$ e Fe. 


\section{Resultados e discussão}

Este capítulo descreve os resultados obtidos para cada técnica envolvida e as devidas comparações entre as técnicas. Como grande parte dos resultados envolve o desenvolvimento da metodologia, muitos procedimentos experimentais do processamento e análise de imagens encontram-se descritos neste capítulo.

\section{1.}

Porosimetria por intrusão de mercúrio

Os resultados das análises de PIM da $1^{\mathrm{a}}$ etapa encontram-se na Figura 57.

A Figura 57-a apresenta as curvas de intrusão obtidas para todas as amostras da $1^{\text {a }}$ etapa. A pressão foi convertida para diâmetro através da equação 2 , explicada na seção 2.3.

A Figura 57-b apresenta a derivada das curvas cumulativas. A partir desta curva, é possível dizer que o diâmetro médio dos poros e o diâmetro de percolação estão entre 8-11 $\mu \mathrm{m}$. 


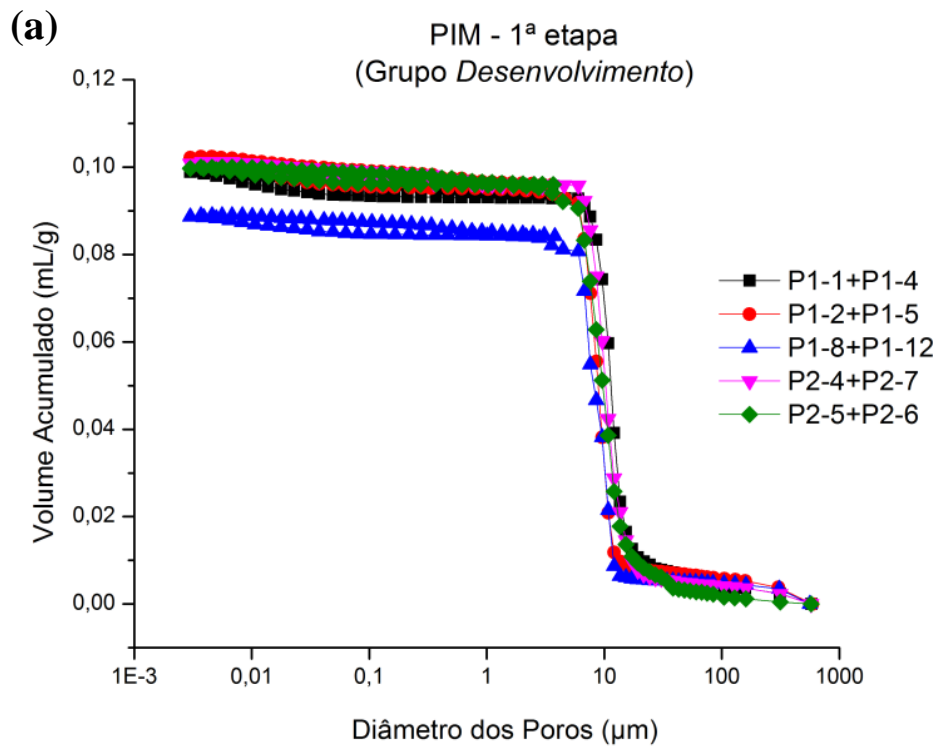

(b)

PIM - $1^{\text {a }}$ etapa

(Grupo Desenvolvimento)

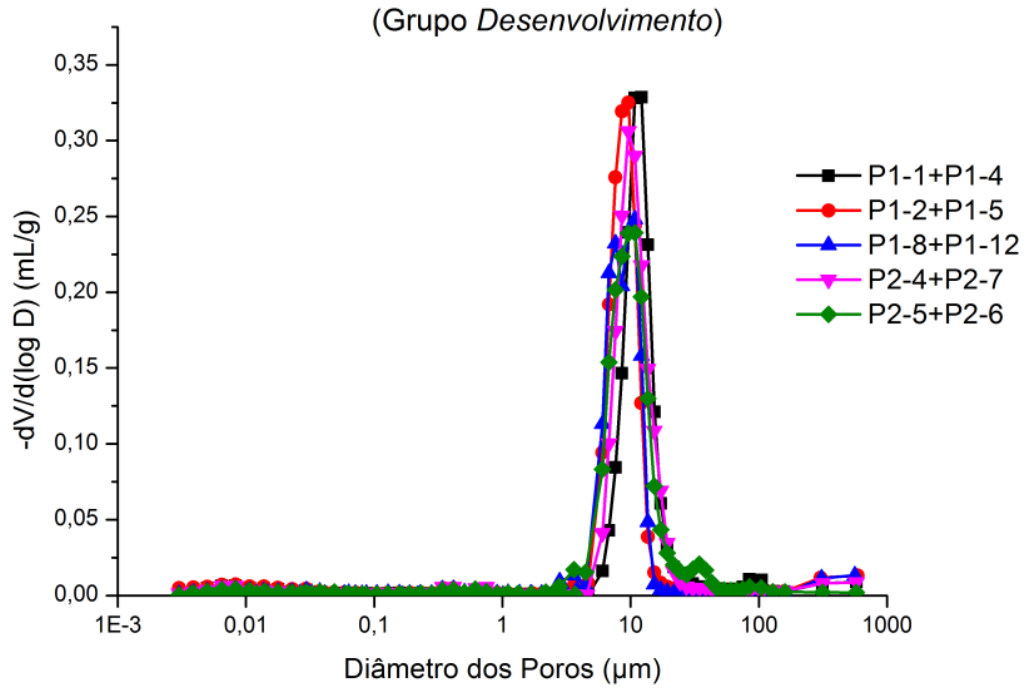

Figura 57 - Análise de PIM - $1^{\mathrm{a}}$ etapa 


\section{2.}

Microtomografia de raios $X$

\subsection{1.}

\section{Processamento digital de imagens}

O processamento das imagens seguiu a sequência padrão já explicada anteriormente na seção 3.3.4.

\subsubsection{Aquisição de imagens (fatias 2D e volumes 3D)}

Esta seção apresenta as imagens e volumes obtidos com as diferentes lentes e resoluções testadas neste trabalho, para que se possa visualizar as características das imagens em cada aquisição e também a região que é analisada sob as diferentes condições.

A Figura 58 mostra uma imagem de uma fatia 2D (a) e uma imagem do modelo 3D (b) da aquisição feita com a lente de 0.4X. Pode-se perceber que, com esta lente e com as condições utilizadas, consegue-se analisar a pelota completa. A resolução, neste caso, é de aproximadamente $8 \mu \mathrm{m}$. 

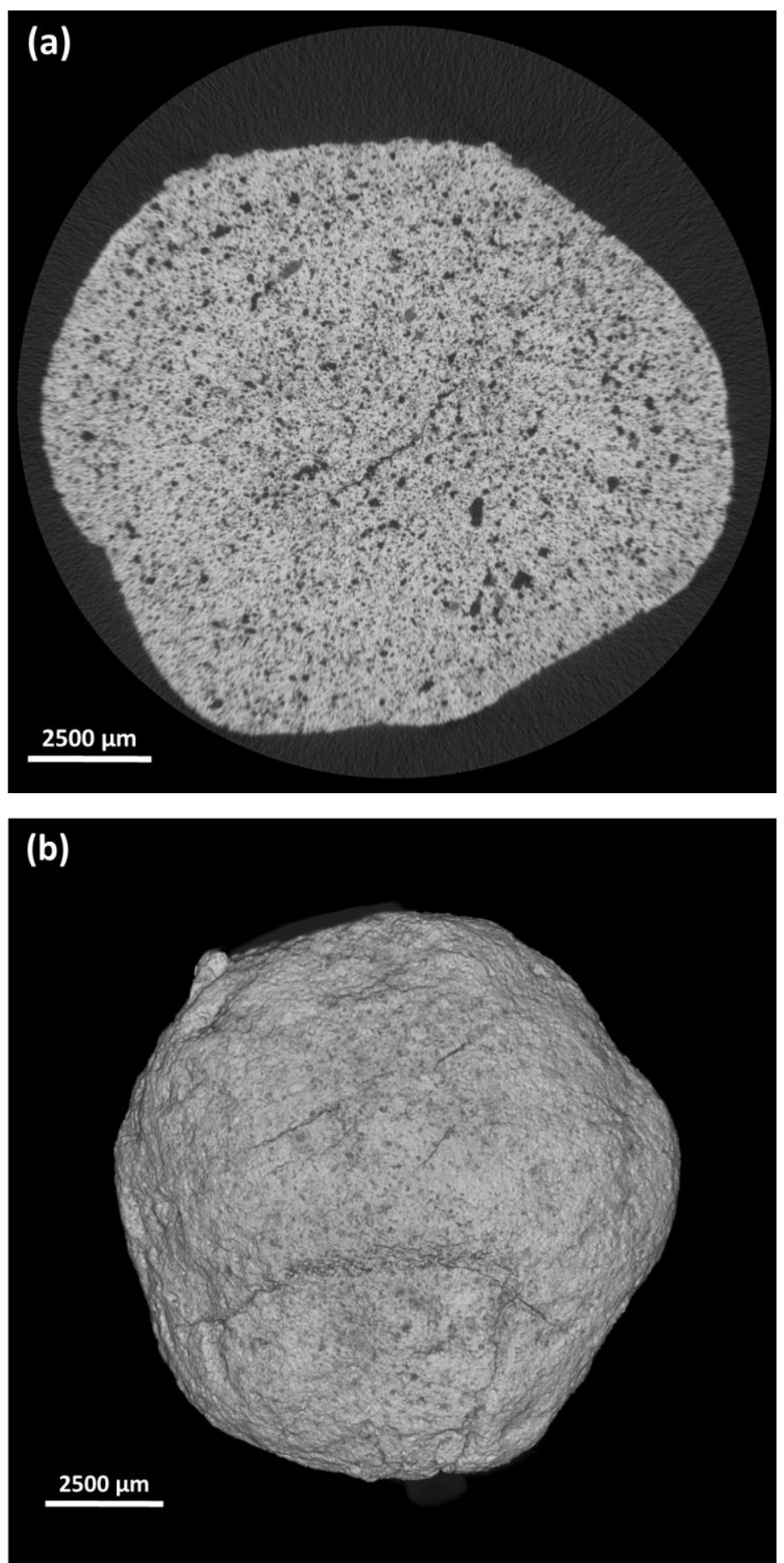

Figura 58 - Aquisição em 0.4X (Resolução $8 \mu \mathrm{m}$ ): (a) Fatia 2D;

(b) Volume 3D.

A Figura 59 apresenta uma imagem da camada 2D e do volume $3 \mathrm{D}$ da aquisição feita com a lente de $4 \mathrm{X}$. A região de análise, neste caso, é um pequeno cilindro interno na amostra. 

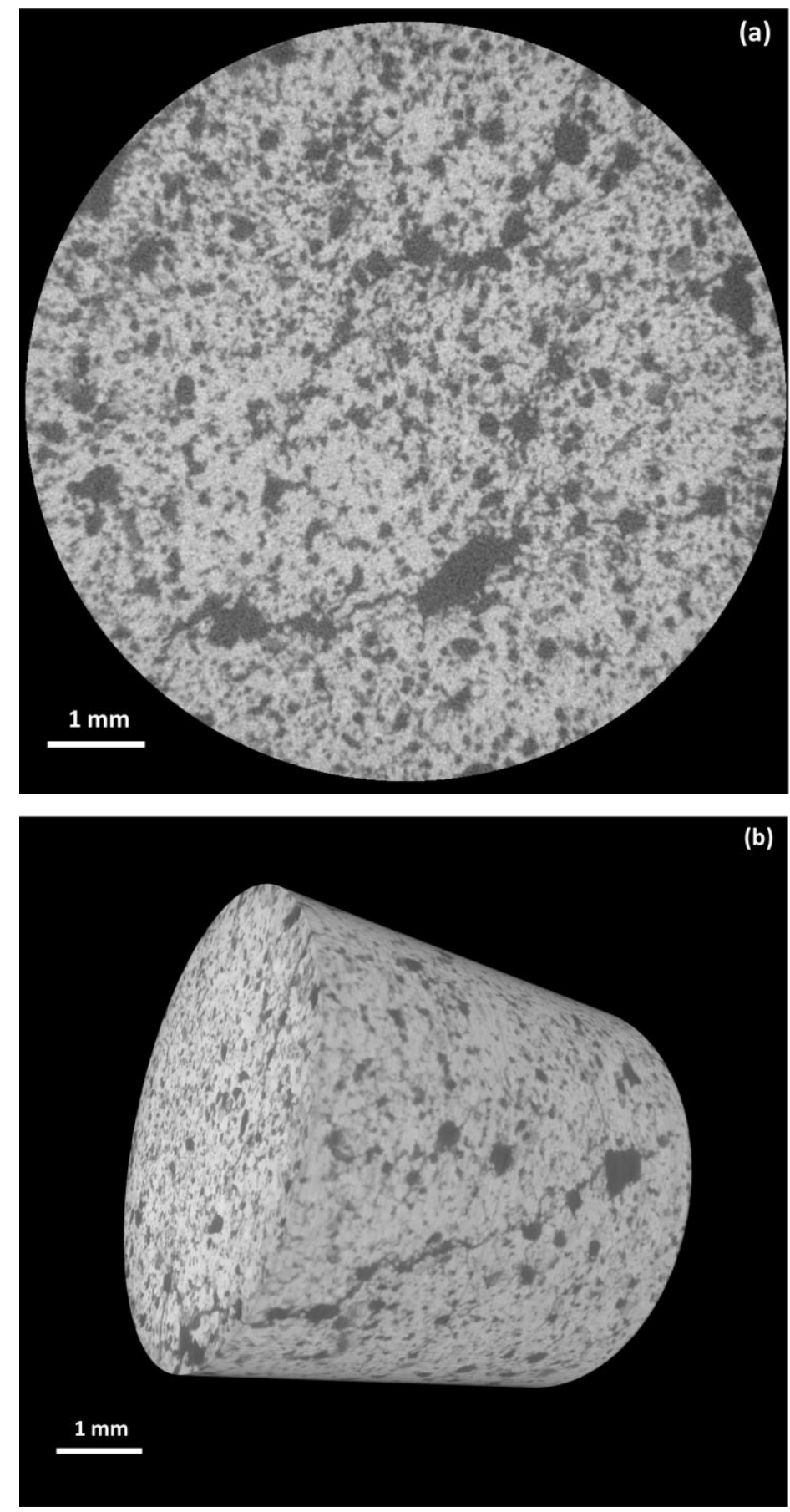

Figura 59 - Aquisição em 4X (Resolução $4 \mu \mathrm{m}$ ): (a) Fatia 2D; (b) Volume 3D.

A Figura 60 apresenta exatamente a região de análise a $4 \mathrm{X}$ em relação à de $0.4 \mathrm{X}$. Percebe-se que o campo analisado pela lente de $4 \mathrm{X}$ é muito pequeno e pode não ser tão representativo quanto a análise de uma pelota completa. 

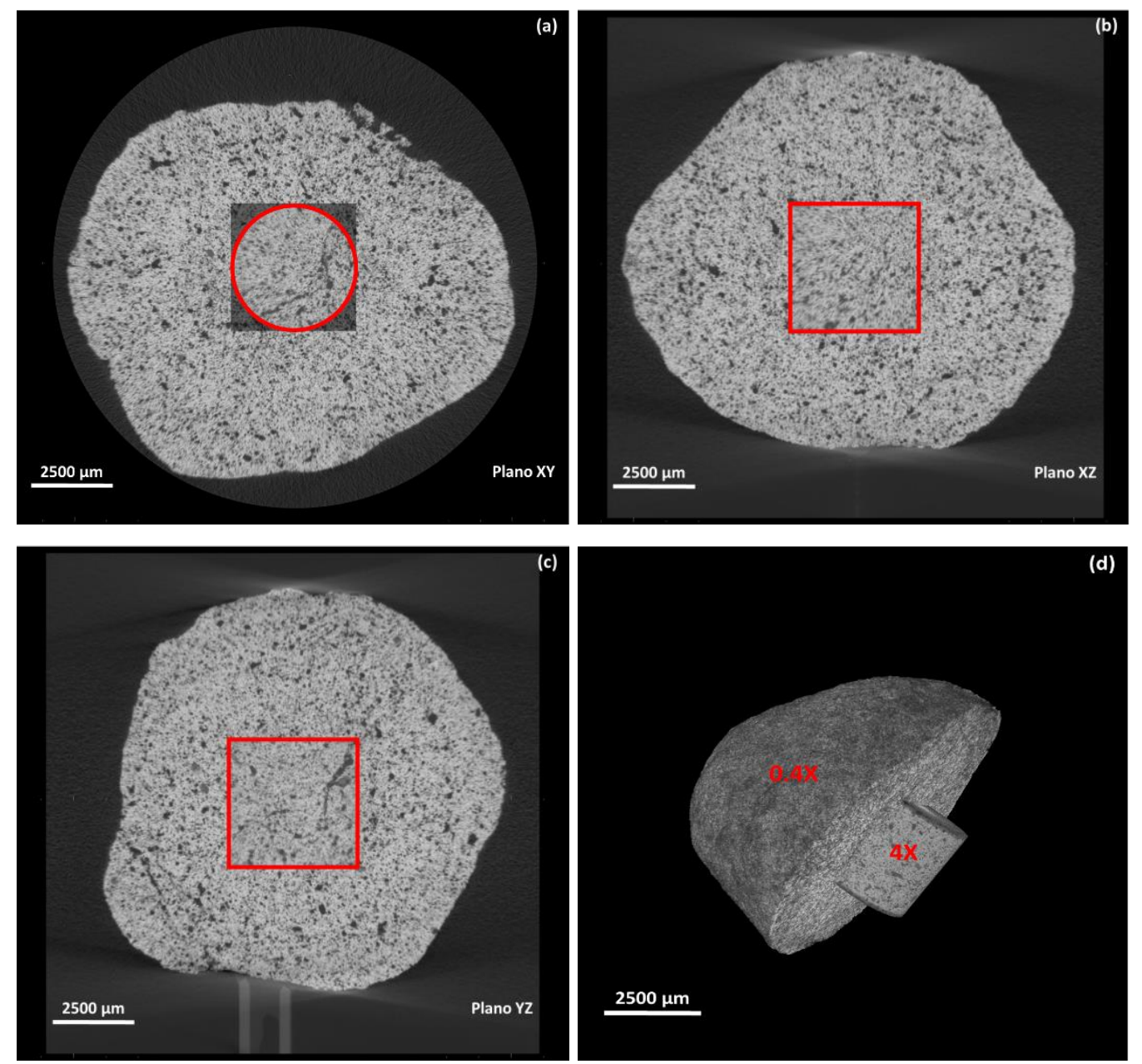

Figura 60 - Região analisada pela lente de $4 X$ em relação a lente de $0.4 X$ : (a)

Plano XY; (b) Plano XZ; (c) Plano YZ; (d) Corte do volume em 0.4X para visualização do volume $4 X$.

A Figura 61 e a Figura 62 apresentam as fatias 2D e os volumes 3D das aquisições feitas com a lente de $0.4 \mathrm{X}$ (resolução de $\sim 4 \mu \mathrm{m}$ ) e $4 \mathrm{X}$ (de uma das partes do mosaico, com resolução de $\sim 2 \mu \mathrm{m}$ ). 


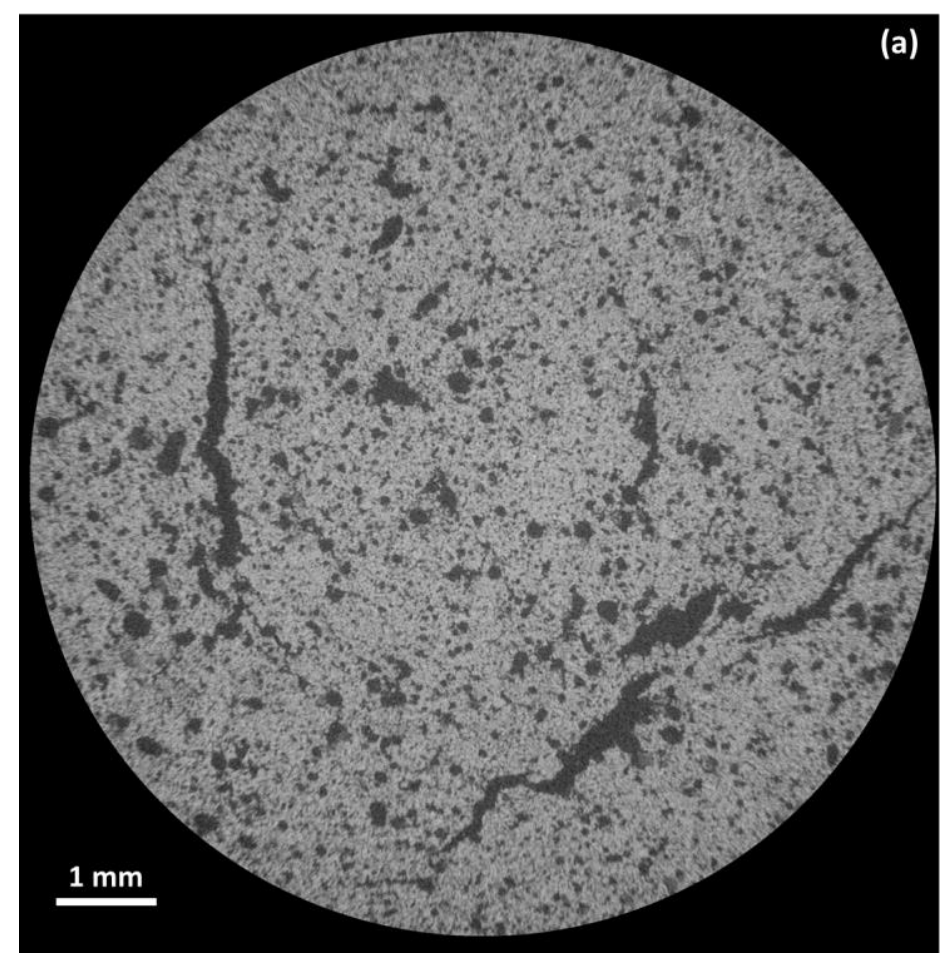

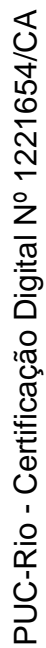

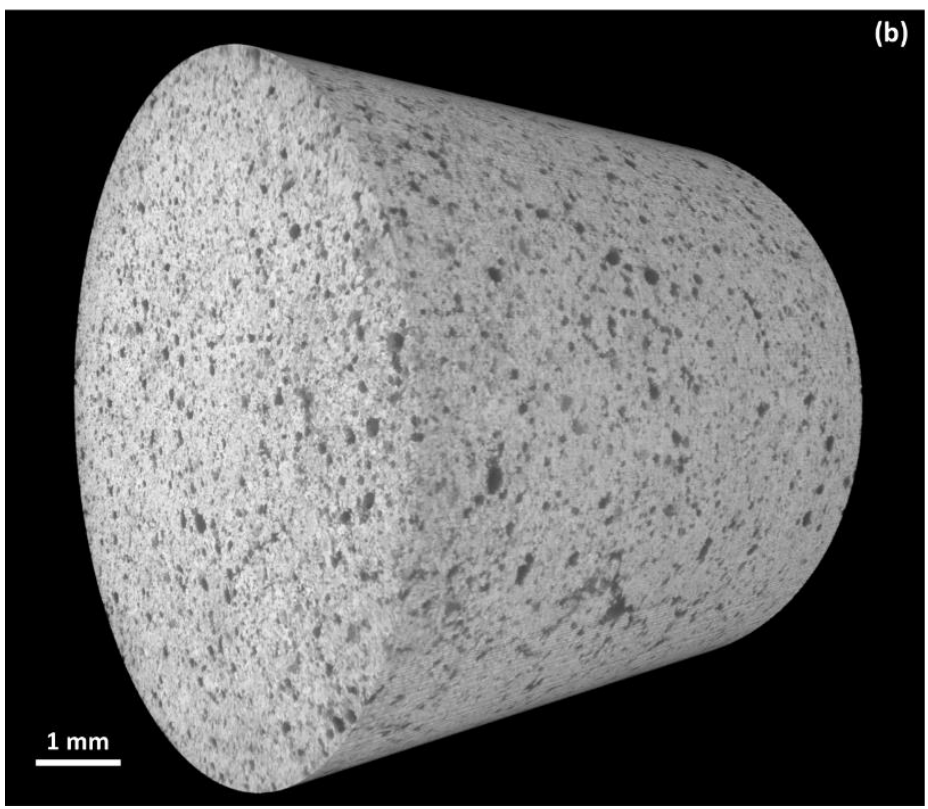

Figura 61 - Aquisição em 0.4X (Resolução $4 \mu \mathrm{m}$ ): (a) Fatia 2D; (b) Volume 3D. 

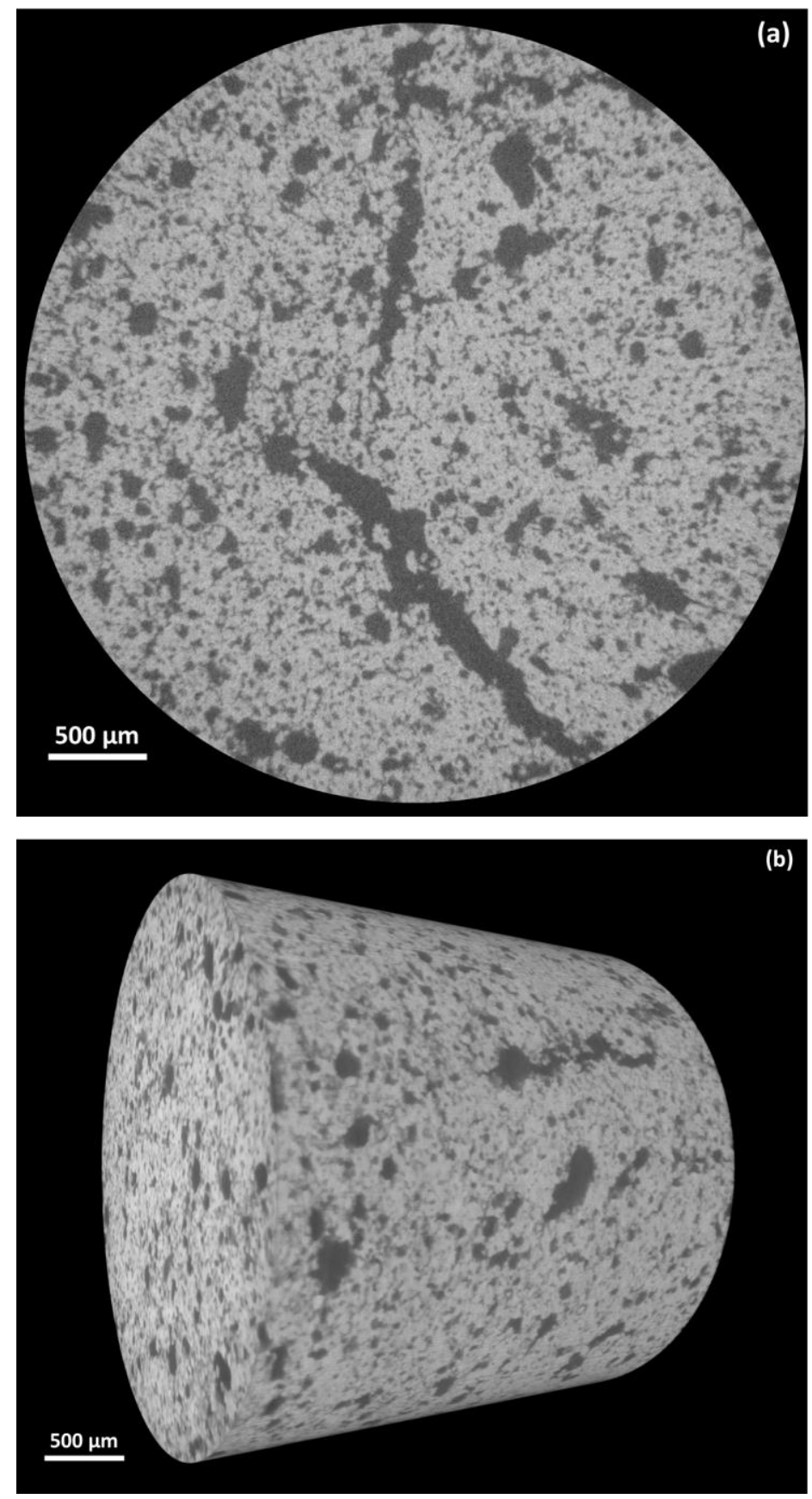

Figura 62 - Aquisição em 4X (Resolução $2 \mu \mathrm{m}$ ): (a) Fatia 2D; (b) Volume 3D.

A Figura 63-a ilustra a região referente ao mosaico obtido com a lente de $4 \mathrm{X}$ dentro da região analisada pela lente de 0.4X. Mesmo com a utilização do mosaico, a região analisada ainda é muito menor em relação à amostra como um todo. Além disso, o tempo total de análise, incluindo aquisição, reconstrução e processamento das imagens, é extremamente grande, tornando a análise inviável. Devido a isso não foi dado prosseguimento neste tipo de análise. 
Já a Figura 63-b ilustra a região referente à análise obtida com a lente de $0.4 \mathrm{X}$ com resolução de $4 \mu \mathrm{m}$, em relação à pelota inteira analisada pela lente de $0.4 \mathrm{X}$ com resolução de $8 \mu \mathrm{m}$. Observa-se que a região de análise é bem representativa, com condições de análise mais viáveis comparadas à obtenção de mosaico em 4X. 

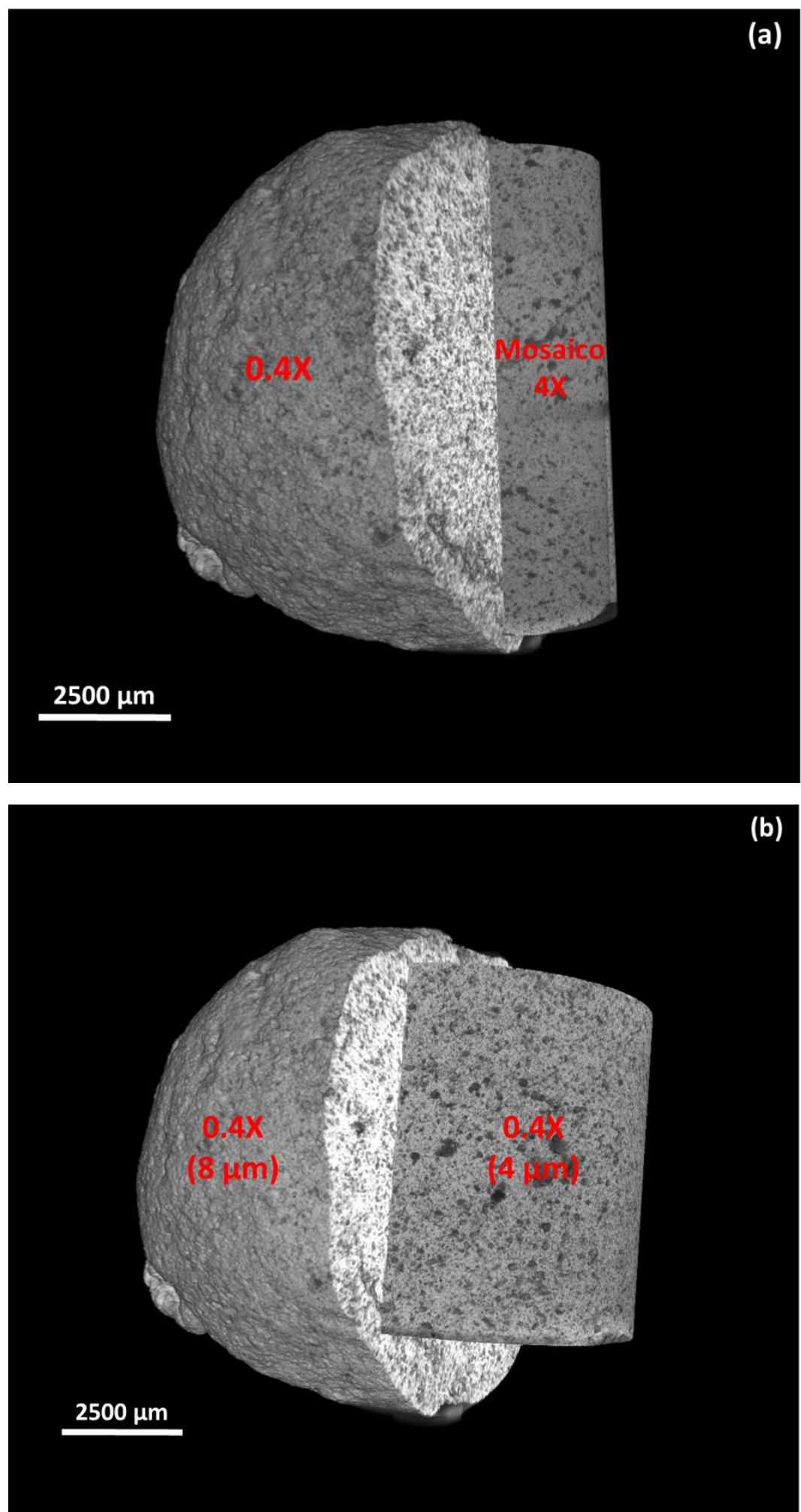

Figura 63 - (a) Região analisada pelo mosaico obtido pela lente de $4 \mathrm{X}$ em relação à região analisada pela lente de $0.4 \mathrm{X}$; (b) Região analisada pela lente de $0.4 \mathrm{X}$ com melhor resolução em relação à região analisada a $0.4 \mathrm{X}$ com pior resolução. 


\subsubsection{Pré-processamento}

O pré-processamento utilizado neste trabalho consistiu nas seguintes etapas:

\section{- Filtragem com Non-Local Means:}

Aplicou-se um filtro para redução de ruídos, que são bastante comuns nas imagens geradas por MicroCT. O filtro utilizado foi o denominado "Non Local Means Denoise" (NLM), disponível como um plugin do software FIJ//ImageJ [45]. É um filtro muito sofisticado, baseado no algoritmo de médias não-locais, considerado recentemente como uma das ferramentas mais importantes na filtragem de ruídos em imagens digitais.

A técnica propõe que o cálculo da estimativa de cada pixel sem ruído da imagem seja feito a partir de uma média ponderada de diferentes partes da imagem e não apenas localmente.

A comparação da imagem original com a imagem após a aplicação do filtro pode ser visualizada na Figura 64. A melhora na distinção entre as fases fica ainda mais perceptível comparando-se os histogramas das duas imagens. Os picos no histograma da imagem filtrada são bem mais definidos do que na imagem original, facilitando a separação das fases na etapa de segmentação. 

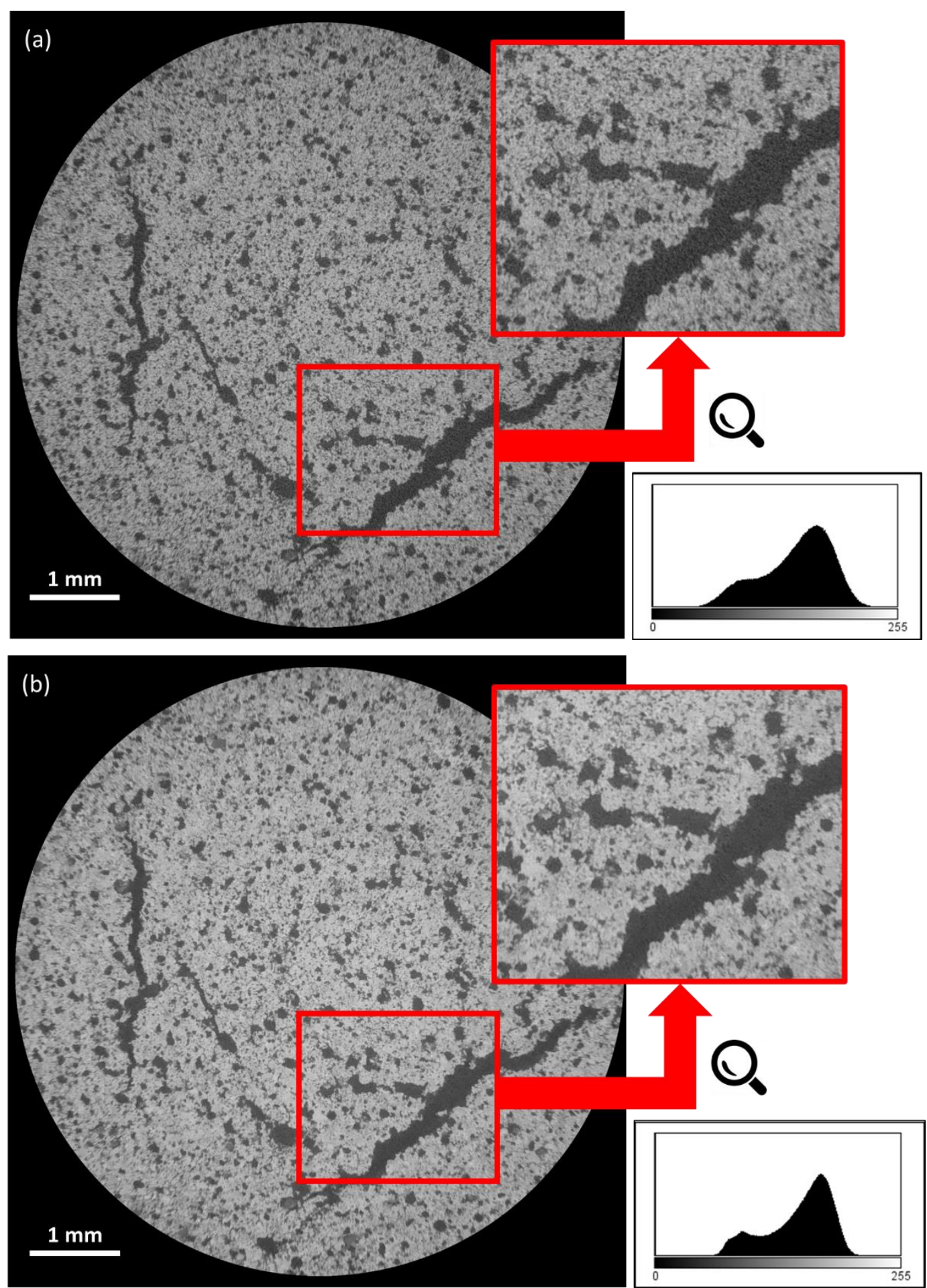

Figura 64 - (a) Imagem original; (b) Imagem após aplicação do filtro Non-Local Means

\section{- $\quad$ Realce de bordas com Delin:}

O realce de bordas foi feito com a função de delineamento, que encontra os pixels de transições entre as fases e decide a qual fase esses pixels pertencem. A decisão é baseada na proximidade do tom de cinza do pixel em questão com uma 
das fases. Assim, as transições entre as fases tornam-se mais abruptas, dando a sensação de maior nitidez na imagem [46]. A imagem com o realce de bordas pode ser visualizada na Figura 65. O histograma da referida imagem mostra os picos das fases mais bem definidos ainda.

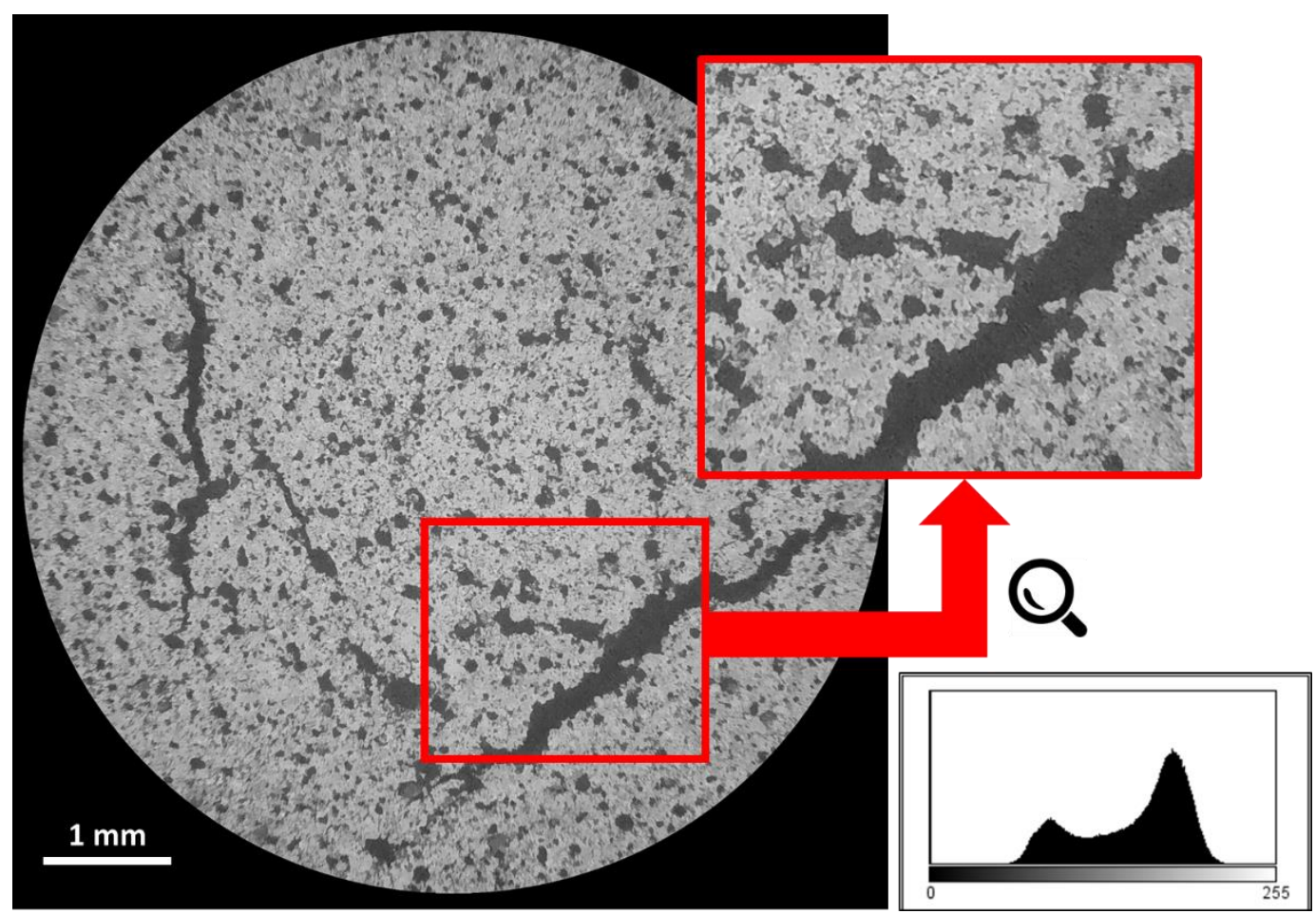

Figura 65 - Imagem resultante da aplicação do realce de bordas (Delin)

\section{- Ajuste do contraste com Enhance Contrast:}

A melhora do contraste foi feita com a função chamada Enhance Contrast disponível no software ImageJ/FIJI. Esta função melhora o contraste da imagem através da expansão do histograma, com a saturação de $0,4 \%$ dos pixels, garantindo que todas as camadas 2D tenham a mesma faixa tonal. A Figura 66-a e a Figura 66c apresentam duas camadas distintas que não passaram pela aplicação de expansão do contraste. Os histogramas correspondentes destas duas imagens encontram-se deslocados um em relação ao outro, evidenciado pela linha pontilhada em vermelho. Já a Figura 66-b e a Figura 66-d representam as mesmas camadas após a melhora do contraste com seus respectivos histogramas. Nota-se que, agora, é possível utilizar um mesmo valor fixo de limiar de separação entre as fases, pois as posições dos picos das fases existentes são praticamente as mesmas. 

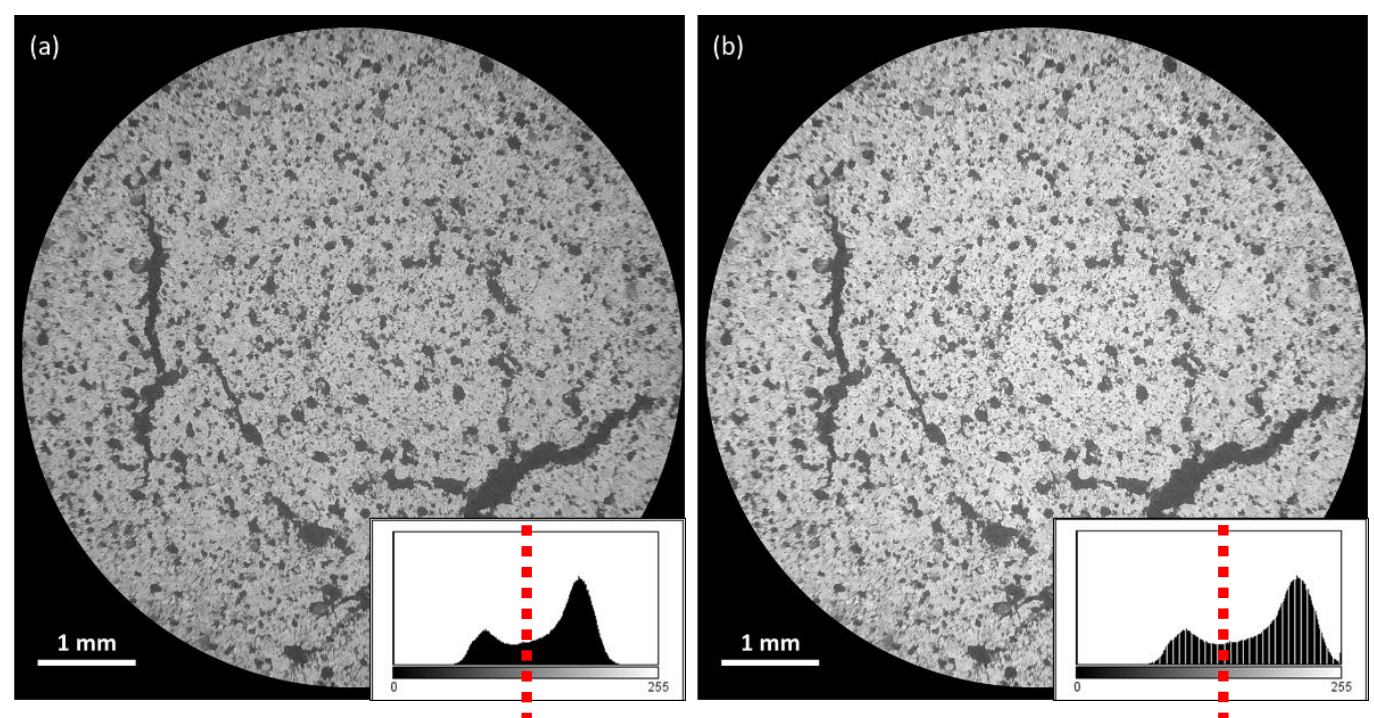

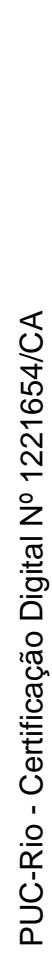
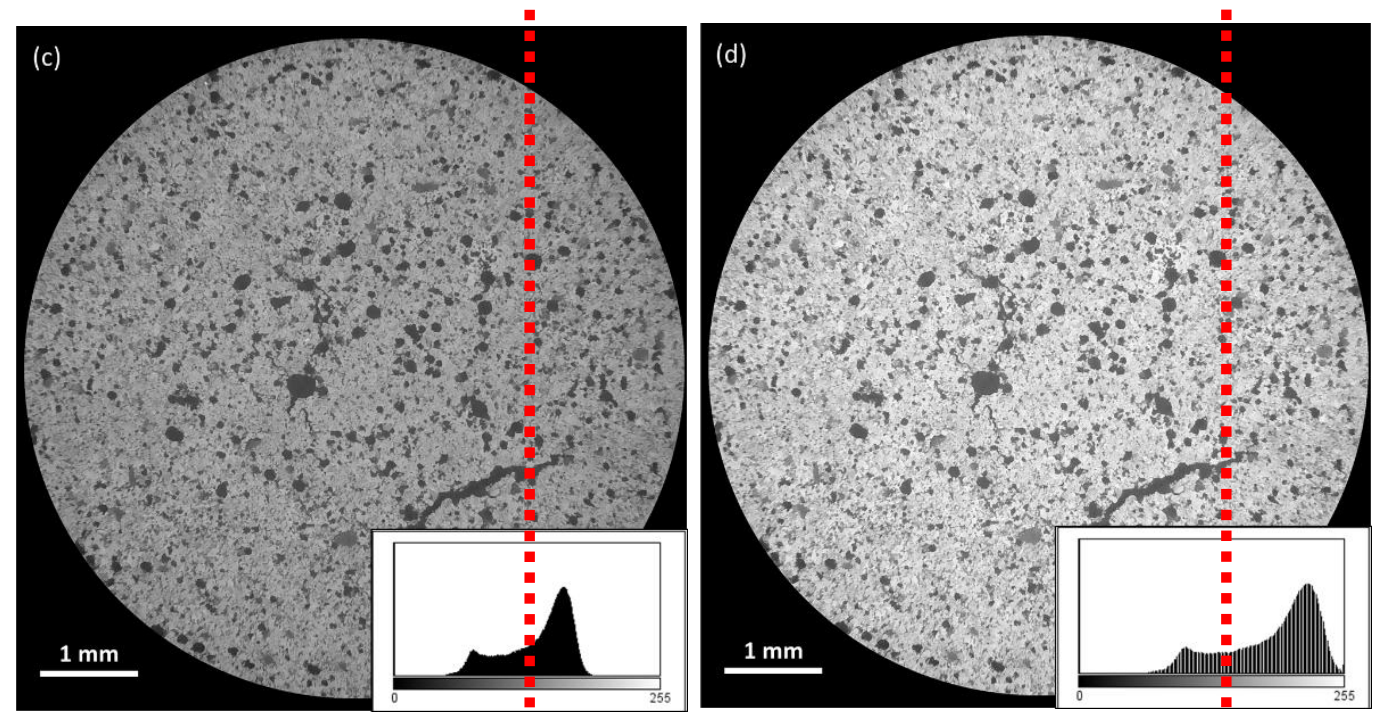

Figura 66 - Imagem resultante da aplicação do ajuste de contraste (Enhance

Contrast)

\subsubsection{Segmentação}

A segmentação foi feita interativamente, com a escolha de um limiar fixo para todas as camadas 2D das amostras. $\mathrm{O}$ valor do tom de corte para a segmentação altera a quantidade de pixels que são medidos.

Para obtenção da percentagem de poros, verificando-se que as imagens de MicroCT de pelotas de minério de ferro, mesmo após todo o pré-processamento explicado anteriormente, são ainda difíceis de segmentar, escolheu-se 5 valores de limiares de segmentação, com uma diferença de 5 tons entre eles, para cada amostra.

Então, para cada volume gerado a partir da segmentação com estes valores, extraiu-se o volume dos poros. Assim, os valores de porosidade estimados de cada 
amostra estão dentro de uma faixa determinada por esses valores de limiares. Para melhor entendimento, um exemplo da segmentação (em 2D) é mostrado na Figura 67. Neste caso, o valor de porosidade é considerado dentro da faixa de 19,27\%$26,02 \%$, obtida pela segmentação com os valores de limiares de 125 a 145, que são os valores mínimo e máximo de tons de corte para esta amostra.
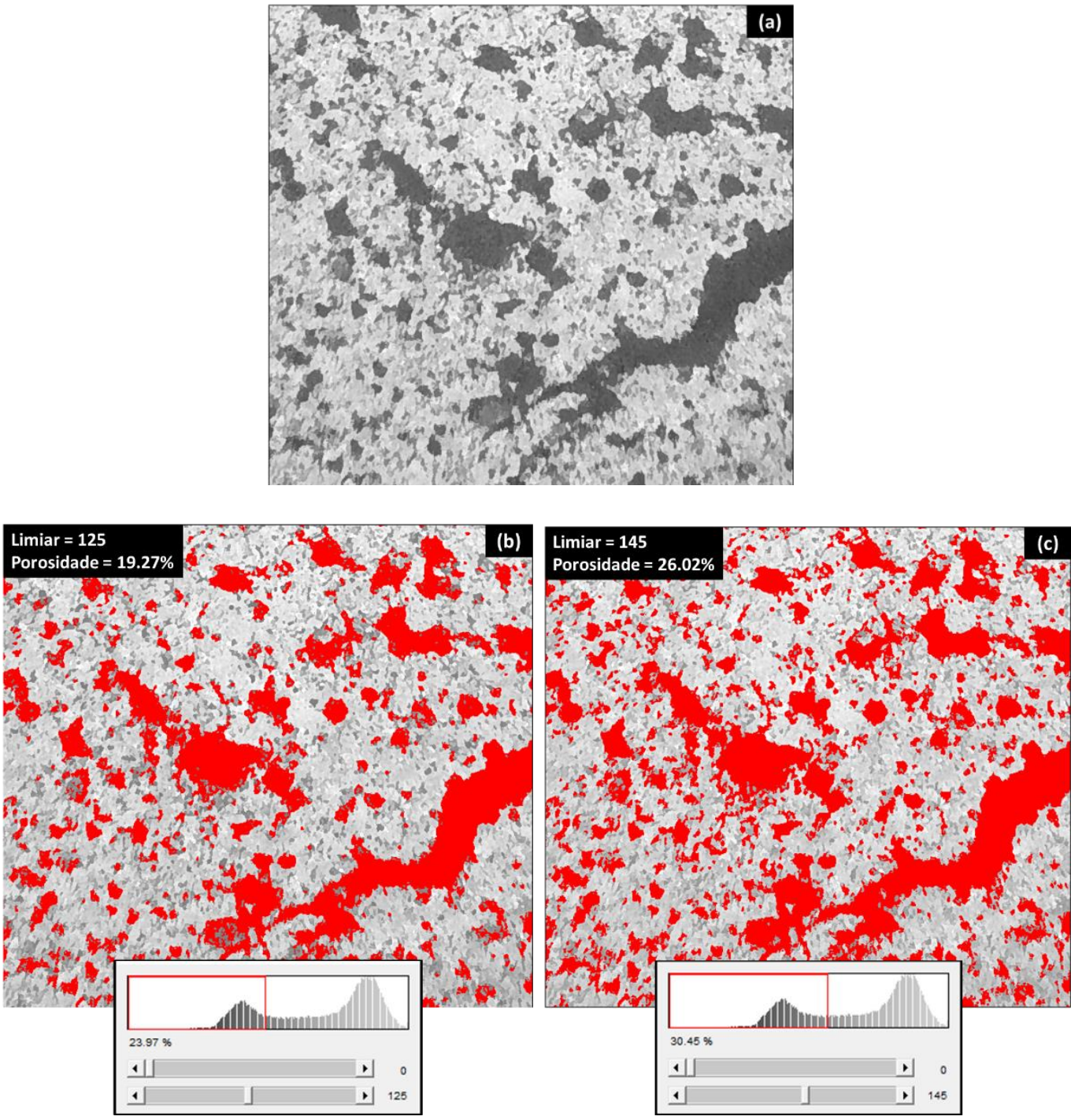

Figura 67 - (a) Ampliação de uma região da imagem original; (b) Segmentação: Limiar $=125$, Porosidade $=19,27 \%$; (c) Segmentação: Limiar $=145$, Porosidade $=26,02 \%$.

A imagem binária resultante da segmentação com um dos limiares citados é apresentada na Figura 68. 


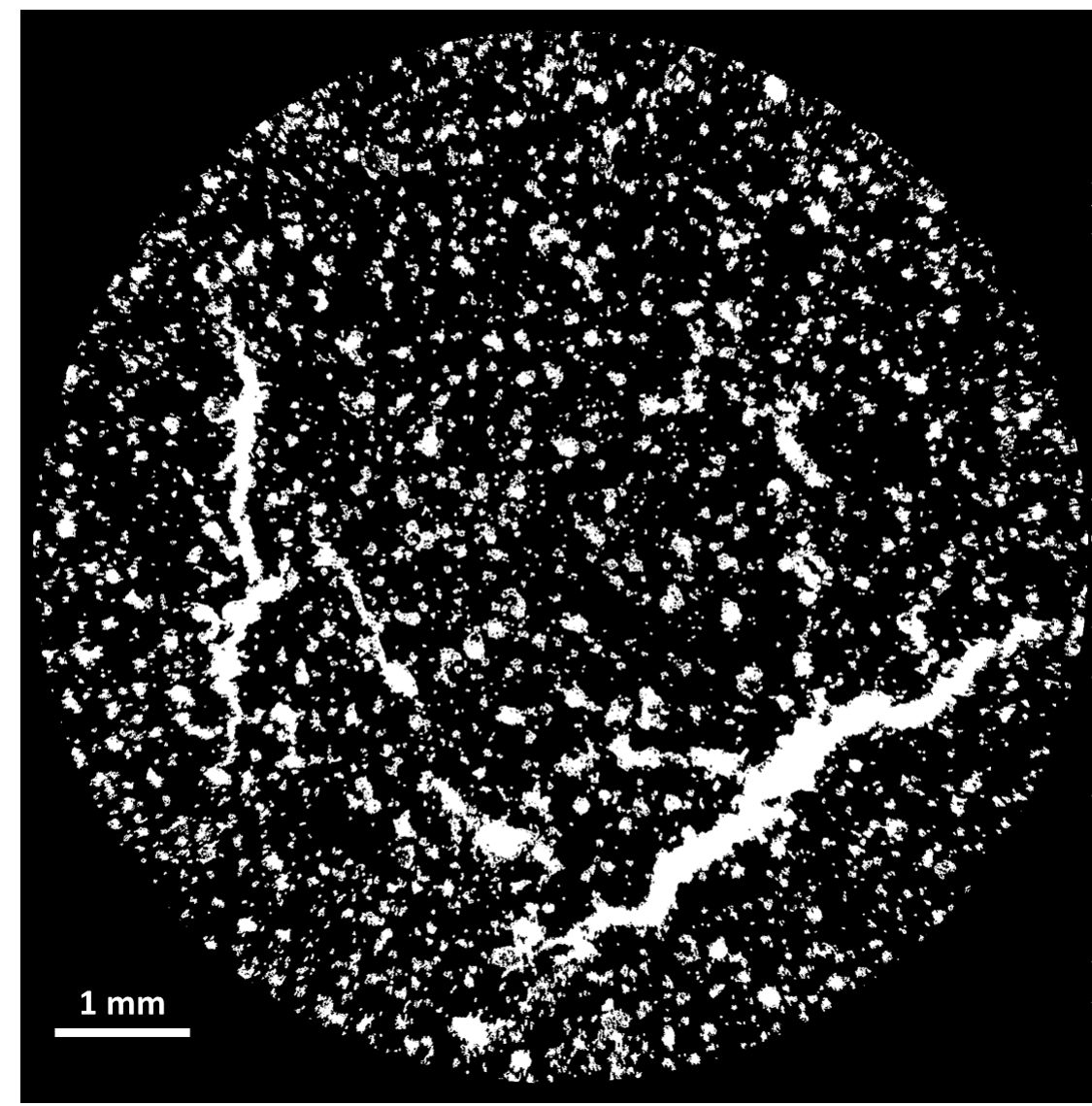

Figura 68 - Imagem binária resultante da segmentação dos poros

\subsubsection{Pós-processamento}

O pós-processamento, neste caso, teve como objetivo a separação dos poros totais em poros abertos e fechados pois, para os valores de porosidade serem comparáveis com a porosidade obtida por PIM, apenas deve ser levada em consideração a porosidade aberta. Além disso, este tipo de separação de poros permite avaliar a distribuição e quantificação dos poros fechados separadamente, que não são analisados pelas técnicas tradicionais, porém são muito relevantes no que diz respeito à resistência física das pelotas.

\section{- Determinação do percentual de porosidade total}

Para obter rapidamente os valores de porosidade total, é necessária uma pequena sequência de processamento no CTAn. Vale comentar que, nesta etapa, o 
software considera os pixels pretos como poros, e distingue os percentuais de porosidade total em porosidade aberta e porosidade fechada.

A lógica do processamento para a obtenção dos valores de porosidade pode ser entendida na sequência abaixo:

\section{A) Thresholding}

Esta função consiste na segmentação da fase sólida resultando numa imagem binária, na qual os pixels pretos correspondem aos poros (e fundo da imagem) e os pixels brancos a todas as demais fases. O tom de corte é um tom acima do correspondente à fase de poros.

A Figura 69-a e a Figura 69-b apresentam as imagens binárias resultantes da segmentação das fases, adquiridas com a lente de $0.4 \mathrm{X}$ e $4 \mathrm{X}$ respectivamente. 

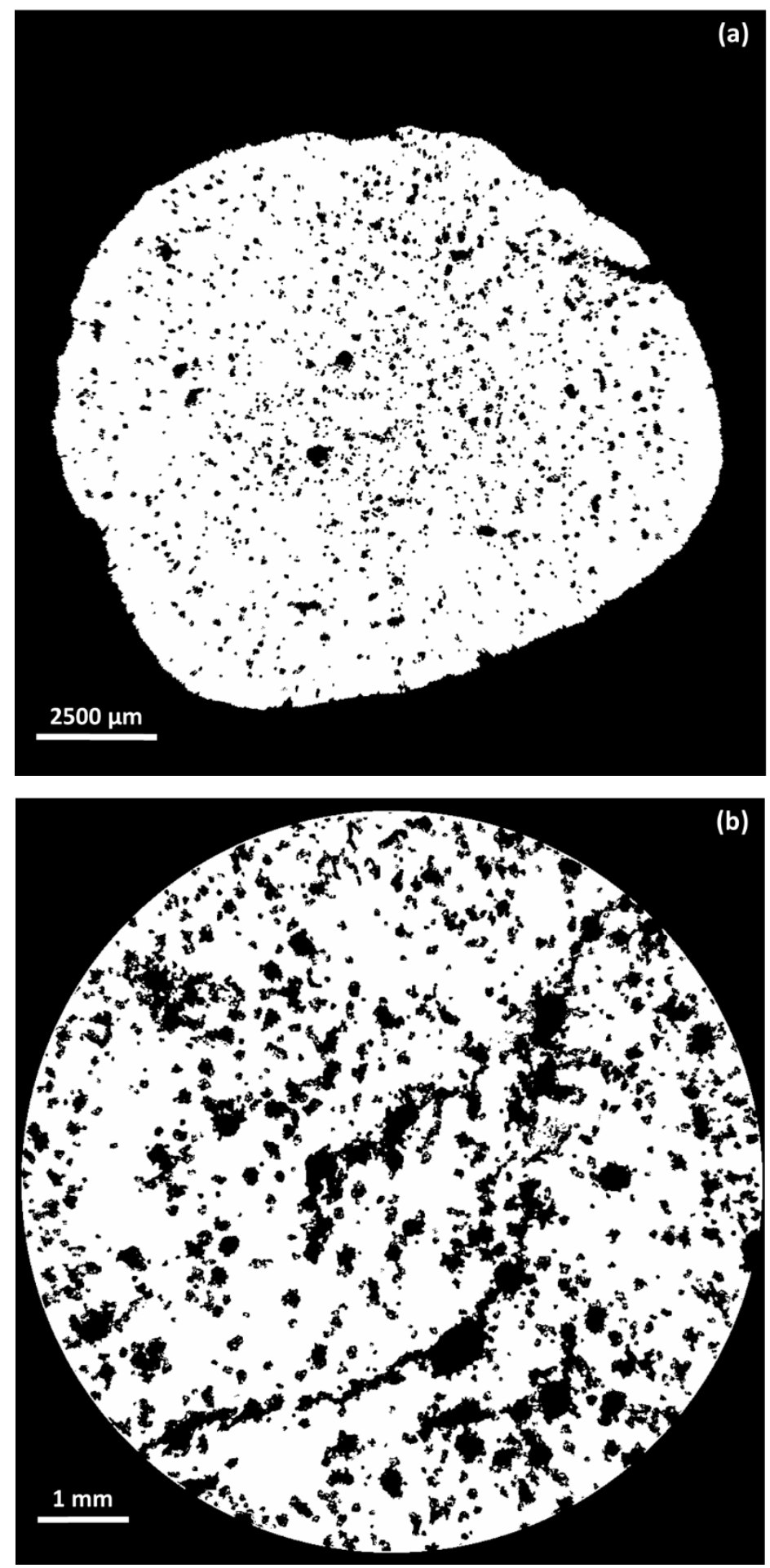

Figura 69 - Segmentação das fases: (a) 0.4X; (b) 4X.

\section{B) ROI Shrink-wrap}

Este processamento permite fazer uma fronteira seguindo exatamente a borda de um objeto em uma imagem binária. Dessa forma, pode-se utilizar esta área 
delimitada como uma região de interesse (ROI) para medidas, como a de porosidade, por exemplo.

Além disso, existe um parâmetro disponível nesta função que pode ser variado, chamado de "Stretch over holes", que faz com que a ROI seja esticada sobre os buracos em contato com a periferia da imagem, o que torna possível a identificação dos poros abertos. O valor de "Stretch over holes" utilizado neste trabalho foi de um diâmetro igual a 100 pixels, ou seja, a ROI é esticada sobre buracos que tenham diâmetro abaixo deste valor.

A Figura 70 apresenta a imagem resultante da aplicação do ROI Shrink-wrap sobre a imagem da Figura 69.

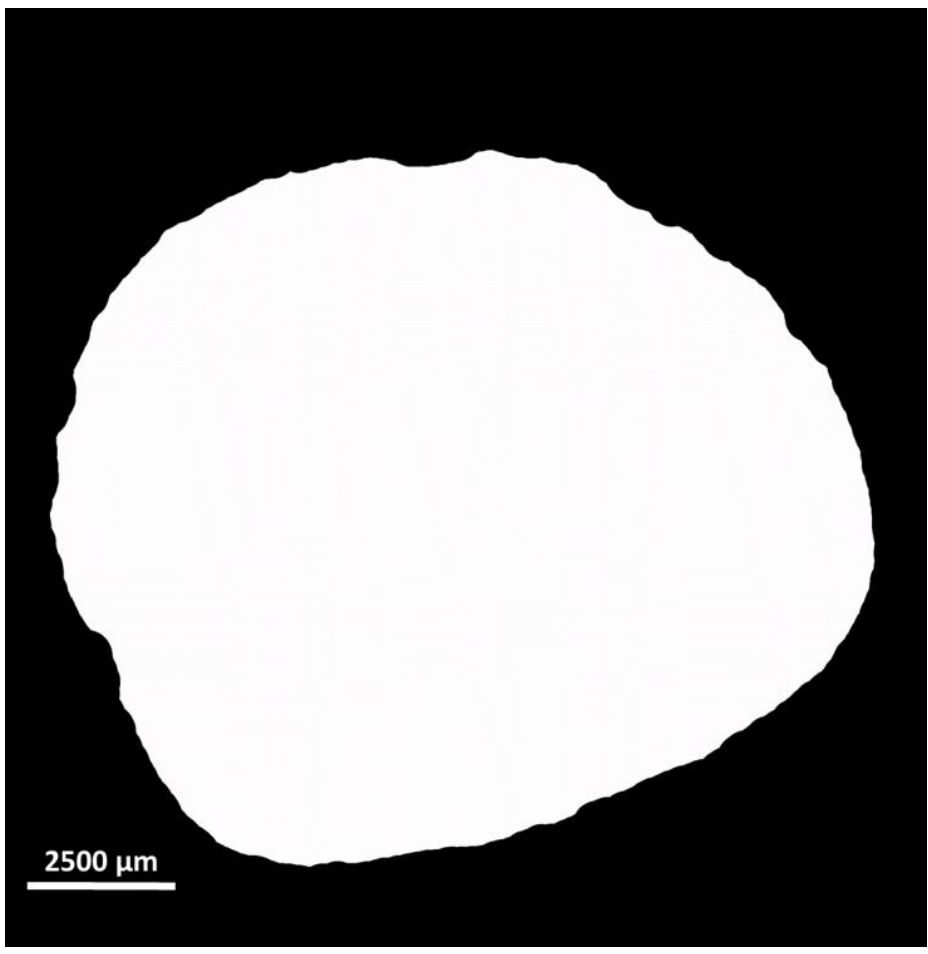

Figura 70 - Imagem resultante do ROI Shrink-wrap

A Figura 71 evidencia um exemplo de buraco que foi fechado pela aplicação do ROI Shrink-wrap. 

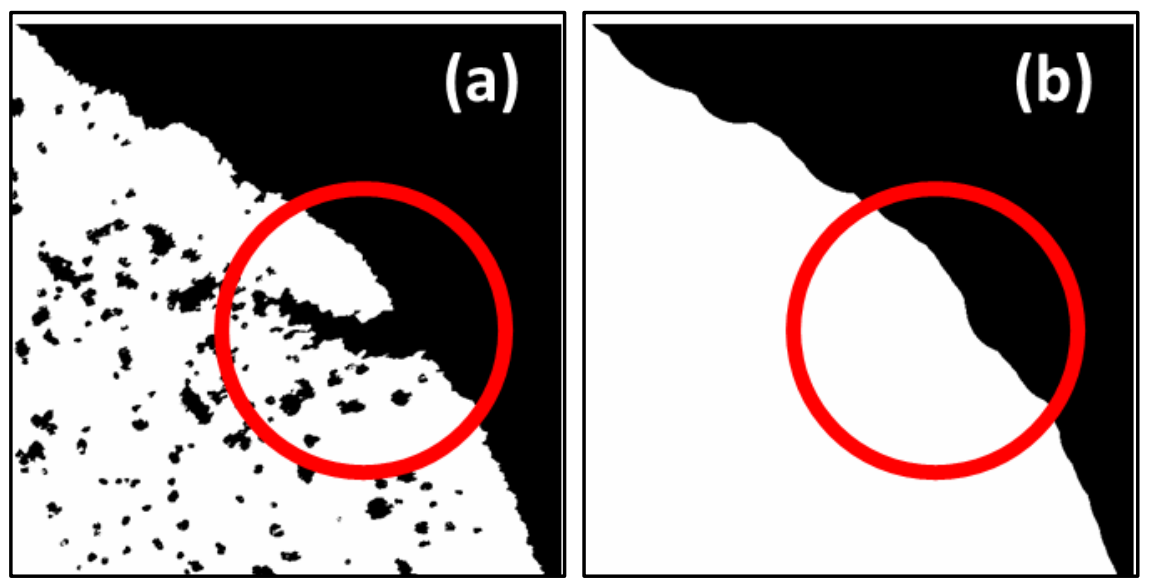

Figura 71 - Criação da ROI: (a) Aumento de uma região da Figura 69; (b) Aumento de uma região da Figura 70.

No caso das imagens obtidas pela lente de $4 \mathrm{X}$ não foi necessário utilizar esta função, já que a análise corresponde a uma região interna da pelota e, por isso, as camadas 2D que contêm a amostra são sempre circulares, formando um volume cilíndrico. A ROI das imagens obtidas pela lente de 4X são como na Figura 72.

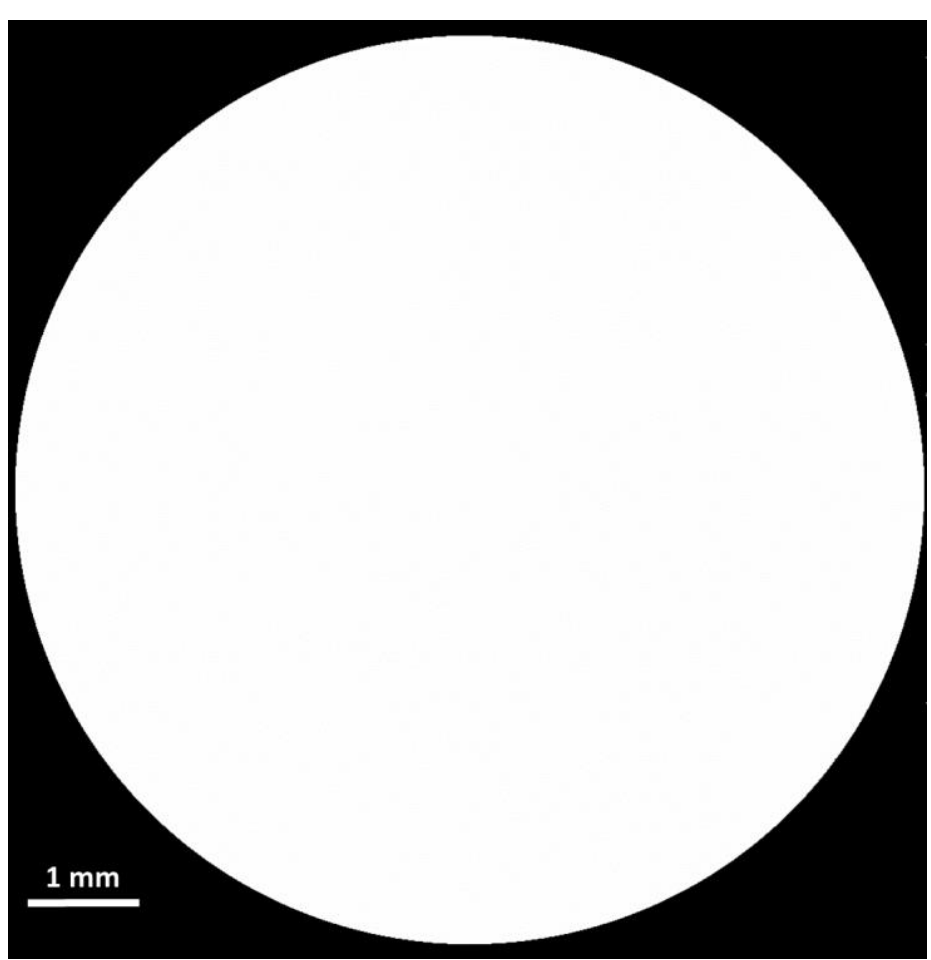

Figura 72 - ROI das imagens obtidas pela lente de $4 \mathrm{X}$ 


\section{C) 3D Analysis}

Após criada a imagem segmentada e a ROI, realizou-se uma subtração entre as duas imagens para obter a imagem de todos os poros, como mostrado na Figura 73.
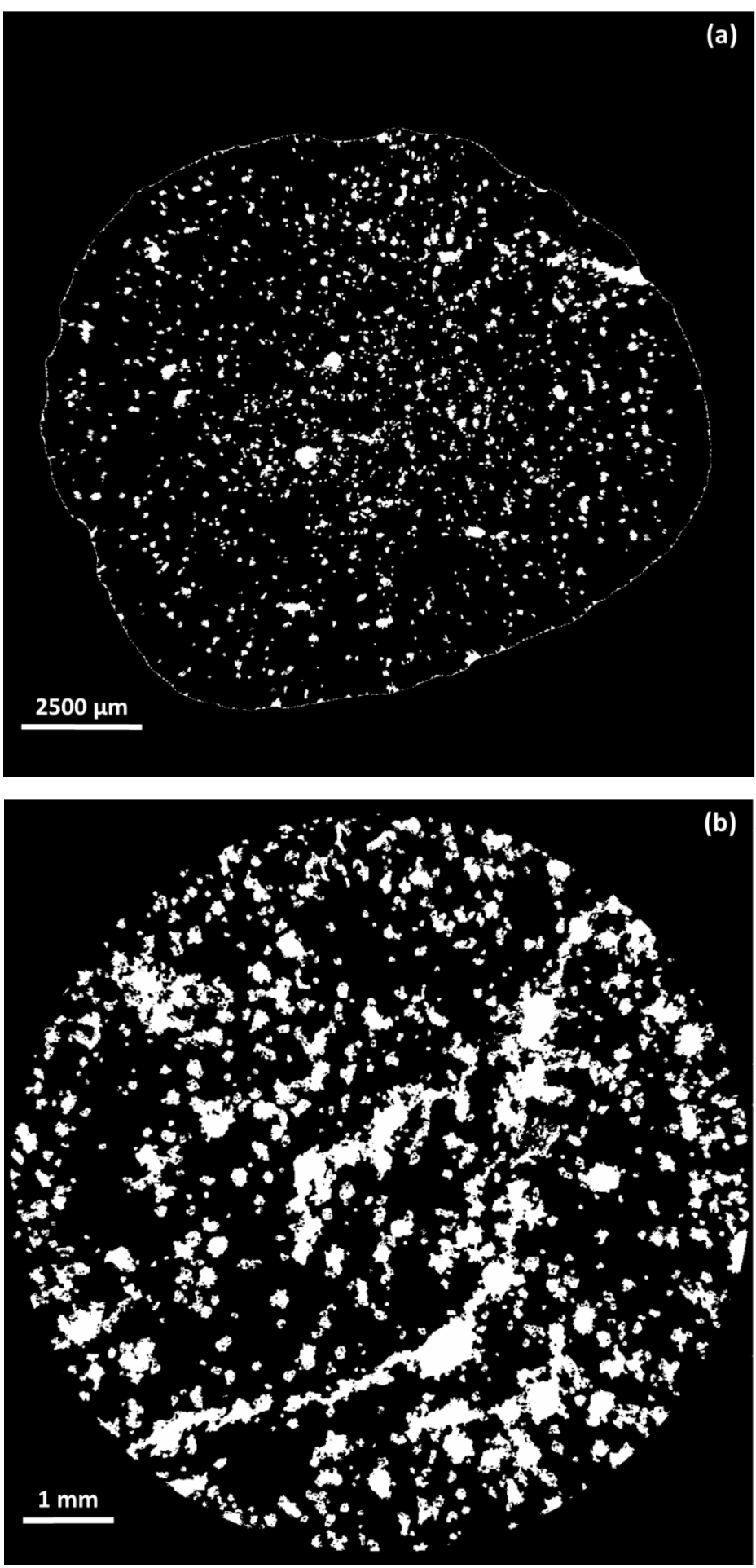

Figura 73 - Poros total: (a) $0.4 \mathrm{X}$; (b) 4X. 
Após gerar esta imagem, quantificou-se a porosidade total (\%) calculada pelo volume de todos os poros (abertos e fechados). Nesta função, o software é capaz de medir automaticamente os percentuais de porosidade aberta e fechada separadamente, a partir das equações 9 e 10 respectivamente, sem que seja necessária a obtenção das imagens de poros abertos e fechados, como descrito no processamento de determinação do tamanho dos poros, explicado logo adiante.

$\%$ Poros abertos (P.A.) $=\frac{\text { Volume de P.A. }}{\text { Volume da ROI }}$

$\%$ Poros Fechados $(P . F)=.\frac{\text { Volume de P.F. }}{(\text { Volume da ROI - Volume de P.A. })}$

Observe que, segundo a definição do software, a porosidade fechada é calculada diferentemente da porosidade aberta, pois é considerada como uma propriedade do material [47].

A distribuição espacial da porosidade total pode ser visualizada na Figura 74. 

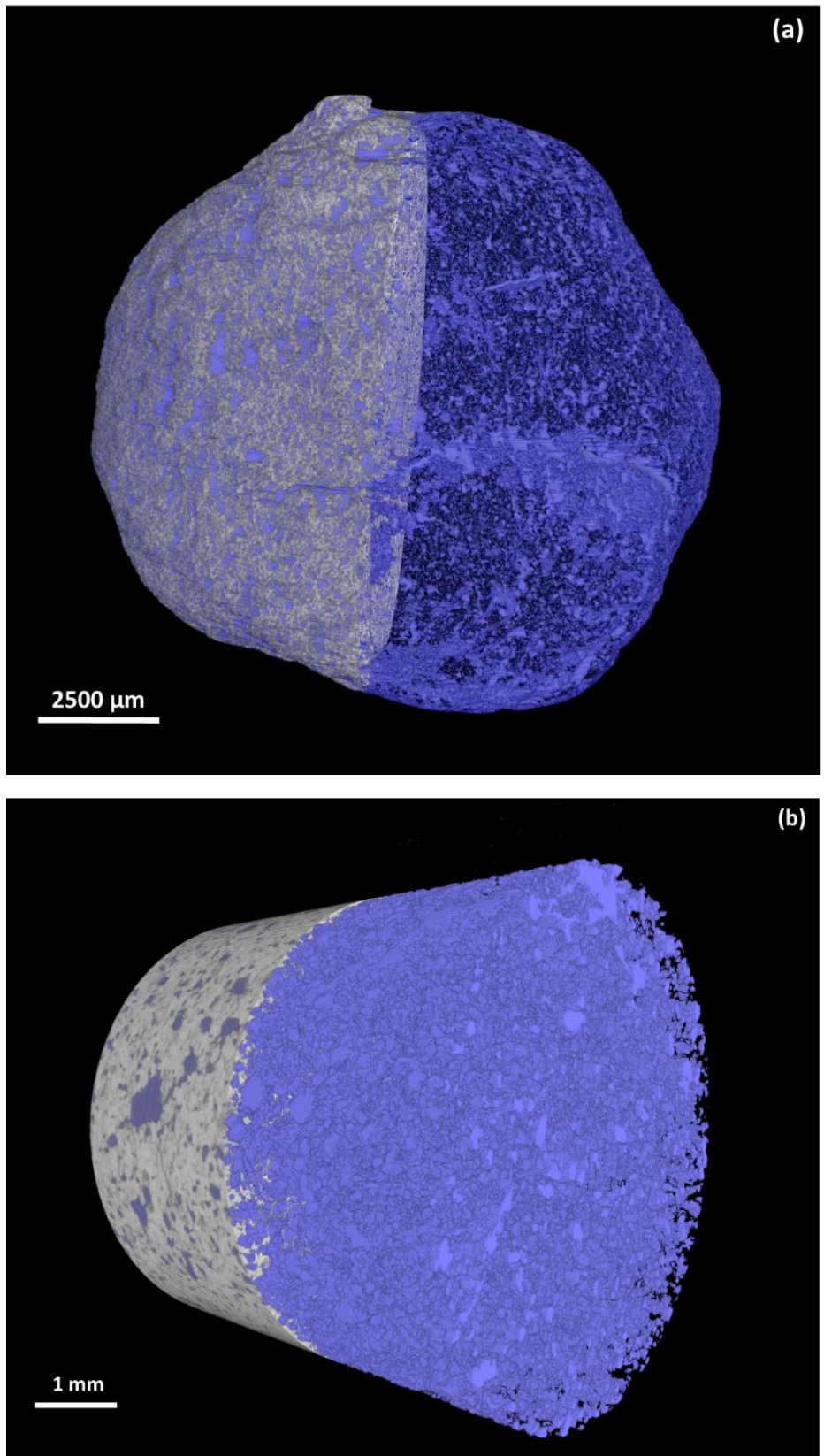

Figura 74 - Porosidade total: (a) $0.4 \mathrm{X}$; (b) $4 \mathrm{X}$.

- Determinação do tamanho dos poros abertos

\section{A) Thresholding}

Foi feita uma segmentação da imagem para separação dos poros das demais fases, idem à Figura 69. 


\section{B) Despeckle 3D}

Aplicou-se uma função denominada Despeckle, que permite selecionar ou remover objetos em imagens binárias, podendo ser feito em 2D ou 3D. Utilizou-se a opção de remover poros, a qual remove todas as regiões em preto (poros) que são cercadas por pixels brancos (sólido). Isso pode ser feito em 2D ou 3D, mas, neste caso, escolheu-se a opção tridimensional da função. A imagem resultante encontrase na Figura 75.

Note que os poros delimitados pela marcação em vermelho, na Figura 75-a, são poros rodeados por pixels brancos na imagem $2 \mathrm{D}$, porém são poros que, tridimensionalmente, estão abertos para a superfície e, por isso, não são removidos. Já nas imagens obtidas com a lente de 4X, conforme a Figura 75-b, quase todos os poros são considerados poros abertos, devido à conexão com a borda, e não são eliminados

Logo, esta função faz com que apenas poros fechados, em 3D, sejam removidos. 

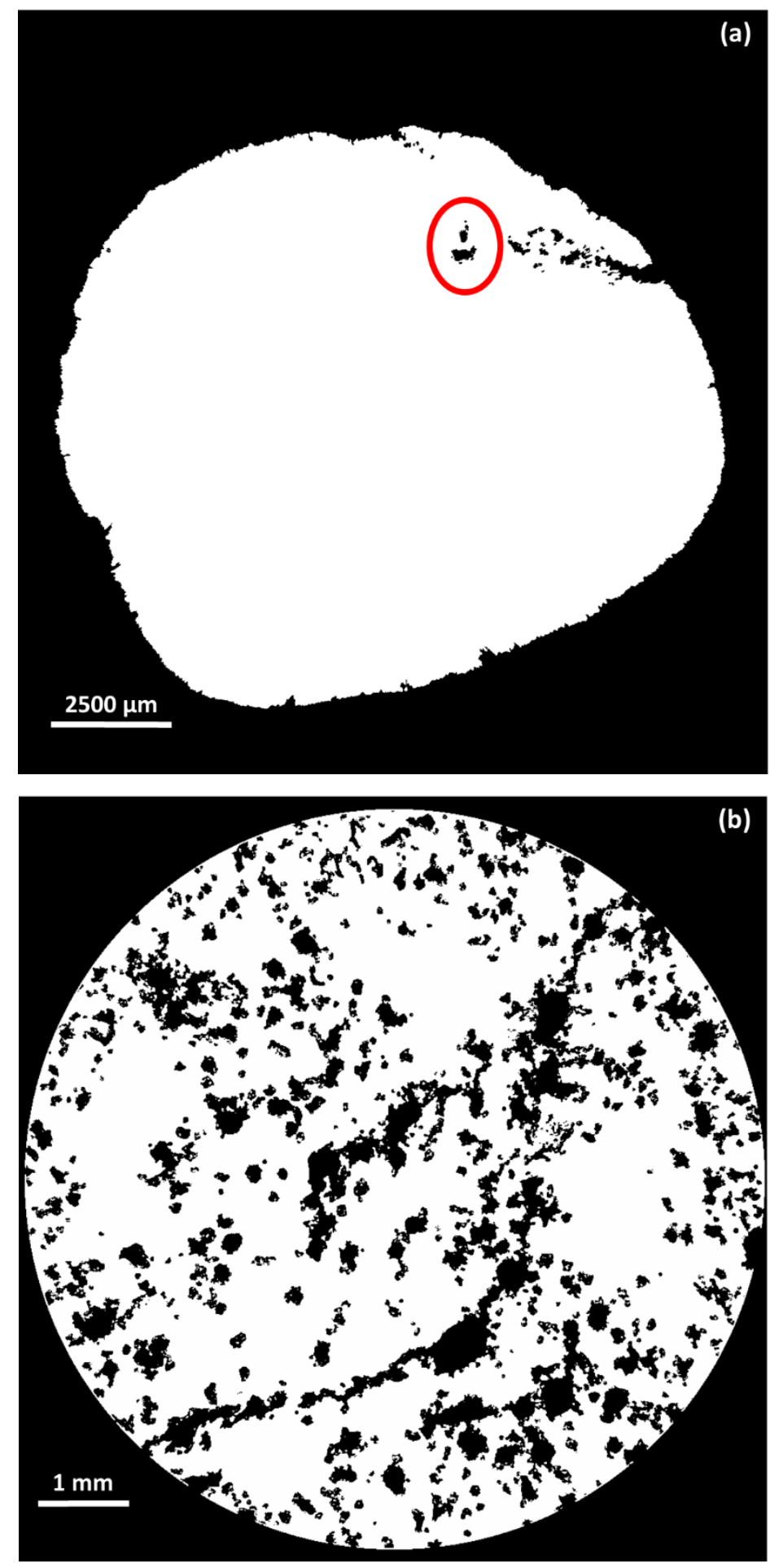

Figura 75 - Imagem resultante da aplicação do Despeckle: (a) 0.4X; (b) 4X.

\section{C) ROI Shrink-wrap 2D}

Novamente foi feita a aplicação da função ROI Shrink-wrap na imagem segmentada (Figura 69), obtendo-se a mesma imagem apresentada na Figura 70. 


\section{D) Bitwise operations (XOR)}

E, por fim, aplicou-se uma operação lógica chamada $X O R$ entre as imagens da Figura 70 e da Figura 75. Esta operação é basicamente a diferença entre as duas imagens, ou seja, a imagem resultante recebe pixels brancos nos locais onde contenham pixels brancos em, pelo menos, uma das duas imagens. Assim, o volume resultante conterá apenas os poros abertos (Figura 76). 


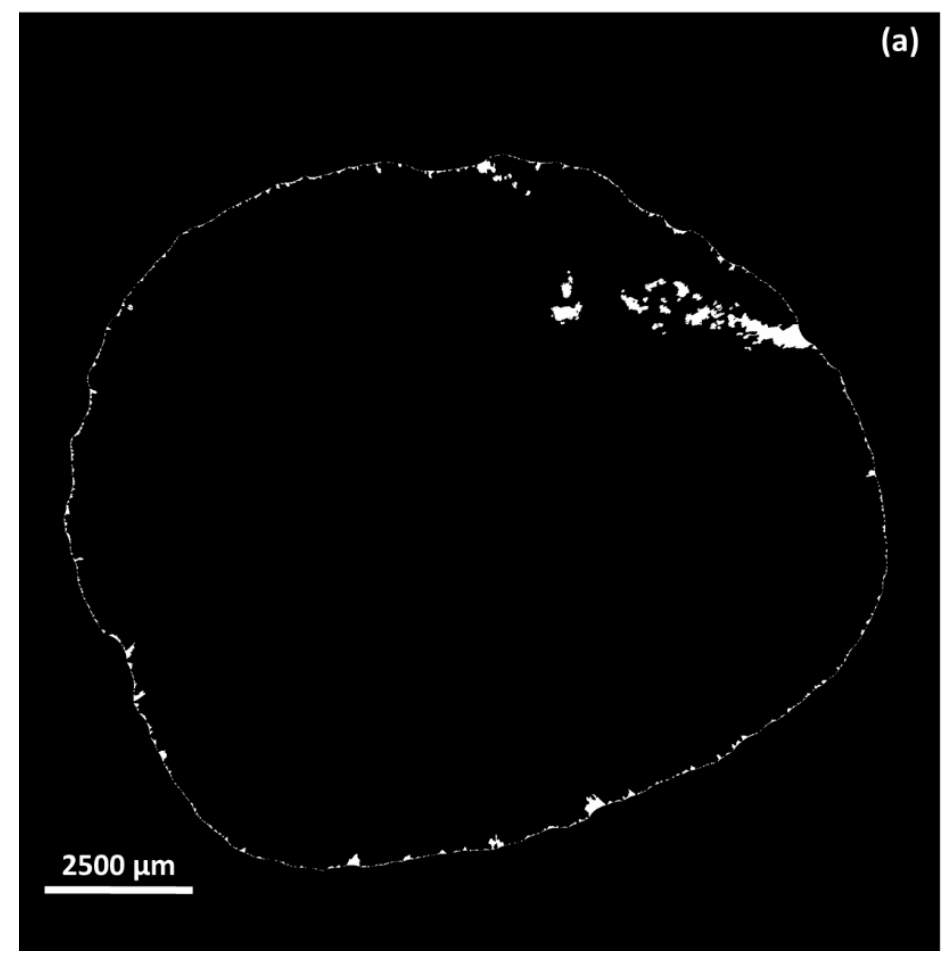

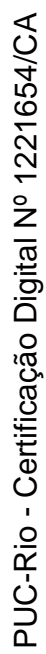

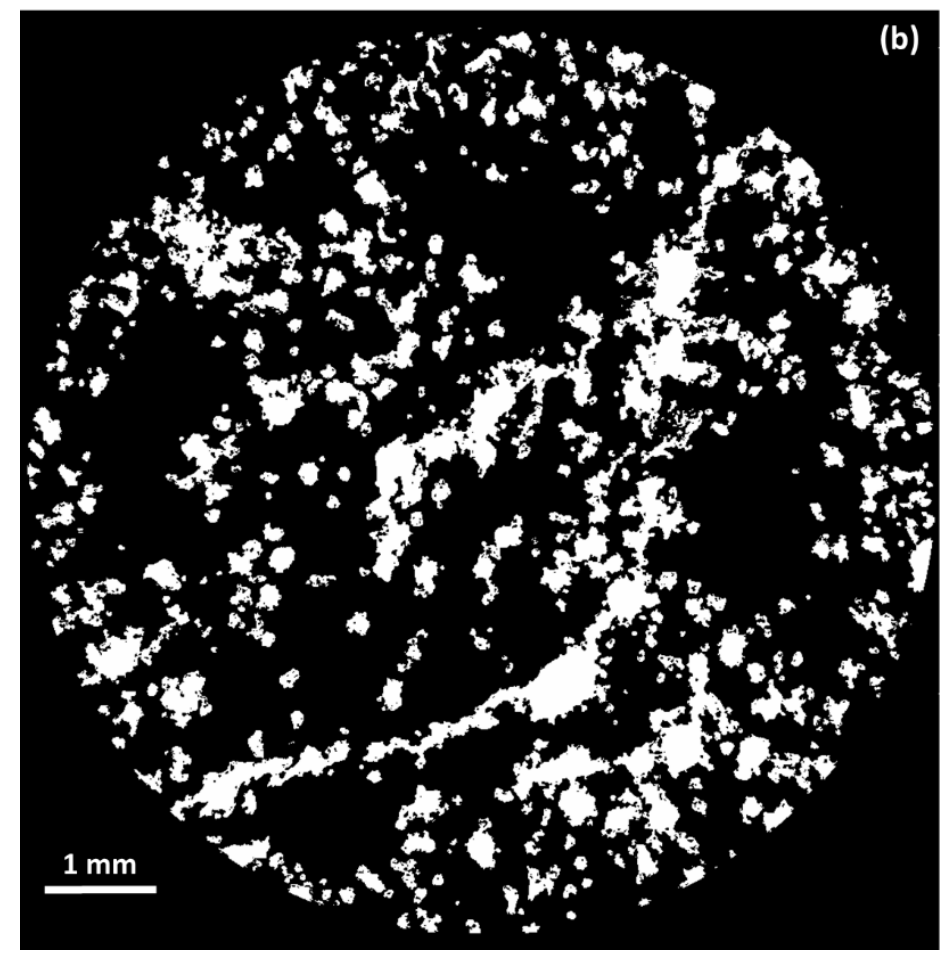

Figura 76 - Imagem resultante da aplicação do XOR - poros abertos: (a) 0.4X;

(b) $4 \mathrm{X}$. 
E) Individual Object Analysis (3D)

Com a pilha de imagens $2 \mathrm{D}$ contendo apenas a porosidade aberta, realizou-se medidas 3D de volume. A partir dos volumes calculados, estimou-se os diâmetros equivalentes de cada poro (objeto) a partir da equação abaixo:

$$
D=\sqrt[3]{\frac{6 V}{\pi}}
$$

Uma visualização da porosidade aberta é mostrada na Figura 77. 

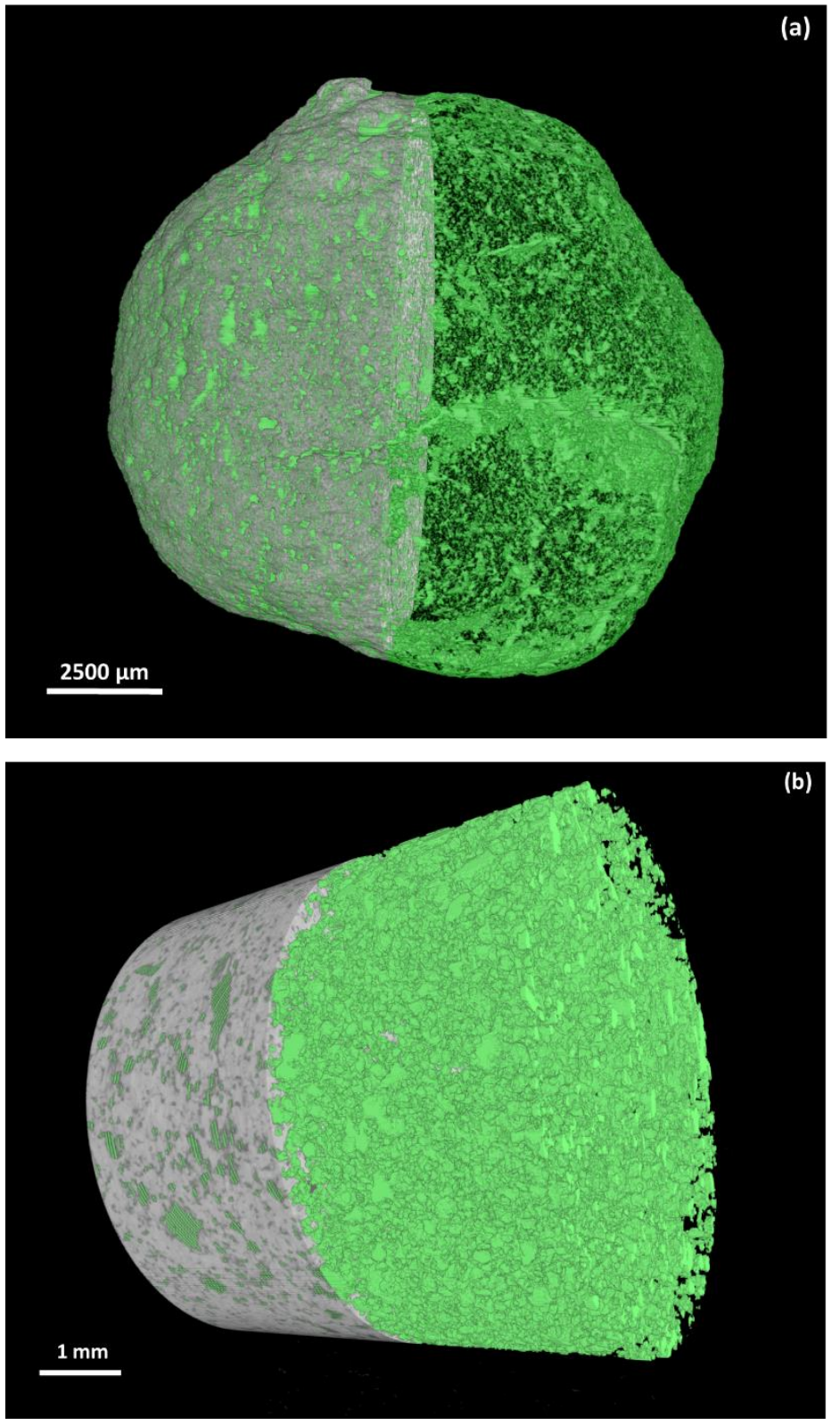

Figura 77 - Corte da pelota mostrando a porosidade aberta (em verde): (a) 0.4X; (b) $4 X$.

- Determinação do tamanho dos poros fechados

\section{A) Thresholding}

Realizou-se uma segmentação nas imagens, analogamente à Figura 69. 


\section{B) Bitwise operations (NOT)}

Aplicou-se uma operação lógica denominada NOT, a qual inverte os valores dos pixels, isto é, pixels pretos se tornam brancos e vice-versa, conforme mostrado na Figura 78.
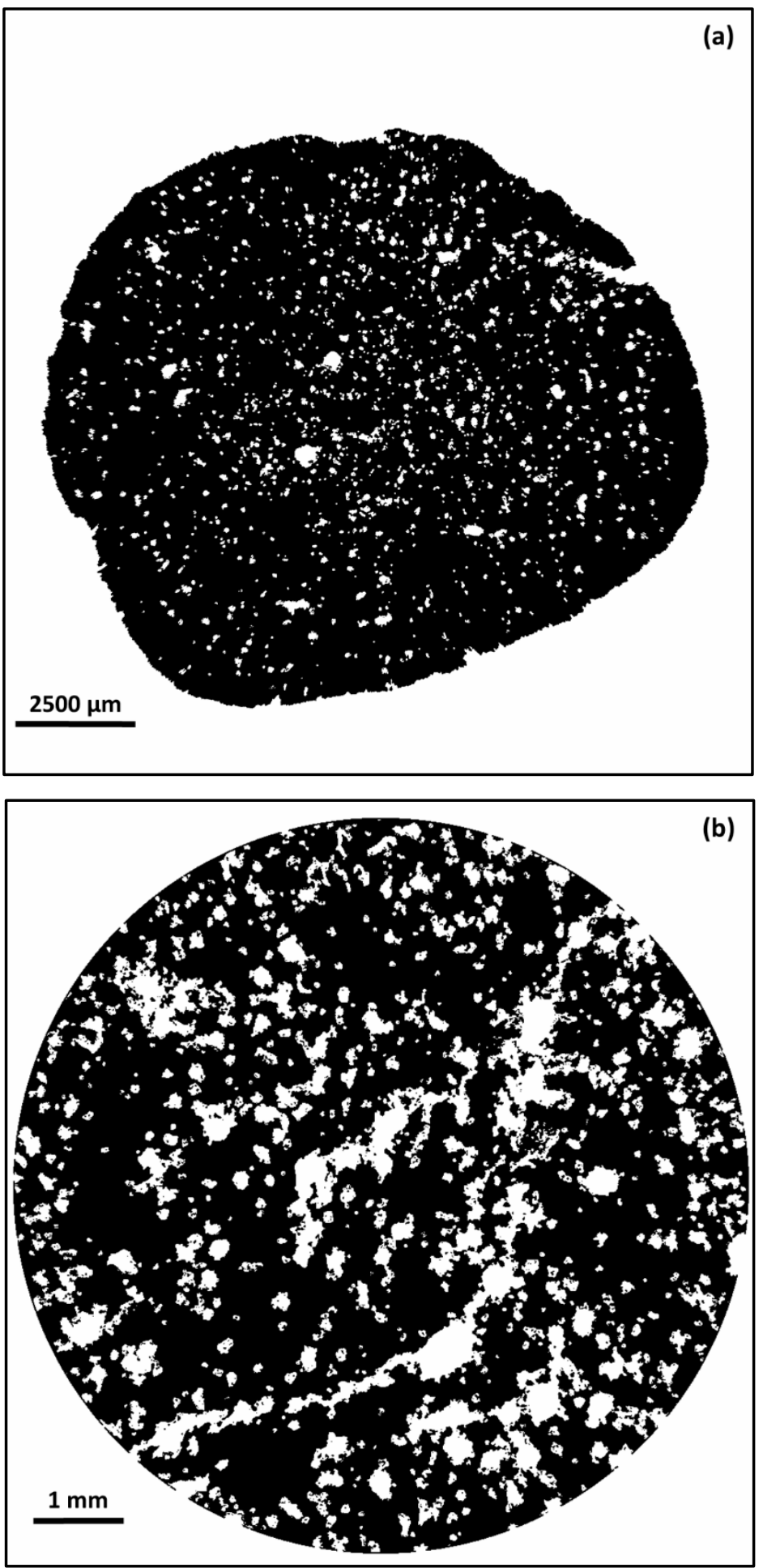

Figura 78 - Aplicação do NOT na imagem segmentada: (a) 0.4X; (b) 4X. 


\section{C) Despeckle 3D}

Novamente aplicou-se a função Despeckle, gerando as imagens da Figura 75.

\section{D) Bitwise operations (NOT)}

Aplicou-se uma operação NOT na imagem resultante da aplicação do Despeckle (Figura 75), gerando a imagem mostrada na Figura 79. 


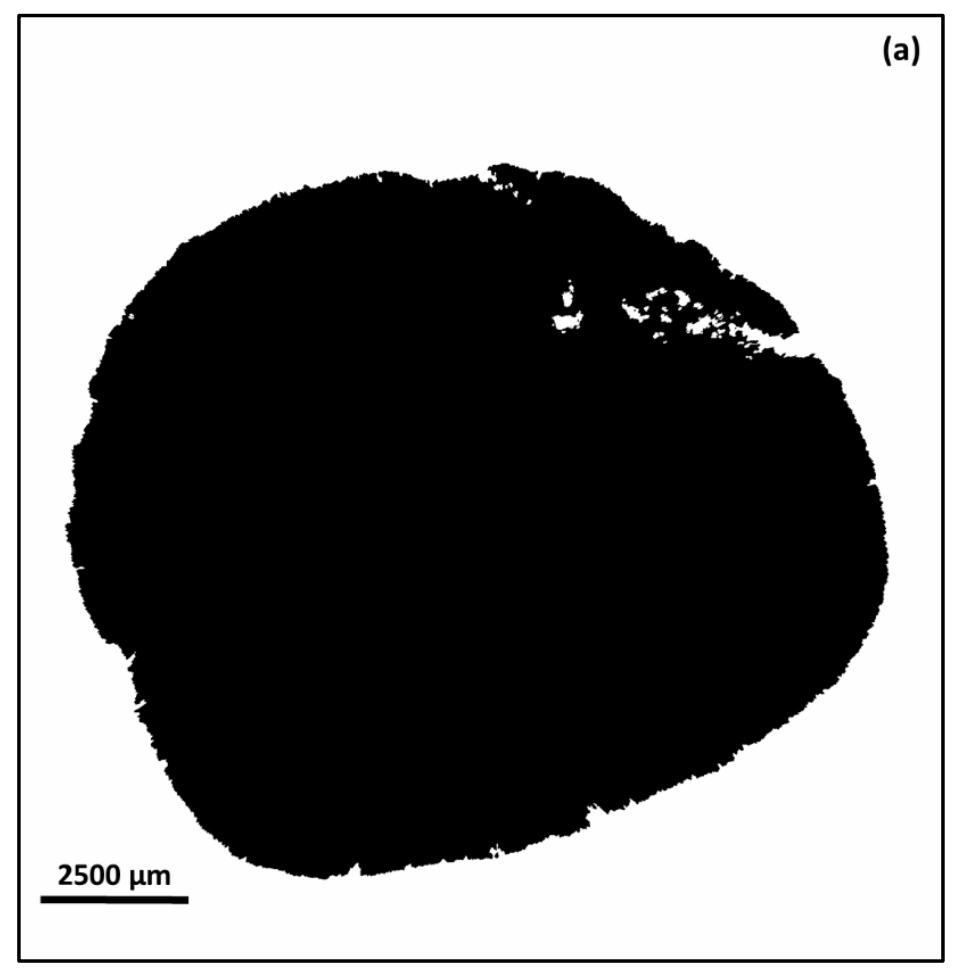

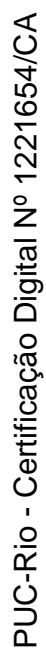

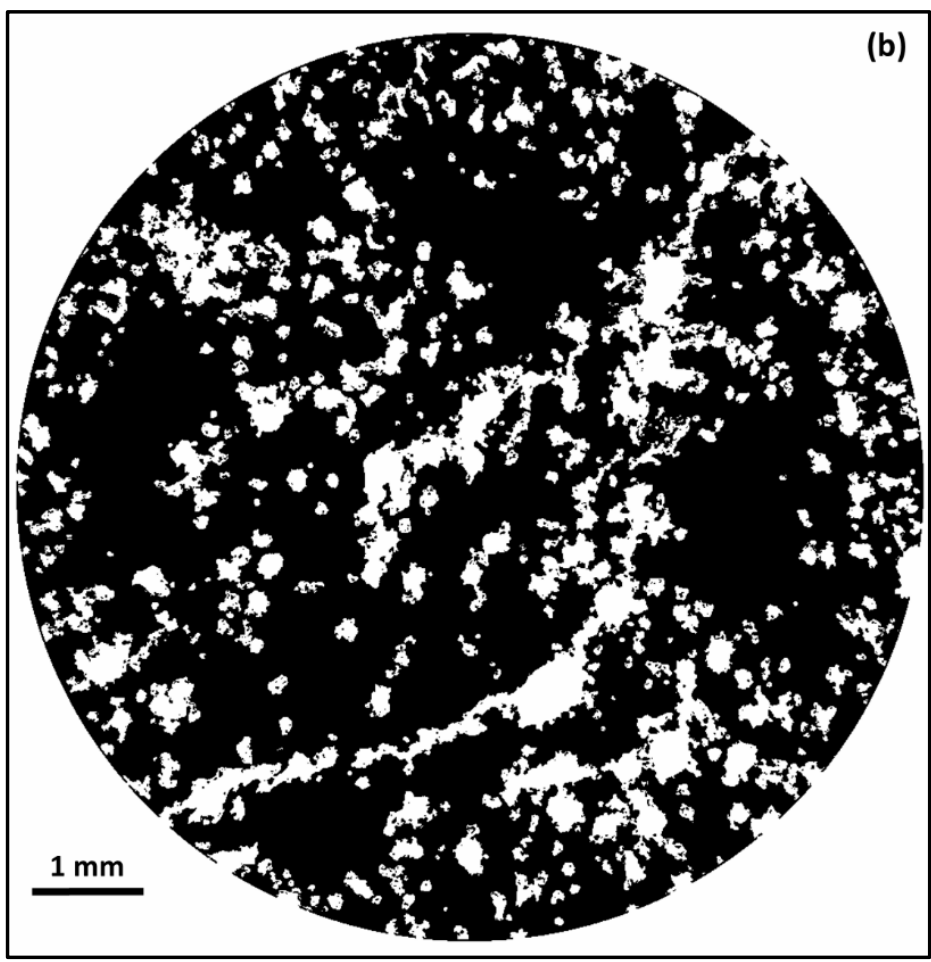

Figura 79 - Aplicação do NOT na imagem resultante do Despeckle (Figura 75):

(a) $0.4 \mathrm{X}$; (b) $4 \mathrm{X}$.

\section{E) Bitwise operations (XOR)}

Por fim, aplicou-se uma operação XOR entre as imagens da Figura 78 e da Figura 79, resultando na imagem da Figura 80, que corresponde aos poros fechados. 

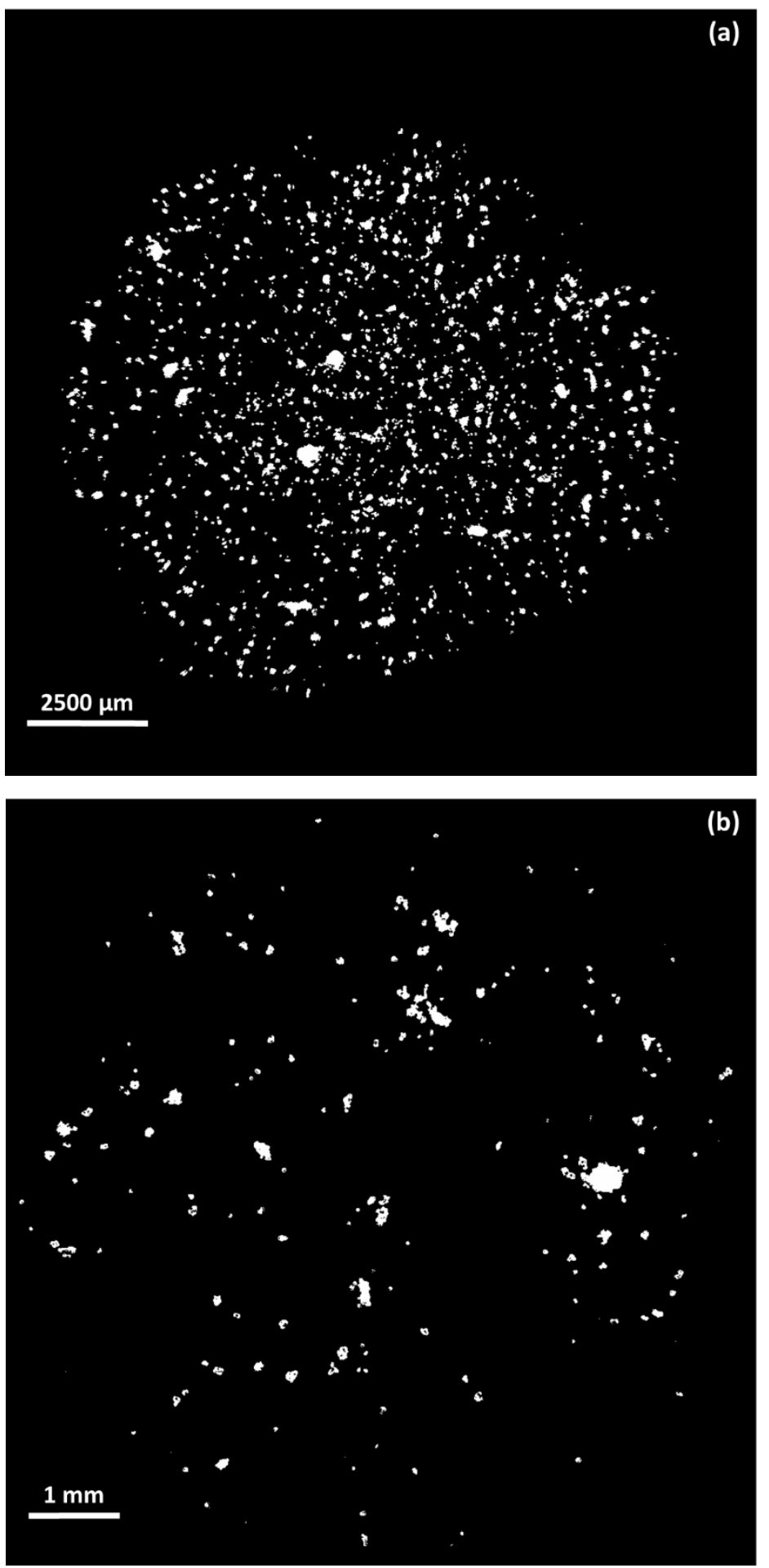

Figura 80 - Imagem resultante da aplicação do XOR - poros fechados: (a) 0.4X; (b) $4 \mathrm{X}$ 


\section{F) Individual Object Analysis (3D)}

De forma idêntica às medidas dos poros abertos, mediu-se o volume dos poros fechados, estimando posteriormente o diâmetro equivalente dos poros.

A distribuição espacial da porosidade fechada pode ser visualizada na Figura 81.
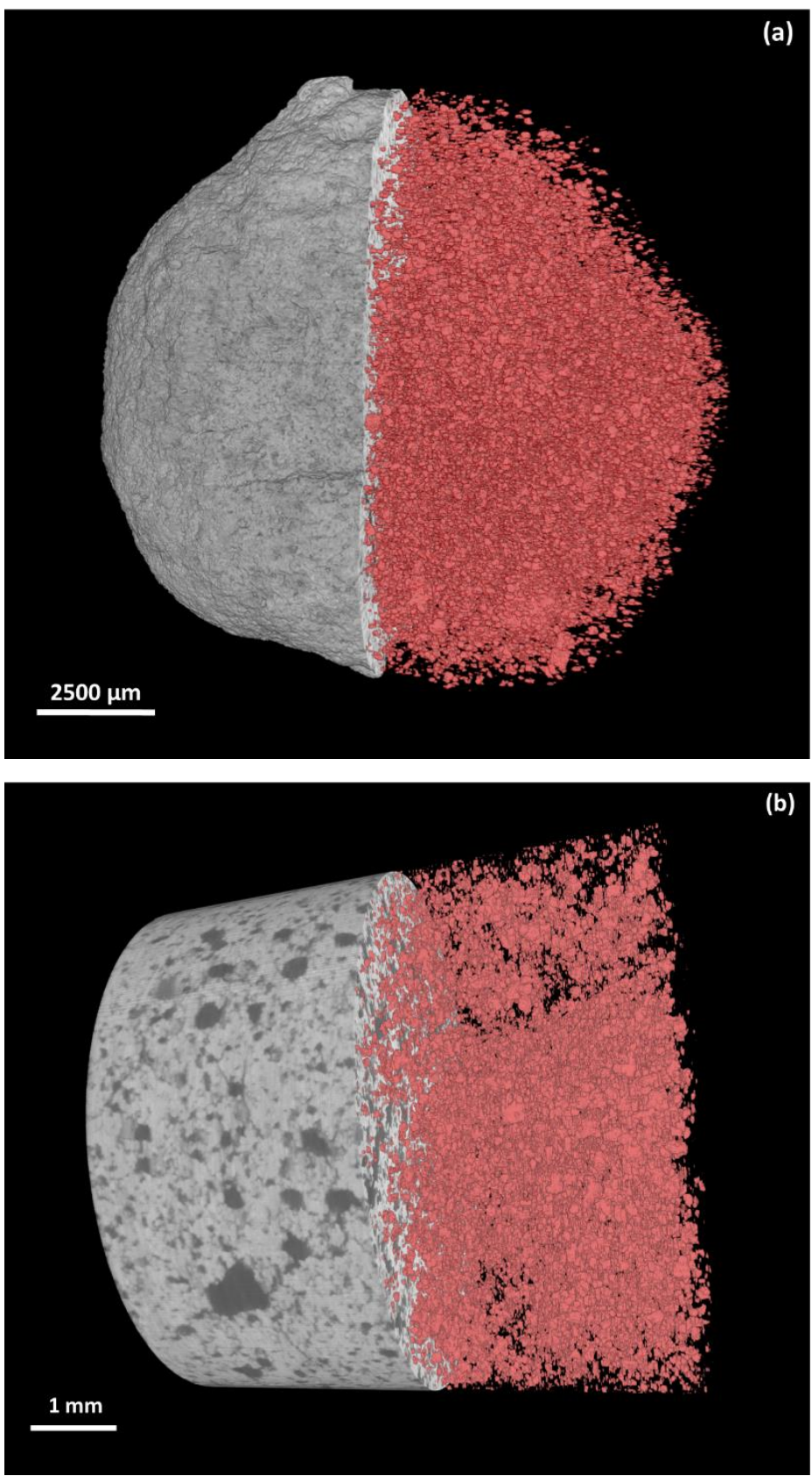

Figura 81 - Corte da pelota mostrando a porosidade fechada (em vermelho) 
Na Figura 82, pode-se visualizar a distribuição espacial de ambas as porosidades (aberta e fechada) num corte da pelota.
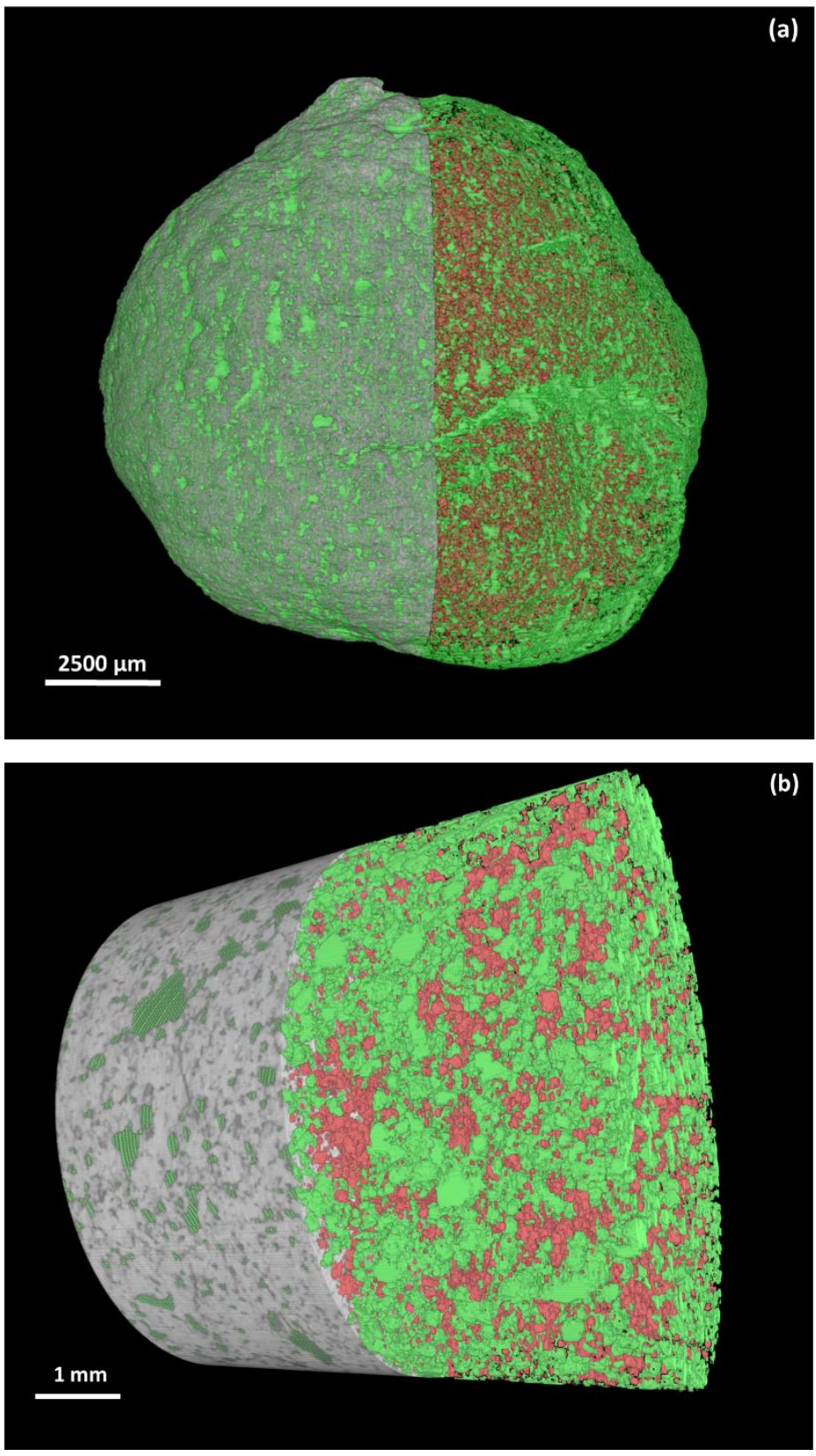

Figura 82 - Corte da pelota mostrando a porosidade aberta (em verde) e fechada (em vermelho): (a) 0.4X; (b) 4X.

A Figura 83 e a Figura 84 exemplificam as inúmeras possibilidades de se visualizar a distribuição espacial da porosidade (aberta ou fechada ou ambas) com uma escala de cores relacionadas às medidas de volume ou a qualquer outro parâmetro de tamanho ou forma disponível pelo software. Além disso, pode-se 
filtrar os poros dentro de uma faixa de tamanho ou forma, permitindo a análise de trincas, que são objetos maiores e mais alongados do que os poros, como o exemplo mostrado na Figura 85. Neste caso, pode ser uma trinca sem conectividade com a superfície, a qual não seria detectada pela técnica de PIM.
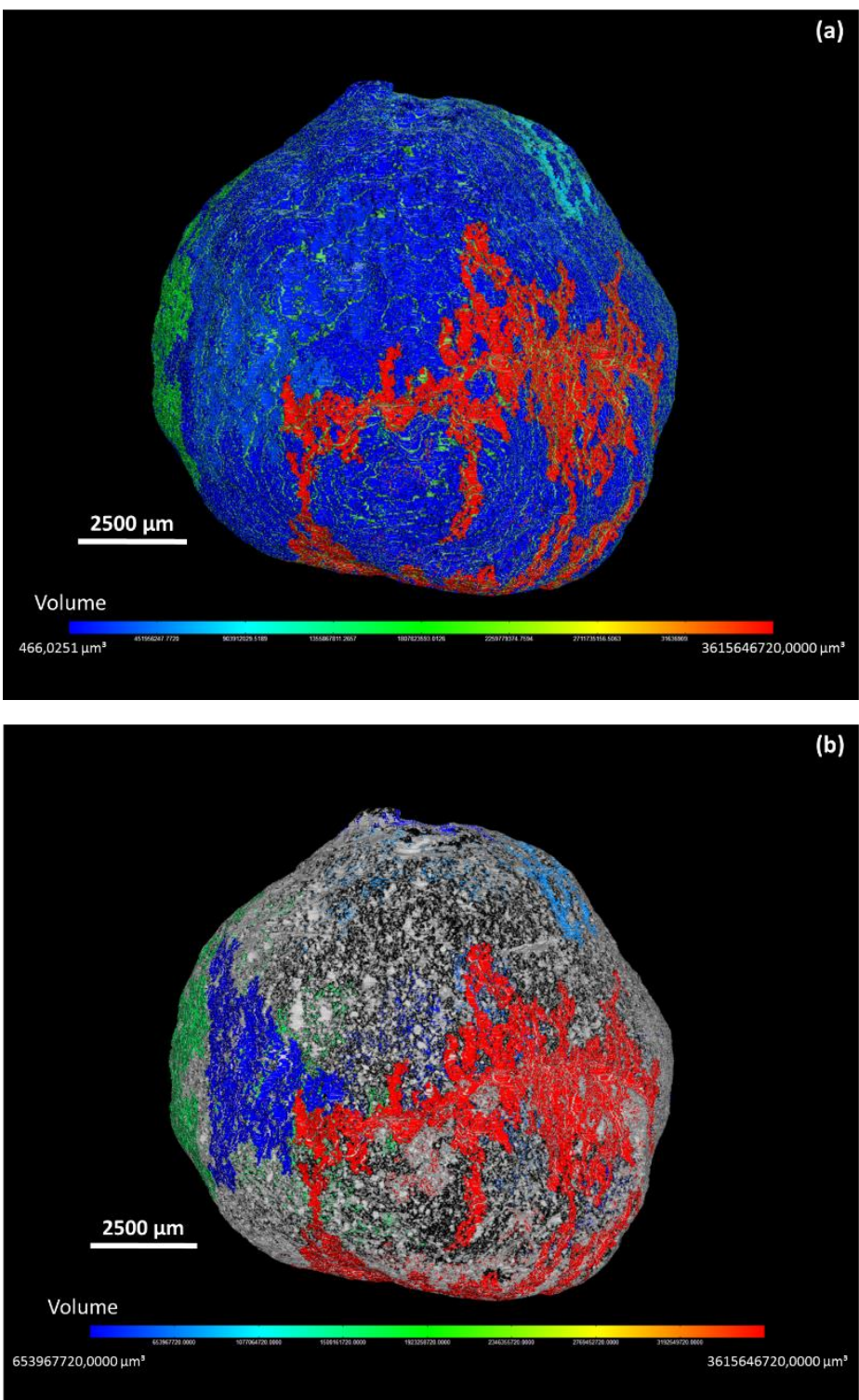

Figura 83 - Distribuição de volume da porosidade aberta em 0.4X: (a) Todos os poros abertos; (b) Poros abertos dentro de uma faixa de tamanho. 

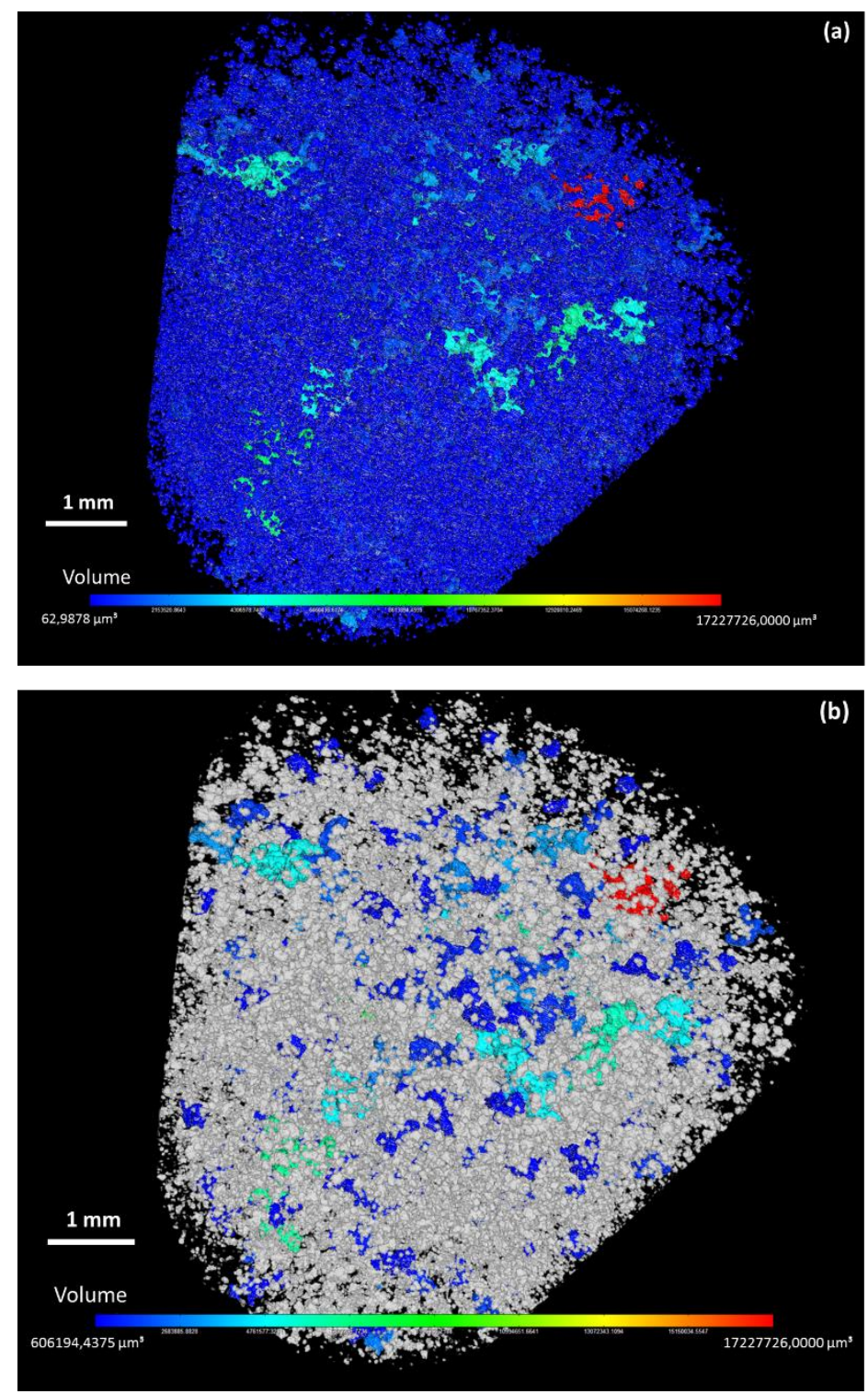

Figura 84 - Distribuição de volume da porosidade fechada em 4X: (a) Todos os poros fechados; (b) Poros fechados dentro de uma faixa de tamanho (os poros em branco são poros com valores fora da faixa de tamanho selecionada). 


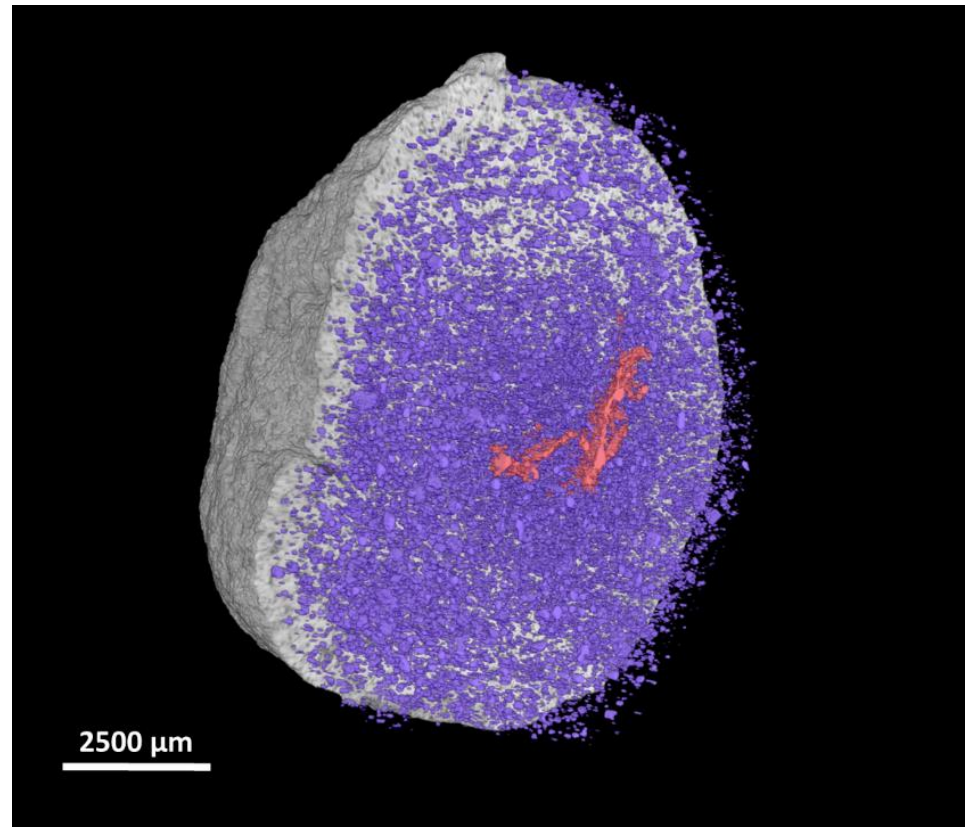

Figura 85 - Corte da pelota mostrando os poros fechados: poros pequenos (em roxo); trinca (em vermelho).

\subsection{2. \\ Otimização da análise}

\subsubsection{Definição da resolução}

Como explicado a respeito da $1^{\mathrm{a}}$ etapa deste trabalho, comparou-se os resultados obtidos em MicroCT com os obtidos por PIM. Os resultados se encontram na Figura 86. A barra de erro corresponde aos valores de porosidade obtidos com diferentes limiares de segmentação das imagens.

Os valores de porosidade, tanto aberta quanto total, são muito baixos comparados com a técnica de PIM. Uma possível explicação para esta grande diferença entre as duas técnicas seria a de que a resolução utilizada neste caso (de aproximadamente $8 \mu \mathrm{m}$ ) não foi suficiente para permitir a quantificação de boa parte dos poros. Com base nos resultados de PIM, a média de diâmetro dos poros está entre 8-11 $\mu \mathrm{m}$, um valor muito próximo da resolução desta análise em MicroCT.

Como nesta etapa também foram feitas análises em MicroCT com a lente de $4 \mathrm{X}$, atingindo uma resolução de aproximadamente $4 \mu \mathrm{m}$, foi feita a mesma comparação entre os resultados. Os valores são apresentados na Figura 87. 
Porosidade de PIM e MicroCT (Lente de 0.4X - Resolução de $8 \mu \mathrm{m}$ )

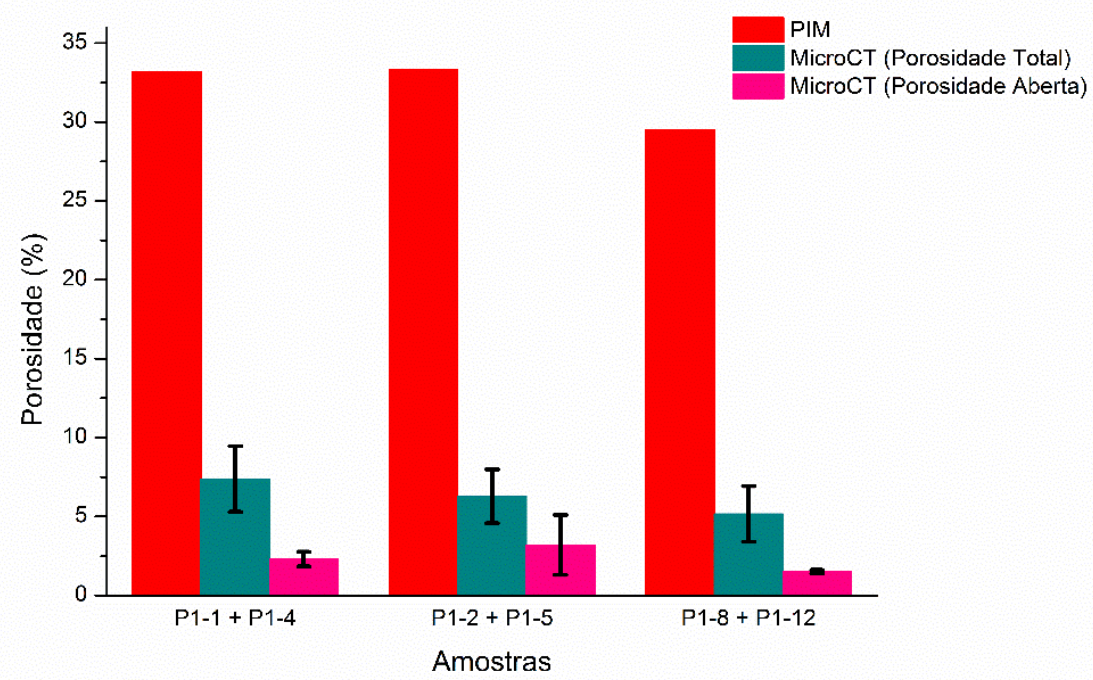

Figura 86 - Comparação da porosidade por PIM e MicroCT (Resolução de $8 \mu \mathrm{m}$ )

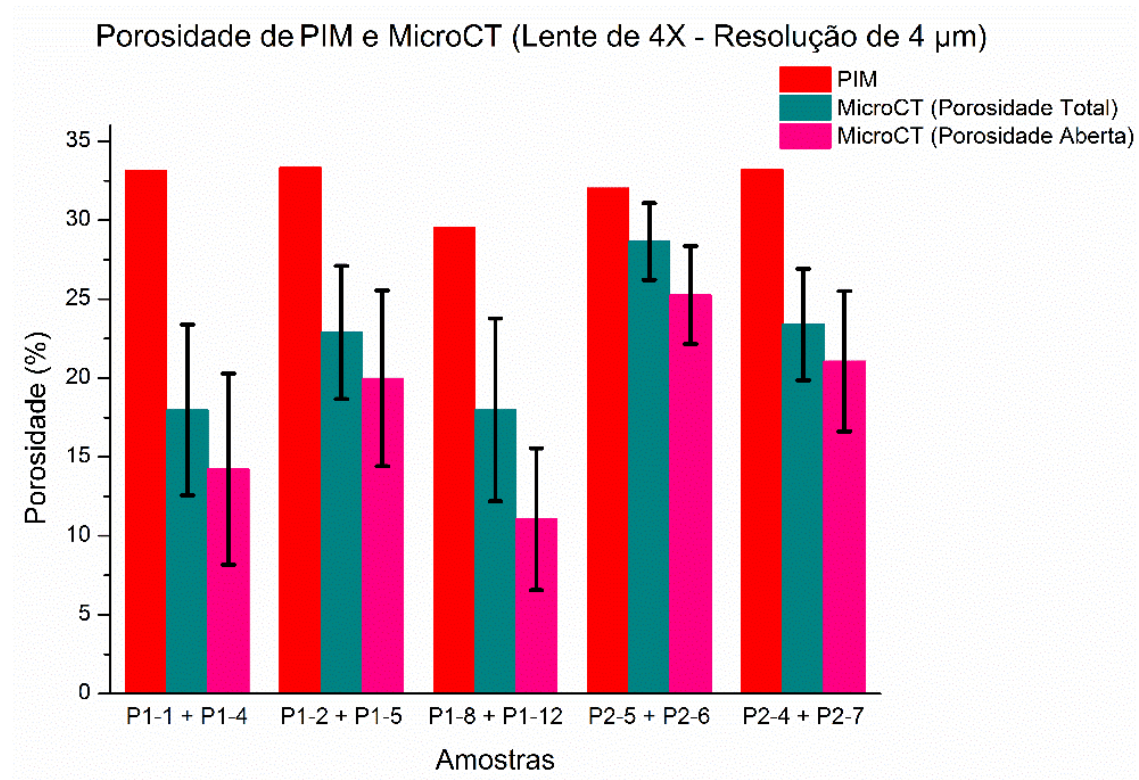

Figura 87 - Comparação da porosidade por PIM e MicroCT (Resolução de $4 \mu \mathrm{m}$ )

Desta vez, os valores de MicroCT se aproximaram mais dos de PIM. A porosidade aberta também cresceu bastante. No entanto, como as análises com a lente de $4 \mathrm{X}$ correspondem a uma região cilíndrica interna da pelota, todos os poros existentes nas extremidades deste cilindro e todos os conectados a eles são considerados poros abertos. Portanto, os poros abertos neste caso são gerados 
artificialmente pela metodologia e podem não representar exatamente a porosidade aberta da amostra.

Apesar dos valores terem se aproximado mais, uma pequena região interna da pelota pode não representar a amostra como um todo. Além disso, a região interna analisada neste caso corresponde ao centro da pelota, que costuma ser mais poroso.

Para estudar a hipótese de que a resolução é um dos motivos do aumento nos valores de porosidade, analisou-se um mesmo campo em imagens obtidas com a lente de $0.4 \mathrm{X}$ e com a lente de $4 \mathrm{X}$. Os resultados são mostrados na Figura 88.
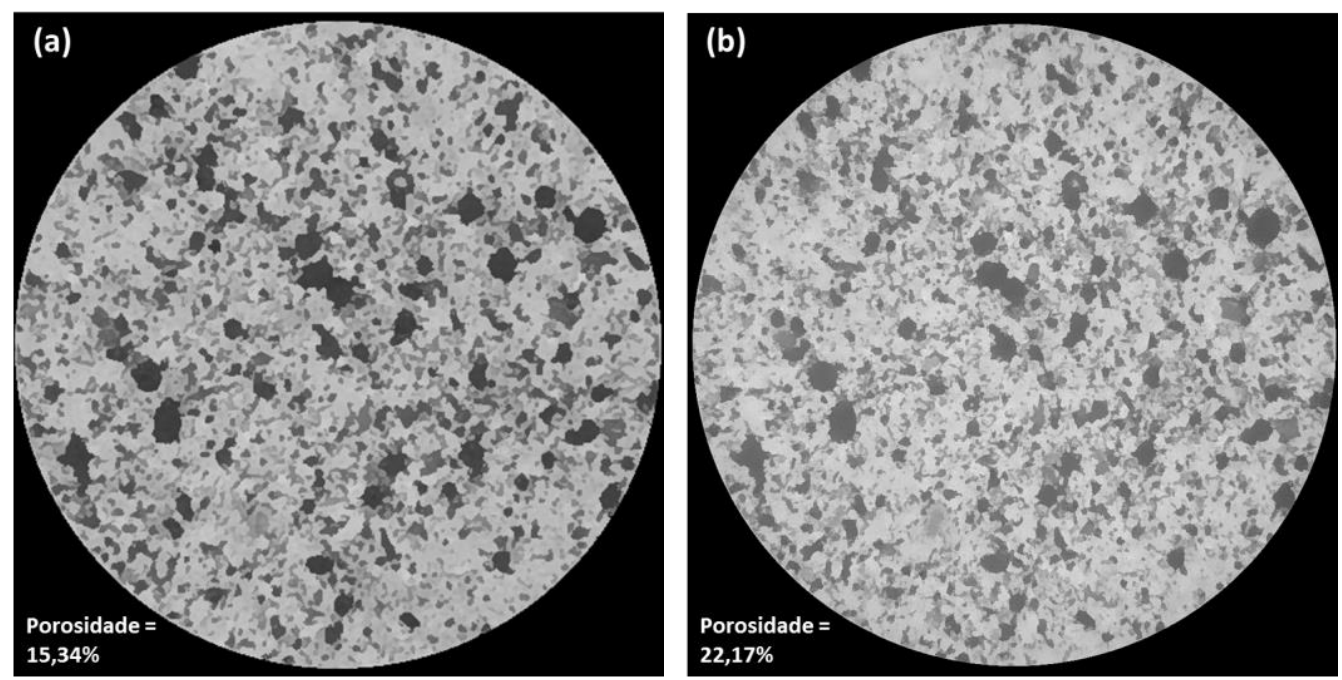

Figura 88 - Comparação de porosidade em um mesmo campo: (a) 0.4X; (b) 4X.

Os valores de porosidade medidos na imagem de $0.4 \mathrm{X}$ foi de $15,39 \%$, enquanto que, na imagem de $4 \mathrm{X}$, foi de $22,17 \%$. Dessa forma, confirmou-se a necessidade de analisar a pelota com resoluções melhores, como a de $4 \mu \mathrm{m} /$ pixel.

Visando solucionar a questão de representatividade da amostra, buscou-se novas análises com melhores resoluções e maior região amostral. Porém, esses dois quesitos demandam tempos de análise muito maiores, o que tornaria a técnica pouca prática.

Por isso, buscou-se otimizar o número de projeções e faixa angular de rotação da amostra na tentativa de reduzir o tempo de aquisição de imagens em MicroCT. Os resultados dos testes encontram-se na seção a seguir. 


\subsubsection{Número de projeções e faixa angular de rotação}

Reconstruiu-se as camadas 2D de uma das pelotas utilizando-se 800, 1600 e 3200 projeções. Os respectivos resultados de uma fatia 2D de cada reconstrução são mostrados na Figura 89.

Visualmente, só se consegue perceber que a reconstrução feita a partir de 800 projeções é muito ruim ampliando bastante a imagem. No entanto, os histogramas das imagens apresentadas na Figura 89 deixam claro que a imagem reconstruída a partir de 800 projeções é bem ruidosa, apresentando os dois picos das fases existentes sobrepostos, o que dificultaria a etapa de segmentação. Embora a aplicação do filtro Non Local Means e do delineamento de bordas com o Delin tenha melhorado a imagem, não foi suficiente para que os picos no histograma ficassem tão bem definidos como nas demais imagens, como mostrado na Figura 90-a. Além disso, os histogramas da Figura 90-b e Figura 90-c apresentam uma pequena saliência entre os picos principais, revelando uma possível fase não distinguível na imagem a partir de 800 projeções.

Sabendo-se que a etapa de segmentação é crítica e de difícil decisão na escolha dos limiares, concluiu-se que a imagem a partir de 800 projeções não seria adequada para prosseguir na análise. 

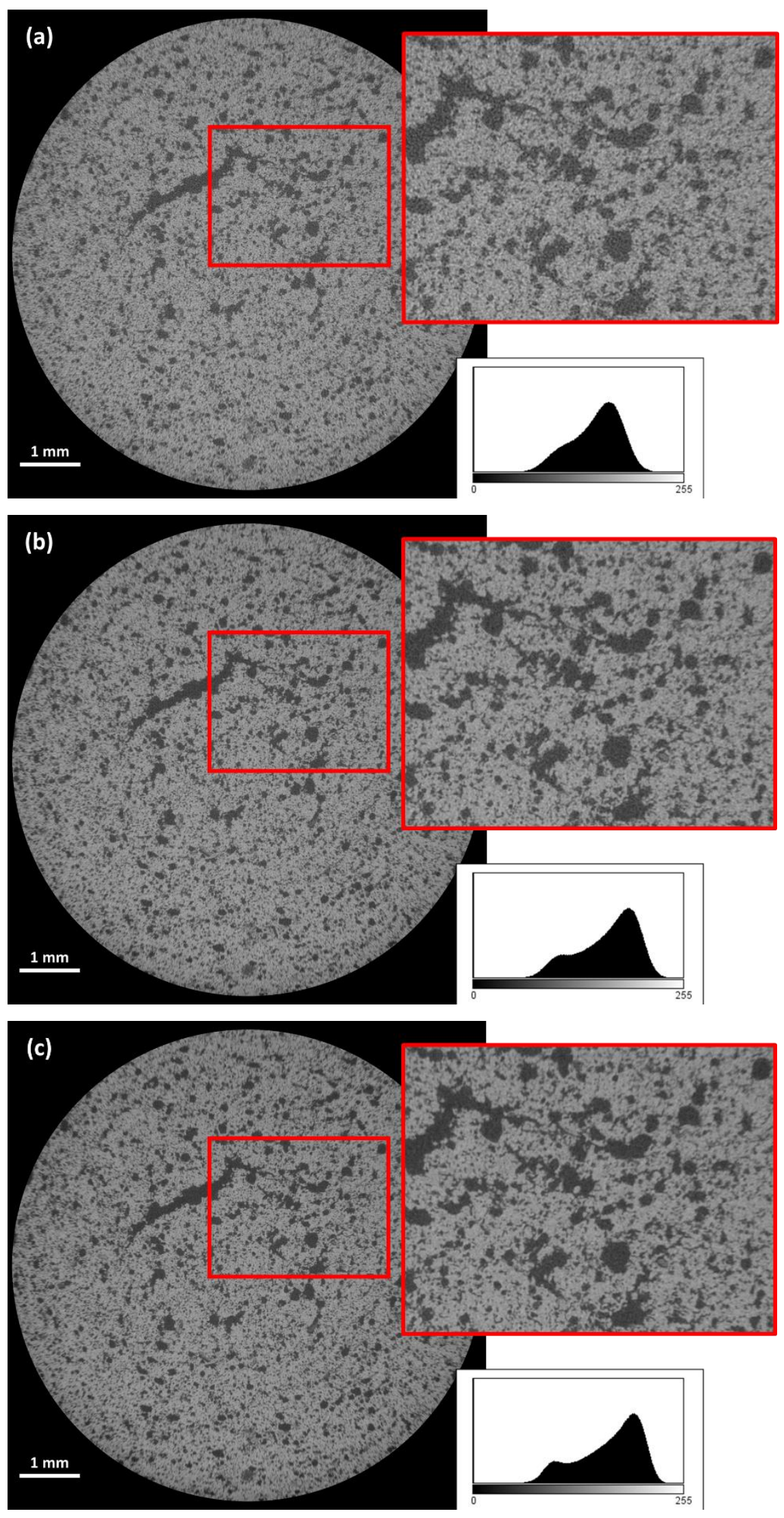

Figura 89 - Camadas 2D reconstruídas com: (a) 800 projeções; (b) 1600 projeções; (c) 3200 projeções. 
(a)

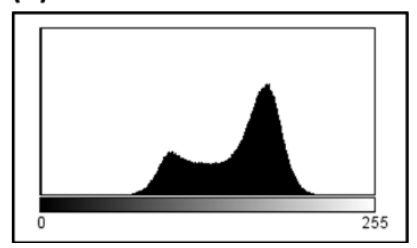

(b)

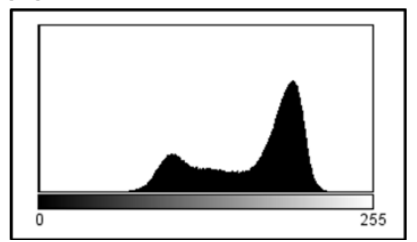

(c)

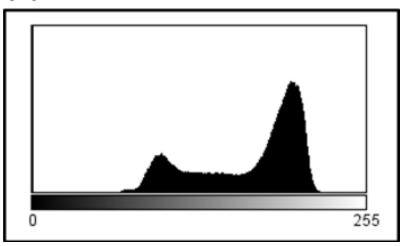

Figura 90 - Histogramas das imagens da Figura 89 após a aplicação do filtro Non Local Means e do Delin: (a) 800 projeções; (b) 1600 projeções; (c) 3200 projeções.

Já as imagens reconstruídas a partir de 1600 e 3200 projeções são muito parecidas visualmente e apresentam os histogramas muito parecidos. Para ter uma análise mais completa, também avaliou-se quantitativamente a fração de poros nestas duas imagens e os resultados encontram-se na Tabela 11.

Tabela 11 - Comparação quantitativa de medida de porosidade em camadas 2D obtidas com diferentes números de projeções

\begin{tabular}{|c|c|}
\hline Imagem 2D & Porosidade $(\boldsymbol{\%})$ \\
\hline $\mathbf{1 6 0 0}$ projeções & 15,62 \\
\hline 3200 projeções & 15,99 \\
\hline
\end{tabular}

Com estes resultados, concluiu-se que a reconstrução a partir de 1600 projeções é suficientemente boa, permitindo reduzir o tempo de análise das pelotas no MicroCT de 35h para 18h. Assim, decidiu-se fazer todas as análises em MicroCT das pelotas do Grupo 2 adquirindo somente 1600 projeções.

Cabe ressaltar que este teste foi feito apenas para a análise com a lente de $0.4 \mathrm{X}$. Isto porque já havia sido decidido dar continuidade às análises utilizando-se somente a lente de $0.4 \mathrm{X}$ com uma resolução melhor em torno de $4 \mu \mathrm{m}$, como já explicado anteriormente.

Avaliou-se também a reconstrução a partir da rotação da amostra até $180^{\circ}$, na tentativa de reduzir ainda mais o tempo de análise. Os resultados obtidos são mostrados na Figura 91. 
Novamente, só se consegue avaliar a qualidade das imagens com uma ampliação maior. Mas pelos respectivos histogramas verifica-se que as imagens reconstruídas somente com os ângulos de $0-180^{\circ}$ não apresentam os picos das fases bem definidos. Porém, de forma análoga ao teste feito com o número de projeções, aplicou-se os filtros de redução de ruído Non Local Means e de delineamento de bordas Delin e observou-se que os histogramas das imagens obtidas a partir da rotação da amostra de 0 a $180^{\circ}$ não apresentaram o pequeno pico intermediário de uma outra possível fase, conforme a Figura 92, o que poderia dificultar ainda mais a segmentação das fases. Sendo assim, ficou decidido manter as análises com a rotação completa da amostra. 

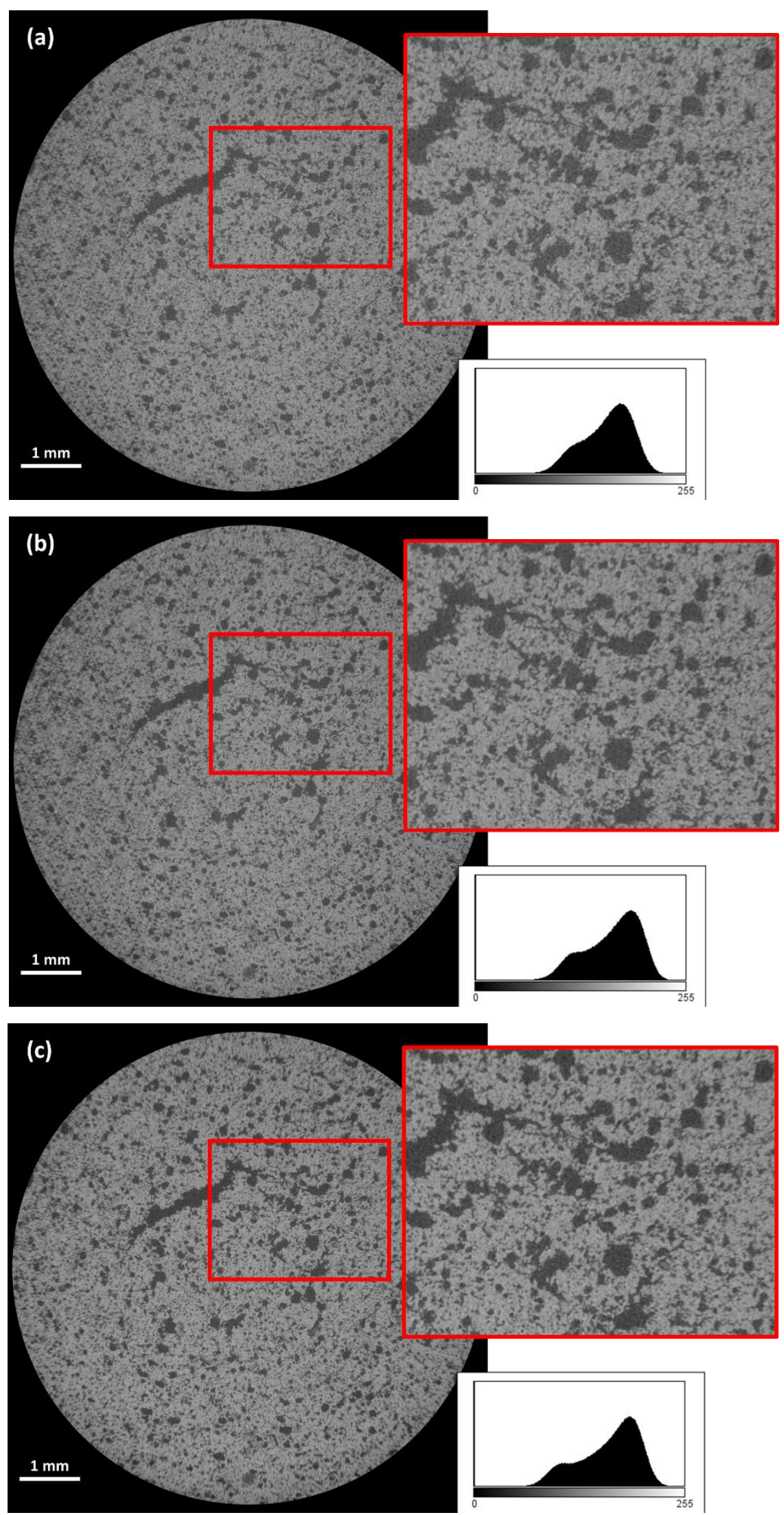

Figura 91 - Camadas 2D reconstruídas com: (a) 800 projeções com rotação da amostra de $0-180^{\circ}$; (b) 1600 projeções com rotação da amostra de $0-180^{\circ}$; (c) 1600 projeções com rotação da amostra de $0-360^{\circ}$. 
(a)

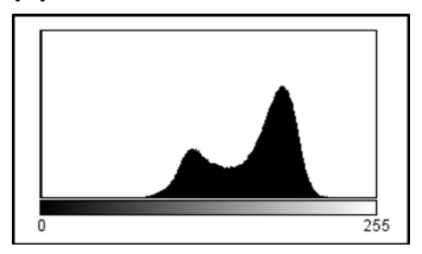

(b)

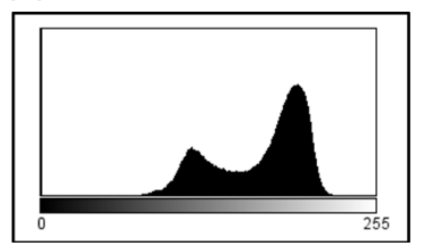

(c)

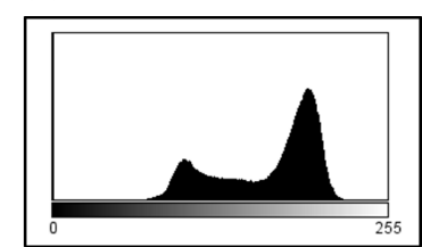

Figura 92 - Histogramas das imagens da Figura 91 após a aplicação do filtro Non Local Means e do Delin: (a) 800 projeções com rotação da amostra de 0-180'; (b) 1600 projeções com rotação da amostra de $0-180^{\circ}$; (c) 1600 projeções com rotação da amostra de $0-360^{\circ}$.

\subsection{3.}

\section{Comparação da porosidade - PIM x MicroCT (2ª etapa - grupo aplicação)}

Com a resolução de trabalho definida em $4 \mu \mathrm{m}$, com uma região de análise representativa da amostra, foi feita a comparação dos novos resultados obtidos por MicroCT com os obtidos por PIM. Os resultados são apresentados na Figura 93.

Porosidade de PIM e MicroCT (Lente de 0.4X - Resolução de $4 \mu \mathrm{m}$ )

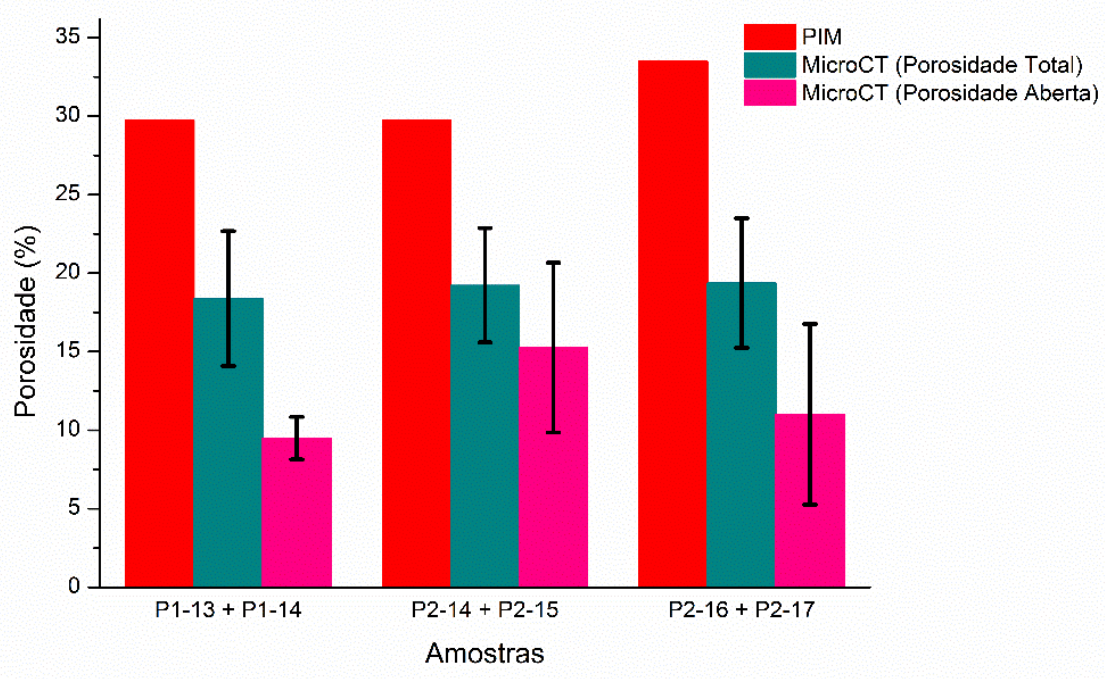

Figura 93 - Comparação da porosidade por PIM e MicroCT (Resolução de $4 \mu \mathrm{m}$ )

Os valores de porosidade ainda são muito mais baixos do que os da técnica de PIM. Vale ressaltar que nesta análise, a porosidade aberta, em certos casos, é gerada artificialmente pela metodologia, visto que as extremidades da região de 
análise não correspondem necessariamente às extremidades reais da amostra. Isto porque a resolução requerida é limitada pela distância do detector, que, por sua vez, limita o campo da amostra a ser analisado.

Como constatado na análise da $1^{\mathrm{a}}$ etapa, a resolução do sistema afeta significativamente a quantificação da porosidade. As análises de PIM das amostras desta $2^{a}$ etapa, mostraram que os diâmetros médios dos poros são ainda menores do que os da $1^{\text {a }}$ etapa, medindo entre $7-9 \mu \mathrm{m}$. Isto pode ser observado na curva de distribuição de diâmetro da Figura 94.

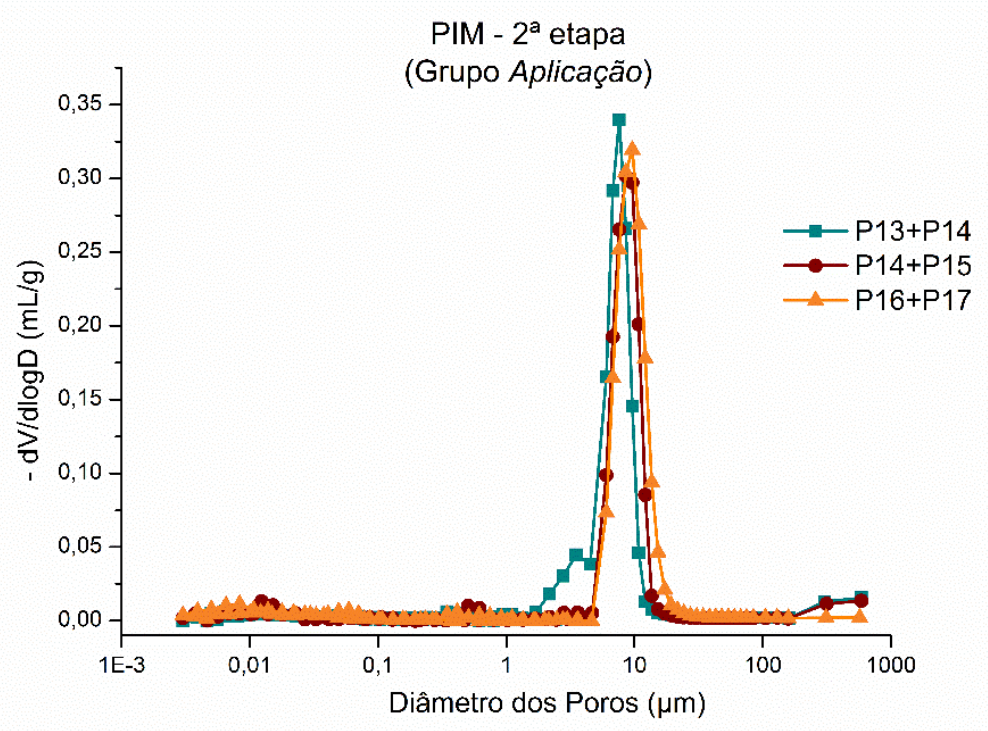

Figura 94 - Análise de PIM - 2ª etapa

Outro fator que afeta as medidas de porosidade por MicroCT é o limiar de segmentação das imagens. As barras de erro das análises de MicroCT no gráfico da Figura 93 mostra o impacto da escolha do limiar na determinação da porosidade. A incerteza associada é ainda maior na quantificação da porosidade aberta. Isso pode ser explicado pelo fato de que, ao aumentar o limiar de segmentação, mais pixels de outros tons são incluídos na segmentação e mais objetos vão sendo conectados entre si e, consequentemente, conectados à superfície, sendo considerados poros abertos.

Uma característica importante da análise em MicroCT é a quantificação da porosidade supostamente tratada como fechada, que não é quantificada pela técnica de PIM. A partir da metodologia proposta, todas as amostras apresentaram certa 
quantidade de poros fechados, que podem afetar a qualidade da pelota no que diz respeito à resistência física.

\subsection{4.}

\section{Comparação da distribuição de diâmetro de poros - PIM x MicroCT} (2 etapa - grupo aplicação)

As curvas de distribuição de diâmetro de poros obtidas por MicroCT e PIM são apresentadas na Figura 95. Os valores de percentagem de poros para MicroCT são em função de contagem de poros e para PIM são em relação ao volume de poros.

Sabendo-se que a porosidade aberta, para as análises dessas amostras da $2^{\mathrm{a}}$ etapa, é também gerada artificialmente pela metodologia, optou-se por comparar a porosidade total de MicroCT com a porosidade aberta de PIM.

(a)

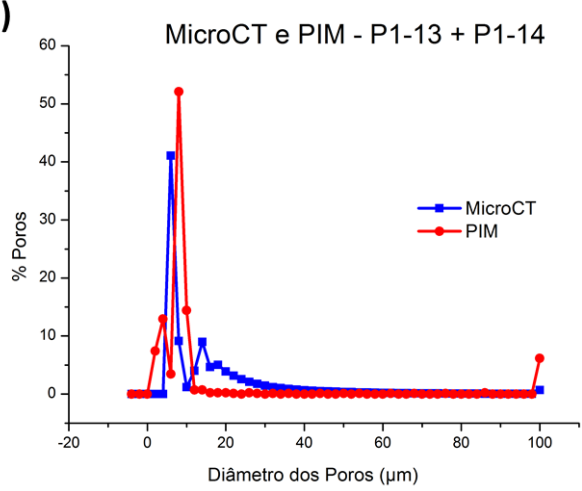

(b)

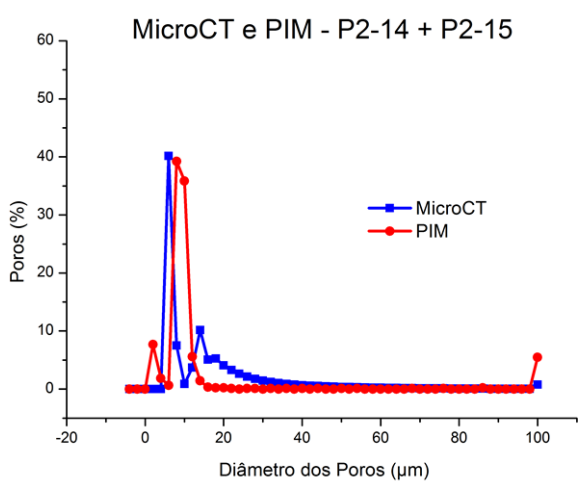

(c)

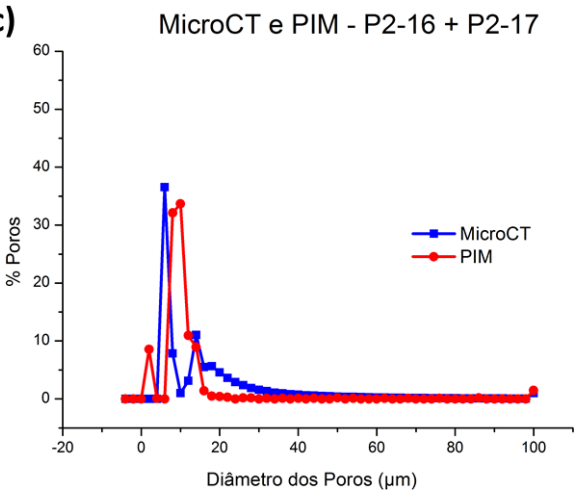

Figura 95 - Comparação da distribuição de diâmetro de poros entre MicroCT e PIM: (a) Amostras P1-13+P1-14; (b) Amostras P2-14+P2-15; (c) Amostras P2$16+\mathrm{P} 2-17$. 
Observa-se que há um pequeno pico, nas curvas de PIM, deslocado para a esquerda em relação às curvas de MicroCT. Isso se explica pelo fato de PIM ser capaz de analisar poros muito menores do que MicroCT é capaz de analisar devido à resolução. Dessa forma, um pequeno pico de poros entre 0 e $4 \mu \mathrm{m}$ aparece em todas as análises de PIM e não aparece nas análises em MicroCT.

Sendo assim, um dos motivos para que os valores de porosidade por PIM sejam maiores do que os obtidos por MicroCT é dada pela resolução da técnica, que não permite, nestas condições, analisar esses poros muito pequenos. No entanto, parte desses poros pequenos é sobrestimado na técnica de PIM, pois corresponde aos poros do tipo Garganta (explicado na seção 2.3), não representando o tamanho real de alguns poros.

Observa-se também que o pico maior de MicroCT está um pouco deslocado para a esquerda em relação ao pico maior de PIM, ou seja, a maior quantidade de poros medida em MicroCT tem menor diâmetro comparado ao de PIM. Uma possível explicação para isso é a de que, como a imagem é bem ruidosa, objetos espúrios muito pequenos são segmentados juntamente com os poros, fazendo com que o diâmetro médio do primeiro pico seja menor. Outra hipótese é a de que poros maiores (conectados por uma garganta) estejam sendo desconectados em virtude da resolução da imagem, divididos em outros poros menores.

Outra característica importante observada nos gráficos é a presença de um pequeno pico, perto de $20 \mu \mathrm{m}$, nas análises em MicroCT. Como este pico não é observado nas análises em PIM, plotou-se a distribuição de poros abertos e fechados de MicroCT separadamente, para uma das análises, a fim de entender a interferência dos tipos de poros no perfil dos gráficos. O resultado encontra-se na Figura 96. 


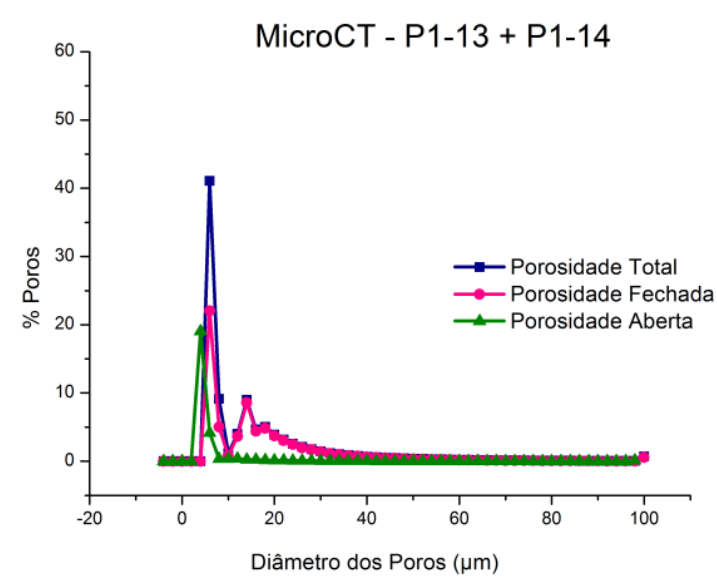

Figura 96 - Distribuição de diâmetro dos poros por MicroCT, com a separação em poros abertos e fechados, para as amostras $\mathrm{P} 1-13+\mathrm{P} 1-14$.

Com a Figura 96, verifica-se que o segundo pico presente nas análises de MicroCT se deve totalmente à porosidade fechada, a qual não é medida por PIM. No entanto, parte do primeiro pico, que seria equivalente ao maior pico de PIM, também é constituída por poros fechados.

O aumento do limiar de segmentação tem bastante impacto na definição de porosidade aberta e fechada, pois pode conectar poros que antes eram considerados objetos separados por uma fase não incluída na faixa de segmentação. Sendo assim, aumentou-se significativamente o limiar propositalmente, a fim de considerar quase todos os poros conectados à superfície (abertos). As curvas obtidas para esta análise estão apresentadas na Figura 97. 


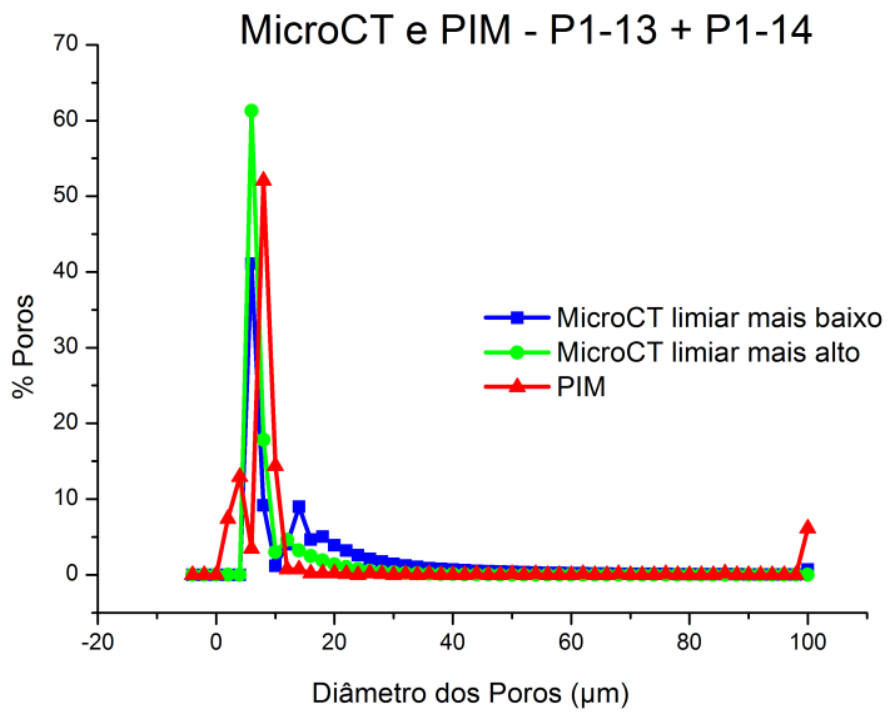

Figura 97 - Curvas de distribuição de diâmetro de poros comparando-se variação de limiar

Pode-se verificar que o primeiro pico da curva de MicroCT com o limiar mais alto aumentou, chegando a ultrapassar o maior pico da curva de PIM. Além disso, o segundo pico de MicroCT, referente aos poros fechados, diminuiu. Isso confirma que, com o aumento do limiar, poros que antes eram considerados fechados foram conectados e passaram a ser considerados poros abertos. Mas, apesar do exagero no aumento do limiar, o gráfico ainda apresentou um pequeno pico de porosidade fechada na curva de MicroCT, mostrando que possivelmente existe porosidade fechada nas amostras, que não é detectada por PIM.

Além da questão da análise da porosidade fechada, que é um dos objetivos da metodologia proposta, a técnica de MicroCT é capaz de medir poros muito maiores do que os medidos pela PIM. Não é possível visualizar a quantidade desses poros nos gráficos mostrados acima, pois estão presentes em muito menor quantidade, não configurando uma percentagem representativa. 


\section{3. \\ Microscopia ótica}

\subsection{1. Processamento digital de imagens}

Antes de tudo, foi necessário encontrar a camada na MicroCT correspondente à camada da MO. Para isso, utilizou-se uma rotina em ambiente Matlab, que escolhe a camada com a máxima correlação cruzada em relação à imagem de MO. Como o objetivo nesta comparação é de apenas medir a porosidade e não correlacionar fases entre as duas técnicas, optou-se por não registrar a camada de MicroCT selecionada com a camada de MO, a fim de não gerar distorções ou perder parte das imagens. Apenas aplicou-se uma rotação manual para que as camadas ficassem em posições equivalentes.

Uma vez escolhida a imagem de MicroCT correspondente, prosseguiu-se na metodologia de processamento das imagens.

No pré-processamento, para as imagens de MO, foi aplicado apenas o filtro de realce de bordas Delin, para que os picos das fases nos histogramas ficassem mais bem definidos e, consequentemente, facilitar a etapa de segmentação. A comparação dos histogramas antes e após a aplicação do Delin pode ser visualizada na Figura 98, onde pode-se verificar o surgimento de um pequeno pico (Figura 98b), que antes da aplicação não estava muito visível, confirmando a melhora na imagem com o referido processamento.
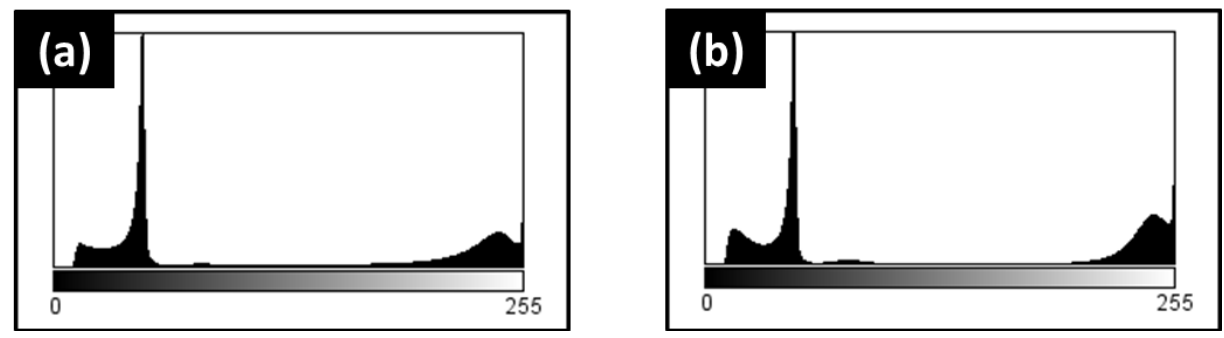

Figura 98 - Histogramas das imagens de MO: (a) Antes da aplicação do realce de bordas; (b) após a aplicação do realce de bordas.

As imagens de MicroCT passaram pelo mesmo pré-processamento explicado na seção 4.2.1.2, com a aplicação do filtro Non Local Means e do realce de bordas Delin. 
A obtenção das medidas de porosidade nas imagens de MO e MicroCT seguiu a mesma sequência descrita na seção 4.2.1.4 para a determinação da porosidade total.

Foi feita uma segmentação da fase sólida, isto é, tudo o que não é poro e fundo da imagem da Figura 99.
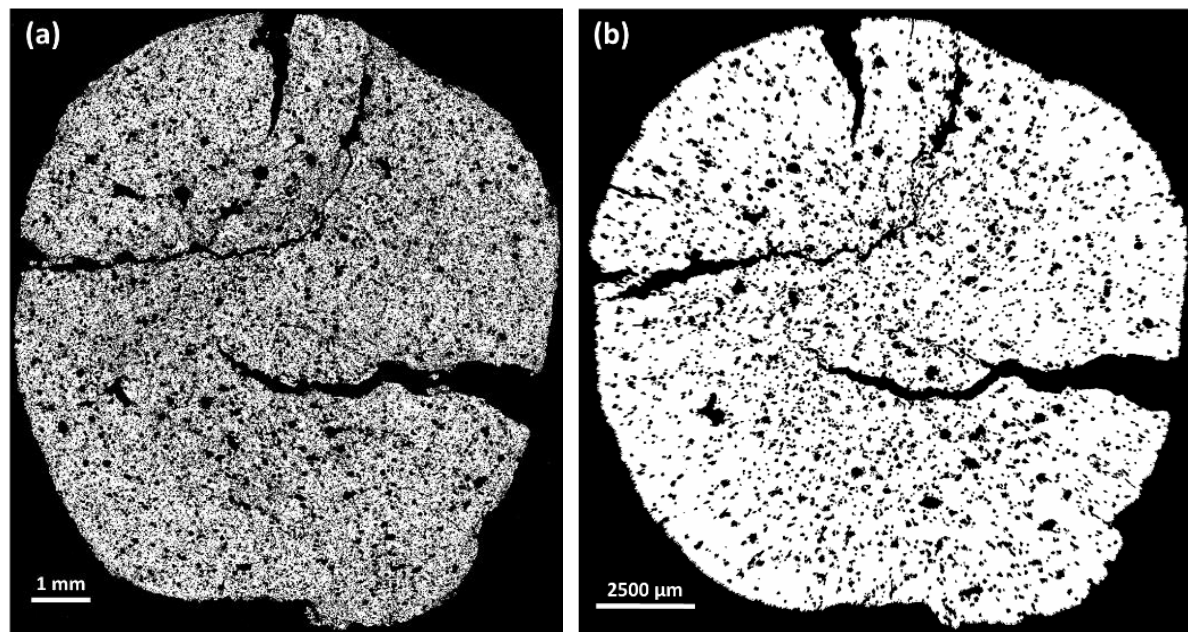

Figura 99 - Imagem binária da segmentação: (a) MO; (b) MicroCT

Em seguida, aplicou-se a função ROI Shrink Wrap, para a criação de uma região de interesse que se estique sobre os buracos, até mesmo aqueles que estão em contato com a borda da pelota. No entanto, como a imagem de MO é muito grande, 11851x13418 pixels no caso da imagem aqui apresentada, mesmo utilizando-se o valor máximo (diâmetro de 100 pixels) permitido de Stretch Over Holes, nem todos os buracos foram fechados pela ROI criada, como pode ser visto na Figura 100. Dessa forma, buscou-se um valor de Stretch Over Holes que fizesse com que os mesmos buracos que não foram fechados pela ROI na imagem de MO também não fossem fechados na imagem de MicroCT. O valor de Stretch Over Holes, então, para as imagens de MicroCT, ficou definido em 26 pixels de diâmetro. 

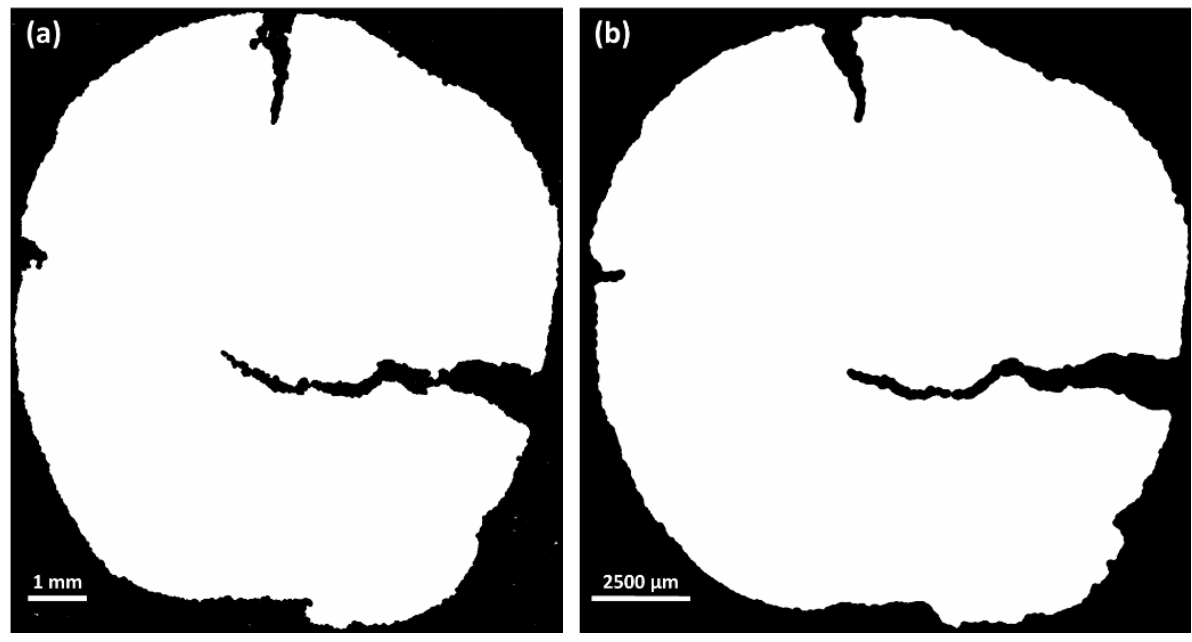

Figura 100 - ROI criada: (a) MO; (b) MicroCT

Para obtenção da imagem de poros (Figura 101), foi feita uma subtração entre as imagens da Figura 100 e da Figura 101 e, por fim, obteve-se a percentagem de porosidade total.
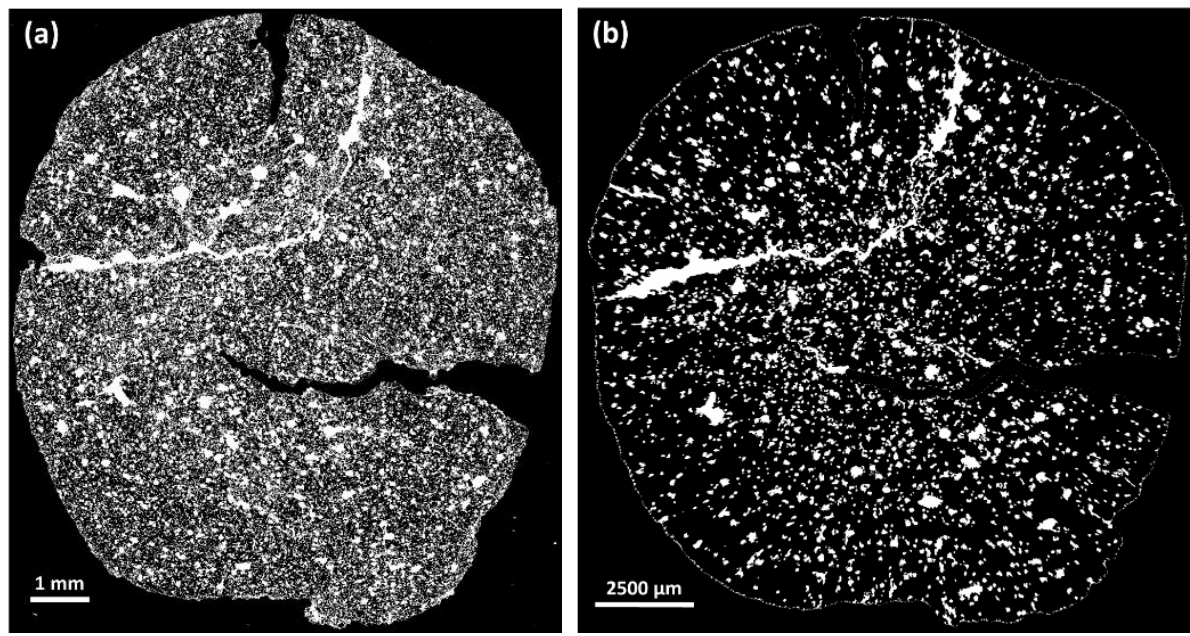

Figura 101 - Imagem de poros: (a) MO; (b) MicroCT

Todo esse procedimento foi feito apenas para as amostras da $1^{\mathrm{a}}$ etapa. Não foi possível encontrar as camadas de MicroCT correspondentes às imagens de MO para as amostras da $2^{\mathrm{a}}$ etapa, do Grupo Aplicação, pois não foi feita a análise em MicroCT das pelotas completas. Sendo assim, é muito difícil encontrar pontos de referência para encontrar a camada em MicroCT, cuja região analisada corresponde a uma mesma região da imagem de MO. 
Todas as camadas em MicroCT com as imagens correspondentes em MO do Grupo Desenvolvimento, da $1^{\text {a }}$ etapa, encontram-se no Apêndice A deste trabalho.

\subsection{2.}

\section{Comparação da porosidade - MicroCT x MO}

Os resultados da comparação dos valores de porosidade entre MicroCT e MO das amostras da $1^{\text {a }}$ etapa, que foram analisadas por essas duas técnicas, são apresentados na Figura 102.

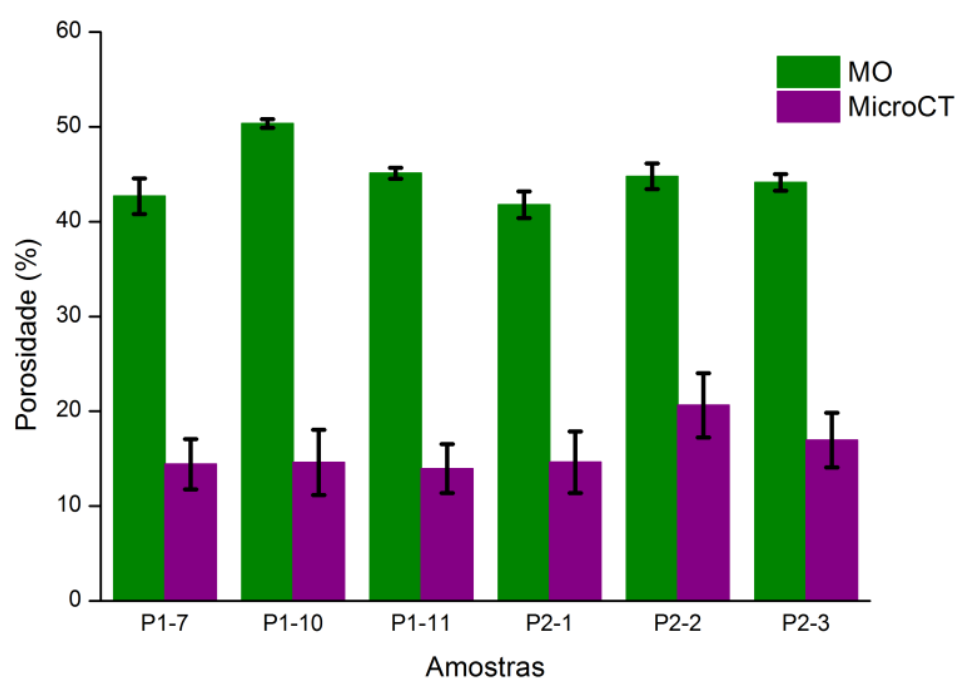

Figura 102 - Comparação da porosidade entre MO e MicroCT

Verifica-se que os valores de porosidade pela técnica de MicroCT são menores do que os quantificados por MO. Mais uma vez esse comportamento pode ser explicado pela resolução da MicroCT ser pior. Dessa forma, poros abaixo da resolução do sistema, que conseguem ser medidos por MO, não são medidos em MicroCT.

Também pode-se observar, através da barra de erros, que a escolha do limiar de segmentação das fases é menos impactante no processamento das imagens de MO do que no de MicroCT. Isto também se deve à pior resolução de MicroCT comparada à de MO.

Porém, observou-se também que, em alguns casos, como o da amostra P1-7, poros ou trincas podem ser gerados fisicamente na preparação de amostras para 
MO, não sendo uma característica original da amostra. A camada equivalente de MicroCT pode ser visualizada na Figura 103. Observa-se que os planos apresentam alguma diferença, que pode ter sido gerada por inclinação da amostra na etapa de preparação. Apesar disso, a imagem de MO apresenta uma trinca muito mais aberta, possivelmente ocasionada no corte da pelota para o embutimento.
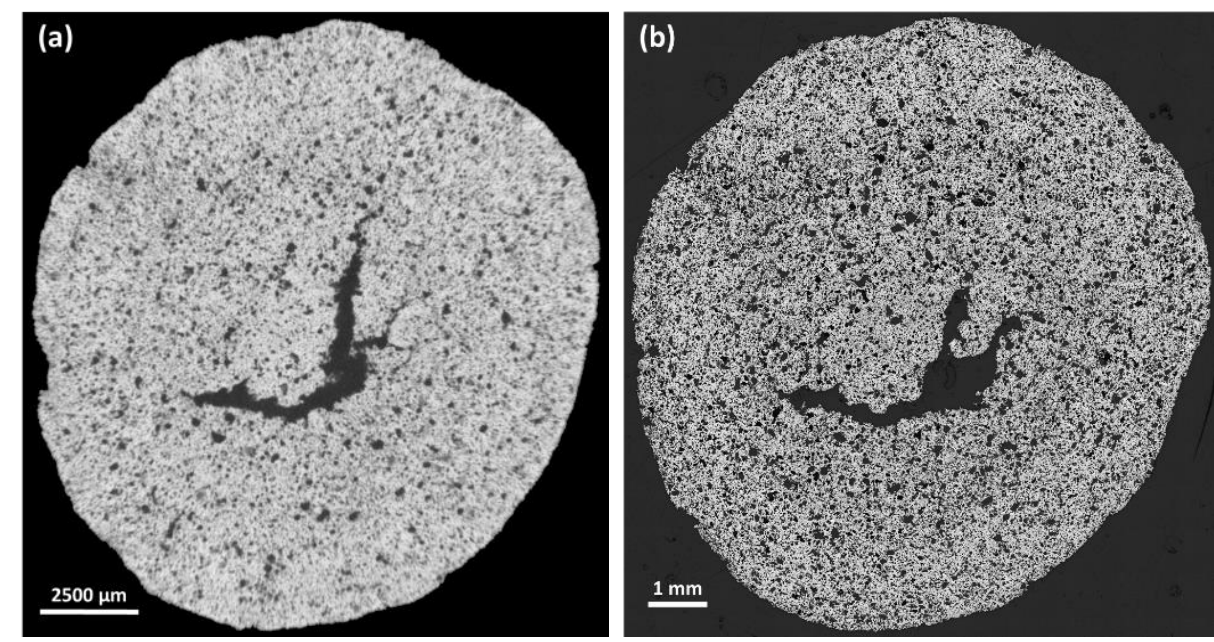

Figura 103 - Camadas correspondentes: (a) MicroCT; (b) MO.

\section{4. \\ Microscopia eletrônica de varredura}

A análise em MEV foi feita com o objetivo de mostrar os poros muito pequenos que não são medidos pela MicroCT, pois a resolução máxima alcançada foi insuficiente para visualizá-los.

A resolução testada com a MicroCT variou de $8 \mu \mathrm{m}$ a $2 \mu \mathrm{m} /$ pixel. No caso da MO, a resolução testada foi de 1,06 $\mu \mathrm{m} /$ pixel com a lente objetiva de 10X, podendo chegar a $0,53 \mu \mathrm{m} /$ pixel com a lente objetiva de 20X. Já a PIM consegue detectar poros de até $0,003 \mu \mathrm{m}$. Com isso, buscou-se reproduzir as referidas resoluções no $\mathrm{MEV}$, para se avaliar qualitativamente os poros em cada uma delas. As imagens obtidas em diferentes aumentos encontram-se na Figura 104, variando-se as resoluções de $8 \mu \mathrm{m}$ a $70 \mathrm{~nm} /$ pixel.

A máxima resolução obtida foi de $30 \mathrm{~nm}$, como mostra a Figura 105. Nesta imagem, consegue-se visualizar poros bem pequenos, que não são medidos nas imagens com piores resoluções. 
Para mostrar o impacto da resolução na medição da porosidade, cortou-se regiões quase equivalentes nas imagens com diferentes resoluções, tais como, 8 $\mu \mathrm{m} /$ pixel (resolução da MicroCT utilizada na $1^{\mathrm{a}}$ etapa), $4 \mu \mathrm{m} /$ pixel (resolução da MicroCT utilizada na $2^{\mathrm{a}}$ etapa), $1 \mu \mathrm{m} /$ pixel (resolução da MO com a lente de 10X) e $0,5 \mu \mathrm{m} /$ pixel (resolução da MO com a lente de 20X), conforme apresentado na Figura 106. Não foi possível encontrar exatamente a mesma região de (c) e (d) em (a) e (b) devido à baixa resolução. O destaque em vermelho nas imagens (a) e (b) se referem a aproximadamente a mesma região de (c) e (d). Fica evidente que existem poros muito pequenos impossíveis de serem medidos com piores resoluções como a obtida com a MicroCT.

Além da análise de observação de poros em diferentes resoluções, também foi feito um mapeamento de raios $\mathrm{X}$ em um campo da amostra para que se pudesse confirmar as fases presentes, certificando-se de que a fase segmentada nas imagens de MicroCT é realmente a de poros. Os elementos encontrados foram ferro, silício, cálcio e alumínio. Os mapas obtidos são mostrados na Figura 107.

A análise em MicroCT não foi capaz de diferenciar os silicatos, podendo, portanto, estarem incluídos na fase de poros na etapa de segmentação. 


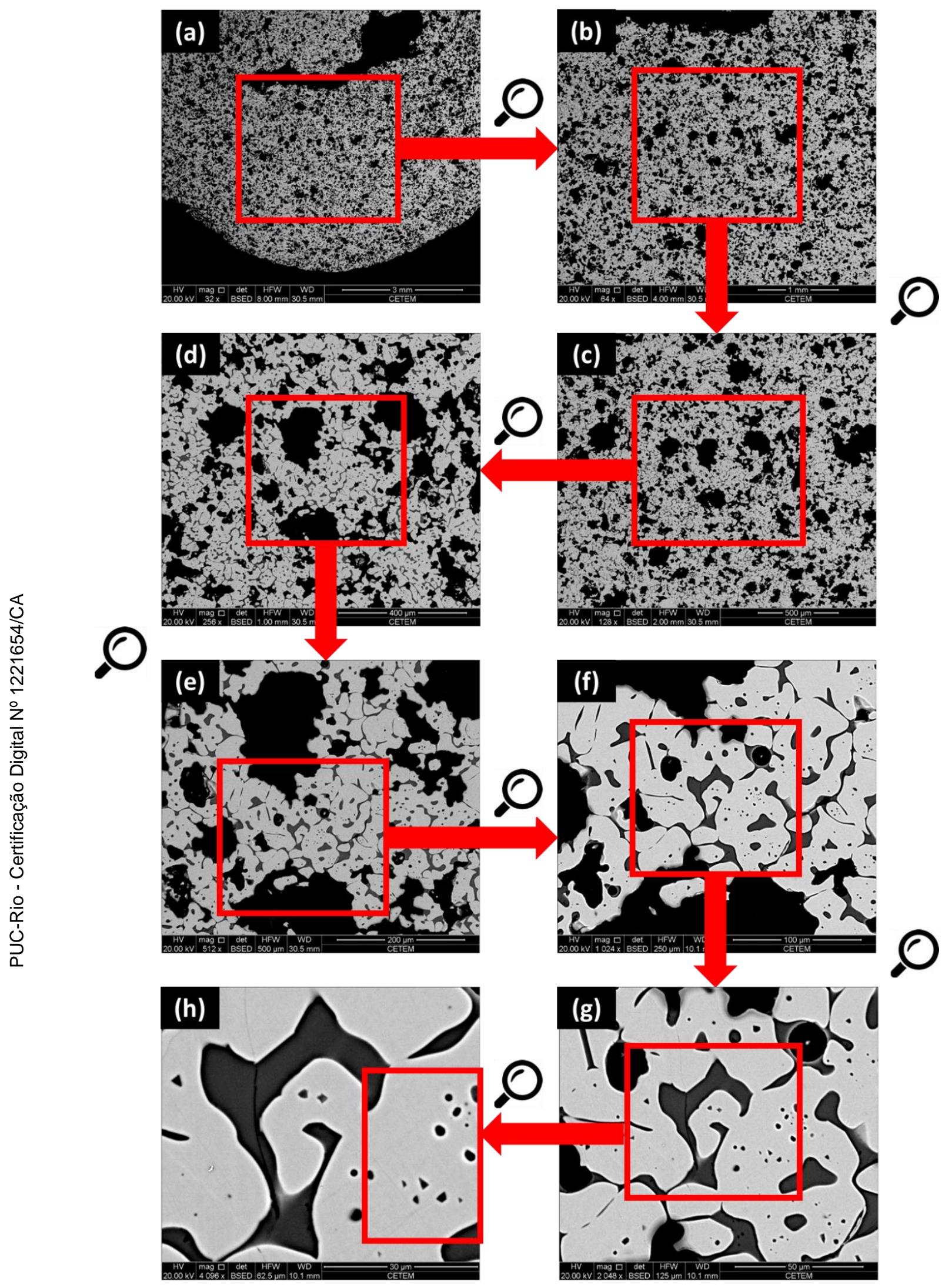

Figura 104 - Análise em MEV - Imagens variando a resolução de $8 \mu \mathrm{m}$ a 70 $\mathrm{nm} /$ pixel. A região em destaque de (h) foi analisada por um aumento maior ainda (30 nm/pixel). 


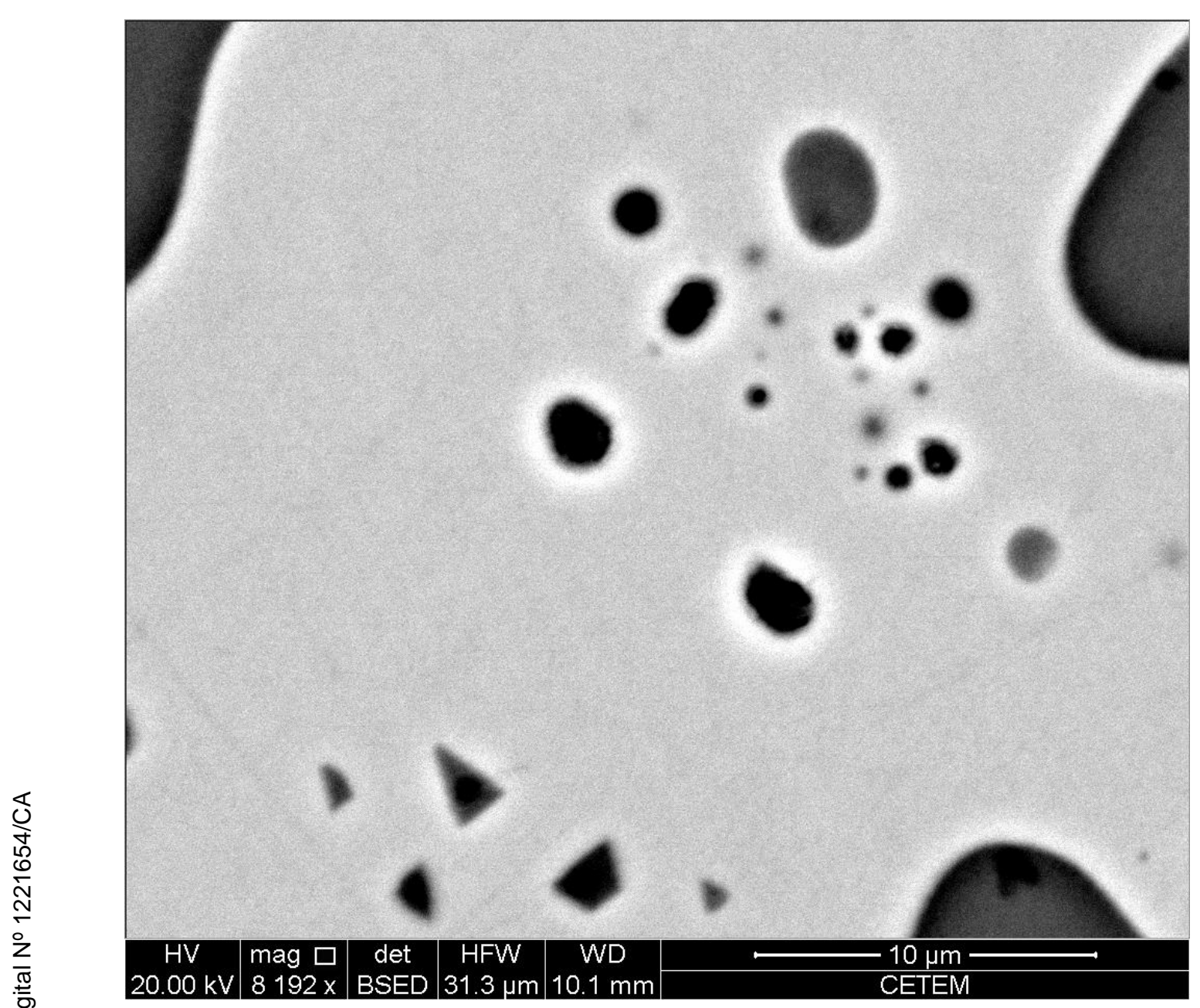

Figura 105 - Imagem de MEV de um campo com resolução de 30 nm/pixel referente à região em destaque na última imagem da Figura 104. 

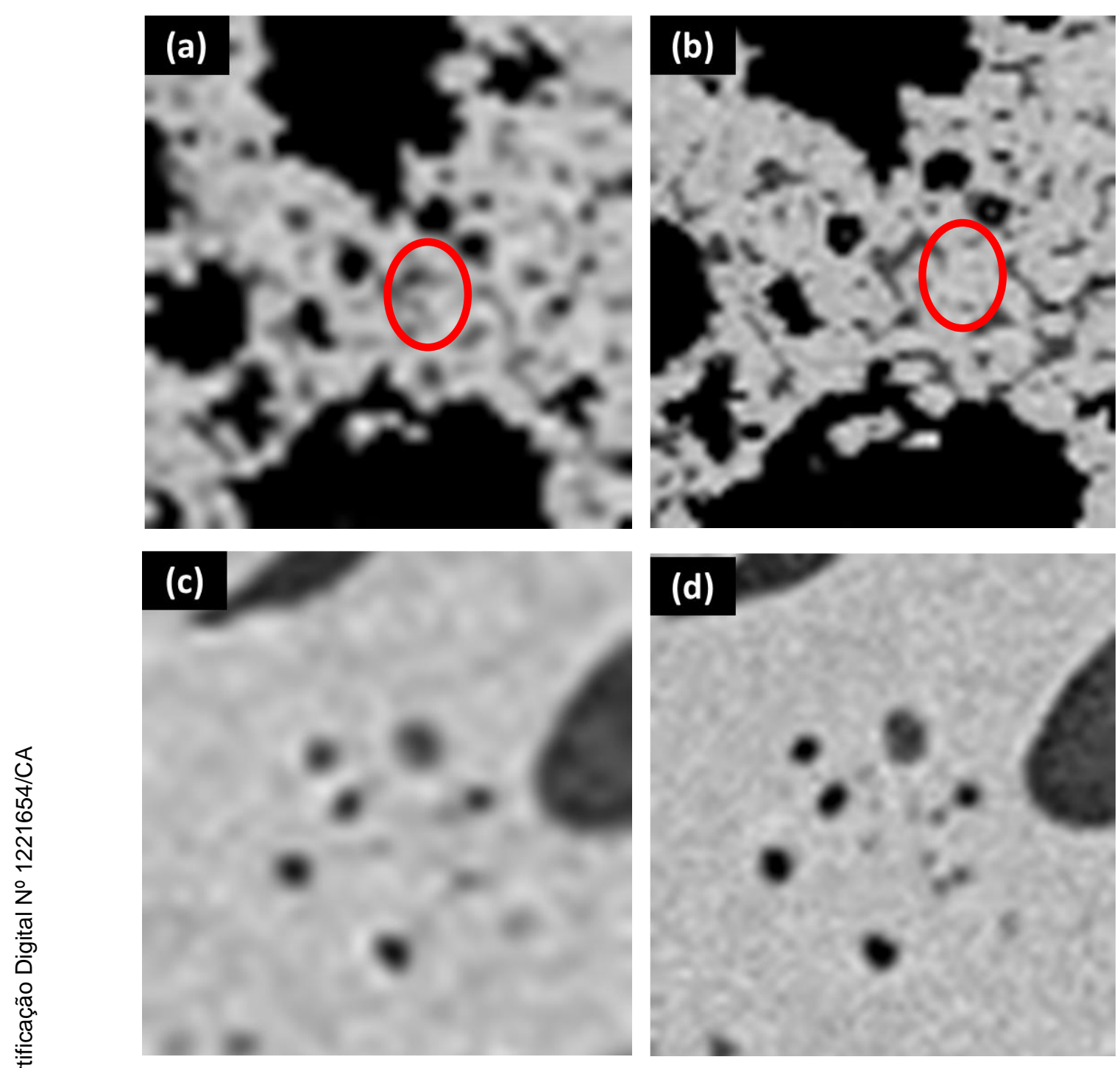

Figura 106 - Cortes das imagens em diferentes resoluções. O destaque em vermelho em (a) e (b) se referem a regiões próximas de (c) e (d): (a) $8 \mu \mathrm{m} /$ pixel; (b) $4 \mu \mathrm{m} /$ pixel; (c) $1 \mu \mathrm{m} /$ pixel; (d) $0,5 \mu \mathrm{m} /$ pixel. 

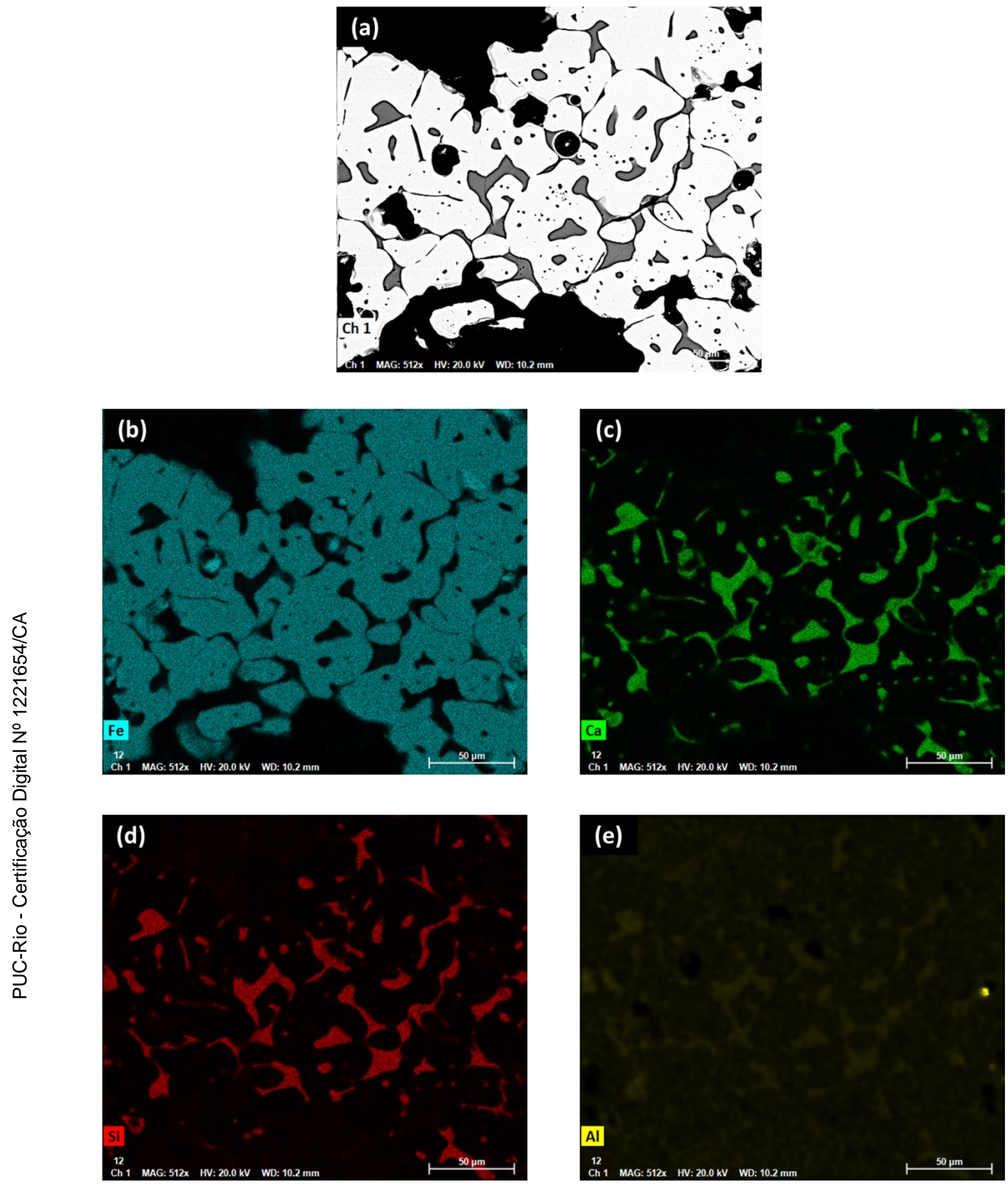

Figura 107 - Mapeamento de raios X: (a) Imagem de elétrons retroespalhados;

(b) $\mathrm{Fe}$; (b) $\mathrm{Ca}$; (c) $\mathrm{Si}$; (e) Al. 


\section{5 \\ Conclusões e trabalhos futuros}

O presente trabalho abordou a caracterização da porosidade em pelotas de minério de ferro por meio do processamento e análise de imagens, adquiridas por microtomografia de raios X. Para isso, desenvolveu-se uma metodologia para quantificação de porosidade, capaz de medir separadamente poros abertos e fechados e obter a distribuição de tamanho dos poros. O método proposto utilizou uma sequência de processamento de imagens tradicional no espaço $2 \mathrm{D}$, e $3 \mathrm{D}$ quando necessário. Para validar a técnica, os resultados foram comparados com técnicas clássicas, como porosimetria por intrusão de mercúrio (PIM) e microscopia ótica (MO).

$\mathrm{Na}$ comparação dos resultados de porosidade entre as técnicas de PIM e de MicroCT, com a resolução de MicroCT definida inicialmente, os valores foram quase $80 \%$ maiores com a técnica de PIM.

Otimizando-se a resolução, os valores de porosidade encontrados em MicroCT foram ainda muito menores do que em PIM, porém com uma diferença menor do que $50 \%$ para a porosidade total.

Na comparação dos valores de porosidade entre MO e MicroCT, os resultados diferiram em mais de 50\%, mostrando mais uma vez a influência da resolução na quantificação dos poros.

Dessa forma, ficou constatado que a resolução é uma das limitações da técnica e a sua respectiva melhora implica no aumento do tempo de aquisição, o que também é uma limitação. A escolha do limiar de segmentação das fases nas imagens de MicroCT também apareceu como uma limitação, afetando diretamente na quantificação das porosidades total, aberta e fechada.

A efetiva substituição de PIM por MicroCT na análise de porosidade em pelotas exigirá, fundamentalmente, uma redução do tempo de aquisição e processamento. Além disso, em função das diferenças dos processos físicos envolvidos em PIM e MicroCT, e da grande diferença de resolução entre as 
técnicas, as faixas de valores típicos para a porosidade serão diferentes, o que exigirá a adoção de um novo padrão para este tipo de análise.

Todavia, a metodologia desenvolvida produziu resultados adequados e coerentes com relação aos parâmetros avaliados, como a resolução do sistema, por exemplo. A técnica possibilita a visualização da distribuição espacial dos poros e a análise da porosidade fechada, que, apesar das limitações já mencionadas anteriormente, é essencial, visto que poros fechados podem afetar a resistência física da pelota. Mais do que isso, a MicroCT pode revelar muita informação, até então inacessível, que pode impactar o beneficiamento e a pelotização, visando a melhoria das propriedades através do projeto de pelotas. Além disso, pelotas verdes (ou cruas), isto é, pelotas que não passaram pela etapa de queima, possuem quase nenhuma resistência física e, devido a isso, não se consegue analisá-las por técnicas destrutivas. A MicroCT é uma ótima opção na análise de porosidade, que também é importante para as etapas de produção desses materiais.

A fim de reduzir as limitações da técnica apresentadas, propõe-se algumas possibilidades de trabalhos futuros. Nas condições otimizadas no presente trabalho foi impossível analisar a pelota inteira. Existe um novo modelo de detector, chamado Flat Panel [48], disponível para a evolução do modelo de MicroCT utilizado neste trabalho, que permite análises de amostras ainda maiores $(12 \mathrm{~cm}$ de diâmetro), com aquisições de 2 a 5 vezes mais rápidas. Dessa forma, pode-se analisar a pelota completa com ótima resolução.

Como a busca de melhor resolução e regiões maiores de análise implica num tempo maior de análise, a caracterização por MicroCT torna-se inviável para controle de qualidade e aplicações rotineiras. Também como proposta para trabalhos futuros, a pesquisa sobre a técnica de DART (Técnica de Reconstrução Algébrica Discreta) [49-50] é muito promissora. A técnica permite reconstruir imagens de MicroCT a partir de poucas projeções. Para isso, as fases, que deverão ser poucas, do material a ser analisado, e os seus respectivos tons de cinza para a reconstrução da imagem devem ser conhecidos.

Com relação às caracterizações de porosidade de pelotas de minério de ferro, pode-se incluir como trabalhos futuros a análise de trincas, possibilitada pela separação entre objetos (poros) com diferentes tamanhos e formas. 


\section{Bibliografia}

[1] LUZ, A. B.; LINS, F. A. F. Introdução ao tratamento de minérios. Comunicação Técnica elaborada para a $4^{a}$ Edição do Livro de Tratamento de Minérios, p. 3-16, 2004.

[2] IBRAM. Informação sobre a economia mineral brasileira 2015. Disponível em: <www.ibram.org.br/sites/1300/1382/00005836.pdf >. Acesso em: 18 jan. 2016.

[3] ALICEWEB2. Disponível em: <http://aliceweb.desenvolvimento.gov.br/>. Acesso em: 18 jan. 2016.

[4] WAGNER, D. T.; ROUCO, H. V.; GOMES, O. F. M.; PACIORNIK, S.; VIEIRA, M. B. Caracterização de pelotas de minério de ferro por microscopia digital e análise de imagens. Tecnologia em Metalurgia e Materiais, São Paulo, v. 5, n. 4, p. 215-218, 2009.

[5] RUSS, J. C.; DEHOFF, R. T. Practical Stereology. 2.ed. Springer Science+Business Media. p. 345. New York, 2000.

[6] BHUIYAN, I. U; et al. Consideration of X-ray microtomography to quantitatively determine the size distribution of bubble cavities in iron ore pellets. Powder Technology. v. 233, p. 312-318, 2013.

[7] AUGUSTO, K. S. Identificação automática do grau de maturação de pelotas de minério de ferro. Dissertação de Mestrado. Rio de Janeiro, 2012.

[8] MEYER, K. Pelletizing of iron ores. Springer-Verlag. Berlin, Heidelberg, and Verlag Stahleisen mbH, Düsseldorf, 1980.

[9] LUZ, A. B.; SAMPAIO, J. A.; FRANÇA, S. C. A. Tratamento de minérios. 5.ed. Rio de Janeiro: CETEM/MCT, 2010. p. 705-748.

[10] PACIORNIK, S.; AUGUSTO, K. S. Caracterização tridimensional de aglomerados de minério de ferro. 43rd Ironmaking and Raw Materials Seminar \& 14th Brazilian Symposium on Iron Ore \& 1st Brazilian Symposium on Agglomeration of Iron Ore. Belo Horizonte, 2013. 
[11] DEHOFF, R. T. Engineering of microstructures. Materials Research. v. 2, n. 2, p. 111-126. 1999.

[12] CALLISTER, W. D. Ciência e engenharia de materiais: uma introdução. LTC. $7^{\text {a }}$ edição. Rio de Janeiro, 2008.

[13] KLOBES, P.; MEYER, K.; MUNRO, R. G. Porosity and specific surface area measurements for solid materials. National Institute of Standards and Technology. Setembro, 2016.

[14] ANDREOLA, F; et al. Techniques used to determine porosity. American Ceramic Society Bulletin. Julho, 2000.

[15] YANG, Y. H. Fundamental study of pore formation in iron ore sinter and pellets. Doctoral Thesis. University of Wollongong - Department of Materials Engineering. Austrália, 1990.

[16] SIVRIKAYA, O; AROL, A. I. Alternative binders to bentonite for iron ore pelletizing - Part I: Effects on physical and mechanical properties. HOLOS. v. 3, p. 94-103. Turquia, 2014.

[17] GIESCHE, H. Mercury porosimetry: a general (practical) overview. Weinheim, 2006.

[18] WASHBURN, E. W. Note on a method of determining the distribution of pore sizes in a porous material. v. 7, p. 115-116, 1921.

[19] MATA, V. L. G. Caracterização de meios porosos - Porosimetria, modelização 3D e tomografia seriada - Aplicação a suportes catalíticos. Dissertação de Mestrado. Portugal, 1998.

[20] MANTOVANI, I. F. Microtomografia e nanotomografia de raios $\mathbf{X}$ aplicada à caracterização multiescalar de sistemas porosos carbonáticos. Tese de Doutorado. Florianópolis, 2013.

[21] VOLUME and Density Definitions and Determination Methods - Supplier Data By Micromeritics. Disponível em: <http://www.azom.com/article.aspx?ArticleID=3214\#_Background > . Acesso em: 5 mai. 2016.

[22] LEITNER, J. Application of mercury porosimetry in evaluating the quality of iron ore pellets. Powder Technology. v. 29, p. 199-203, 1981.

[23] CUNHA, M. A.; GIOSA, J. A.; GONÇAlveS, I. N.; SANTOS, C. P. Difração de raios $\mathbf{X}$ e textura dos materiais. Disponível em: < 
https://www.academia.edu/3712564/Cristalografia>. Acesso em: 10 nov. 2014.

[24] EFEITO

fotoelétrico.

Disponível

em:

<http://efeitofotoeletricoecompton.webnode.com.br/explicação>. Acesso em: 10 nov. 2014.

[25] EFEITO Compton.

Disponível

em: $<$ http://efeitofotoeletricoecompton.webnode.com.br/efeito-compton/>. Acesso em: 10 nov. 2014.

[26] RAIOS X

X. Disponível

em:

<http://www.oocities.org/tomografiademadeira/interacao.html >. Acesso em: 10 nov. 2014.

[27] NERSISSIAN, D. Y. Determinação das dimensões do ponto focal de tubos de raios $X$ utilizando um sensor $C C D$ e o método das funções de transferências. Tese de Doutorado. Universidade de São Paulo, São Paulo, 2004.

[28] ALVES, H. D. L. Análise da porosidade de sedimentos geológicos usando a técnica de microtomografia computadorizada. Dissertação de Mestrado. Universidade Federal do Rio de Janeiro, Rio de Janeiro, 2012.

[29] LANDIS, E. N.; KEANE, D. T. X-ray microtomography. Materials Characterization, v. 61, p. 1305-1316, 2010.

[30] CARL Zeiss X-Ray Microscopy. Resolution of a 3D X-ray Microscope Defining Meaningful Resolution Parameters. Disponível em: $<$ http://info.xradia.com/rs/270-LXH-

014/images/TechNote_Resolution.pdf>. Acesso em: 20 mar. 2016.

[31] ULIANA, et al. Microtomografia de alta resolução no setor mineral. HOLOS, Ano 30, v. 3, p. 11-19, 2014.

[32] ZEISS Xradia 510 Versa. Submicron X-ray imaging: Flexible working distance at the highest resolution.

[33] GOMES, O. F. M. Processamento e análise de imagens aplicados à caracterização automática de materiais. Dissertação de Mestrado. Pontifícia Universidade Católica do Rio de Janeiro, Rio de Janeiro, 2001.

[34] FORSBERG, F; HJORTSBERG, E. X-ray microtomography for sequential imaging and analysis of iron ore pellets under reduction. 2012. 
[35] SHATOKHA, V; KOROBEYNIKOV, I; MAIRE, E. On the application of 3D X-ray microtomography for studies in the field of iron ore sintering technology. 2012.

[36] SILVA, D. C. B. et al. Evolução da estrutura interna de pelotas em diferentes estágios de produção registrada por meio de tomografia computadorizada de raios X. Revista $\mathrm{ABM}$ - Metalurgia, Materiais \& Mineração, v. 70, p. 417-421, 2014.

[37] ROCHA, E. P.; CASTRO, J. A. Characterization and three-dimensional reconstruction of pores of self-reducing pellets done by EAF dust. Materials Research. v. 17, p. 47-55, 2013.

[38] LABUS, M. Comparison of computer image analysis with mercury porosimetry in sandstone porosity measurement. Geological Quartely. v. 45, n. 1, p. 75-79, 2001.

[39] KLOBES, P.; et al. Rock porosity determination by combination of X-ray computerized tomography with mercury porosimetry. Fresenius Journal of Analytical Chemistry. v. 357, p. 543-547, 1997.

[40] REIS NETO, J. M.; et al. A microtomografia computadorizada de raios x integrada à petrografia no estudo tridimensional de porosidade em rochas. Revista Brasileira de Geociências. v. 41, n. 3, p. 498-508, 2011.

[41] FIJI. Disponível em: <https://fiji.sc/>. Acesso em: 5 jul. 2016.

[42] CTAn. Disponível em: <http://bruker-microct.com/products/ctan.htm>. Acesso em: Acesso em: 5 jul. de 2016.

[43] ORS Visual. Disponível em: 〈http://www.theobjects.com/en/>. Acesso em: 5 jul. 2016.

[44] GOLDSTEIN, J. I.; et al. Scanning electron microscopy and X-ray microanalysis. A text for biologists, materials scientists and geologists. 2.ed. Springer, 1992.

[45] NON local means denoise. Disponível em: <http://imagej.net/Non_Local_Means_Denoise>.Acesso em: 15 jun. 2016.

[46] GONZALEZ, R. C.; WOODS, R.E. Digital image processing. 2.ed. Prentice- Hall. Upper Saddle River - NJ, 2002. 
[47] BRUKER. 3D visualization of open and closed porosity. Disponível em: <http://www.umanitoba.ca/faculties/health_sciences/medicine/units/cacs/sa m/media/MN010_3D_visualization_of_open_and_closed_porosity.pdf $>$. Acesso em: 20 mar. 2016.

[48] ZEISS Xradia 520 Versa. Disponível em: <http://www.zeiss.com/microscopy/en_de/products/x-ray-microscopy/zeissxradia-520-versa.html\#options\%23fpx-anchor>. Acesso em: 2 ago. 2016.

[49] SIJBERS, J.; BATENBURG, K. J. DART: A practical reconstruction algorithm for discrete tomography. IEEE Transactions on image processing. v. 20, n. 9, 2011.

[50] Palenstijn, W. J.; BAtenburG, K.; SiJBers, J. The ASTRA tomography toolbox. Proceedings of the 13th International Conference on Computational and Mathematical Methods in Science and Engineering, 2013. 


\section{Apêndice A - Imagens correspondentes de MicroCT e MO}
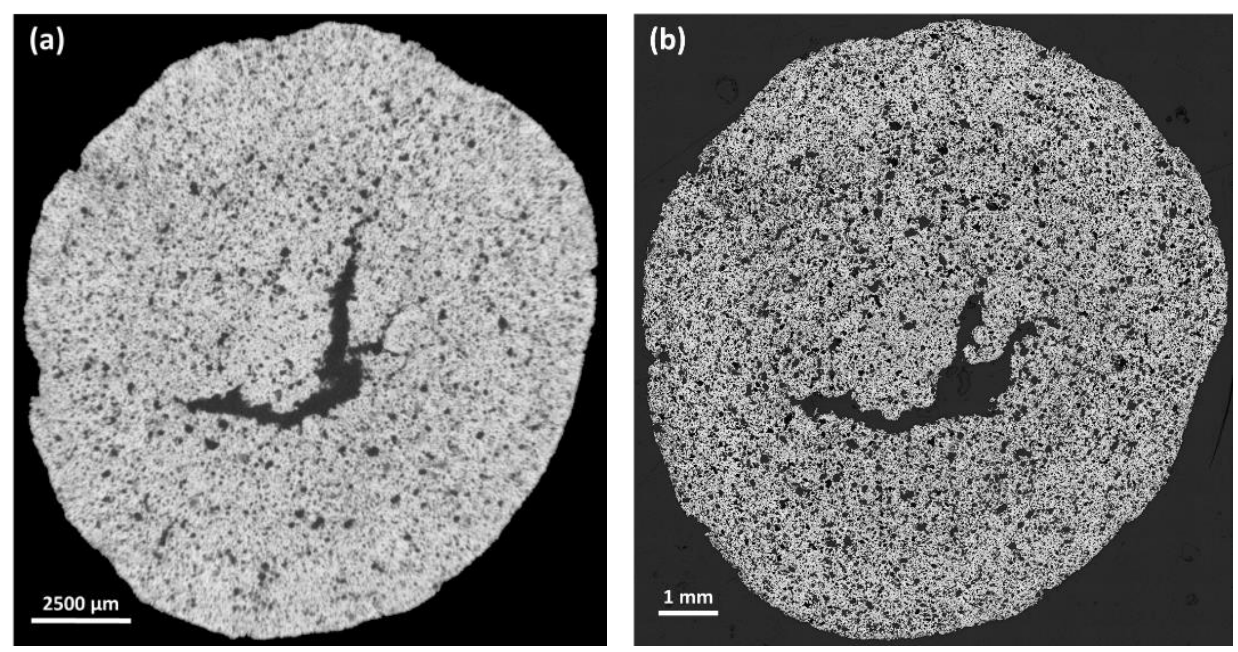

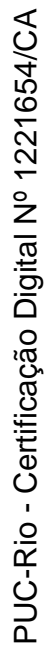

Figura 108 - Amostra P1-7: (a) MicroCT; (b) MO
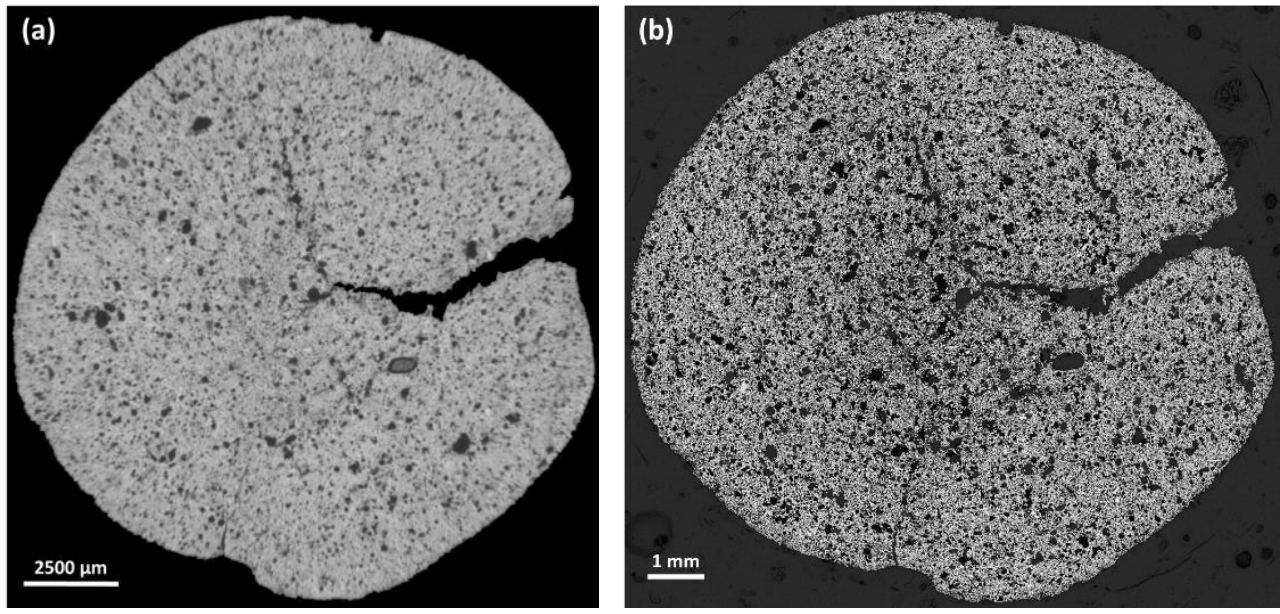

Figura 109 - Amostra P1-10: (a) MicroCT; (b) MO 

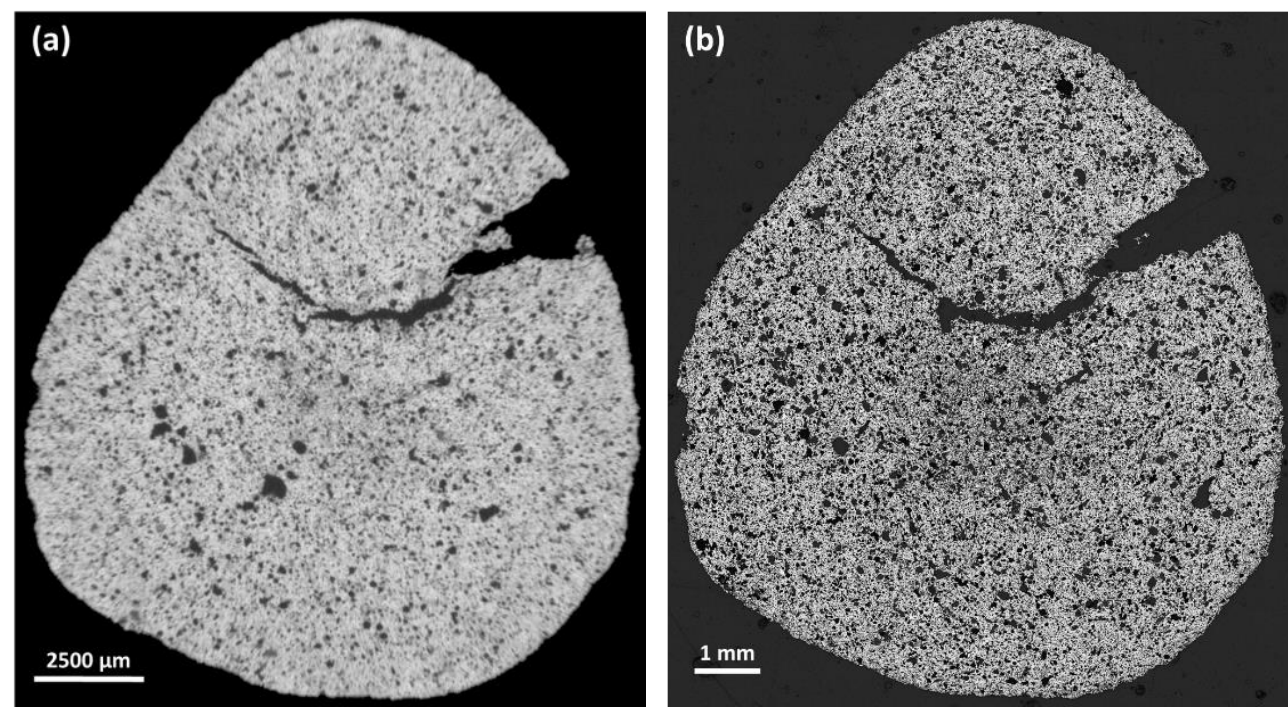

Figura 110 - Amostra P1-11: (a) MicroCT; (b) MO
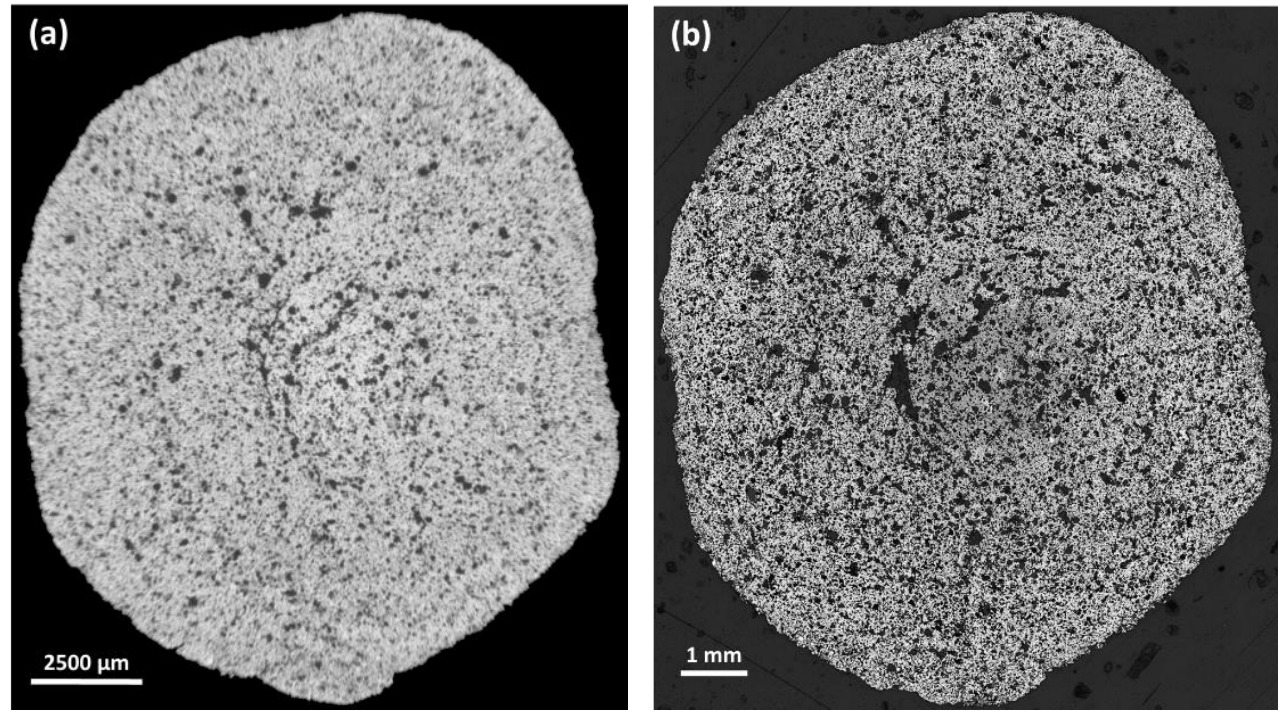

Figura 111 - Amostra P2-1: (a) MicroCT; (b) MO 

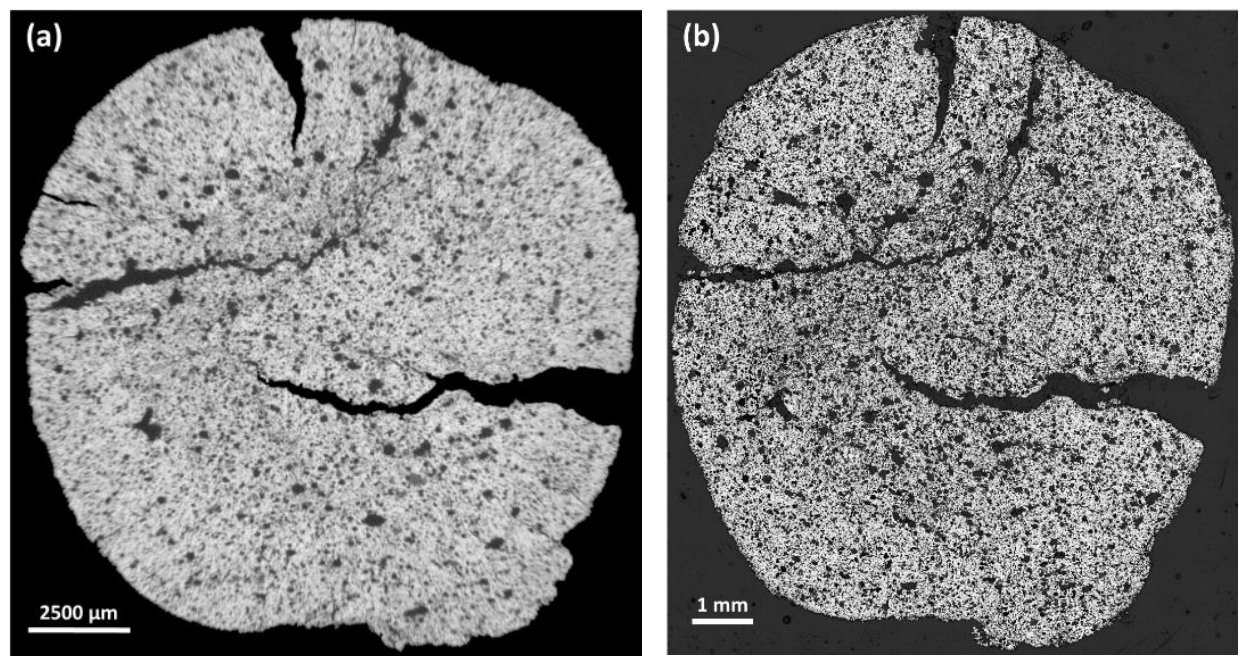

Figura 112 - Amostra P2-2: (a) MicroCT; (b) MO
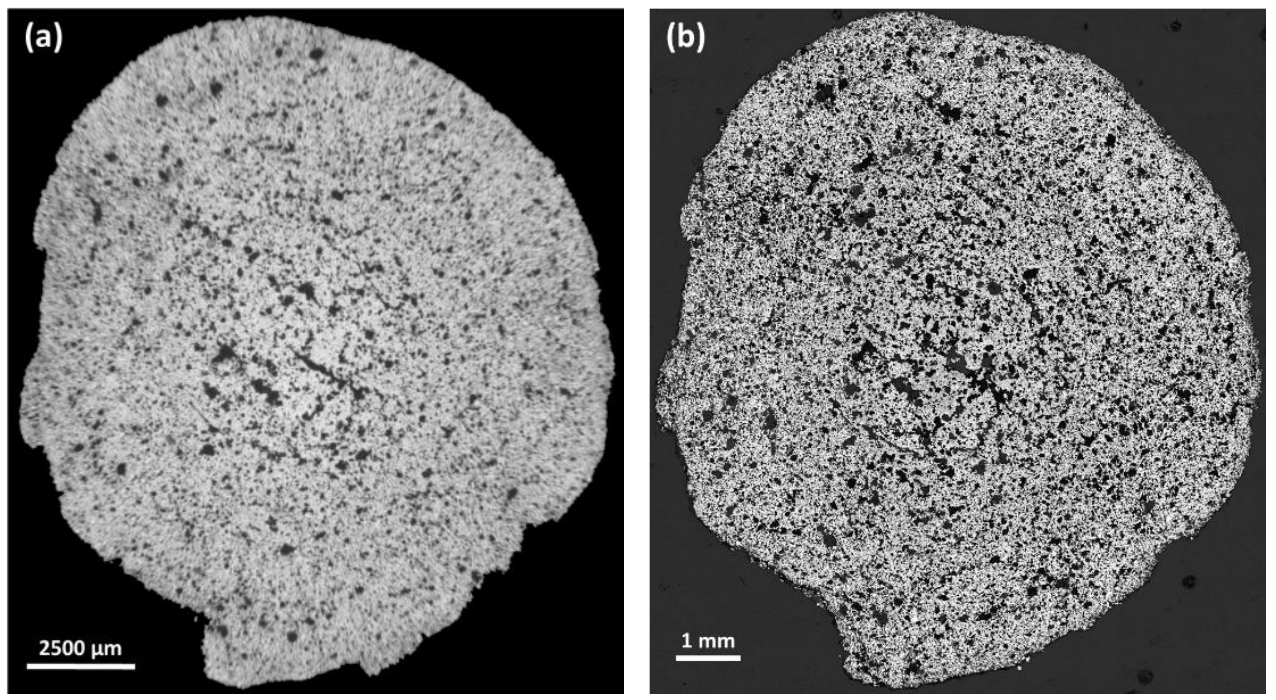

Figura 113 - Amostra P2-3: (a) MicroCT; (b) MO 